VANESSA SERIACOPI

\title{
SIMULAÇÃO NUMÉRICA DO CAMPO DE TENSÕES NA MICROESTRUTURA DO AÇO FERRAMENTA AISI H13 DURANTE O FORJAMENTO A QUENTE
}


VANESSA SERIACOPI

\section{SIMULAÇÃO NUMÉRICA DO CAMPO DE TENSÕES NA MICROESTRUTURA DO AÇO FERRAMENTA AISI H13 DURANTE O FORJAMENTO A QUENTE}

Dissertação apresentada à Escola Politécnica da Universidade de São Paulo para obtenção do título de Mestre em Engenharia. 


\section{SIMULAÇÃO NUMÉRICA DO CAMPO DE TENSÕES NA MICROESTRUTURA DO AÇO FERRAMENTA AISI H13 DURANTE O FORJAMENTO A QUENTE}

Dissertação apresentada à Escola Politécnica da Universidade de São Paulo para obtenção do título de Mestre em Engenharia.

Área de Concentração: Engenharia Mecânica de Projeto de Fabricação.

Orientadora: Profa. Dra. Izabel Fernanda Machado 
Este exemplar foi revisado e corrigido em relação à versão original, sob responsabilidade única do autor e com a anuência de seu orientador.

São Paulo, de maio de 2013.

Assinatura do autor

Assinatura do orientador

Seriacopi, Vanessa

Simulação numérica do campo de tensões na microestrutura do aço ferramenta AISI H13 durante o forjamento a quente / V. Seriacopi. - versão corr. -- São Paulo, 2013. $150 \mathrm{p}$.

Dissertação (Mestrado) - Escola Politécnica da Universidade de São Paulo. Departamento de Engenharia Mecatrônica e de Sistemas Mecânicos.

1. Tensão dos materiais (Simulação numérica) 2. Aço ferramenta 3. Forjamento 4. Microestrutura I. Universidade de São Paulo. Escola Politécnica. Departamento de Engenharia Mecatrônica e de Sistemas Mecânicos II. t. 


\section{DEDICATÓRIA}

Dedicado à minha mãe, ao Sócrates e ao Bóris pela confiança e amor incondicional hoje e sempre. 


\section{AGRADECIMENTOS}

À professora Izabel Fernanda Machado pela dedicação e por todos os ensinamentos, indo além do seu papel de orientadora de modo a contribuir de forma ampla para a minha formação (acadêmica, profissional e pessoal).

À FAPESP, pelo apoio financeiro (Processo: 2011/03817-2), proporcionado pela bolsa de mestrado, para a realização da pesquisa aqui apresentada.

Ao grande amigo Wilson Carlos da Silva Júnior, que confiou desde o início no meu trabalho, me incentivou e me desafiou a desenvolver cada vez mais os meus conhecimentos, e continuou sempre me apoiando em todos os quesitos.

Ao professor Amilton Sinatora, pelo aceite da minha integração ao Laboratório de Fenômenos de Superfície e pelo constante incentivo à disseminação da pesquisa e da busca pelo aprendizado no laboratório.

Aos professores Roberto Martins e Rodrigo Stoeterau pelos questionamentos, críticas construtivas e sugestões feitas ao longo do trabalho de mestrado desenvolvido.

A todos da família do Laboratório de Fenômenos de Superfície com a qual, sem dúvida, tive um grande aprendizado por meio da participação em discussões interativas. Agradeço, em especial, à Ane e ao Gil pela amizade, pela paciência e pelos sábios e prontificados conselhos. E ao Luiz, ao Eleir, ao Cristiano e ao Newton, aos quais sou muito grata pela enorme disposição, e paciência, em me ajudar na parte de simulação numérica me alertando em pequenos detalhes, que fizeram uma grande diferença.

À minha querida mãe, por estar em todos os momentos me apoiando e enchendo a minha vida de alegria; ajudando-me, enfim, a vencer todas as barreiras impostas ao longo da jornada percorrida. 
"The whole of science is nothing more than a refinement of everyday thinking".

(Albert Einstein)

"Se não funciona ou não dá certo... Não desista! Pesquise para descobrir porque não deu certo (corre-se o risco de nunca terminar...)".

(mensagem deixada por Leonardo da Vinci, segundo descrição do Prof. Dr. Deniol Tanaka) 


\section{RESUMO}

A falha devido à ocorrência de fadiga térmica de materiais utilizados como ferramentas para trabalho a quente é identificada durante serviço e ocorre devido ao acúmulo de dano localizado. O aço AISI H13 é comumente utilizado em ferramentas para a conformação a quente devido à sua boa tenacidade à fratura e resistência ao desgaste, e considerável resistência à perda de dureza a quente. Este trabalho teve como motivação estudar a relação entre a microestrutura do aço $\mathrm{H} 13$ e os carregamentos térmicos e mecânicos, que possam levar à falha de ferramentas para forjamento a quente. Para este estudo, fez-se uso de meios computacionais (simulação numérica) aliados aos conhecimentos de caracterização microestrutural e do comportamento mecânico dos materiais. Nesta abordagem, elabora-se uma malha na microestrutura do referido aço no software OOF $2^{\circledR}$, do NIST, e as análises são feitas a partir da aplicação do método dos elementos finitos com o emprego do software Abaqus ${ }^{\circledR}$. Com isso, torna-se possível examinar o efeito de aspectos microestruturais, como a influência dos precipitados, na ocorrência de tensões e de deformações na microestrutura de forma a obter um mapeamento de regiões críticas ao dano e à falha na ferramenta de forjar a quente. Os estudos são baseados e comparados com trabalhos já publicados, e simulam carregamentos e variações de temperatura no material em questão de modo a verificar as condições que favorecem a nucleação de trincas por fadiga térmica. Como principais conclusões e contribuições obtidas da análise realizada, podem ser destacadas: (i-) as regiões críticas que vêm a propiciar a nucleação de trincas térmicas são os precipitados e as interfaces; (ii-) no campo de tensões, a propriedade das fases que exerce a maior influência é o módulo de elasticidade; (iii-) os diferentes coeficientes de expansão térmica das fases geram deformações térmicas mais elevadas e tensões compressivas nas interfaces; (iv-) as deformações térmicas nos precipitados são superiores às da matriz devido à influência no campo de tensões; ( $v$-) em termos de tensões térmicas, o momento do ciclo térmico mais crítico para a matriz é o resfriamento; e (vi-) ao passo que, nos precipitados, a etapa mais crítica é o aquecimento.

Palavras-chave: Simulação Numérica. Microestrutura. Forjamento a Quente. Aço Ferramenta. 


\begin{abstract}
Failure due to thermal fatigue can occur in hot working tool materials and its onset takes place in the regions where the highest stress and strain are reached. AISI H13 steel is often used as a hot working tool since it has good toughness and wear resistance, and also a sensible resistance to loss of hot hardness. This study was carried out by means of finite element method (FEM) combined with microstructural characterization and mechanical behavior of materials analysis. According to this approach, $\mathrm{H} 13$ steel microstructure, in which carbides could be observed, was

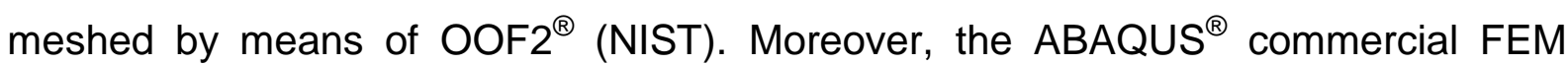
software was used to simulate thermal and mechanical loading applied in the tool throughout mechanical processing. The conducted analysis allowed to observe the effect of precipitates on stress-strain distribution at different temperatures and loads. Hence, critical regions, in which damage could be favored as well failure onset in the microstructure of the hot forging tool, are displayed. The investigation was based on and compared to literature results and it showed that it can be possible to design the microstructure of hot forging materials, in which an improvement in the thermal fatigue resistance could be improved. The main remarks and conclusions of this work are as follows: (i-) precipitates and interfaces are preferential regions to nucleation and growth of cracks, and they seem to work as stress concentrators; (ii-) modulus of elasticity of phases has the strongest influence in the stress fields of the microstructure; (iii-) the mismatch between thermal expansion coefficients of the phases leads to compressive stresses on interfaces and also the highest thermal strain; (iv-) thermal strains are higher on the precipitates than on the steel matrix; ( $v-$ ) elastic-plastic properties of steel matrix influenced on thermal cycles. In addition, cooling is the most critical condition of thermal stresses by analyzing each thermal cycle in this phase; and (vi-) whereas the precipitates have elastic behavior, and the most critical step is the heating, in which the maximum temperature of the cycle is reached.
\end{abstract}

Keywords: Numerical Simulation. Microstructure. Hot Forging. Tool Steel. 


\section{LISTA DE ILUSTRAÇÕES}

Figura 1 - Níveis estruturais descritos por Hornbogen (1984).

Pág.

28

Figura 2 - llustração do processo de forjamento a quente com a utilização de prensa hidráulica; as imagens ampliadas servem para mostrar a sequência geral envolvida neste processo. (UDOMPHOL, 2007)

Figura 3 - Principais classificações do forjamento. (SHIRGAOKAR, 2005)

Figura 4 - Carregamentos mecânicos, e seus respectivos sentido e direção, associados aos processos de conformação mecânica: (a-) laminação; (b-) forjamento. Simbologia: $F=$ força aplicada para a conformação; $v=$ velocidade de conformação. (BEDDOES; BIBBY, 1999)

Figura 5 - Forjamento com ferramenta do tipo martelo de queda com prancha. (DIETER, 1988)

Figura 6 - Forjamento com ferramenta do tipo martelo de queda atuado por ação pneumática. (DIETER, 1988)

Figura 7 - Forjamento com ferramenta do tipo prensa hidráulica. (adaptado de DIETER, 1988)

Figura 8 - Forjamento com ferramenta do tipo prensa mecânica com manivela. (DIETER, 1988)

Figura 9 - Comparação entre a força aplicada e a velocidade de avanço das ferramentas de forjamento: martelo de queda (a e c); prensa hidráulica (b e d). Nota-se, também, que o tempo de contato entre ferramenta e peça é maior no caso da prensa do que no martelo. (RODRIGUES; MARTINS, 2010)

Figura 10 - Diagrama de fases Fe-C com microestruturas representativas de aços, do ferro- $\alpha$ e do ferro- $\gamma$. MO corresponde a microscopia óptica. (adaptado de CALLISTER JÚNIOR, 2007)

Figura 11 - Microestruturas (MEV) do aço ferramenta 55NiCrMoV7, mostrando em (a-) a matriz martensítica em ripas, decorrente de têmpera do material, e em (b-) obtém-se, após tratamento térmico, a martensita revenida com a presença de precipitados. (ZHANG; DELAGNES; BERNHART, 2004) 
Figura 12 - Diagrama CCT para o aço AISI H13, cuja fase austenítica foi resfriada a partir de $1030^{\circ} \mathrm{C}$. Simbologia: $\mathrm{A}=$ austenita; $\mathrm{C}=$ carbonetos; $\mathrm{F}=$ ferrita; $\mathrm{B}=$ bainita; $\mathrm{P}=$ perlita; $\mathrm{M}=$ martensita; $\mathrm{HV}=$ dureza Vickers; $A c_{1 \mathrm{~b}}=$ mínima temperatura para $\mathrm{a}$ existência da austenita; e $A c_{1 \mathrm{e}}=$ temperatura máxima para a ocorrência de carboneto na microestrutura. (ROBERTS; KRAUSS; KENNEDY, 1998)

Figura 13 - Seção do diagrama de fases do aço AISI H13 elaborado a partir do software THERMOCALC. Simbologia: $\alpha$ é a ferrita; e $\gamma$ é a austenita. (HU et al., 2006a)

Figura 14 - Curva de revenido para o aço AISI H13. (adaptada de BABU; RIBEIRO; SHIVPURI, 1999)

Figura 15 - Esquema dos mecanismos de danos encontrados comumente nas matrizes de forjamento a quente. (KANNAPPAN, 1969 apud BARRAU et al., 2002)

Figura 16 - Ocorrência de desgaste e de trincas por fadiga em um punção de forjamento a quente. (MESQUITA; HADDAD; BARBOSA, 2008)

Figura 17 - Seção de uma trinca de propagação perpendicular à superfície interna de um tubo do BWR (reator de água em ebulição) causada por fadiga térmica (ALVARENGA JÚNIOR, 2006).

Figura 18 - Aparatos experimentais de fadiga térmica: (a) Máquina de ensaio de fadiga térmica desevolvida por Berling e Slot em 1969. (b) Máquina de ensaio de fadiga térmica mais atual (legenda: A é a bobina de indução; B é o sistema de rotação de eixo e $C$ é um soprador de ar para medição de temperatura). (SILVA, 2006; ALVARENGA JÚNIOR, 2006)

Figura 19 - Trincas térmicas em diferentes CPs. (a) variações de temperatura no ensaio do $\mathrm{CP}$ de aço matriz+NbC (com composição química nominal em massa: $0,83 \% \mathrm{C} ; 2,0 \% \mathrm{~W}$; 3,0\%Mo; 4,6\%Cr; 1,0\%V; 2,5\%Ni); (b) CP de aço matriz+NbC, após o ensaio de fadiga térmica com regiões rosa (conjunto de trincas).(c) Outro CP, trabalhado por Serantoni Silva (2003), no qual se visualiza a propagação das trincas radiais (indicados por A) e das trincas circunferenciais (indicados por B). (Serantoni Silva, 2003; Silva, 2006).

Figura 20 - Seção transversal do CP ensaiado sob fadiga térmica, mostrando o detalhe da trinca nucleada em um carboneto. (MEV- elétrons retroespalhados). (Silva, 2006) 
Figura 21 - Propagação da trinca térmica ao longo da célula eutética de carbonetos de NbC. (Silva, 2006)

Figura 22 - Operação de recalque: (a-) disposição de um tarugo entre duas matrizes; (b-) deformação da peça sem a presença de atrito na interface; (c-) deformação da peça com a presença de atrito na interface. Simbologia: $D=$ matriz; $B=$ tarugo; $F=$ força aplicada. (ASM INTERNATIONAL, 1995)

Figura 23 - Sistema tribológico e os fatores envolvidos no meio interfacial (região de contato). Simbologia: $\psi=$ índice de plasticidade; $E^{\prime}=$ módulo de elasticidade equivalente; $p_{y}=$ pressão de escoamento; $\mathrm{H}=$ dureza do material mais mole; $\mathrm{F}_{\mathrm{F}}=$ força de atrito; $F_{N}=$ força normal; $A_{r}=$ área real de contato; $A_{o r}=$ área inicial real de contato; $\beta=$ raio da ponta das asperezas; $\sigma^{*}=$ desvio das alturas das asperezas; $\theta$ =inclinação das asperezas. (ASM INTERNATIONAL, 1995)

Figura 24 - Interação entre a ferramenta e a peça em várias situações de contato: (a-) com baixa pressão de contato nas asperezas (baixa conformidade); (b-) com pressão de contato moderada nas asperezas (média conformidade); (c-) com alta pressão de contato nas asperezas (total conformidade). (VALBERG, 2010)

Figura 25 - llustração de três modelos de atrito considerados mais representativos das situações encontradas nos processos de conformação. À esquerda, é fornecido o gráfico da tensão de atrito versus a pressão de contato para os distintos modelos. Já à direita, nota-se o nome de cada modelo. Simbologia: $\tau$ é a tensão de atrito, $\mu$ é o coeficiente de atrito, $\mathrm{k}$ é a tensão de escoamento de cisalhamento, $\mathrm{m}$ é o fator de atrito por cisalhamento constante f é o fator que denota o atrito na área de contato real $(0 \leq f \leq 1)$, e $\alpha$ é a razão entre a área real e área aparente de contato. (VALBERG, 2010)

Figura 26 - Representação das componentes de tensões atuantes em um material, vista sob o aspecto tridimensional. (adaptado de DIETER, 1988)

Figura 27 - Decomposição das tensões principais em um sólido. (MORAIS, 2012)

Figura 28 - Gráfico representativo dos critérios de Rankine, Tresca e von Mises para duas dimensões. $\sigma_{0}$ é a tensão de escoamento; $\sigma_{1}$ e $\sigma_{2}$ são as tensões principais no material; e $\sigma_{3}$ é a tensão assumida como nula. (MEYERS; CHAWLA, 2009) 
Figura 29 - Perfil de temperatura em uma placa "infinita", sendo que é assumida a condição de regime permanente para a troca de calor por condução. (adaptado de GEIGER; POIRIER, 1973)

Figura 30 - Fluxograma da análise por elementos finitos elaborado por Bathe (1996) e adaptado por Moreno (2000).

Figura 31 - Tensões de von Mises na microestrutura de cilindro de laminação de tiras a quente, decorrido um ciclo térmico: (a-) visão geral das tensões na microestrutura bifásica; (b-) concentrações de tensões na interface matriz-precipitado e no interior do precipitado, respectivamente. (adaptado de SERANTONI SILVA, 2003)

Figura 32 - Perda de dureza da matriz de forjamento a quente, a partir de uma posição da sua superfície denominada de distância crítica. (adaptada de MESQUITA; HADDAD; BARBOSA, 2008)

Figura 33 - Microestruturas de aço ferramenta consultadas na literatura: (a-) micrografia do AISI H13, adaptada do trabalho de Hu et al. (2006b), que possui uma matriz martensítica e precipitados do tipo carboneto $\mathrm{M}_{23} \mathrm{C}_{6}$; (b-) micrografia do AISI H13, com a seguinte composição química: $\mathrm{Fe}-0.40 \% \mathrm{C}-0.8 \% \mathrm{Si}-5.25 \% \mathrm{Cr}-$ $1 \% \mathrm{~V}-1.35 \% \mathrm{Mo}$; ataque químico: $2 \%$ nital (ASM INTERNATIONAL, 2004); (c-) micrografia do DIEVAR, ilustrando a morfologia e distribuição dos carbonetos de cromo.

Figura 34 - Microestrutura do aço AISI H13, adaptada de ASM Internacional (2004). A área foi delimitada em $60 \mu \mathrm{m}$ de comprimento e $40 \mu \mathrm{m}$ de largura. (a-) imagem real; (ii-) imagem segmentada, considerando o devido fator de escala.

Figura 35 - Esquema da área microestrutural prevista para o estudo térmico.

Figura 36 - Desenho esquemático dos carregamentos e das condições de contorno impostas para a análise de convergência.

Figura 37 - Cinco malhas de elementos finitos com graus de refinamento distintos, e que foram geradas sobre a microestrutura do aço AISI H13 por meio do software OOF2 ${ }^{\circledR}$.

Figura 38 - Curva de convergência resultante da análise das malhas na microestrutura do aço ferramenta AISI H13. O valor assintótico é previsto por meio do resultado analítico obtido para a energia de deformação, e pode ser levada em consideração uma possível correção em função dos valores distintos de coeficiente de Poisson das fases. 
Figura 39 - Distribuição térmica no aço AISI H13, aplicado como ferramenta em um processo de forjamento a quente: (a-) resultado após resfriamento da superfície da ferramenta; (b-) resultado imediatamente após o ciclo de forjamento (temperatura máxima verificada para a ferramenta). (SJÖSTRÖM, 2004)

Figura 40 - Desenho esquemático das condições de contorno e carregamento puramente térmico definidos para o primeiro modelo numérico elaborado.

Figura 41 - Desenho esquemático das condições de contorno e carregamento definidas para 0 modelo numérico termomecânico elaborado.

Figura 42 - Localização das amostras de elementos estudados para as duas fases presentes na microestrutura do aço AISI H13.

Figura 43 - Variação de temperatura $\left[{ }^{\circ} \mathrm{C}\right]$ ao longo da área microestrutural, após os momentos de: (a) aquecimento e (b) resfriamento dos ciclos térmicos impostos.

Figura 44 - Distribuição da tensão máxima principal [MPa] na matriz e nos carbonetos do aço AISI H13, ao término dos 10 ciclos térmicos nas seguintes etapas: (a-) pós-aquecimento; (b-) pósresfriamento.

Figura 45 - Distribuição da tensão de von Mises [MPa] na matriz e nos carbonetos do aço AISI H13, ao final dos 10 ciclos térmicos nas seguintes etapas: (a-) pós-aquecimento; (b-) pósresfriamento.

Figura 46 - Distribuição da deformação térmica na matriz e nos carbonetos do aço AISI H13, ao final dos 10 ciclos térmicos nas seguintes etapas: (a-) pós-aquecimento; (b-) pósresfriamento.

Figura 47 - Tensões de von Mises [MPa] e temperatura $\left[{ }^{\circ} \mathrm{C}\right]$ na microestrutura da ferramenta após: (a-) o aquecimento até $600^{\circ} \mathrm{C}$; e (b-) o resfriamento até $225^{\circ} \mathrm{C}$. Em (c-), tem-se a deformação plástica obtida como resultado na microestrutura do aço $\mathrm{H} 13$ ao atingir a temperatura de $600{ }^{\circ} \mathrm{C}$.

Figura 48 - Localização das amostras de precipitados da microestrutura do aço $\mathrm{H} 13$, com área de $60 \times 40 \mu \mathrm{m}^{2}$, nas quais foram feitas as análises de microtensões. 
Figura 49 - Variação da tensão máxima principal na superfície de onze Pág. precipitados do aço AISI H13.

Figura 50 - Resposta da tensão máxima principal com a variação da continuidade do carboneto.

Figura 51 - Evolução no comportamento de tensões de von Mises [MPa] na microestrutura do aço ferramenta AISI H13, decorrente $1 \mathrm{~s}$ de aquecimento em paralelo com a aplicação de carregamento mecânico. 


\section{LISTA DE TABELAS}

Tabela 1 - Comparação dos processos de fabricação por conformação, diferenciados conforme o parâmetro temperatura de operação. (RODRIGUES; MARTINS, 2010)

Pág.

Tabela 2 - Comparação entre os valores previstos para a velocidade de avanço de ferramentas para forjamento. (adaptado de ALTAN, 1973 apud DIETER, 1988)

Tabela 3 - Nomenclatura de aços ferramenta definida pelo AISI. (AVNER, 1974)

Tabela 4 - Composição química nominal, em massa, do aço AISI H13. (ASM INTERNATIONAL, 2005b)

Tabela 5 - Dados de um processo de forjamento de uma ponta de eixo. (adaptada de MESQUITA; HADDAD; BARBOSA, 2008)

Tabela 6 - Resumo de formulações de tensões e deformações térmicas relacionadas a um material isotrópico.

Tabela 7 - Propriedades do carboneto, considerado elástico e presente no aço AISI H13, empregadas no modelo numérico. (BAUCCIO, 1994)

Tabela 8 - Propriedades térmicas e elastoplásticas da matriz do aço AISI H13 consideradas nas simulações numéricas realizadas. Para complementar, a densidade do material corresponde a 7800 $\mathrm{kg} / \mathrm{m}^{3}$ e o coeficiente de Poisson é 0,3. (AFAZOV; RATCHEV; SEGAL, 2011)

Tabela 9 - Fração volumétrica das duas fases presentes na microestrutura imposta do aço AISI H13: matriz martensítica e carboneto de cromo.

Tabela 10 - Informações do número de nós e dos elementos das malhas testadas para a análise de convergência.

Tabela 11 - Comparação entre os resultados obtidos por simulação numérica e os resultados teóricos para a tensão, em um mesmo elemento para todas as malhas, e para a energia de deformação.

Tabela 12 - Propriedades do forjado: aço AISI 1045. (DUAN et al, 2009; DAVIES et al, 2003) 
Tabela 13 - Comparação entre os valores das tensões resultantes de von

Pág. Mises e de Rankine nos elementos 1 e 2, posicionados na superfície da microestrutura.

Tabela 14 - Comparação entre as microtensões teóricas e simuladas por MEF em alguns carbonetos de cromo da microestrutura do aço AISI H13. 


\section{LISTA DE ABREVIATURAS E SIGLAS}

$\begin{array}{ll}\text { ASM } & \text { American Society for Metals } \\ \text { AISI } & \text { American Iron and Steel Institute } \\ \text { BC } & \text { Boundary Condition (Condição de contorno) } \\ \text { BWR } & \text { Boiling Water Reactor (Reator de água em ebulição) } \\ \text { CCC } & \text { Estrutura cristalina cúbica de corpo centrado } \\ \text { CCT } & \text { Continuous Cooling Transformation (Diagrama de resfriamento } \\ & \text { contínuo) } \\ \text { CFC } & \text { Estrutura cristalina cúbica de faces centradas } \\ \text { CP } & \text { Corpo de Prova } \\ \text { EPD } & \text { Estado plano de deformações } \\ \text { EPT } & \text { Estado plano de tensões } \\ \text { MCI } & \text { Microscopia de Campo lônico } \\ \text { MEF } & \text { Método dos Elementos Finitos, ou Finite Elements Method } \\ & \text { (FEM) } \\ \text { MEV } & \text { Microscópio Eletrônico de Varredura } \\ \text { MET } & \text { Microscópio Eletrônico de Transmissão } \\ \text { MO } & \text { Microscópio Óptico } \\ \text { NIST } & \text { National Institute of Standards and Technology }\end{array}$




\section{LISTA DE SÍMBOLOS}

A

$\mathrm{Ac}_{1 \mathrm{~b}}$

$\mathrm{Ac}_{1 \mathrm{e}}$

Aor

$A_{r}$

B

C

$c_{p}$

d

D

$D_{m}$

E

$E^{\prime}$

$E_{\text {ef }}$

$\mathrm{E}_{\mathrm{POT}}$

$\mathrm{E}_{1}$

$\mathrm{E}_{2}$

$f$

$\mathrm{F}$

$\mathrm{F}_{\mathrm{F}}$

$\mathrm{F}_{\mathrm{N}}$

$f_{V 1}$

$f_{V 2}$

$\mathrm{g}$

G

$\mathrm{h}$

$\mathrm{H}$

Área do êmbolo do pistão/ Área de troca térmica

Mínima temperatura para a existência da austenita

Temperatura máxima para a ocorrência de carboneto na microestrutura

Área inicial real de contato

Área real de contato

Tarugo

Continuidade de carbonetos

Calor específico à pressão constante

Razão entre $R_{1}$ e $R_{2}$, sendo $R_{1}$ o raio do carboneto e $R_{2}$ é a distância entre as superfícies dos carbonetos

Matriz

Distância média livre entre carbonetos

Módulo de elasticidade

Módulo de elasticidade equivalente

Módulo de elasticidade efetivo da microestrutura bifásica

Energia potencial

Módulo de elasticidade do carboneto

Módulo de elasticidade da matriz

Fator expressando o atrito na área real de contato

Força aplicada para a conformação

Força de atrito

Força normal

Fração volumétrica da matriz

Fração volumétrica dos precipitados

Aceleração da gravidade

Módulo de cisalhamento

Coeficiente de troca térmica entre o sólido e o fluido circundante

Dureza do material mais mole 
$h_{k}$

$J_{1}, J_{2} e J_{3}$

$\mathrm{k}$

[k]

$k_{e}$

$k_{m}$

$k_{p}$

$\mathrm{K}_{\mathrm{t}}$

$\mathrm{K}_{\mathrm{IC}}$

L

$\mathrm{m}$

MC

$\mathrm{M}_{2} \mathrm{C}$

$\mathrm{M}_{3} \mathrm{C}$

$\mathrm{M}_{6} \mathrm{C}$

$\mathrm{M}_{7} \mathrm{C}_{3}$

$\mathrm{M}_{23} \mathrm{C}_{6}$

$\mathrm{m}_{\mathrm{p}}$

$p$

$p_{y}$

$q_{k}$

$\mathrm{T}$

$\mathrm{t}$

$T_{f}$

$\mathrm{T}_{\text {ferramenta }}$

$T_{\text {min }}$

$\mathrm{T}_{\text {peça }}$

$T_{S}$

U

V

Coeficiente de transferência de calor por condução

Momento de inércia do volante

Invariantes do tensor da tensão-desvio

Condutividade térmica

Matriz simétrica de rigidez do material

Condutividade térmica efetiva do material bifásico

Condutividade térmica da matriz martensítica

Condutividade térmica do precipitado

Fator intensificador de tensões

Tenacidade à fratura

Comprimento da placa

Fator de atrito por cisalhamento constante

Carbonetos ricos em vanádio

Carbonetos ricos em molibdênio, embora com redução da porcentagem de molibdênio em relação ao $\mathrm{M}_{6} \mathrm{C}$

Carbonetos secundários, ricos em ferro

Carbonetos ricos em molibdênio

Carbonetos metaestáveis, ricos em cromo

Carbonetos estáveis, ricos em cromo

Massa do pilão

Pressão pneumática que atua no avanço do êmbolo do pistão

Pressão de escoamento

Fluxo de calor por condução

Temperatura

Tempo

Temperatura do fluido

Temperatura inicial da ferramenta

Temperatura mínima à qual o material é submetido

Temperatura inicial da peça

Temperatura da superfície do sólido

Energia de deformação elástica

Velocidade de conformação/ Velocidade do pilão no início da conformação por forjamento 


\begin{tabular}{|c|c|}
\hline V & Volume da placa \\
\hline W & Energia total \\
\hline$x$ & Dimensão característica da placa \\
\hline$\alpha$ & Coeficiente de expansão térmica do material \\
\hline$\alpha$ (ferro) & Ferrita \\
\hline$\alpha(T)$ & Coeficiente de expansão térmica em função da temperatura \\
\hline$\alpha_{1}$ & Coeficiente de expansão térmica do carboneto \\
\hline$\alpha_{2}$ & Coeficiente de expansão térmica da matriz \\
\hline$\beta$ & Raio da ponta das asperezas \\
\hline$\Delta \alpha$ & $\begin{array}{l}\text { Diferença entre os coeficientes de expansão térmica das fases } \\
\text { do material }\end{array}$ \\
\hline$\Delta \mathrm{T}$ & Diferença de temperatura no material bifásico \\
\hline$\{\varepsilon\}$ & Vetor da deformação \\
\hline$\left\{\varepsilon_{m}\right\}$ & Vetor da deformação mecânica \\
\hline$\varepsilon_{m}(T)$ & Deformação mecânica em função da temperatura \\
\hline$\varepsilon_{t}(T)$ & Deformação térmica em função da temperatura \\
\hline$\left\{\varepsilon_{t}\right\}$ & Vetor da deformação térmica \\
\hline$\varepsilon_{t o t}(T)$ & Deformação total em função da temperatura \\
\hline $\begin{array}{l}\varepsilon_{x}, \varepsilon_{y} \text { e } \varepsilon_{z} \\
\gamma \text { (ferro) }\end{array}$ & $\begin{array}{l}\text { Deformações atuantes nas diferentes direções do material } \\
\text { Austenita }\end{array}$ \\
\hline$\gamma_{x y}, \gamma_{y z}$ e $\gamma_{z x}$ & $\begin{array}{l}\text { Deformações por cisalhamento atuantes nos diferentes planos } \\
\text { do material }\end{array}$ \\
\hline$\mu$ & Coeficiente de atrito \\
\hline$v$ & Coeficiente de Poisson \\
\hline$v_{1}$ & Coeficiente de Poisson do carboneto \\
\hline $\mathrm{v}_{2}$ & Coeficiente de Poisson da matriz \\
\hline$\theta$ & Inclinação das asperezas \\
\hline$\rho$ & Densidade \\
\hline$\{\sigma\}$ & Vetor da tensão \\
\hline$\sigma^{*}$ & Desvio das alturas das asperezas \\
\hline$\sigma_{i j}$ & Tensor (soma das componentes desvio e hidrostática) \\
\hline$\sigma_{i j}^{\prime}$ & Tensor da tensão-desvio \\
\hline
\end{tabular}




$\begin{array}{ll}\sigma_{k k} & \text { Representante da soma das tensões principais } \\ \sigma_{m} & \text { Tensão média ou hidrostática } \\ \sigma_{m} \delta_{i j} & \text { Tensor da tensão hidrostática } \\ \sigma_{n} & \text { Tensão Normal Média na Peça } \\ \left\{\sigma_{t}\right\} & \text { Vetor da tensão térmica } \\ \sigma_{x}, \sigma_{y} \text { e } \sigma_{z} & \text { Tensões normais atuantes nas diferentes direções do material } \\ \sigma_{0} & \text { Tensão de escoamento/ Tensão de escoamento uniaxial } \\ \sigma_{1}, \sigma_{2} \text { e } \sigma_{3} & \text { Tensões principais, sendo que } \sigma_{\mathrm{x}} \text {, } \sigma_{\mathrm{y}} \text { e } \sigma_{z} \text { são as tensões } \\ & \text { principais, conforme o sistema cartesiano de coordenadas } \\ \tau & \text { Tensão de cisalhamento } \\ \tau_{m a ́ x} & \text { Tensão máxima de cisalhamento } \\ \tau_{o c t} & \text { Tensão de cisalhamento octaédrica } \\ \tau_{x y}, \tau_{y z} \text { e } \tau_{z x} & \text { Tensões de cisalhamento atuantes nos diferentes planos do } \\ \nabla^{2} & \text { material } \\ \omega_{f} & \text { Velocidade angular da manivela após a conformação por } \\ \omega_{0} & \text { Índice de plasticidade } \\ & \text { Operadoraplaciano la peça }\end{array}$




\section{SUMÁRIO}

$1 \quad$ INTRODUÇÃO 23

2 OBJETIVOS 26

$3 \quad$ REVISÃO DA LITERATURA 27

3.1 DEFINIÇÃO DE MICROESTRUTURA 27

3.2 PROCESSOS DE CONFORMAÇÃO PLÁSTICA: FORJAMENTO A QUENTE $\quad 29$

3.3 CENÁRIO CARACTERÍSTICO DA FERRAMENTA NO TRABALHO A QUENTE

3.3.1 Aço AISI H13 como ferramenta no forjamento a quente

3.4 DANOS EM AÇOS FERRAMENTA DURANTE O FORJAMENTO A QUEENTE

3.4.1 Fundamentos de fadiga térmica de materiais metálicos 51

3.4.2 Trincas por fadiga térmica (nucleação e propagação) 54

3.5 CONCEITOS REFERENTES AO ATRITO EXISTENTE NA INTERFACE PEÇA-FERRAMENTA NA CONFORMAÇÃO MECÂNICA

3.6 SOLICITAÇÕES NA FERRAMENTA DURANTE O FORJAMENTO A QUENTE

3.6.1 Equacionamento das tensões mecânicas (condição isotérmica) 64

3.6.2 Critérios para avaliação do campo de tensões mecânicas no material da ferramenta

$\begin{array}{lll}\text { 3.6.3 Transferência de calor por condução } & 75\end{array}$

3.6.4 Equacionamento das tensões térmicas 79

3.7 SIMULAÇÃO NUMÉRICA PELO MEF 81

3.7.1 Simulação numérica de ciclos térmicos em microestruturas de ferramentas de conformação mecânica 
4 MATERIAIS E MÉTODOS

5 RESULTADOS E DISCUSSÕES

5.1 ASPECTOS GERAIS VERIFICADOS NOS RESULTADOS OBTIDOS DO MODELO TÉRMICO

5.2 INFLUÊNCIA DAS PROPRIEDADES DAS FASES NA RESPOSTA DO CAMPO DE TENSÕES TÉRMICAS NA MICROESTRUTURA DA FERRAMENTA

5.3 INFLUÊNCIA DAS PROPRIEDADES DAS FASES E DA TEMPERATURA NA DEFORMAÇÃO ELÁSTICA DO MATERIAL DA FERRAMENTA

5.4 EFEITO DO TEMPO NA DETERMINAÇÃO DAS TEMPERATURAS IMPOSTAS NOS CICLOS

5.5 DIFICULDADES NA PRÉ-DEFINIÇÃO DO NÚMERO DE CICLOS A SEREM SIMULADOS NUMERICAMENTE

5.6 COMPARAÇÃO DO MODELO NUMÉRICO COM A TEORIA

5.7 IMPLICAÇÕES DA EXISTÊNCIA DE CARREGAMENTOS MECÂNICOS NA MICROESTRUTURA DA FERRAMENTA DE FORJAMENTO A QUENTE

6 CONCLUSÕES

7 TRABALHOS FUTUROS 


\section{INTRODUÇÃO}

A conformação mecânica de um material metálico é descrita, basicamente, como um processo de deformação plástica que visa à modificação da forma deste material no estado sólido (RODRIGUES; MARTINS, 2010). Essa deformação leva à produção de pré-formas (por exemplo: chapas, barras e tubos), peças e/ou componentes mecânicos para aplicação em diversos setores da indústria. Especificamente, no caso do forjamento, objeto de estudo da presente pesquisa, o princípio da conformação é classificado como deformação plástica maciça. (ASM INTERNATIONAL, 2005a).

Tendo em vista a temperatura de fusão do material que passa pela conformação mecânica, Zhao e Controls (2000) consideram as seguintes faixas de temperatura de operação:

$>$ a frio: peça conformada em temperaturas abaixo de $30 \%$ de sua temperatura de fusão;

a morno: peça conformada em temperaturas entre $30 \%$ e $60 \%$ de sua temperatura de fusão;

$>$ a quente: peça conformada em temperaturas acima de $60 \%$ de sua temperatura de fusão.

A análise do processo de forjamento pode ter focos diferentes. A maioria dos autores (HARTLEY; PILLINGER, 2006; SHARMA; RAJ, 2008; WEl et al., 2012) direciona seus estudos à peça a ser forjada a quente, considerando então a ferramenta como rígida. Com isso, muitos trabalhos da literatura remetem à análise da peça ou material a ser forjado.

Por outro lado, muitas expectativas ainda se apresentam relacionadas a um melhor entendimento do comportamento mecânico da ferramenta, tanto do ponto de vista macro como microestrutural. Durante o forjamento a quente, a ferramenta é exposta a um grande número de ciclos de carregamentos térmicos e mecânicos, ditados pela elevada pressão mecânica e pela transferência de calor a partir do contato com a peça, ficando dessa forma sujeita aos mecanismos de dano, principalmente ao desgaste abrasivo e à fadiga térmica. (BEHRENS et al., 2008) 
Um importante recurso para se avaliar o comportamento mecânico das ferramentas em serviço no forjamento a quente é a simulação numérica, cujo determinante de sua aplicação é a redução no fator tempo; e, em alguns casos, a economia de custos. Entretanto, no que se refere à fadiga térmica das ferramentas em questão, muitos autores (CALISKANOGLU et al., 2002; PERSSON; HOGMARK; BERGSTRÖM, 2004; MENG et al., 2012) optam pela parte experimental para a realização de suas análises. Desta maneira, o assunto referente à simulação numérica pelo método dos elementos finitos (MEF) nesta área, apesar de existirem, são passíveis de novos estudos a fim de abranger um campo mais amplo de conhecimento nesse assunto.

Do ponto de vista econômico, Doege et al. (1994) apud Deshpande (2011) descrevem que a relevância do estudo dos mecanismos de dano da parte ferramental empregada no forjamento, bem como a otimização dos seus materiais, consiste no fato de que:

$>$ de 10 a $15 \%$ dos custos globais deste processo de conformação dizem respeito à ferramenta em questão. Porém, contabilizando custos diretos e indiretos envolvidos na parte de ferramentas da forjaria, a porcentagem de custos global atingida seria de $70 \%$;

> como aspectos específicos deste custo, podem ser apontados: (i-) material constituinte das matrizes; (ii-) usinagem destas matrizes; (iii-) tratamento térmico após o processo de usinagem; (iv-) retrabalho das ferramentas por usinagem ou mesmo substituição, após a mesmas estarem em serviço, com a finalidade de eliminar as camadas superficiais deformadas plasticamente ou que sofreram revenimento; e (v-) custos, com mão-de-obra especializada, envolvidos no set-up do conjunto máquina-operatriz e ferramenta que, segundo Babu, Ribeiro e Shivpuri (1999) pode variar de 10 minutos a 4 horas.

Podem ser apontados, de forma resumida, alguns aspectos como a motivação para o desenvolvimento da pesquisa aqui tratada:

> Na literatura, a maioria dos autores (EVANS; SCHARNING, 2001; ZHANG et al., 2009; OLIVARES; CAMACHO; SEBASTIÁN, 2012), que estuda o processo de fabricação por conformação a quente, volta a sua atenção à peça - em virtude disso, surge a importância de se analisar a ferramenta; 
> Por outro lado, os autores (BERNHART et al., 1999; SJÖSTRÖM; BERGSTRÖM, 2004; KIM et al., 2005; SILVA, 2006), que analisam a ferramenta do processo, direcionam em geral a sua abordagem para os mecanismos de dano por desgaste ou por fadiga térmica, fazendo a análise do ponto de vista experimental e/ou estatístico;

A relevância da aplicação da simulação numérica consiste, em muitos casos, na redução no fator tempo (economia de custos). Todavia, os estudos de simulação se encontram com abordagens, relacionadas à ferramenta, passíveis de melhorias;

> Não obstante, poucas são as referências da literatura destinadas à parte da microestrutura da ferramenta. Segundo Serantoni Silva (2003), a pesquisa direcionada à influência de elementos microestruturais, para se estudar o comportamento da fadiga térmica em ferramentas de conformação, ainda não é reportada na literatura internacional, possivelmente em virtude do apelo tecnológico atribuído aos trabalhos nos dias atuais. Até o final de 2012, essa consideração continua a ser válida, sendo que trabalhos que se destinam a estudar a microestrutura da ferramenta de conformação a quente ainda são raros.

Desse modo, na sequência do presente trabalho, tem-se a abordagem do estudo aqui proposto conforme a divisão descrita:

- no capítulo 2, são fornecidos os objetivos a serem atingidos com a pesquisa de mestrado;

- no capítulo 3, é feita uma revisão da literatura sobre o tema proposto, abrangendo desde os conceitos fundamentais de forjamento a quente até a parte destinada à simulação numérica por MEF, focando no dano por fadiga térmica da ferramenta de conformação a quente;

- no capítulo 4, é relatada a parte relacionada aos materiais e métodos empregados para 0 desenvolvimento das análises térmicas e mecânicas por MEF da microestrutura da referida ferramenta de forjamento a quente;

- no capítulo 5, são reportados os resultados e as discussões dos campos de tensões resultantes da análise por simulação numérica, discorrida na metodologia;

- no capítulo 6, são apresentadas as conclusões obtidas a partir da pesquisa realizada neste trabalho;

- no capítulo 7, são propostos trabalhos futuros para a continuidade deste estudo;

- para finalizar, são expostas as referências da literatura utilizadas. 


\section{OBJETIVOS}

O objetivo deste trabalho é estudar as respostas em termos de tensões e deformações térmicas na microestrutura do aço AISI H13, aplicado como ferramenta durante o forjamento a quente. Para isto, utiliza-se o método dos elementos finitos, com base na aplicação de uma microestrutura real, sendo que o estudo aqui discorrido vai ser focado na avaliação de regiões propensas à ocorrência de dano, em escala microestrutural, com relação à nucleação de trincas por fadiga térmica. 


\section{REVISÃO DA LITERATURA}

Neste item será fornecido o embasamento teórico necessário para fundamentar o desenvolvimento do estudo da microestrutura do aço ferramenta para trabalho a quente, AISI H13, contendo os principais aspectos para o caso específico de aplicação no forjamento a quente. Dentre os assuntos a serem tratados no corrente capítulo, destacam-se: (i-) fornecimento da definição de microestrutura, uma vez que, ao longo deste trabalho, este conhecimento será elementar para discorrer sobre as seções subsequentes; (ii-) conceitos gerais referentes à conformação mecânica a quente; e cenário da ferramenta no decorrer do trabalho a quente, direcionando a abordagem ao forjamento; (iii-) descrição específica de propriedades mecânicas e térmicas bem como resposta microestrutural do aço AISI H13; (iv-) teoria associada aos mecanismos de dano, em especial por fadiga térmica, que pode vir a se manifestar na ferramenta de conformação a quente; ( $v$-) fundamentos relacionados ao meio interfacial peça-ferramenta, com ênfase na importância do atrito; (vi-) conceitos relacionados às solicitações térmicas e mecânicas na ferramenta bem como critérios para avaliação do campo de tensões no aço ferramenta selecionado; e (vii-) fundamentos e aplicação de simulação numérica, visando ao emprego do método dos elementos finitos.

\subsection{DEFINIÇÃO DE MICROESTRUTURA}

Segundo Hornbogen (1984), a microestrutura é um nível estrutural situado entre a fase (cristalina ou amorfa) e a estrutura macroscópica. A figura 1 mostra a dimensão dos elementos microestruturais, mas de um modo geral esses elementos estão entre $1 \mathrm{~nm}$ até cerca de $100 \mu \mathrm{m}$.

Outra definição relata que a microestrutura de um material é composta pelas fases e pelos defeitos cristalinos (contornos de grão, contornos de macla, falhas de empilhamento, lacunas, interstícios e discordâncias, por exemplo) presentes nas mesmas. Ela é determinada, essencialmente, por sua composição química e pelo 
processamento do material (solidificação, tratamento térmico, conformação mecânica, entre outros). Algumas vezes, a microestrutura pode se alterar durante a sua aplicação. (PADILHA, 2000)

Além disso, o termo "microestrutura" é empregado, em muitos casos, para designar características do material que são visíveis apenas por técnicas de microscopia. Tais técnicas podem abranger várias escalas de resolução, podendo ser exemplificadas pela aplicação do microscópio óptico (MO), do microscópio eletrônico de varredura (MEV) e de transmissão (MET). A microscopia de campo iônico (MCl) trouxe avanços no sentido de estender a definição de microestrutura com uma maior resolução na sua grandeza. (HORNBOGEN,1984)

Várias propriedades dos materiais possuem uma estreita relação de dependência com a microestrutura, e como exemplo das referidas propriedades, tem-se: o limite de escoamento; o alongamento; a tenacidade; a resistência ao impacto e ao desgaste, entre outros. Pode-se dizer, também, que tais propriedades são estabelecidas conforme a quantidade, o tamanho, a morfologia e a distribuição das fases e dos defeitos cristalinos na microestrutura. (PADILHA, 2000)

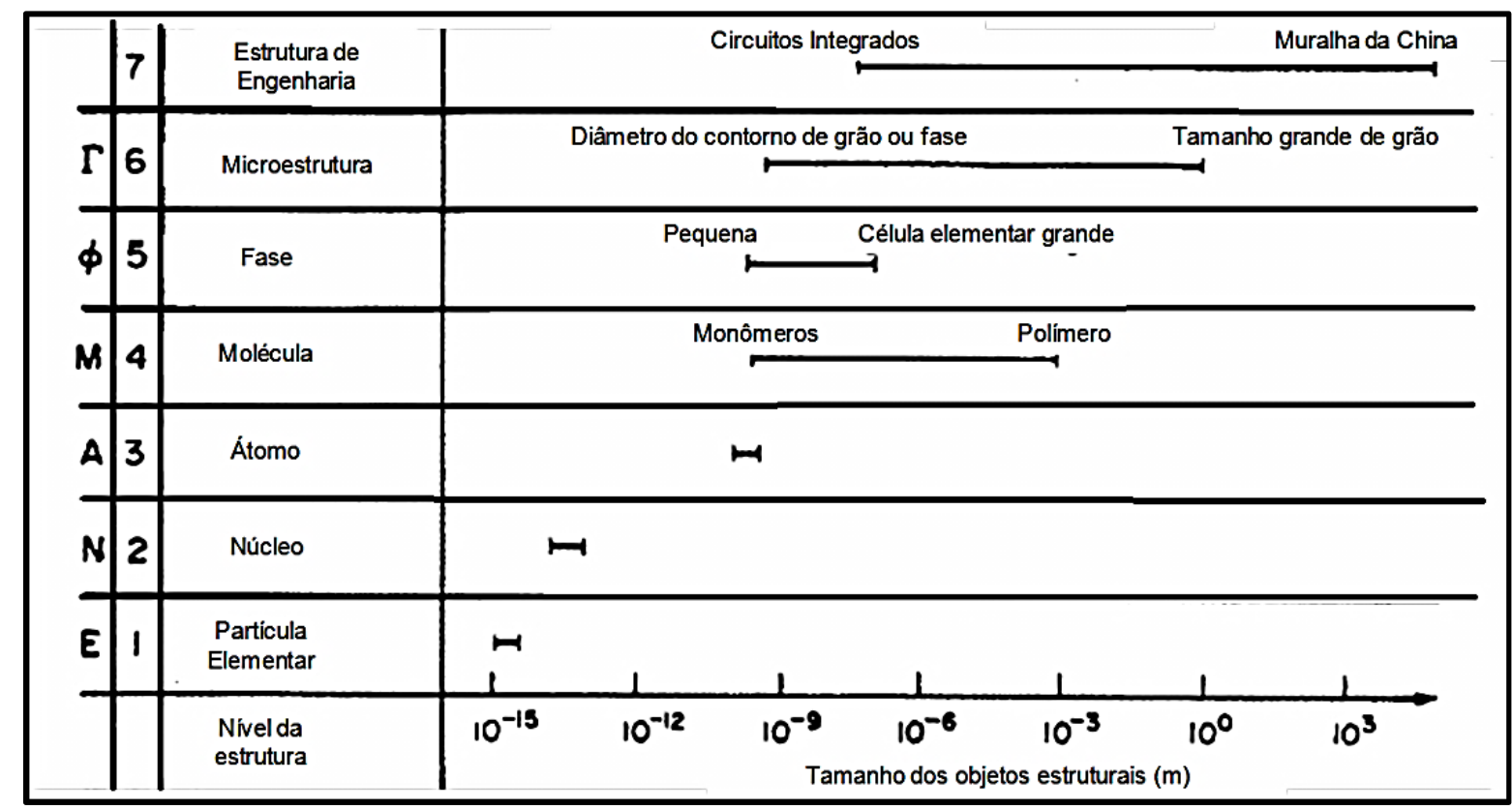

Figura 1- Níveis estruturais descritos por Hornbogen (1984). 


\subsection{PROCESSOS DE CONFORMAÇÃO PLÁSTICA: FORJAMENTO A QUENTE}

No processo de forjamento a quente, uma peça é deformada plasticamente entre duas ferramentas ou matrizes por meio da ação de uma prensa ou de um martelo, resultando na modificação da geometria e das propriedades desta peça. Assim, o forjamento (figura 2) pode ser definido como uma operação de conformação mecânica que ocorre no aspecto volumétrico do material. Conforme descrito pelo ASM International (2005a), as características predominantes em tais processos são sintetizadas em:

- A peça sofre deformação plástica permanente, o que acarreta na alteração significativa de sua forma ou seção transversal;

- A região da peça que se deforma plasticamente é, em geral, muito maior que os locais que permanecem no regime elástico; nessas condições, a recuperação elástica após o mecanismo de deformação pode ser considerada desprezível.

Em relação às classificações que podem ser atribuídas ao forjamento, destacam-se na figura 3 os três tipos mais gerais propostos a este processo de conformação com uma breve descrição acerca de cada um deles.

Para complementar as informações relacionadas ao trabalho de conformação a quente, na tabela 1 são descritas, de forma comparativa, as vantagens e as desvantagens relativas aos processos de fabricação a frio, a morno e a quente. 


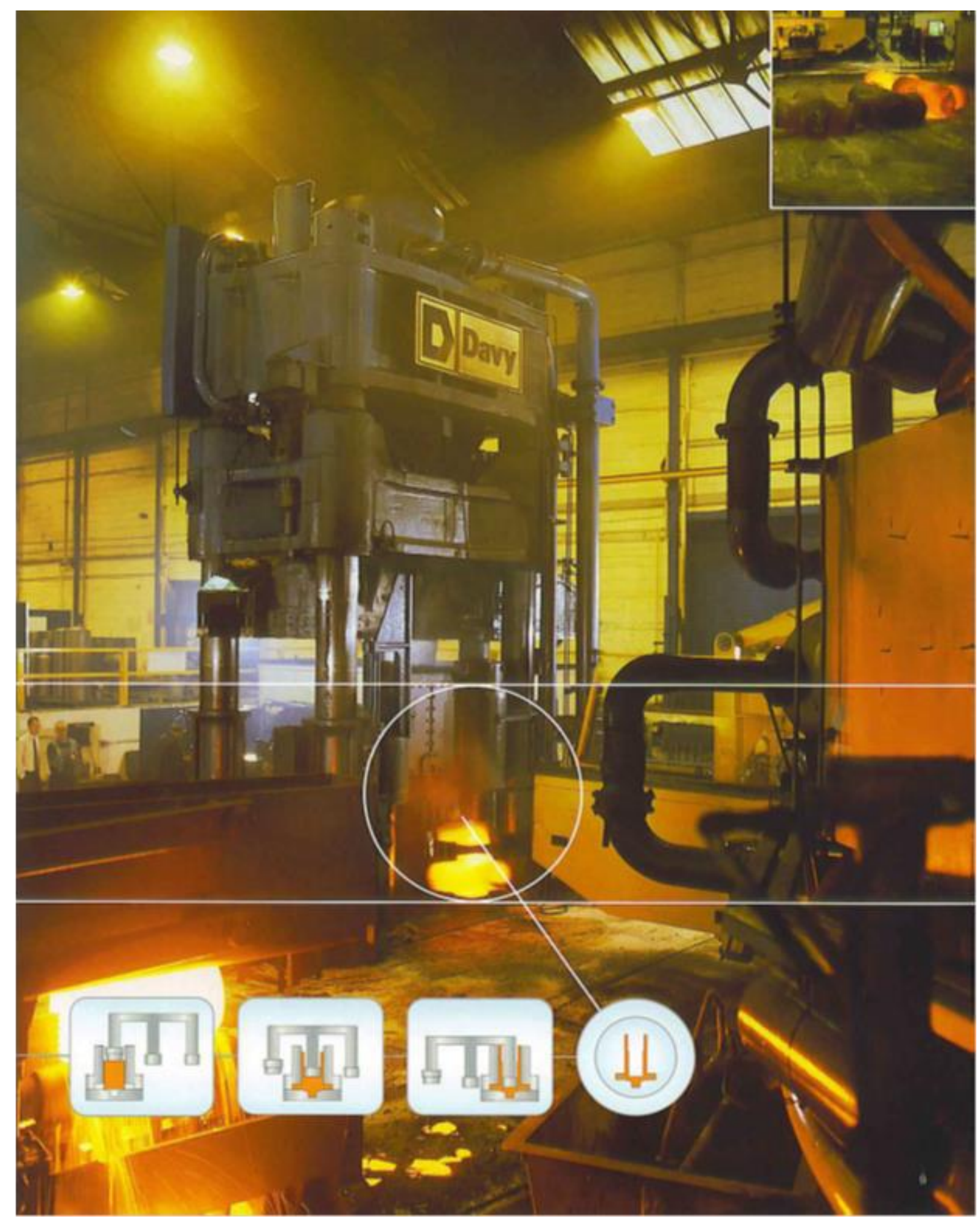

Figura 2 - Ilustração do processo de forjamento a quente com a utilização de prensa hidráulica; as imagens ampliadas servem para mostrar a sequência geral envolvida neste processo. (UDOMPHOL, 2007) 


\section{Forjamento em Matriz}

\section{Fechada com Rebarba}

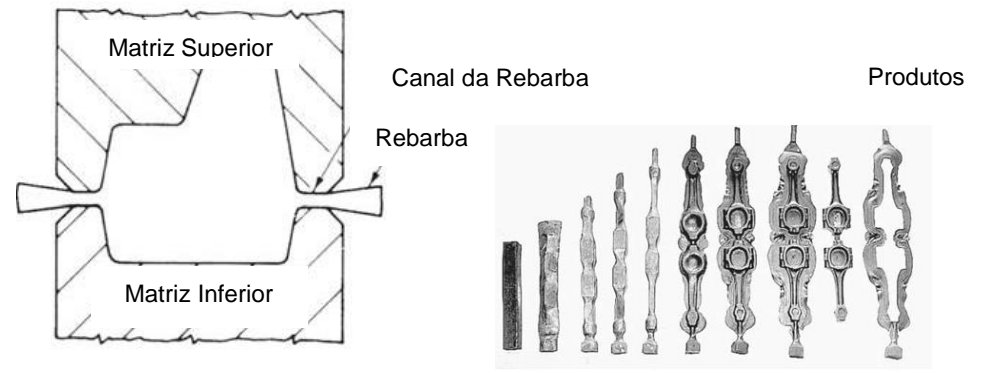

\section{Forjamento em Matriz}

\section{Fechada sem Rebarba}
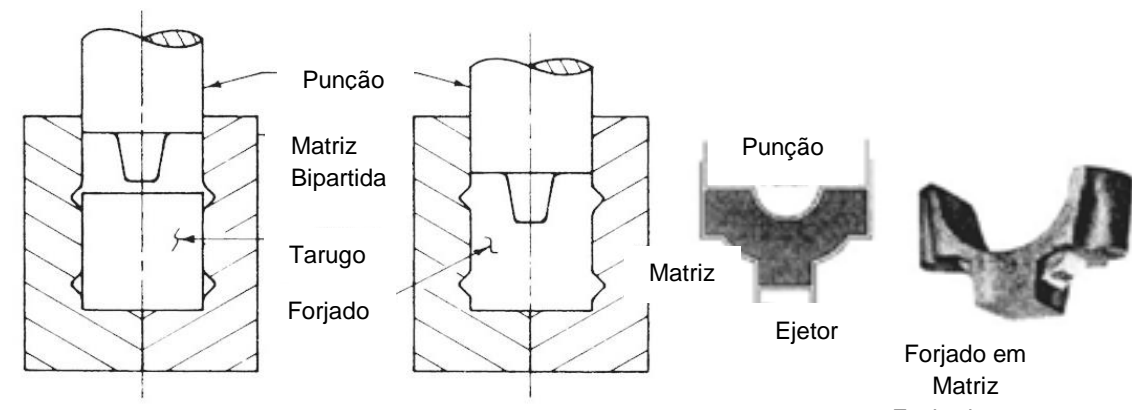

Fechada sem

Rebarba

\section{Forjamento em Matriz}

Aberta

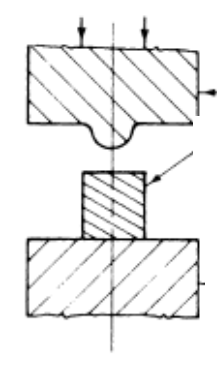

O tarugo é conformado a quente entre as duas metades da matriz, tal que o escoamento na cavidade da matriz é restrito. Há um registro "torneira" no canal da rebarba que determina a espessura e a quantidade de material que irá quantidade de material que irá vai depender do ajuste de vai depender do ajuste de mecânica desta peça e a zona de expansão do seu material. Portanto, o excesso de material da peça é extrudado, formando a rebarba.

O punção age sobre o tarugo de modo a propiciar a deformação a quente ou a frio deste. O escoamento do material pela matriz é projetado visando a não ocorrência de perdas (isto é, sem rebarbas). O punção e a matriz podem ser fabricados a partir de diferentes materiais.

O forjamento a quente acontece quando o metal é pressionado (por uma prensa ou por um martelo) contra uma única matriz. 
Tabela 1 - Comparação dos processos de fabricação por conformação, diferenciados conforme o parâmetro temperatura de operação. (RODRIGUES; MARTINS, 2010)

\begin{tabular}{cl}
\hline $\begin{array}{c}\text { Trabalho de } \\
\text { conformação }\end{array}$ & \multicolumn{1}{c}{ Vantagens } \\
\hline A frio & - Em contrapartida dos trabalhos a morno e a \\
& quente, ocorre o aumento da resistência \\
& mecânica e da dureza do material conformado, \\
& devido ao encruamento. Outra vantagem consiste \\
& no fato de minimizar os efeitos da contracaão e \\
& oxidação, que são facilitadas a altas temperaturas \\
& de processamento, resultando em acabamentos \\
& superficiais e tolerâncias dimensionais melhores \\
& no caso do trabalho a frio.
\end{tabular}

A morno

A quente
- Em contrapartida ao trabalho a frio, as cargas para a ocorrência da deformação são menores. As etapas de recozimento podem também ser reduzidas em função do menor encruamento;

- Em contrapartida ao trabalho a quente, fornece melhorias no acabamento superficial porque reduz o efeito da oxidação na superfície, e melhora a precisão dimensional;

- Em contrapartida aos trabalhos a frio e a morno, a deformação plástica do material é facilitada (tensão de escoamento diminui a partir do aumento da temperatura), podendo ocorrer recristalização. Com a ocorrência da recristalização, pode ser favorecida a granulação mais fina no material. Devido à difusão dos átomos, pode-se também verificar um processo de homogeneidade de composição.

\section{Desvantagens}

- Em contrapartida dos trabalhos a morno e a quente, os limites de escoamento do material são maiores, e a ductilidade é menor. Podem ocorrer, ainda, fissuras e lascas, limitando a geometria a ser fabricada a frio.

rapartida ao trabalho a quente, propicia um aumento no limite de escoamento no material forjado. A força de conformação é maior do que na deformação a quente.

- Em contrapartida ao trabalho a frio, no trabalho a quente o material não precisa ser tratado termicamente antes do processo de conformação. O material trabalhado a quente oxida ou ainda descarboneta, no caso de aços, podendo haver perdas de material da peça conformada a quente;

- Em contrapartida aos trabalhos a frio e a morno, proporciona maior desgaste das ferramentas de conformação bem como dificulta o uso de lubrificantes no meio interfacial. Além disso, as tolerâncias dimensionais da peça são maiores em decorrência dos gradientes térmicos; - Por fim, a microestrutura é mais heterogênea no caso da peça trabalhada a quente do que no caso da peça trabalhada a frio e posteriormente recozida. 
Em relação ao carregamento mecânico imposto à ferramenta (matriz), tem-se no forjamento a ação dos equipamentos sobre as matrizes de modo a provocar o seu movimento. Esta atuação da máquina proporciona à ferramenta de forjamento uma determinada força em conjunto com certa velocidade, de acordo com o esquema mostrado na figura 4. A título ilustrativo, na referida figura, confrontam-se os carregamentos mecânicos propostos para a laminação e os carregamentos mecânicos encontrados para o forjamento.
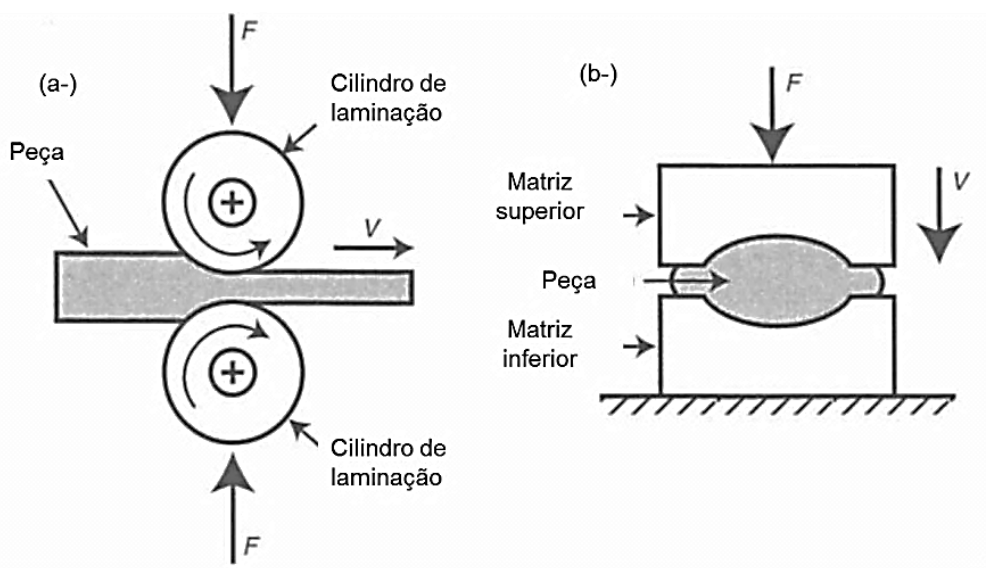

Figura 4 - Carregamentos mecânicos, e seus respectivos sentido e direção, associados aos processos de conformação mecânica: (a-) laminação; (b-) forjamento. Simbologia: $F$ = força aplicada para a conformação; $v$ = velocidade de conformação. (BEDDOES; BIBBY, 1999)

A classificação atribuída às ferramentas de forjamento pode ser dividida em dois grupos: (i-) conforme o equipamento, tem-se o martelo de queda e as prensas (mecânica, hidráulica ou parafuso); e (ii-) de acordo com o processo, distingue-se em forjamento em matriz aberta e forjamento em matriz fechada.

Perante as considerações relatadas por Dieter (1988), podem-se diferenciar, basicamente, as seguintes classificações:

- martelo de queda livre - a força compressiva de conformação da peça depende do peso, ou pilão, em queda livre. Os martelos de queda são, ainda, subdivididos em duas categorias:

- martelo de queda com prancha: é observado na figura 5 que, neste caso, o movimento tanto da matriz superior quanto do pilão é determinado pelo atrito entre os cilindros e a prancha, que age no engripamento da prancha em questão. Quando a prancha é liberada do contato, ocorre a queda do pilão mediante efeito da gravidade, originando o golpe de conformação. Nesta configuração de máquina ferramenta, e tendo em vista o tamanho e a sua capacidade, proporciona-se uma 
média de 60 a 150 golpes por minuto. A energia deste tipo de máquina é restrita de acordo com a energia potencial ( $\left.E_{\mathrm{POT}}\right)$, designada pela eq.(1), sendo que a energia é fornecida à peça para produzir a sua respectiva deformação plástica:

$$
\mathrm{E}_{\mathrm{POT}}=\underbrace{\mathrm{m}_{p} \cdot \mathrm{g}}_{\text {força peso }} \cdot \underbrace{\mathrm{h}}_{\text {altura de queda }}
$$

Em que: $m_{p}$ é a massa do pilão; $g$ é a aceleração da gravidade; e $h$ é a altura de queda do pilão.

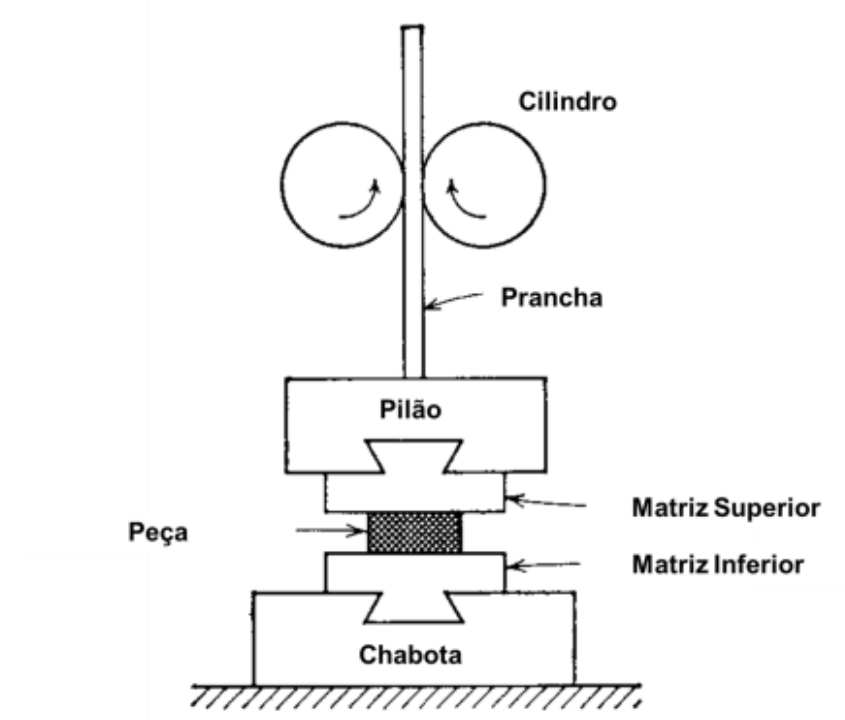

Figura 5 - Forjamento com ferramenta do tipo martelo de queda com prancha. (DIETER, 1988)

- martelo de queda atuado pela ação pneumática ou dupla ação: o pilão, neste caso, sofre uma aceleração pelo avanço de um pistão, que, por sua vez, é impulsionado pela compressão de ar, em conjunto com a ação da gravidade (figura 6). Assim, o retorno do êmbolo do pistão também ocorre por meio da ação pneumática. Sendo uma máquina ferramenta de maior capacidade que o martelo de queda com prancha, a energia total $(\mathrm{W})$ proveniente dos seus golpes é calculada conforme a eq.(2).

$$
\mathrm{W}=\frac{1}{2} m \mathrm{v}^{2}+p A h=(m g+p A) h
$$

Onde: $m_{p}$ é a massa do pilão; $v$ é a velocidade do pilão no início da conformação por forjamento; $p$ é a pressão pneumática que atua no avanço do êmbolo do pistão; A é 
a área do êmbolo do pistão; h é a altura de queda do pilão; e g é a aceleração da gravidade.

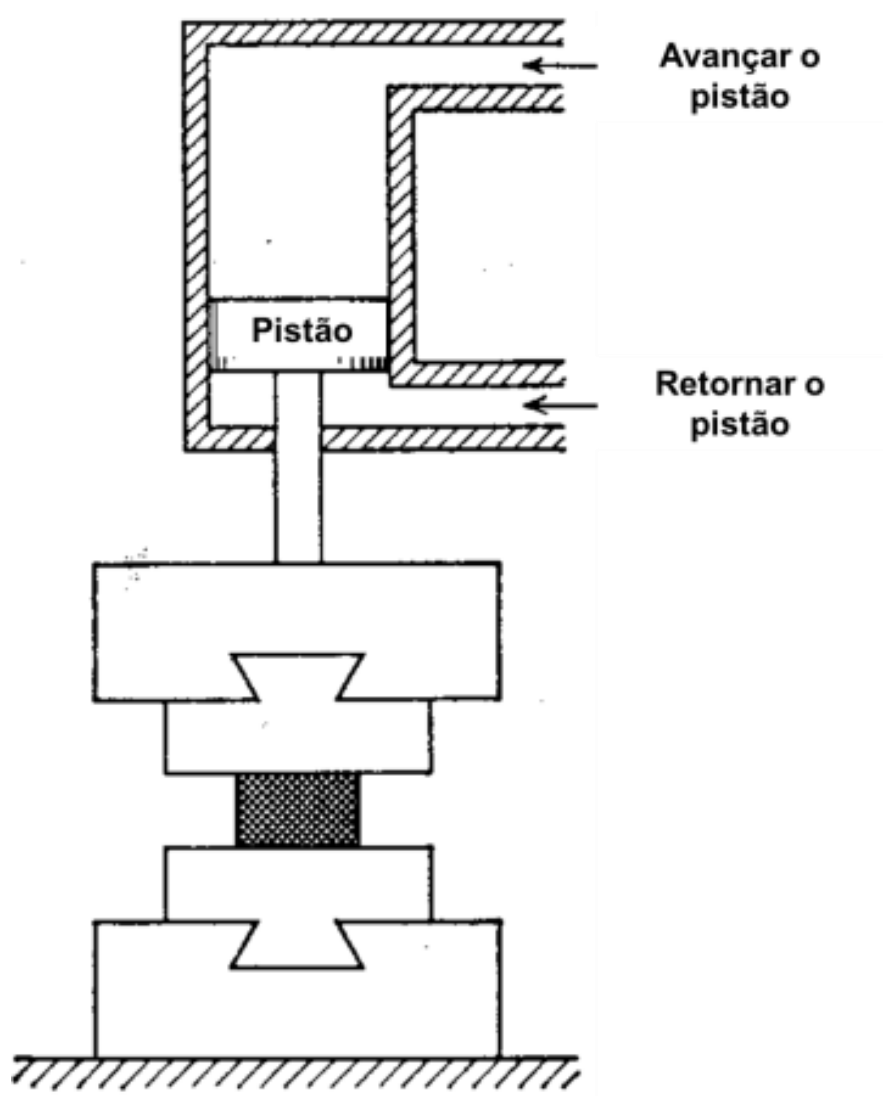

Figura 6 - Forjamento com ferramenta do tipo martelo de queda atuado por ação pneumática. (DIETER, 1988)

- prensa - faz uso da força mecânica ou hidráulica para a execução da conformação da peça metálica, atingindo uma velocidade menor do que os martelos de queda e são subdistribuídas nas categorias que se seguem:

- prensa hidráulica: vista na figura 7, trata-se de uma ferramenta para forjamento que se baseia na pressão hidráulica que move o pistão que irá realizar a conformação. Além disso, acrescenta-se que a força de conformação, nessa situação, atua com uma mesma intensidade em todos os pontos da peça durante a sua completa compressão. Entretanto, o tempo de contato é maior comparado ao forjamento com martelo de queda tendo em vista a baixa velocidade da ferramenta. 


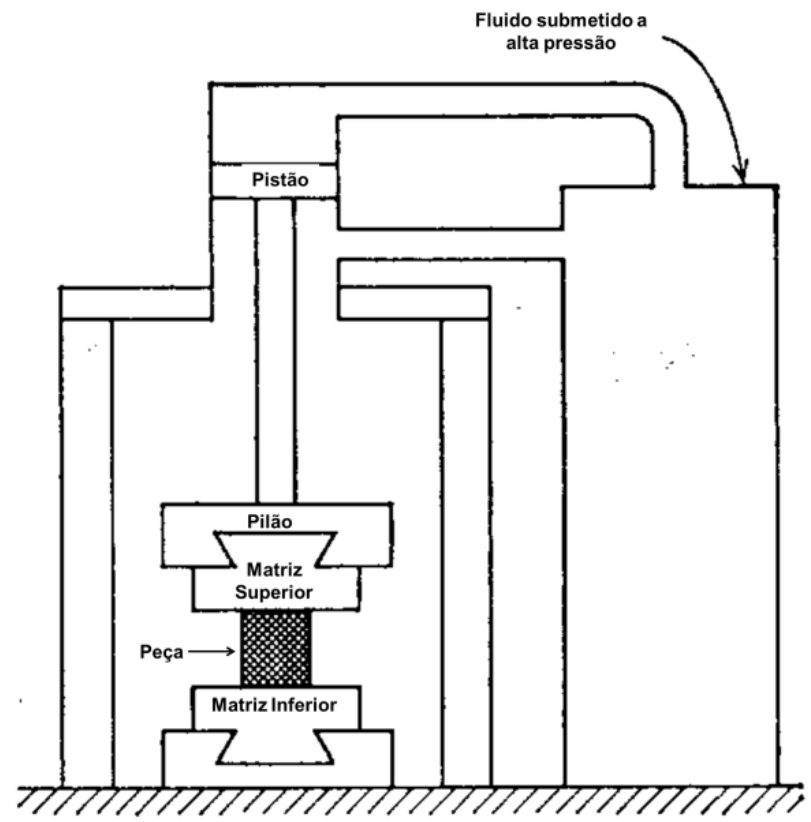

Figura 7 - Forjamento com ferramenta do tipo prensa hidráulica. (adaptado de DIETER, 1988)

- prensa mecânica: tem o seu funcionamento (figura 8) a partir da ação da pressão de uma manivela com movimento de rotação adicionado a um deslizamento linear para realizar a compressão efetivamente. Desse modo, a força é menos intensa comparada à atuante nos casos de aplicação do martelo de queda e da prensa hidráulica. Pode ser previsto que a energia total (W), projetada com base na ação da prensa mecânica, apresenta dependência com a inércia do volante da manivela e das velocidades angulares antes e após da deformação plástica da peça, de acordo com a eq.(3):

$$
\mathrm{W}=\frac{1}{2} I\left(\omega_{0}^{2}-\omega_{f}^{2}\right)
$$

Onde: I é o momento de inércia do volante; $\omega_{0}$ é a velocidade angular original da manivela; e $\omega_{f}$ é a velocidade angular da manivela após a conformação por forjamento da peça.

A pressão atuante, assim como aquela decorrente da prensa hidráulica, é vista como uma compressão e não como um impacto como quando o martelo de queda aparece envolvido no processo de forjamento. Portanto, o sistema para forjamento que emprega a prensa como ferramenta poderia ser modelado com considerações 
quase-estáticas; ao passo que o uso do martelo de queda implica em um modelo mais dirigido ao âmbito dinâmico.

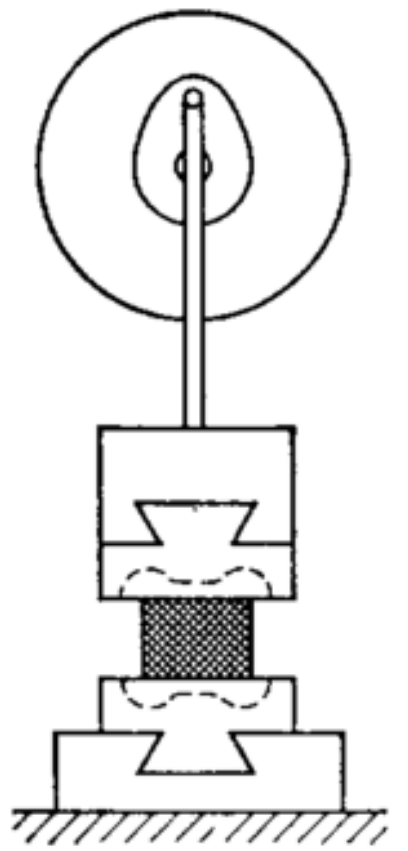

Curso Superior

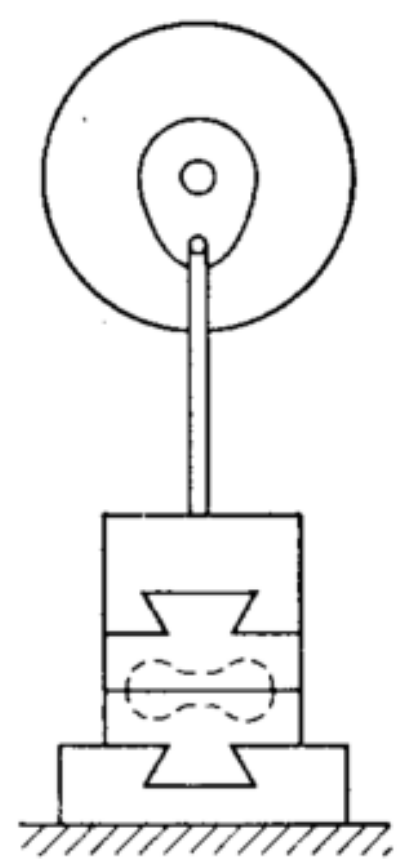

Curso Inferior

Figura 8 - Forjamento com ferramenta do tipo prensa mecânica com manivela. (DIETER, 1988)

A fim de comparar, de modo resumido, a variação da velocidade, da força e do tempo de contato com a peça, segundo a utilização de diferentes ferramentas para forjamento, são apresentadas a tabela 2 e a figura 9.

Tabela 2 - Comparação entre os valores previstos para a velocidade de avanço de ferramentas para forjamento. (adaptado de ALTAN, 1973 apud DIETER, 1988)

\begin{tabular}{cc}
\hline Máquina para Forjamento & Velocidade $\left[\mathbf{m}^{\mathbf{- 1}} \mathbf{}^{\mathbf{c}}\right]$ \\
\hline Martelo de queda livre & $3,6-4,8$ \\
Martelo de dupla ação & $3,0-9,0$ \\
Prensa hidráulica & $0,05-0,3$ \\
Prensa mecânica & $0,06-1,5$ \\
\hline
\end{tabular}



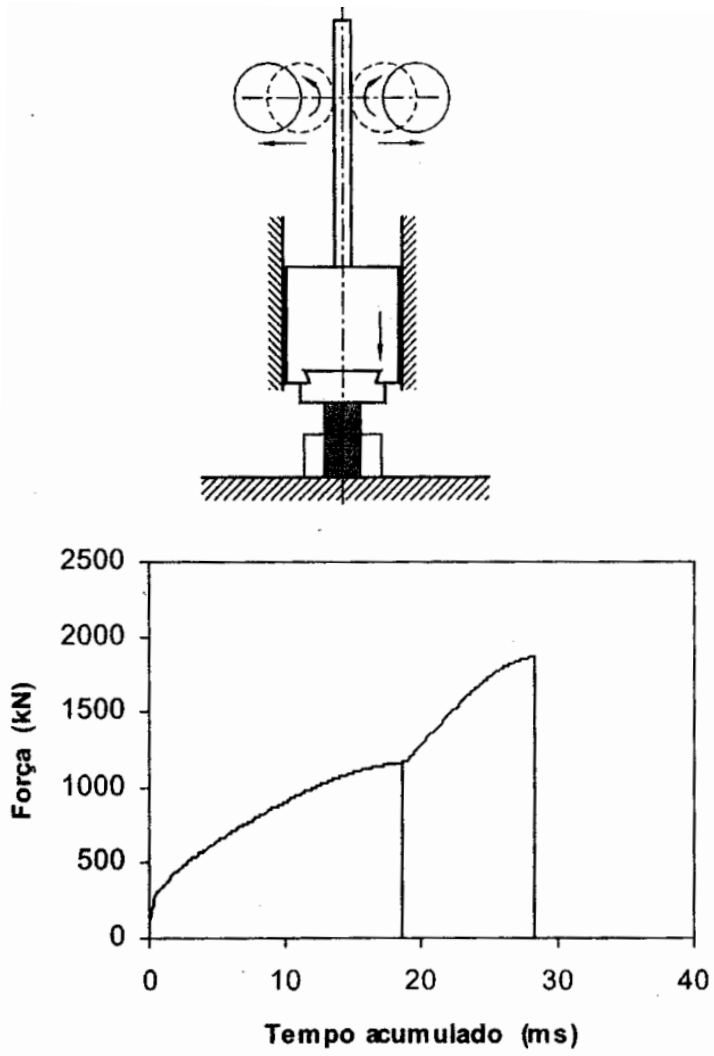

(a)

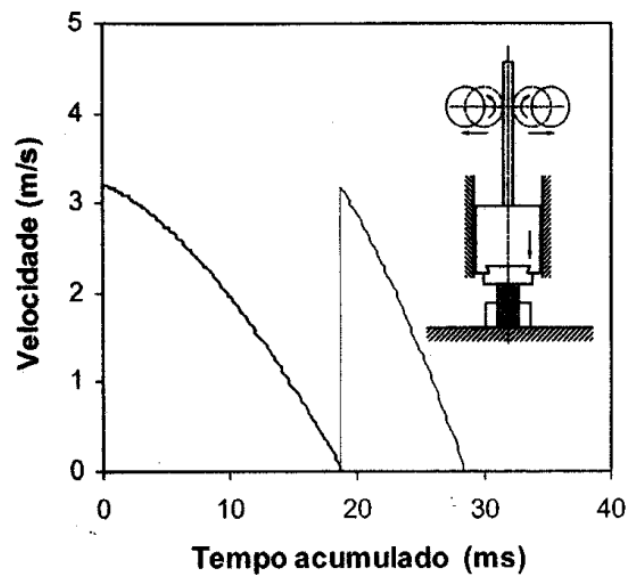

(c)
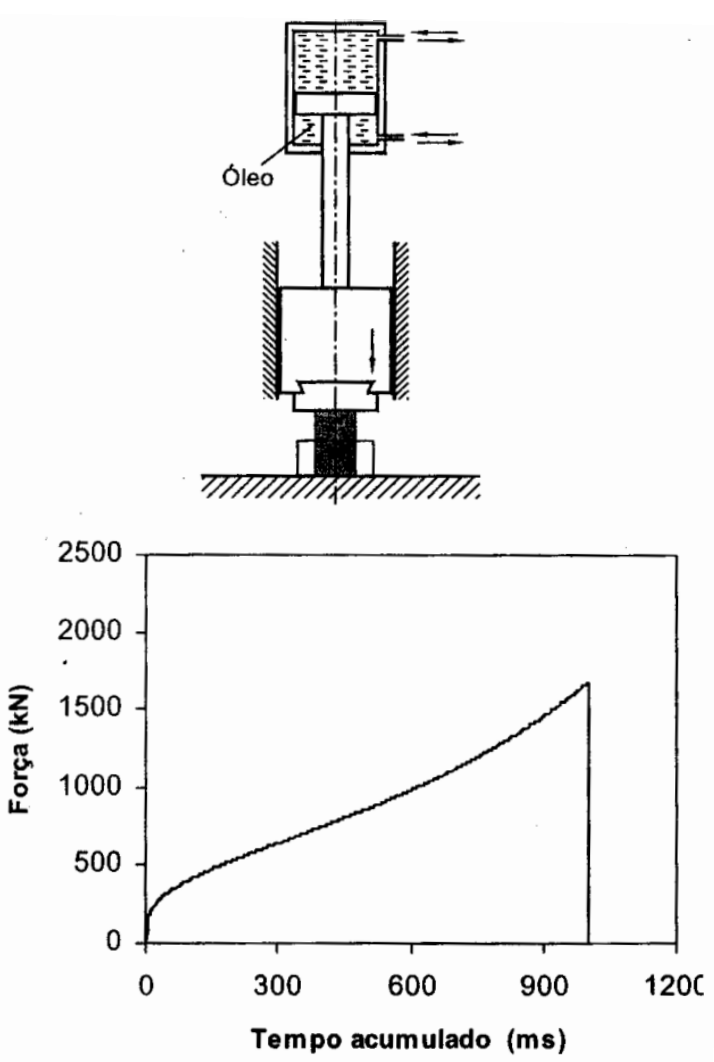

(b)

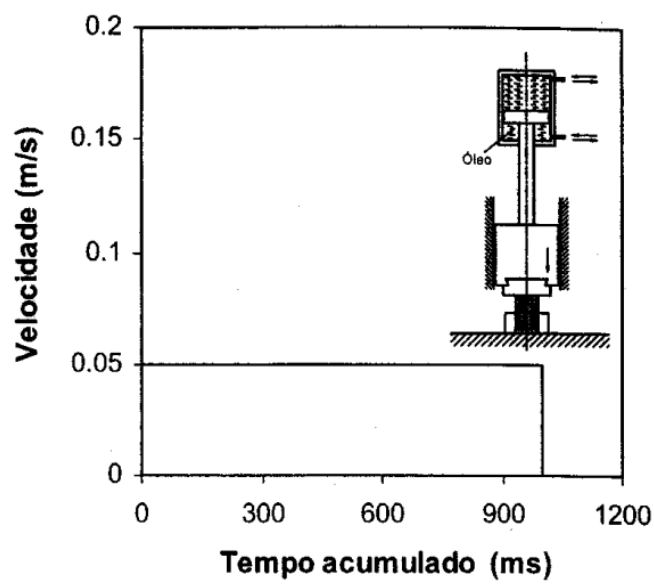

(d)

Figura 9 - Comparação entre a força aplicada e a velocidade de avanço das ferramentas de forjamento: martelo de queda (a e c); prensa hidráulica (b e d). Nota-se, também, que o tempo de contato entre ferramenta e peça é maior no caso da prensa do que no martelo. (RODRIGUES; MARTINS, 2010) 


\subsection{CENÁRIO CARACTERÍSTICO DA FERRAMENTA NO TRABALHO A QUENTE}

Dentre as ferramentas aplicadas na realização do trabalho de conformação a quente, o destaque da presente pesquisa se voltará aos aços ferramenta. A princípio, esses aços podem ser definidos como aços ligados que podem possuir em sua composição elementos como, por exemplo, o cromo, o vanádio, o molibdênio, o tungstênio, o manganês, o silício e o níquel. A adição dos referidos elementos no aço bem como os tratamentos térmicos efetuados no mesmo visam, dentre outros fatores, a contribuir nas suas resistências ao desgaste, à oxidação e à fadiga, e aumentar o seu limite de escoamento. (ROBERTS; KRAUSS; KENNEDY, 1998)

O histórico da ferramenta durante a conformação mecânica a quente de um determinado material é um assunto muito abrangente, envolvendo vários conceitos. Por esta razão, a título de obter uma ampla compreensão, optou-se por apresentar, aqui, uma sequência de fundamentos referentes ao comportamento dos aços ferramenta, no que se refere à estabilidade das fases presentes nestes e à cinética de transformação.

O diagrama de equilíbrio metaestável ferro-carbono (Fe-C) pode ser considerado o ponto em que se inicia o estudo de qualquer aço, uma vez que as fases que aparecem nesse sistema podem ser encontradas também em aços contendo outros elementos de liga. Contudo, os elementos de liga influenciam diretamente na formação e nas propriedades das fases. (HONEYCOMBE, 1985)

$\mathrm{Na}$ figura 10, observam-se as fases presentes em um aço em função da temperatura e da composição química. A fase ferrita (ferro- $\alpha$ ) possui estrutura cristalina cúbica de corpo centrado (CCC); é estável a temperaturas abaixo de $\approx$ $912^{\circ} \mathrm{C}$, sendo que a máxima solubilidade do carbono no ferro ocorre para uma composição de $0,022 \%$ em massa de $\mathrm{C}$ à temperatura de $727 \stackrel{\circ}{\circ}$. Por outro lado, a fase austenita (ferro- $\gamma$ ) apresenta estrutura cristalina cúbica de faces centradas (CFC); esta fase é instável a temperaturas inferiores a $727 \stackrel{\circ}{\circ} \mathrm{C}$, fornecendo uma máxima solubilidade do carbono no ferro em 2,14\% em massa de $C$ na temperatura de $1147^{\circ} \mathrm{C}$. Embora a estrutura cristalina da austenita seja mais compacta que a da ferrita, os interstícios da estrutura CFC são maiores do que os interstícios da estrutura CCC. Em virtude disso, a estrutura ferrítica não é capaz de acomodar nos seus interstícios, tanto os átomos de carbono quanto à estrutura austenítica; sendo 
assim, os átomos de carbono promovem menor deformação na rede de ferro CFC do que na rede CCC. Vale acrescentar que a fase ferrita, em temperaturas abaixo de $768{ }^{\circ} \mathrm{C}$, apresenta ferromagnetismo, ao passo que a austenita é diamagnética. (HONEYCOMBE, 1985)

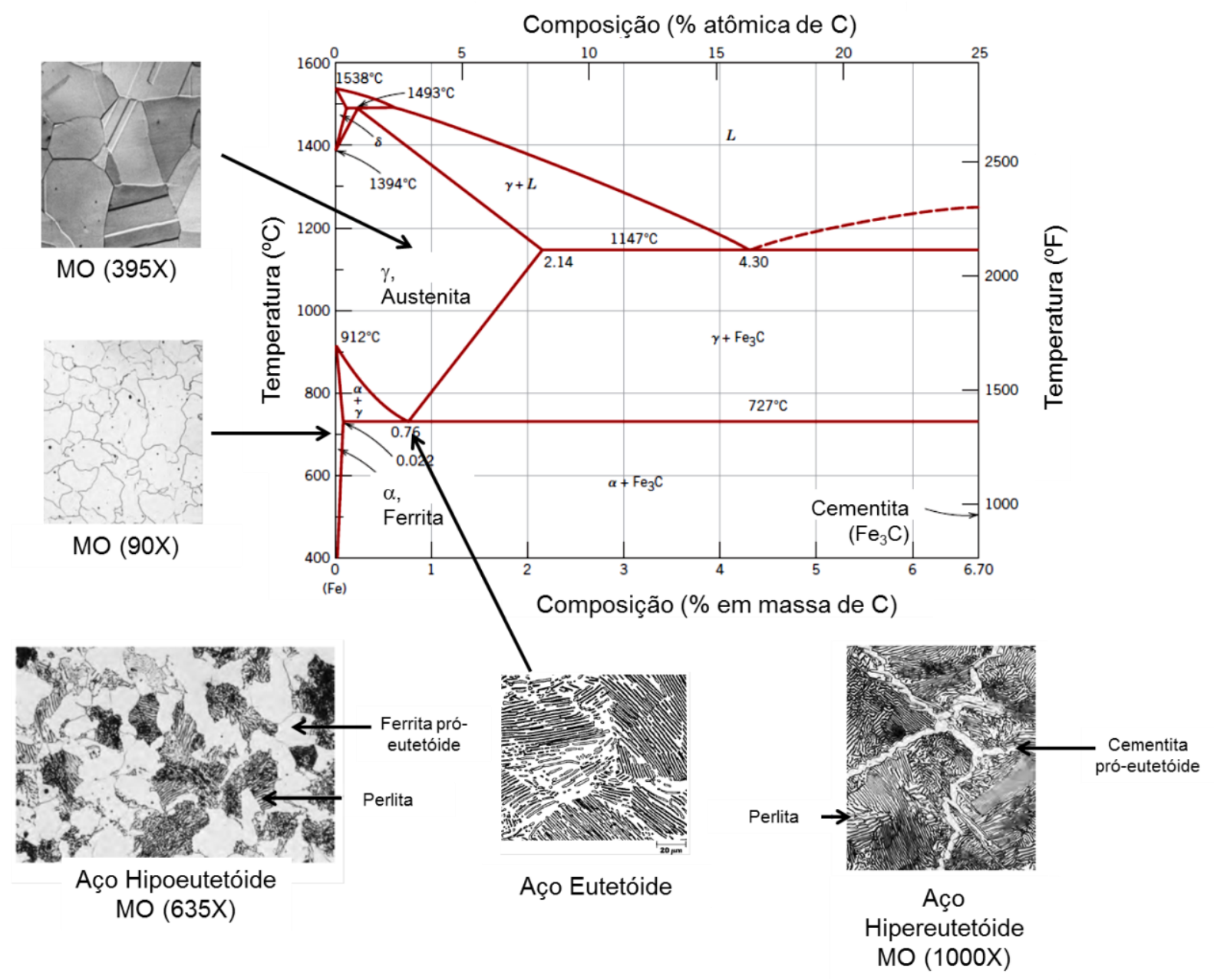

Figura 10 - Diagrama de fases Fe-C com microestruturas representativas de aços, do ferro- $\alpha$ e do ferro- $\gamma$. MO corresponde a microscopia óptica. (adaptado de CALLISTER JÚNIOR, 2007)

Em condições fora do equilíbrio (resfriamento em água, por exemplo), a partir do resfriamento da austenita, forma-se a martensita, que é uma fase com elevada resistência mecânica nos aços. O tratamento térmico para obter a martensita (figura 11a) é a têmpera que é, muitas vezes, seguida de um revenimento. O revenimento, por sua vez, é um tratamento térmico que visa à diminuição de dureza e aumento da tenacidade da martensita (figura 11b). (HONEYCOMBE, 1985) 
(a-)

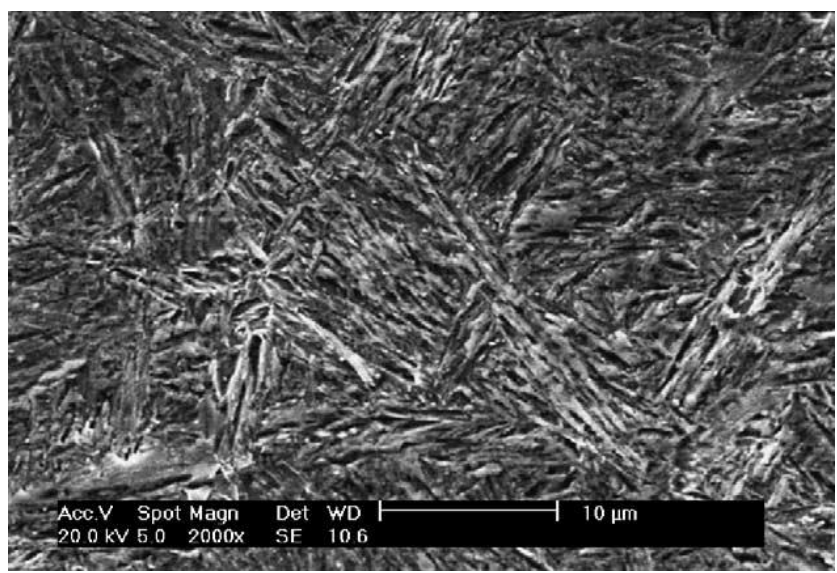

(b-)

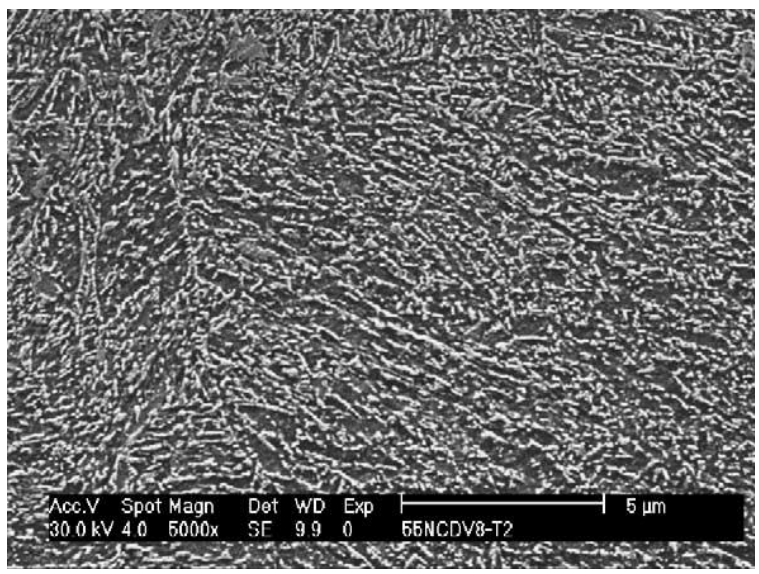

Figura 11 - Microestruturas (MEV) do aço ferramenta 55NiCrMoV7, mostrando em (a-) a matriz martensítica em ripas, decorrente de têmpera do material, e em (b-) obtém-se, após tratamento térmico, a martensita revenida com a presença de precipitados. (ZHANG; DELAGNES; BERNHART, 2004)

A priori, no caso do forjamento a quente, os aços ferramenta podem sofrer alterações em sua microestrutura, como a precipitação de carbonetos (transformação de fases) em sua matriz, que pode acarretar na diminuição de sua dureza. Tal processo é chamado, na maioria das vezes, de revenimento na superfície do material, justificado pela redução no nível de dureza da matriz martensítica. (SJÖSTRÖM; BERGSTRÖM, 2004)

3.3.1 Aço AISI H13 como ferramenta no forjamento a quente

A terminologia aço ferramenta é usada para designar ligas de aço que apresentam em sua composição elementos como o cromo, o molibdênio, e o vanádio, a fim de aprimorar as suas propriedades mecânicas para as condições em que o forjamento ocorre. Segundo o AISI (American Iron and Steel Institute), recomenda-se a simbologia, fornecida na tabela 3, para identificação dos referidos aços ferramenta. (AVNER, 1974) 
Tabela 3 - Nomenclatura de aços ferramenta definida pelo AISI. (AVNER, 1974)

\begin{tabular}{cc}
\hline Símbolo & Descrição \\
\hline W & Aços ferramenta temperados em água \\
S & Aços ferramenta resistentes ao choque \\
O & Aços ferramenta, para trabalho a frio, temperados em óleo \\
A & Aços ferramenta, para trabalho a frio (média liga de carbono), temperados \\
ao ar & Aços ferramenta, para trabalho a frio (alta liga de carbono), com alta \\
porcentagem de cromo
\end{tabular}

No presente trabalho, foi selecionado como objeto de estudo a microestrutura do aço AISI H13, aplicado como ferramenta em operações do forjamento a quente. A composição química nominal, em massa, do aço ferramenta AISI H13 é apresentada na tabela 4. De um modo geral, o AISI H13 possui uma maior resistência ao desgaste quando comparado a outros aços da sua classe como, por exemplo, o AISI H11. Além disso, ao referido aço são atribuídas outras características apreciáveis, tal como uma boa resposta aos tratamentos térmicos de têmpera e revenimento. (ASM INTERNATIONAL, 2005b)

Tabela 4 - Composição química nominal, em massa, do aço AISI H13. (ASM INTERNATIONAL, 2005b)

\begin{tabular}{ccccccc}
\hline$\% \mathbf{C}$ & $\% \mathbf{M n}$ & $\% \mathbf{S i}$ & $\% \mathbf{C r}$ & $\% \mathbf{N i}$ & $\% \mathbf{M o}$ & $\% \mathbf{V}$ \\
\hline $0,32-0,45$ & $0,20-0,50$ & $0,80-1,20$ & $4,75-5,50$ & 0,30 máx. & $1,10-1,75$ & $0,80-1,20$ \\
\hline
\end{tabular}


Dentre o campo de aplicações do aço AISI H13, podem ser destacados o uso em fabricação de moldes de fundição, de forjamento e de extrusão; mandris; pinos de ejetoras; e as contribuições em elementos estruturais e componentes, como nos eixos, cremalheiras e nas barras torcionadas, visto que a sua resistência à fratura é maior que em outros aços (reforçando o exemplo citado do AISI H11) submetidos às mesmas condições de carregamento. (ROBERTS; KRAUSS; KENNEDY,1998)

Em relação às transformações de fase, aplica-se essencialmente o estudo do efeito dos gradientes de temperatura e taxas de resfriamento na microestrutura, utilizando o diagrama de resfriamento contínuo (CCT). Na figura 12, é visto um exemplo de diagrama de resfriamento contínuo para o aço ferramenta AISI H13. Nota-se que a dureza do material diminui conforme o aumento do tempo de resfriamento do material em questão. Cabe o comentário que tais curvas de resfriamento são influenciadas, assim, pela composição química, tamanho do grão da fase austenítica e a homogeneidade desta.

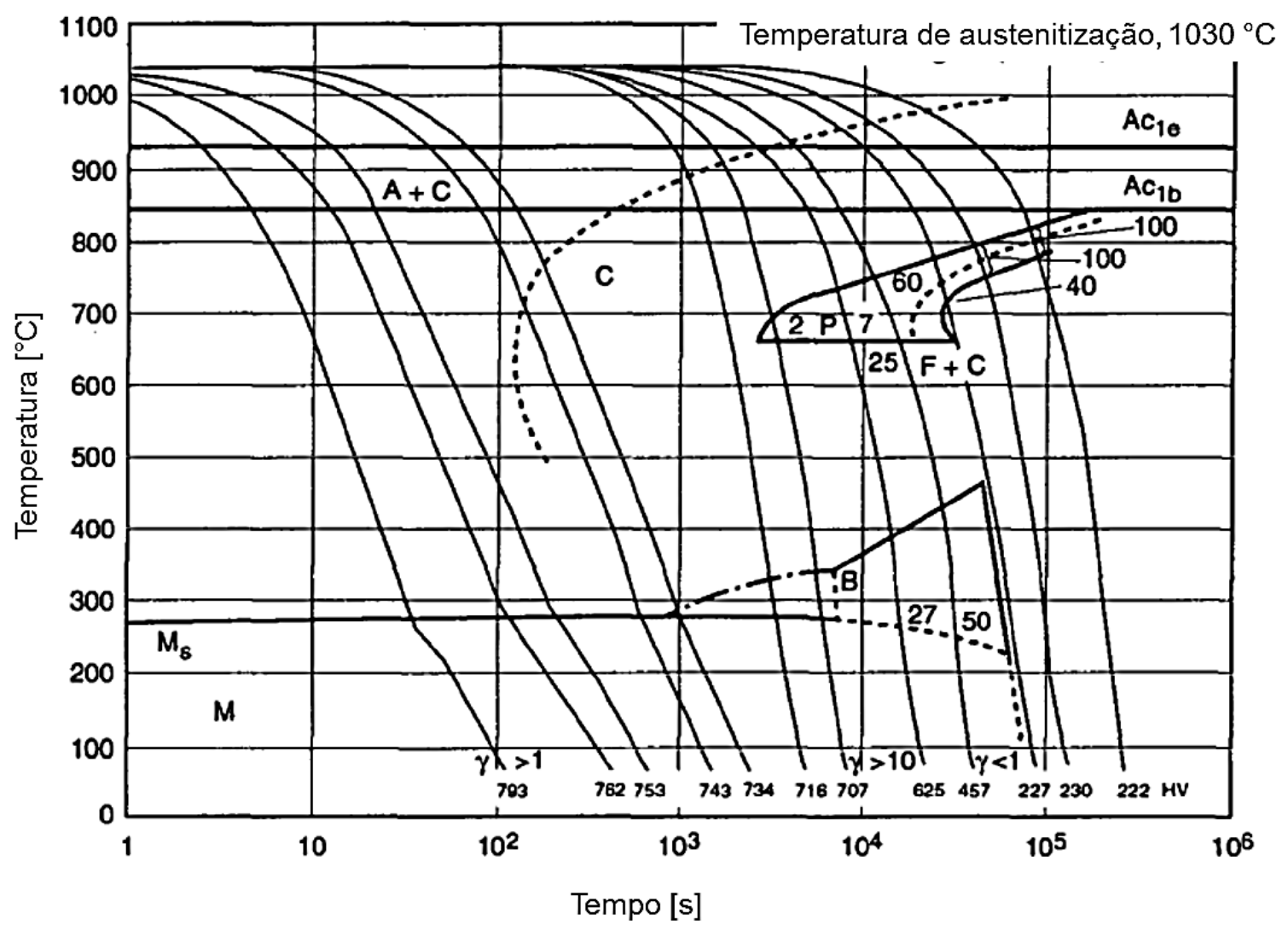

Figura 12 - Diagrama CCT para o aço AISI H13, cuja fase austenítica foi resfriada a partir de 1030 ${ }^{\circ} \mathrm{C}$. Simbologia: $A$ = austenita; $C=$ carbonetos; $F=$ ferrita; $B=$ bainita; $P=$ perlita; $M=$ martensita; $A c_{1 b}$ = mínima temperatura para a existência da austenita; e $A_{c_{1 e}}=$ temperatura máxima para a ocorrência de carboneto na microestrutura. (ROBERTS; KRAUSS; KENNEDY, 1998) 
Durante o trabalho a quente, e como pode ser comprovada pela observação da figura 12, na matriz martensítica do aço ferramenta pode também ocorrer a precipitação de carbonetos durante o revenimento da martensita, ocasionado pelos ciclos de aquecimento e resfriamento atuantes na ferramenta. (HONEYCOMBE, 1985)

Na figura 13, observa-se uma seção do diagrama de fases do referido aço AISI H13. É informado no diagrama que os carbonetos a serem formados, a temperaturas acima de $500{ }^{\circ} \mathrm{C}$, são do tipo MC. A letra inicial M desses carbonetos representa componentes químicos específicos, tais como: MC são carbonetos ricos em vanádio; $M_{6} C$ são carbonetos ricos em molibdênio; $M_{2} C$ são carbonetos ricos em molibdênio, embora com redução da porcentagem de molibdênio em relação ao $M_{6} C ; M_{7} C_{3}$ são carbonetos metaestáveis, ricos em cromo; $\mathrm{M}_{3} \mathrm{C}$ são carbonetos secundários, ricos em ferro; e $\mathrm{M}_{23} \mathrm{C}_{6}$ são carbonetos estáveis, ricos em cromo. (HU et al., 2006a)

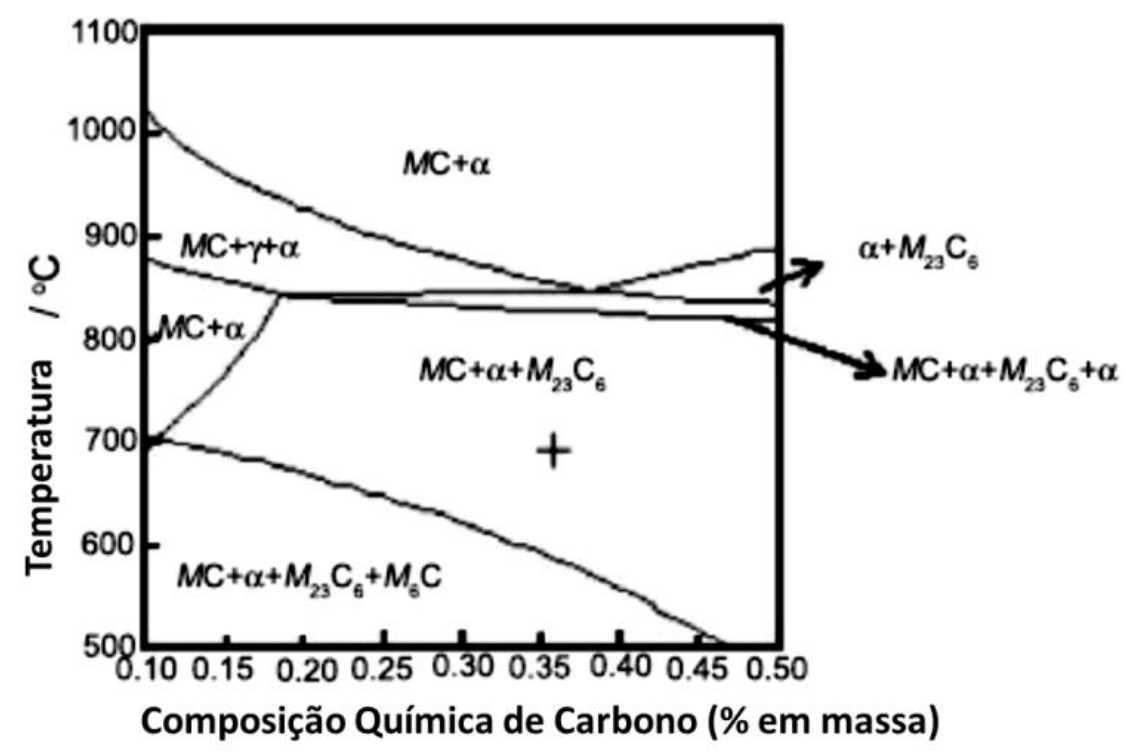

Figura 13 - Seção do diagrama de fases do aço AISI H13 elaborado a partir do software THERMOCALC. Simbologia: $\alpha$ é a ferrita; e $\gamma$ é a austenita. (HU et al., 2006a)

Quando aplicado em forjamento a quente, e tendo em vista a consideração de aços ferramenta com cromo para trabalho a quente, como é o caso do aço AISI H13, são encontrados frequentemente dois carbonetos de cromo na respectiva sequência de transformação: (HONEYCOMBE, 1985)

$$
\text { Matriz Martensítica } \rightarrow \text { Matriz' }+(\mathrm{FeCr})_{3} \mathrm{C} \rightarrow \text { Matriz' }+\mathrm{Cr}_{7} \mathrm{C}_{3} \rightarrow \text { Matriz' }+\mathrm{Cr}_{23} C_{6}
$$


$\mathrm{O} \mathrm{Cr}_{7} C_{3}$ possui estrutura cristalina trigonal, e o $\mathrm{Cr}_{23} C_{6}$ é, por sua vez, CFC. Vale ressaltar que em aços ferramenta constituídos por teores de cromo abaixo de 7\%, em massa, 0 carboneto $M_{23} C_{6}$ vem a se formar induzido pela presença de molibdênio. $O$ carboneto $M_{23} C_{6}$, em geral, nucleia nos contornos de grão da austenita (ou martensita) e sobrepuja o carboneto $M_{7} C_{3}$, crescendo durante 0 envelhecimento do aço de modo a propiciar o desaparecimento do $M_{7} C_{3}$. Ainda, o vanádio pode ser considerado um elemento responsável por reduzir a velocidade de formação do $M_{23} C_{6}$, estabilizando o $M_{7} C_{3}$ em temperaturas na faixa de 400 a $650{ }^{\circ} \mathrm{C}$. (HONEYCOMBE, 1985)

Conforme descrito por Roberts, Krauss e Kennedy (1998), decorrente da microestrutura formada pela matriz martensítica com a presença dos carbonetos, pode ser acrescentado que os aços ferramenta $\mathrm{H} 13$ possuem:

- maior dureza da matriz em uma maior faixa de temperatura de trabalho, quando comparados aos aços ferramenta para trabalho a frio;

- resistência considerável aos choques térmicos e mecânicos, e boa tenacidade, a fim de prevenir a ocorrência de trincas; em virtude disso, esses aços apresentam porcentagem de carbono controlada;

- boa resistência ao desgaste abrasivo e à erosão, sendo os aços desta categoria com maiores valores de dureza a quente;

- resistência às trincas térmicas, mas podendo ocorrer a formação de trincas na superfície da ferramenta, devido aos ciclos térmicos.

\subsection{DANOS EM AÇOS FERRAMENTA DURANTE O FORJAMENTO A QUENTE}

Decorrente das solicitações da ferramenta envolvida em um determinado processo de fabricação a quente, variáveis como pressão e temperatura definem o comportamento mecânico do material empregado na ferramenta em questão. No caso do forjamento a quente, e visando à troca de calor, merece ser destacado o momento de contato da matriz com a peça aquecida, no qual a superfície da ferramenta pode vir a alcançar temperaturas equivalentes ou superiores à sua temperatura de revenimento. Sob tal circunstância, recomenda-se que o material empregado na ferramenta tenha grande resistência mecânica a quente em adição à 
reduzida perda de dureza sob elevadas temperaturas, que estão entre as características do aço AISI H13. (ROBERTS; KRAUSS; KENNEDY, 1998; GABARDO; OKIMOTO, 2011)

Discorridos detalhes a respeito da microestrutura do aço AISI H13, é importante apresentar os principais mecanismos de dano que podem vir a acontecer quando esta ferramenta é exposta aos carregamentos subsequentes de origem térmica e mecânica: (BARRAU et al., 2002)

- desgaste abrasivo;

- desgaste adesivo;

- oxidação superficial;

- fadiga mecânica;

- fadiga térmica;

- deformação plástica.

Do ponto de vista de danos na ferramenta, enfatiza-se que o aço AISI H13, durante o trabalho de conformação a quente, encontra-se exposto ao desgaste abrasivo (que não será aprofundado neste trabalho), à fadiga térmica (que será discorrida com mais detalhes em uma próxima seção deste trabalho, visto que se trata do foco da pesquisa), e às transformações de fases.

Em relação ao desgaste abrasivo da ferramenta, encontram-se trabalhos tanto direcionados à parte experimental propriamente dita (KANG et al., 1999), quanto direcionados à simulação numérica e suas respectivas validações (BEHRENS et. al, 2008; KIM et al., 2005; KIM; CHOI, 2009; ABACHI; AKKÖV; GÖKLER, 2010). Neste caso, a profundidade de alcance do referido desgaste é previsto pela equação de Archard, que tem como principais parâmetros a força normal aplicada e a dureza na superfície da ferramenta, a velocidade de deslizamento na interface peça-ferramenta e o tempo de contato e, por fim, o coeficiente de desgaste adimensional. (ARCHARD, 1953)

A fadiga térmica, por sua vez, é um mecanismo de falha decorrente do efeito cíclico e termomecânico acoplado, havendo regiões de concentração de tensão ao longo do material da ferramenta do forjamento a quente, e ocorre assim a nucleação de trincas térmicas e subsequente propagação dessas trincas em uma direção preferencial. No trabalho de Oliveira, Zoby e Souza (2002), fortaleceu-se a importância do estudo do fenômeno da fadiga térmica. Este trabalho relata que, no 
processo de trabalho a quente por laminação, tanto o desgaste por abrasão quanto a fadiga mecânica, que atuam na superfície da ferramenta (cilindro de trabalho), são eventos inerentes ao processo citado; contudo, a fadiga térmica aparece como um mecanismo sob o qual pode se realizar um controle, por meio do resfriamento do cilindro de laminação.

Um estudo da resistência à fadiga térmica em ferro fundido branco multicomponentes, material empregado no cilindro de laminação de tiras a quente, foi realizado por Serantoni Silva (2003). Este trabalho concluiu que as concentrações das microtensões se procedem na interface matriz-precipitado e no precipitado propriamente dito. A justificativa da autora para tal fato é a diferença de propriedades como coeficiente de expansão térmica e módulo de elasticidade do carboneto e da matriz que tornam os valores de tensões mais altos nas referidas regiões contrastantes.

Como exemplos de outros trabalhos difundidos na literatura que tratam de experimentos de fadiga térmica em aços ferramenta estão:

- Persson, Hogmark e Bergström (2004) propuseram um aparato experimental para simular fadiga térmica de aços ferramenta comumente empregados em matrizes de fundição. O objetivo foi analisar as trincas macroscópicas por fadiga, decorrentes de carregamentos cíclicos de origem térmica, que surgem nesta situação como uma malha de trinca térmica na superfície da ferramenta. Por meio dos ensaios, a deformação da superfície foi, então, monitorada por meio de técnicas de medição sem contato. Concluiu-se que os resultados de tensões e deformações foram capazes de informar acerca da fadiga térmica do material sem o seu perfil de temperatura. Este mecanismo de dano atuante na superfície do material vem acompanhado, na faixa de temperaturas trabalhada $\left(170-700^{\circ} \mathrm{C}\right)$, com a fadiga de baixo ciclo e o amolecimento gradativo dos aços ferramenta.

- Sjöström e Bergström (2004) avaliaram a influência do tratamento térmico na resistência à fadiga térmica de microestruturas de aço ferramenta para trabalho a quente, basicamente constituídos de matriz martensítica e com alto teor de cromo. Foi verificado, nesta pesquisa, que a temperatura de austenitização e a máxima temperatura de ensaio influenciam na propagação das trincas térmicas. A máxima temperatura do ciclo de austenitização, prevista em função da temperatura de revenimento da matriz, foi o parâmetro indicativo da resistência à fadiga térmica a altas cargas térmicas. $\mathrm{O}$ aumento da tenacidade e da ductilidade do material foram, 
por sua vez, os indicativos da resistência à fadiga térmica em condições de cargas térmicas menores.

Em relação ao objetivo de alcançar a maior vida útil da ferramenta de conformação a quente, Mesquita, Haddad e Barbosa (2008) enumeram os seguintes parâmetros como os mais significativos nesse quesito: (i-) elaboração de melhorias no projeto da ferramenta; (ii-) previsão cuidadosa das condições de operação, envolvendo desde a lubrificação da ferramenta até fatores que venham a influenciar a transferência de calor no processo; e (iii-) seleção do aço a ser empregado nesta ferramenta.

$\mathrm{Na}$ parte de mecanismos de dano nas matrizes de forjamento a quente, Mesquita, Haddad e Barbosa (2008) apontam a tenacidade e a resistência a quente do aço ferramenta como as propriedades que determinam a maior ou a menor suscetibilidade do material aos danos, essencialmente relacionados ao desgaste e à fadiga. Os autores realizaram um estudo de caso de aços ferramenta, aplicados em forjamento a quente de peças automobilísticas, e reportaram os aspectos que se seguem:

- a peça de aço a ser forjada, em geral, se encontra a temperaturas superiores a $1100{ }^{\circ} \mathrm{C}$. Assim, a superfície da ferramenta sofre aquecimento a partir do contato com a peça, sendo que a sua temperatura máxima é dependente do tempo do referido contato com o forjado; (MESQUITA; HADDAD; BARBOSA, 2008)

- nas matrizes de forjamento analisadas, ocorre revenimento na região junto à superfície, quando a temperatura das mesmas ultrapassa $550{ }^{\circ} \mathrm{C}$. A resistência à diminuição de dureza, chamada de resistência ao revenimento, das ferramentas é vista, portanto, como uma propriedade de destaque no estudo. (MESQUITA; HADDAD; BARBOSA, 2008)

O gráfico, apresentado na figura 14, indica uma perda de dureza da matriz decorrente do alcance de uma temperatura crítica de, aproximadamente, $550{ }^{\circ} \mathrm{C}$, visto que quando a matriz atinge temperaturas acima deste valor é favorecida a referida queda da sua dureza. 


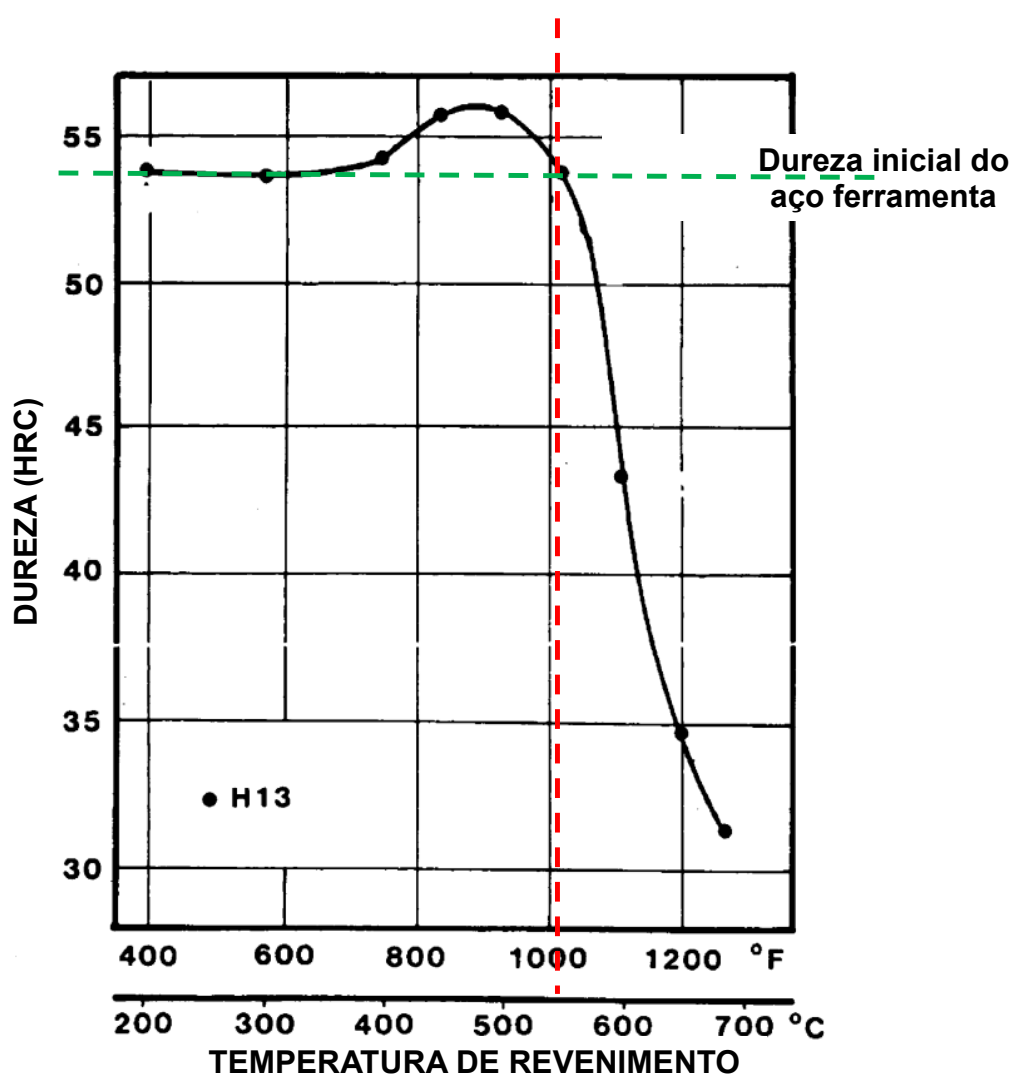

Figura 14 - Curva de revenido para o aço AISI H13. (adaptada de BABU; RIBEIRO; SHIVPURI, 1999)

- outra preocupação, relacionada à ferramenta empregada no forjamento a quente, diz respeito à tenacidade, que pode resultar em: (i-) surgimento de trincas, favorecidas por concentradores de tensão (causados, por exemplo, por questões geométricas da matriz), e que acarretam em finalização da operação de forjamento pela matriz danificada e/ou fadiga mecânica; e (ii-) início de uma malha de trincas térmicas na ferramenta, prejudicando a integridade superficial da peça. Neste caso, além da tenacidade, a condutividade térmica e o coeficiente de expansão térmica atuam de modo representativo no efeito das tensões térmicas. (MESQUITA; HADDAD; BARBOSA, 2008)

Depois de fornecidos os comentários iniciais, é mostrado, na figura 15, um esquema das localizações possíveis dos principais danos que podem vir se manifestar nas matrizes de forjamento a quente. Complementando, na figura 16, podem ser observadas trincas por fadiga e desgaste em um punção de forjamento, que esteve sujeito às condições de processo vistas na tabela 5. Mesquita, Haddad e Barbosa (2008) justificaram o desgaste desta ferramenta em função da sua perda de 
dureza superficial, que passou de 53 HRC para um valor em torno de 42 HRC. Apesar da redução de dureza na superfície do material, a região designada pelos autores como núcleo não sofreu alterações consideráveis em sua dureza. Da parte de trincas por fadiga térmica, os autores atribuem às regiões de menor dureza o papel de área de favorecimento de nucleação de tais trincas.

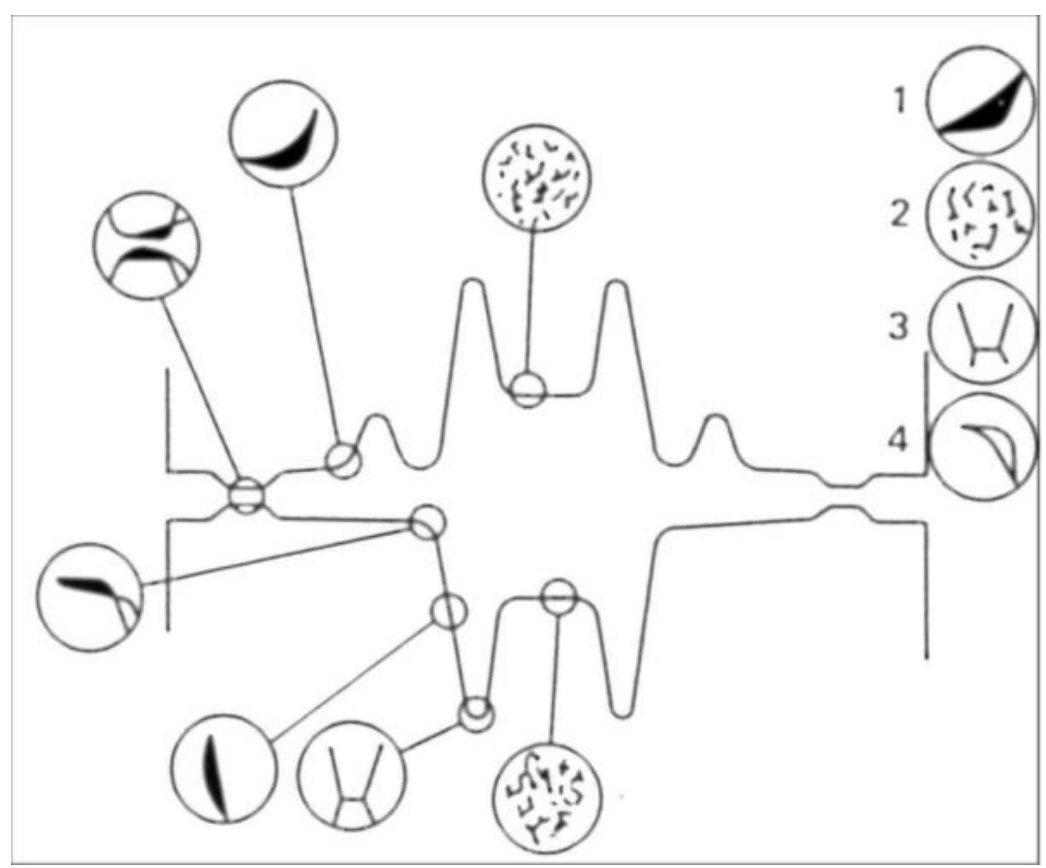

Desgaste Abrasivo

Fadiga Térmica

Fadiga Mecânica

Deformação Plástica

Figura 15 - Esquema dos mecanismos de danos encontrados comumente nas matrizes de forjamento a quente. (KANNAPPAN, 1969 apud BARRAU et al., 2002)

Tabela 5 - Dados de um processo de forjamento de uma ponta de eixo. (adaptada de MESQUITA; HADDAD; BARBOSA, 2008)

Informações do processo de fabricação

(MESQUITA; HADDAD; BARBOSA, 2008)

Ferramenta

Material da Ferramenta

Material da peça

Temperatura inicial da peça

Velocidade de avanço da ferramenta

Refrigeração da ferramenta
Punção de forjamento a quente de precisão.

Aço VHSUPER (H13 modificado).

Aço SAE 1045 e 1050 modificados.

$$
\sim 900^{\circ} \mathrm{C}
$$

Elevada aplicação de golpes/min.

Com água, em intervalos curtos de tempo. 


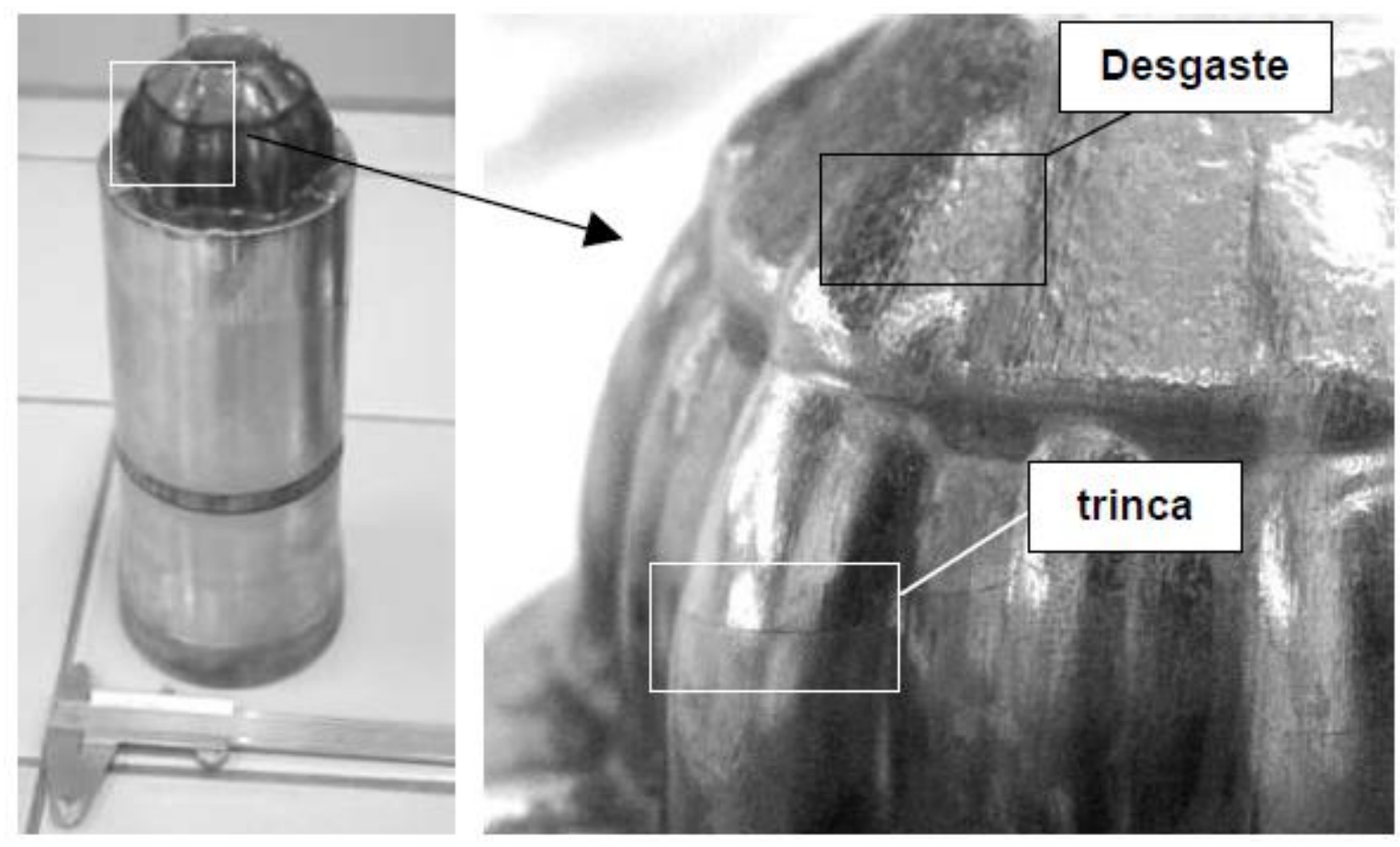

Figura 16 - Ocorrência de desgaste e de trincas por fadiga em um punção de forjamento a quente. (MESQUITA; HADDAD; BARBOSA, 2008)

A fadiga térmica, conforme informado anteriormente, é o objeto de estudo selecionado e será abordada, em maiores detalhes, nos próximos subitens deste trabalho.

\subsubsection{Fundamentos de fadiga térmica de materiais metálicos}

A fadiga é um mecanismo de dano acumulativo e progressivo, que se mostra impulsionado por sucessivos carregamentos cíclicos e no qual se verifica os estágios que se seguem: (i-) formação ou nucleação de microtrincas; (ii-) crescimento ou propagação de trincas por fadiga; e (iii-) fratura ou ruptura levando ao término da vida do componente. A fadiga térmica pode ser definida como um modo de falha que ocorre em materiais e equipamentos que estão submetidos a mudanças bruscas e cíclicas de temperatura, ocasionando danos por choques térmicos repetitivos (trincas térmicas). (ALVARENGA JÚNIOR, 2006; WERONSKI; HEJWOWSKI, 1991)

Por conseguinte, a fadiga térmica de materiais pode se apresentar com dependência direta dos seguintes parâmetros: (a-) microestrutura (diferentes fases); 
(b-) meio-ambiente (a temperatura é um dos fatores mais importantes, especialmente no caso da conformação a quente); (c-) pontos de concentração de tensões que têm o papel de facilitar o desenvolvimento das trincas por fadiga; e (d-) condições de carregamento cíclicos trativos.

Como principais exemplos de componentes e dos locais de grande incidência de fadiga térmica, podem ser enumerados: ferramentas para conformação a quente; os reatores das usinas termoelétricas e termonucleares; as turbinas a gás; as turbinas de aeronaves; e os motores a diesel. (ALVARENGA JÚNIOR, 2006)

Em geral, a fadiga térmica aparece combinada a outros tipos de solicitação sobre a superfície do material. Dentre os mecanismos associados à fadiga térmica, pode-se ressaltar a oxidação, que é causada pela associação das condições de alta temperatura do meio agressivo que predominam, por exemplo, no cilindro de trabalho na laminação a quente. (SERANTONI SILVA, 2003)

Na tese de doutorado de Alvarenga Júnior (2006) é apontado, na revisão da literatura, que muitos autores se preocuparam em entender o mecanismo da fadiga térmica com o intuito de aumentar a vida útil dos materiais empregados em diversos âmbitos. O autor acrescenta que, na década de 1950, houve várias pesquisas a este respeito, valendo ressaltar o equacionamento de Coffin-Manson sobre o efeito da amplitude da deformação plástica em fadiga térmica. Como pode ser verificada na figura 17, a trinca térmica vem a se propagar na superfície de um reator nuclear de água em ebulição (BWR), uma vez que os componentes de diversos tipos de reatores nucleares se encontram sujeitos aos efeitos de carregamento termomecânico.

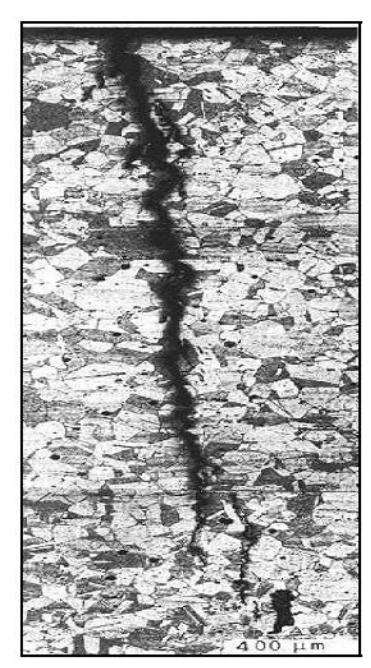

Figura 17 - Seção de uma trinca de propagação perpendicular à superfície interna de um tubo do BWR (reator de água em ebulição) causada por fadiga térmica. (ALVARENGA JÚNIOR, 2006) 
Quanto à simulação numérica da fadiga térmica em aços ferramenta para trabalho a quente, com aplicação de softwares de elementos finitos como o Abaqus ${ }^{\circledR}$ e o Forge ${ }^{\circledR}$, podem ser comentados os seguintes trabalhos:

- Velay et al. (2002) analisaram, por meio de comparação entre resultados empíricos e obtidos de simulação numérica por elementos finitos, a resposta do aço ferramenta $55 \mathrm{NiCrMoV7}$ (para trabalho a quente) submetido à fadiga térmica. Neste trabalho, reforçou-se a ideia que o comportamento do material exposto a este mecanismo de dano é dependente das propriedades atribuídas ao material e dos carregamentos térmicos e mecânicos impostos a ele. O modelo numérico, desenvolvido no software Abaqus $^{\circledR}$, empregou uma geometria em forma de tubo na dimensão da ordem de milímetros, exposta a carregamentos térmicos impostos pelos mecanismos de troca térmica de condução, convecção e radiação. Uma sub-rotina foi criada a fim de designar um modelo constitutivo viscoelastoplástico para o material, de modo a englobar o amolecimento cíclico do material verificado experimentalmente. Além de constatar que o modelo numérico consegue reproduzir, de forma aproximada, os resultados experimentais, foi concluído que a temperatura máxima e a taxa de aquecimento do ciclo são parâmetros que atuam de forma direta na deformação medida na superfície da ferramenta. Tal deformação é utilizada para os cálculos de tensão, que, por sua vez, está associada à previsão da vida da ferramenta.

- Berhens et al. (2010) atribuem às deformações macroscópicas locais, que surgem em virtude dos carregamentos termomecânicos cíclicos, a ocorrência das trincas por fadiga térmica em matrizes de forjamento a quente. Os autores desenvolveram, então, um trabalho por meio de MEF objetivando analisar as condições que propiciam aumentar a vida da ferramenta de forjamento a quente exposta à fadiga de baixo ciclo. Na simulação numérica, a partir do uso do software Forge ${ }^{\circledR}$, foi atribuído ao material da ferramenta em questão o comportamento elastoplástico, com variação de propriedades com a temperatura, e modelos de dano. Os resultados levaram a concluir que as regiões das matrizes de forjamento submetidas às maiores tensões de tração e cisalhamento, e que mostravam grande deformação plástica, foram as mais propícias à nucleação das trincas por fadiga térmica.

Por outro lado, a composição química, o tratamento térmico da superfície e as condições impostas durante o serviço influenciam a microestrutura da ferramenta. A faixa de temperaturas existentes na superfície de contato ferramenta-peça designa, por sua vez, um comportamento determinando mecanismos de dano, como a fadiga 
térmica e a deformação plástica induzida na ferramenta. Alterações na microestrutura podem levar à nucleação de trincas térmicas, e diminuição de resistência devido ao crescimento de precipitados. Por conseguinte, a microestrutura do aço constituinte da ferramenta empregada no trabalho a quente, tem um papel decisivo na vida da ferramenta em questão. (CALISKANOGLU et al., 2002)

\subsubsection{Trincas por fadiga térmica (nucleação e propagação)}

Tendo como base o trabalho de Silva (2006), pode-se iniciar a abordagem relacionada à nucleação de trincas na malha térmica. A autora estudou experimentalmente $o$ desgaste e a fadiga térmica de um aço matriz com adição de carboneto de nióbio.

Os ensaios de fadiga térmica surgiram na década de 1950 (ALVARENGA JÚNIOR, 2006) com o objetivo de entender os fatores que facilitavam este mecanismo de fadiga em ligas empregadas nos trabalhos a quente. Um dispositivo experimental do final da década de 1960 é fornecido na figura 18a.

Com o avanço da tecnologia, mais parâmetros do processo passaram a ser monitorados. Uma breve descrição do ensaio de fadiga térmica com o dispositivo ilustrado na figura 18b (SILVA, 2006) é comentada logo adiante:

- os corpos de prova (CPs) são ensaiados em vários ciclos (de 100 a 500 ciclos) com ou sem repetições. No ensaio, o CP é transportado para o interior da bobina de indução ou para o tanque de resfriamento a água pela ação de um sistema pneumático, e este é acionado pela temperatura medida por um pirômetro (no caso de aquecimento) ou pelo sinal vindo de um temporizador (na situação de resfriamento). Um contador digital localizado no fim de curso superior do cilindro pneumático se encarrega de contabilizar a quantidade de ciclos. Pode haver, ainda, a implantação de um controlador lógico programável responsável por evitar falhas no sistema pneumático ou na parte de refrigeração do CP.(SILVA, 2006) 
(a)

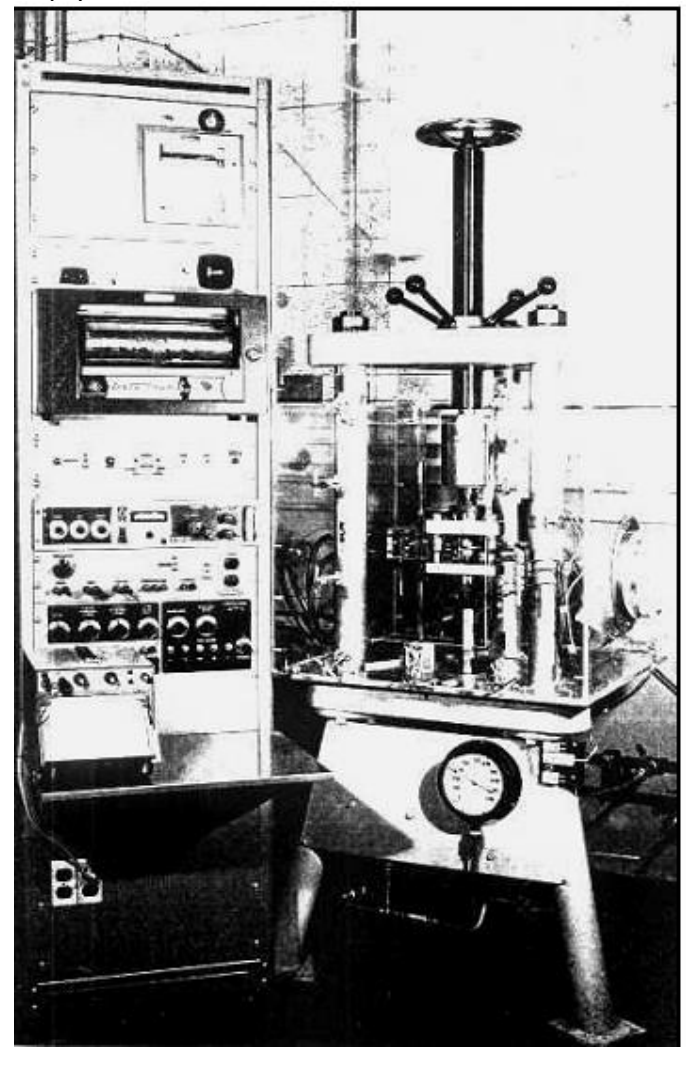

(b)

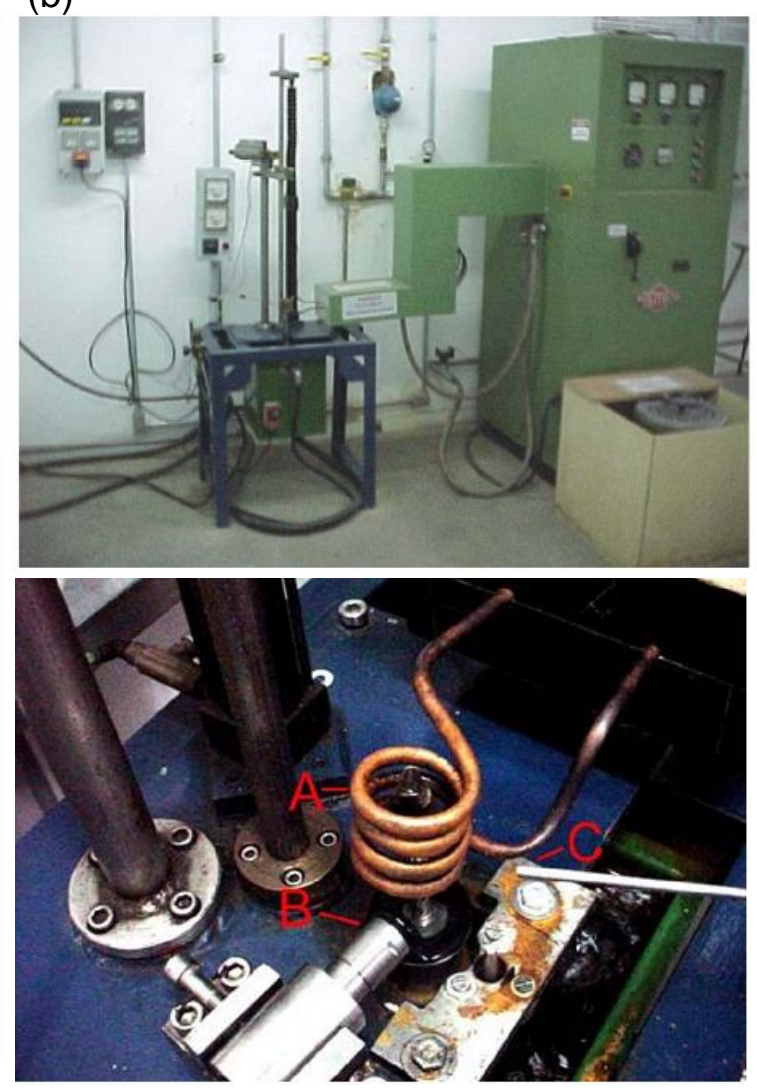

Figura 18 - Aparatos experimentais de fadiga térmica: (a) Máquina de ensaio de fadiga térmica desevolvida por Berling e Slot em 1969. (b) Máquina de ensaio de fadiga térmica mais atual (legenda: A é a bobina de indução; B é o sistema de rotação de eixo e $C$ é um soprador de ar para medição de temperatura). (SILVA, 2006; ALVARENGA JÚNIOR, 2006)

Para o ensaio de fadiga térmica realizado por Silva (2006), aqueceu-se o CP até $650{ }^{\circ} \mathrm{C}$ por $10 \mathrm{~s}$; depois, resfriou-se este $\mathrm{CP}$ em água até que a temperatura ambiente fosse atingida e manteve-se esta temperatura por $45 \mathrm{~s}$ (figura 19a); este ciclo de tratamento térmico foi repetido 100 vezes. O resultado é observado na figura $19 \mathrm{~b}$, sendo que a região em cor de rosa consiste nos pontos de nucleação de trincas.

A partir de um procedimento experimental bem semelhante, Serantoni Silva (2003) obteve, para um CP de uma liga de ferro fundido branco (\% em massa $\rightarrow 1,91$ de $\mathrm{C} ; 4,79$ de $\mathrm{V} ; 1,96$ de $\mathrm{W} ; 2,02$ de $\mathrm{Mo} ; 4,06$ de $\mathrm{Cr}$ ), a propagação de trincas radiais e circunferenciais fornecida na figura $19 \mathrm{c}$. 


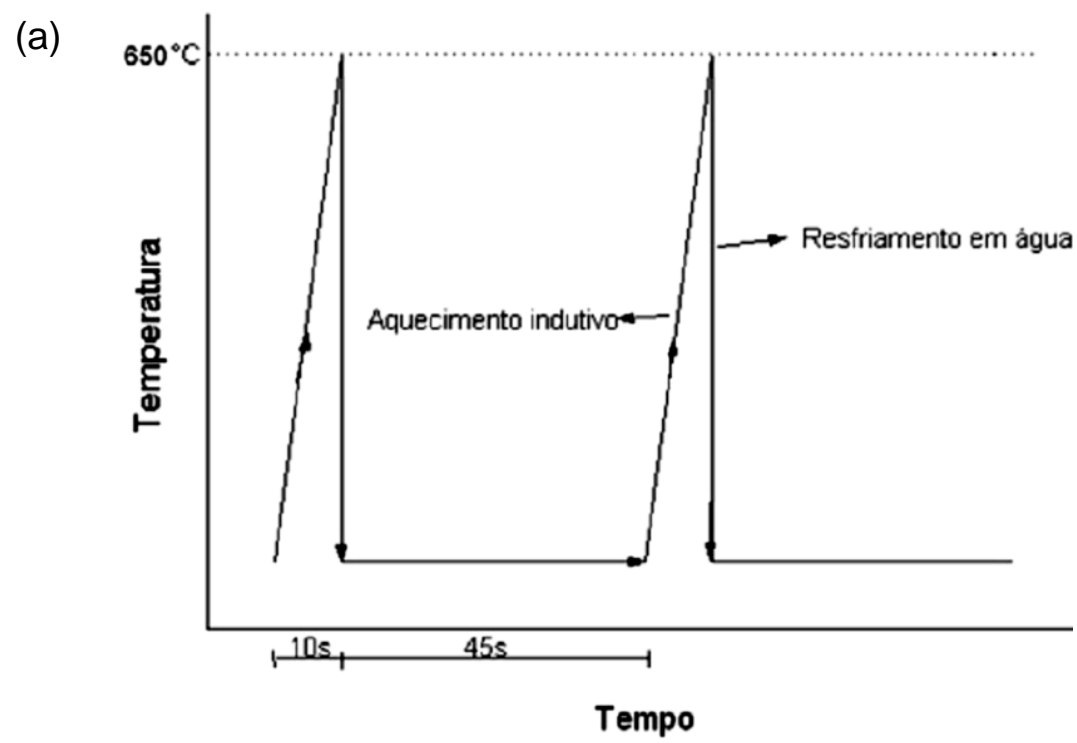

(b)

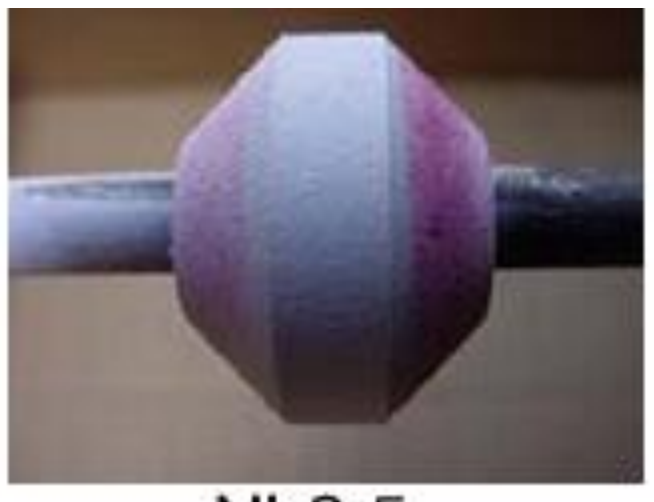

$\mathrm{Nb} 2,5$ (c)

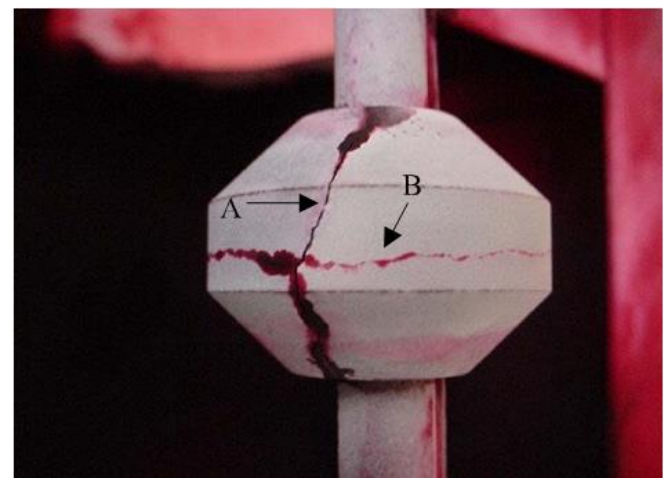

Figura 19 - Trincas térmicas em diferentes CPs. (a) variações de temperatura no ensaio do $\mathrm{CP}$ de aço matriz+NbC (com composição química nominal em massa: 0,83\%C; $2,0 \% \mathrm{~W} ; 3,0 \% \mathrm{Mo} ; 4,6 \% \mathrm{Cr}$; $1,0 \% \mathrm{~V} ; 2,5 \% \mathrm{Ni}$ ); (b) $\mathrm{CP}$ de aço matriz+NbC, após o ensaio de fadiga térmica com regiões rosa (conjunto de trincas).(c) Outro CP, trabalhado por Serantoni Silva (2003), no qual se visualiza a propagação das trincas radiais (indicados por A) e das trincas circunferenciais (indicados por B). (Serantoni Silva, 2003; Silva, 2006).

Dentre as regiões onde a nucleação e crescimento das trincas térmicas são favoráveis nos CPs estão os contornos de grãos, as bandas de deformação proporcionadas pelo carregamento cíclico e, o principal reportado na literatura (SERANTONI SLVA, 2003; SILVA, 2006), os precipitados. Uma imagem da nucleação da trinca mediante existência das partículas de segunda fase foi obtida por MEV e é apresentada na figura 20; observa-se que a trinca foi nucleada em um carboneto próximo à superfície do CP. (SILVA, 2006) 


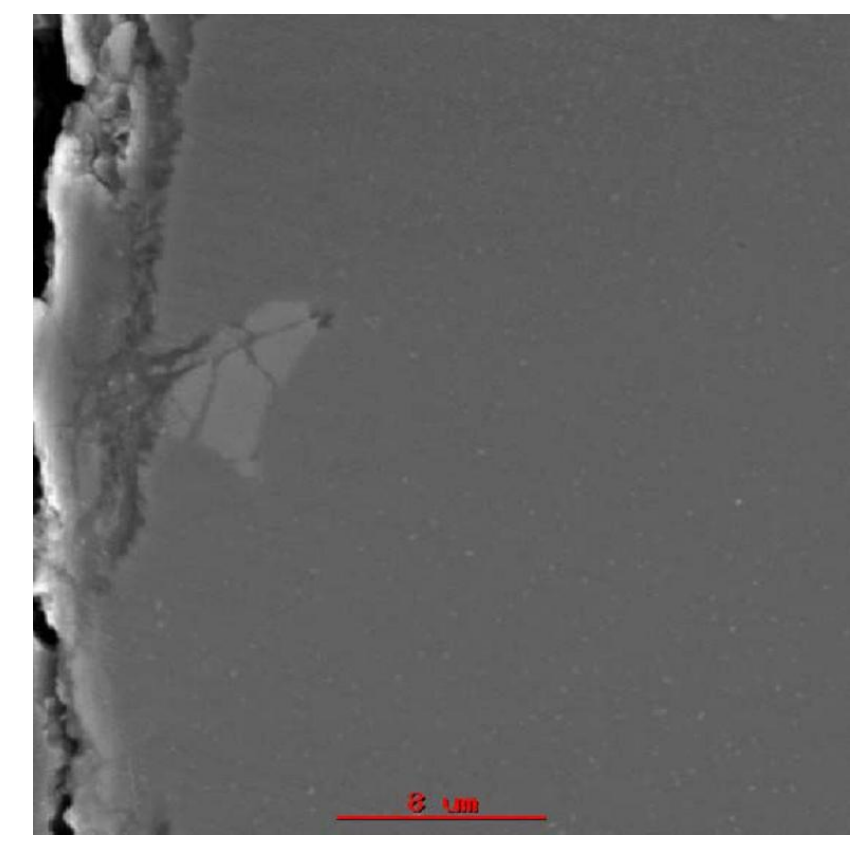

Figura 20 - Seção transversal do CP ensaiado sob fadiga térmica, mostrando o detalhe da trinca nucleada em um carboneto (MEV- elétrons retroespalhados). (Silva, 2006)

Com o contínuo carregamento térmico cíclico do $\mathrm{CP}$ e a interação entre as bandas de deformação e os precipitados, é propiciado o surgimento de concentradores de tensão na interface carboneto/matriz, favorecendo a propagação da trinca térmica. Na figura 21, é representada uma situação ainda mais drástica do que esta: a propagação da trinca ocorre pela interface carboneto/matriz, acarretando na fratura do citado carboneto. (SILVA, 2006)

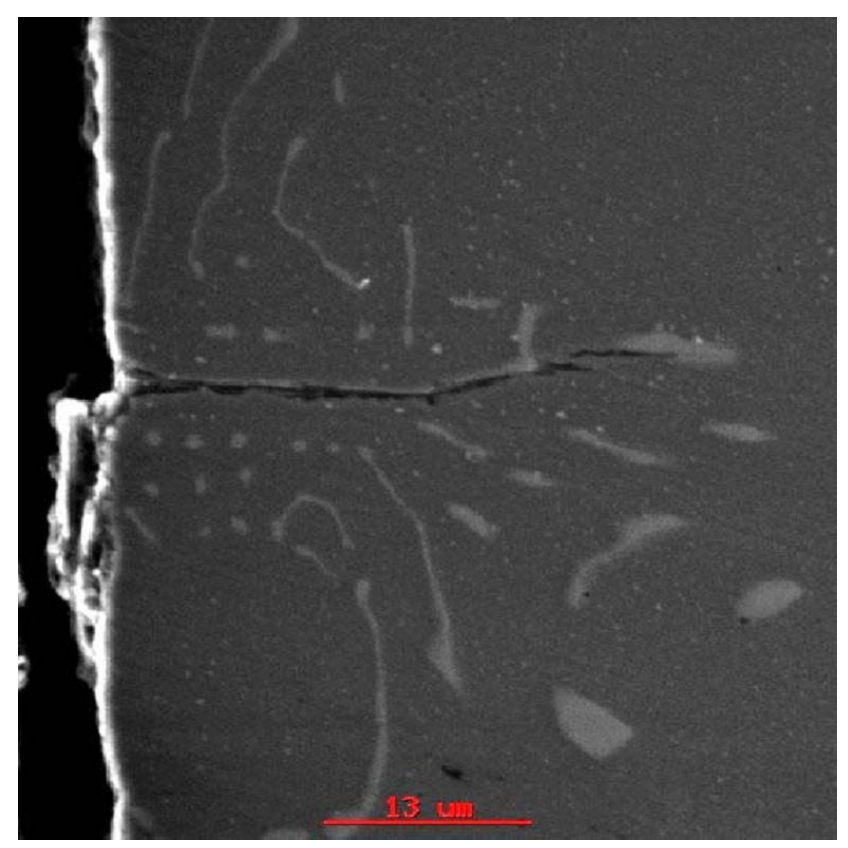

Figura 21 - Propagação da trinca térmica ao longo da célula eutética de carbonetos de NbC. (Silva, 2006) 
Em um trabalho semelhante e antecessor ao de Silva (2006), Serantoni Silva (2003) investigou, por meio de ensaios laboratoriais e caracterização dos materiais, a influência da fração volumétrica de carbonetos de vanádio e molibdênio. $O$ efeito da dureza da matriz também foi investigado, quando o material da ferramenta de conformação foi exposto a ciclos térmicos, de modo a se verificar tanto a nucleação quanto a propagação de trincas térmicas. Observou-se que, ao aumentar a fração volumétrica de carbonetos, aumentava-se consequentemente a taxa de nucleação de trincas. Em contrapartida, ao aumentar a dureza da matriz, diminuía-se a taxa de nucleação de trincas térmicas.

Segundo a análise de Serantoni Silva (2003), concluiu-se que:

(i-) as trincas por fadiga térmica vêm a se manifestar, principalmente, na superfície do material em estudo. A nucleação de tais trincas é propiciada seja por concentradores de tensões mecânicos ou por concentradores de tensões metalúrgicos;

(ii-) as trincas devido à fadiga térmica que ocorrem na matriz do material são decorrentes do efeito da rugosidade que vem a atuar como concentrador de tensão mecânico;

(iii-) o aparecimento de trincas térmicas do material ocorre, na maioria dos casos, devido às partículas de segunda fase na microestrutura do material que atuam, assim, como concentradores de tensões metalúrgicos. Além disso, as trincas, neste caso, podem vir a se manifestar na interface matriz-precipitado e/ou no próprio precipitado;

(iv-) o aumento da razão entre continuidade de carbonetos (C) e distância média livre entre carbonetos $\left(D_{m}\right)$ provocou o aumento na taxa de propagação de trincas. Outro fator que vem a afetar a taxa de propagação de trincas é, portanto, a distribuição dos carbonetos ao longo da matriz;

(v-) o aumento do tempo de ensaio provoca a redução da taxa de propagação da trinca térmica, atuando de modo independente do efeito da fração volumétrica dos precipitados e da dureza da matriz. Por exemplo, nos ensaios de 100 ciclos, houve a propagação instável da trinca ditada pela tenacidade à fratura do material. Já nos ensaios de 500 ciclos, notou-se que a propagação, após os 100 primeiros ciclos, ocorreu governada pela magnitude da tensão.

(vi-) em relação à propagação das trincas por fadiga térmica, esta ocorreu preferencialmente na interface carboneto-matriz ou no carboneto propriamente dito; 
(vii-) o aumento do $\mathrm{CP}$ surtiu como consequência direta o aumento na taxa de nucleação e propagação das trincas térmicas. A justificativa da autora foi o maior gradiente de temperatura ao longo do corpo de prova a partir do aumento nas suas dimensões.

\subsection{CONCEITOS REFERENTES AO ATRITO EXISTENTE NA INTERFACE PEÇA- FERRAMENTA NA CONFORMAÇÃO MECÂNICA}

O atrito é um dos fatores mais importantes nos processos de conformação, uma vez que atua de forma direta na definição do grau de deformação plástica da peça produzida ou fabricada. Pode ser observada, na figura 22 , uma operação denominada de recalque (forjamento em matriz aberta), na qual a deformação de uma geometria cilíndrica (tarugo denotado por B) ocorre entre duas matrizes (denotadas por $\mathrm{D}$ ) devido à aplicação de uma força $\mathrm{F}$. Quando o tarugo é deformado na ausência de atrito (figura 22b), a máxima deformação é alcançada para uma determinada força e relacionada com a força aplicada, sendo que as laterais da peça B ao final da aplicação desta força se apresentam retilíneas. Já no caso da deformação do tarugo com a presença de atrito (figura 22c), a força de atrito se opõe ao escoamento da peça $B$, sendo que uma carga de mesma intensidade é aplicada à ferramenta $\mathrm{D}$, havendo uma parcela de adesão no contato e promovendo uma menor deformação plástica; o resultado é um embarrilamento do tarugo. (ASM INTERNATIONAL, 1995)

Assim, define-se um tribossistema na conformação constituído por componentes, tais como o corpo (peça), o contracorpo (ferramenta), o meio interfacial e o meio ambiente. É essencial comentar que tanto o atrito quanto o desgaste não são propriedades intrínsecas dos materiais; porém, são decorrentes da interação dos referidos componentes do sistema tribológico. Na figura 23, é apresentada uma exemplificação de tribossistema, detalhando os aspectos relativos à interface. (ASM INTERNATIONAL, 1995) 

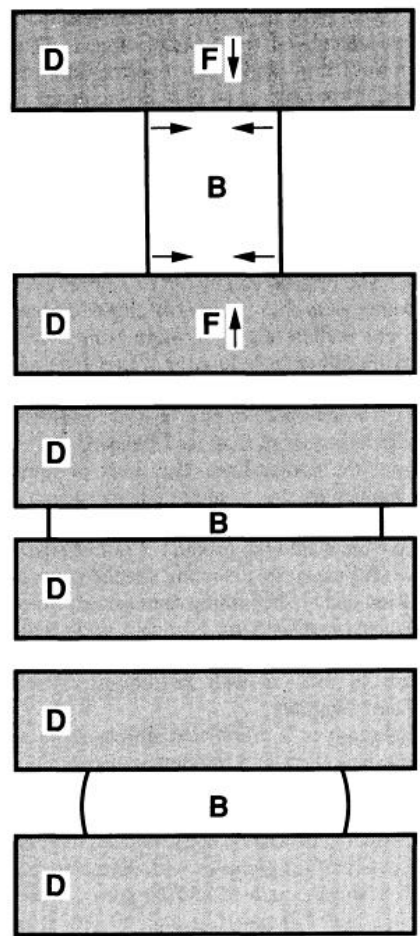

(a)

(b)

(c)

Figura 22 - Operação de recalque: (a-) disposição de um tarugo entre duas matrizes; (b-) deformação da peça sem a presença de atrito na interface; (c-) deformação da peça com a presença de atrito na interface. Simbologia: $D=$ matriz; $B=$ tarugo; $F=$ força aplicada. (ASM INTERNATIONAL, 1995)

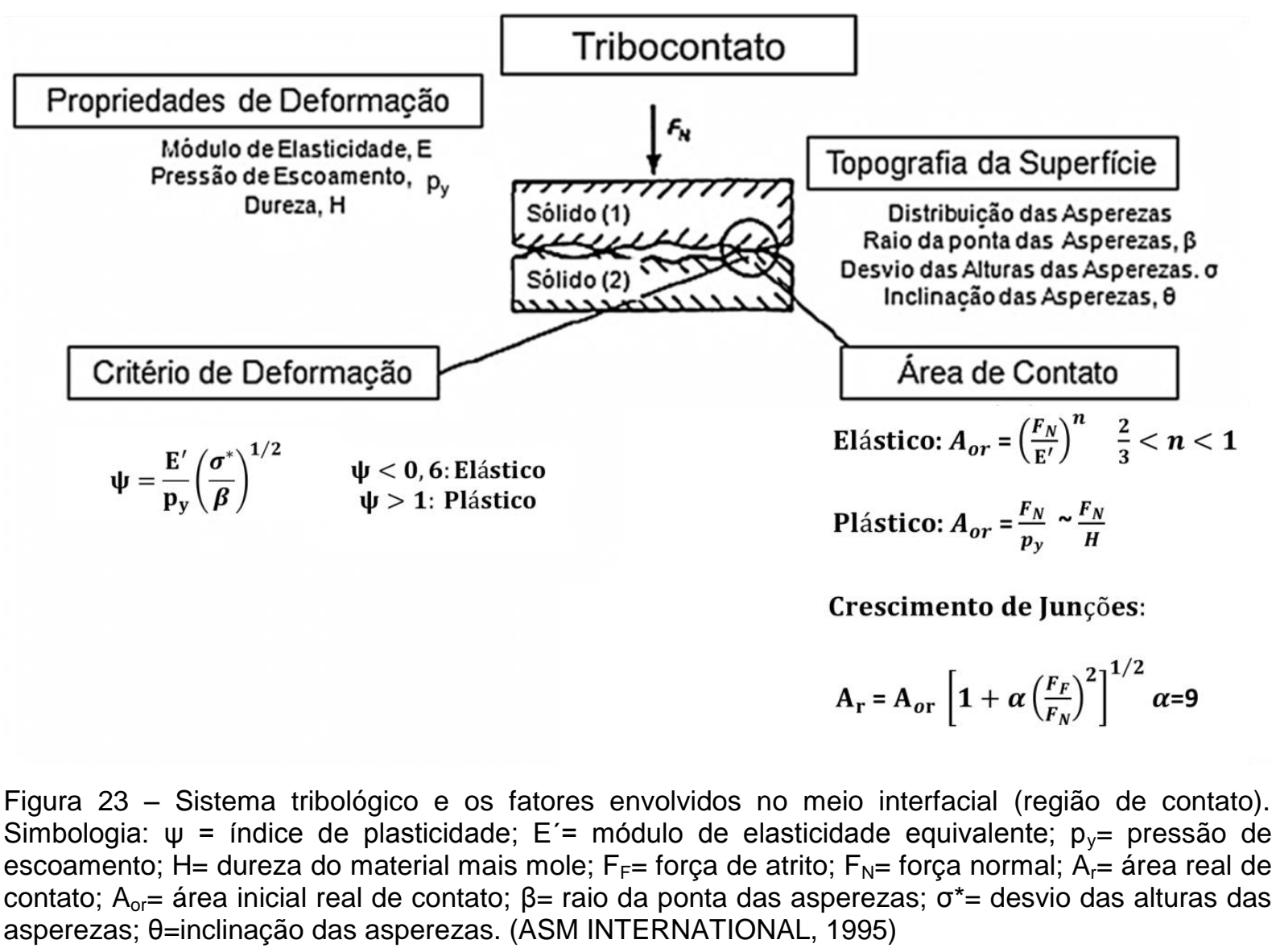


Valberg (2010) enumera, ainda, as seguintes razões para a grande relevância do atrito nos processos de conformação:

- o atrito desempenha um papel na definição das cargas da conformação assim como nas tensões transferidas para as matrizes (ferramentas), ou seja, ele pode trazer consequências tanto na vida da ferramenta quanto no escoamento do metal da peça no decorrer da conformação, sendo que o seu efeito pode ser reduzido por meio da utilização de lubrificantes adequados;

- há uma dependência da integridade e do acabamento superficial da peça no que diz respeito ao filme lubrificante aplicado; caso este seja rompido no decorrer do processo de conformação, a peça resultante pode sofrer danos superficiais, tal como riscamento por partículas abrasivas no desgaste por deslizamento;

- a atuação do atrito na relação entre o lubrificante e os componentes da máquina, nas considerações de custo e na conservação de energia.

Além disso, segundo Valberg (2010), as condições do atrito nos processos de conformação não são suficientemente conhecidas e, portanto, são passíveis da necessidade de mais pesquisas e aprofundamento dos seus conhecimentos. A principal justificativa para tal fato é, talvez, a dificuldade em mensurar o atrito, visto que a tensão de cisalhamento transferida através da interface é muito menor que a tensão normal ou pressão atuante neste contato.

Em relação aos modelos capazes de descrever o atrito na interface da peçaferramenta em questão, examinando as figuras 24 e 25, podem-se ressaltar alguns aspectos de cada um deles, tais como:

- Modelo de atrito de Coulomb $\rightarrow$ indicado para casos em que a pressão de contato seja baixa, visando, por exemplo, ao contato entre corpos em deslizamento; como exemplos de processos de conformação em que é possível assumir esse modelo, tem-se a laminação, trefilação de arame e conformação de chapas. $O$ modelo citado é empregado, então, quando a tensão normal média na peça é menor ou igual à sua tensão de escoamento $\left(\overline{\sigma_{n}} \leq \sigma_{0}\right)$; (VALBERG, 2010) 


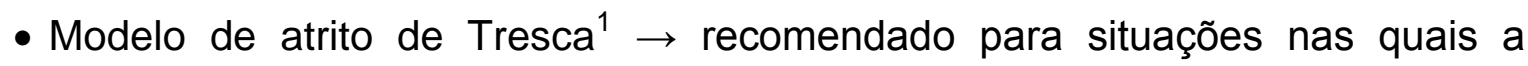
pressão normal de contato atinge um valor muito maior que a tensão de escoamento da peça $\left(\overline{\sigma_{n}} \gg \sigma_{0}\right)$. No caso de altas pressões de contato, portanto, o modelo de atrito de Coulomb pode não reproduzir de forma realística as condições de atrito, e a aplicação do modelo de atrito de Tresca é mais adequada, fornecendo uma melhor descrição do atrito na interface peça-ferramenta. Como exemplo de processos de conformação que são, inevitavelmente, assumidos a altas pressões, tem-se: forjamento e extrusão; (VALBERG, 2010)

- Modelo de Atrito de Waheim-Bay $\rightarrow$ este modelo de transição é, comumente, usado em conformação mecânica a partir de sua combinação com um dos dois outros comentados acima. É descrito na literatura (VALBERG, 2010) como um modelo complexo, capaz de prever um parâmetro de atrito no caso de uma parte da peça permanecer em regime elástico e o restante atingir o esperado regime plástico. Ainda, o autor menciona que tal modelo traz melhores resultados que os outros dois anteriores utilizados de forma separada.

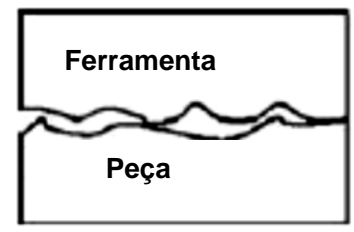

(a)

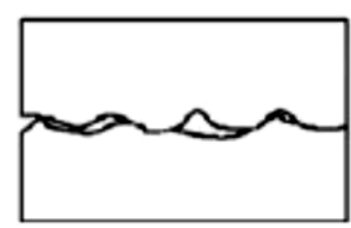

(b)

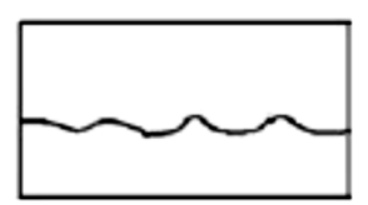

(c)

Figura 24 - Interação entre a ferramenta e a peça em várias situações de contato: (a-) com baixa pressão de contato nas asperezas (baixa conformidade); (b-) com pressão de contato moderada nas asperezas (média conformidade); (c-) com alta pressão de contato nas asperezas (total conformidade). (VALBERG, 2010)

\footnotetext{
${ }^{1} \mathrm{O}$ modelo de atrito de Tresca também é citado, na literatura, como modelo de atrito Prandtl ou, ainda, como modelo da camada limite para descrever o atrito.
} 


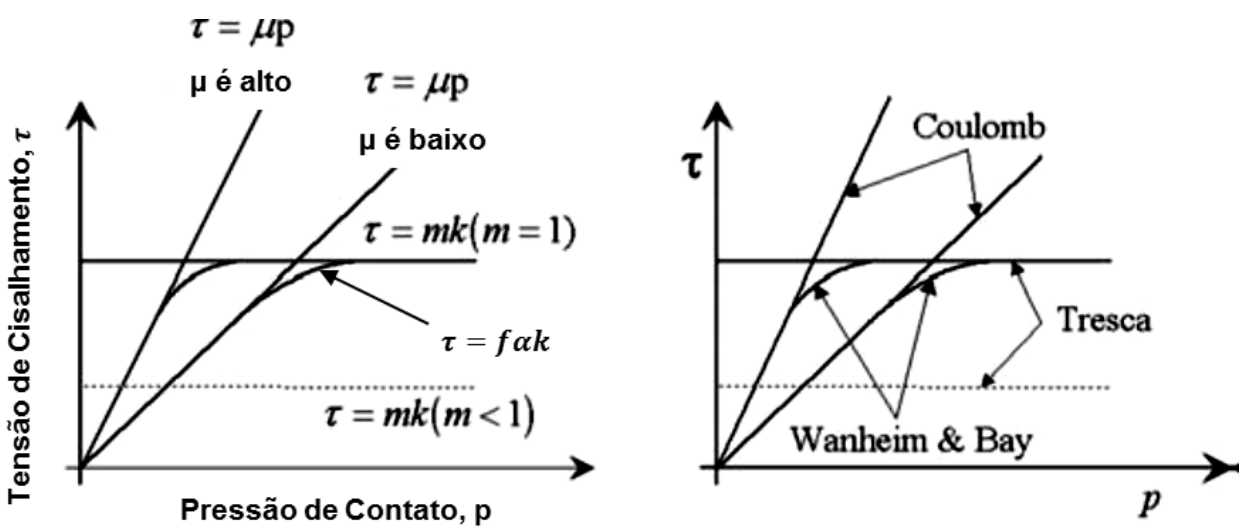

1. Lei de Amonton e Coulomb

$\tau=\mu \mathrm{p}, 0 \leq \mu \leq 0.577$

onde $\mu$ representa o coeficiente de atrito, e p a pressão normal de contato.

2. Lei do atrito constante

$\tau=m \mathbf{k}, 0 \leq \mathbf{m} \leq 1$

Figura 25 - llustração de três modelos de atrito considerados mais representativos das situações encontradas nos processos de conformação. À esquerda, é fornecido o gráfico da tensão de atrito versus a pressão de contato para os distintos modelos. Já à direita, nota-se o nome de cada modelo. Simbologia: $\tau$ é a tensão de atrito, $\mu$ é o coeficiente de atrito, $\mathrm{k}$ é a tensão de escoamento de cisalhamento, $m$ é fator de atrito por cisalhamento constante, f é o fator que denota o atrito na área de contato real $(0 \leq f \leq 1)$, e $\alpha$ é a razão entre a área real e área aparente de contato. (VALBERG, 2010)

\subsection{SOLICITAÇÕES NA FERRAMENTA DURANTE O FORJAMENTO A QUENTE}

A ferramenta de forjar a quente, quando se encontra em operação, está sujeita tanto às tensões e deformações provenientes dos carregamentos mecânicos (força e velocidade), quanto às tensões e deformações oriundas da transferência de calor principalmente com a peça, e em segundo plano com o meio interfacial e meio ambiente (tensões térmicas).

As tensões térmicas são descritas em função das deformações, que têm origem no resfriamento ou no aquecimento do material.

Além dos gradientes de temperatura, de acordo com Guire (2003), cabe acrescentar que as tensões térmicas podem aparecer atribuídas: (a-) às diferenças de coeficientes de expansão térmica ao longo do material como, por exemplo, na 
situação de materiais compósitos e materiais polifásicos; (b-) à anisotropia referente ao coeficiente de expansão térmica do material. Pode-se citar que este parâmetro é diferente nas distintas direções cristalográficas no caso de materiais com estrutura cristalina hexagonal ou tetragonal. Durante um processo de resfriamento do material, é favorecido, neste caso, o aparecimento de tensões térmicas nos contornos de grão que, por sua vez, podem culminar em microtrincas; e (c-) às alterações volumétricas no material decorrentes das transformações de fases; exemplifica-se tal situação tendo em vista a transformação, em aços, da austenita para martensita que vem a proporcionar um aumento de volume ocupado pelos átomos na estrutura cristalina, podendo haver a formação de trincas após a realização da têmpera do aço.

As tensões mecânicas, por sua vez, ocorrem quando uma dada área do material se encontra exposta a forças externas, provocando deformações vistas a princípio como modificações geométricas (no comprimento, por exemplo).

\subsubsection{Equacionamento das tensões mecânicas (condição isotérmica)}

Segundo Cook, Malkus e Plesha (1989), partindo-se da formulação geral das componentes dos vetores de tensão $\{\sigma\}$ e de deformação $\{\varepsilon\}$, em três dimensões, conforme pode ser observado na figura 26 , tem-se:

$$
\begin{aligned}
& \{\sigma\}=\left[\begin{array}{llllll}
\sigma_{x} & \sigma_{y} & \sigma_{z} & \tau_{x y} & \tau_{y z} & \tau_{z x}
\end{array}\right]^{T} \\
& \{\varepsilon\}=\left[\begin{array}{llllll}
\varepsilon_{x} & \varepsilon_{y} & \varepsilon_{z} & \gamma_{x y} & \gamma_{y z} & \gamma_{z x}
\end{array}\right]^{T}
\end{aligned}
$$

Onde: $\sigma_{x}, \sigma_{y}$ e $\sigma_{z}$ são as tensões normais atuantes nas diferentes direções do material; $\tau_{x y}, \tau_{y z}$ e $\tau_{z x}$ são as tensões de cisalhamento atuantes nos diferentes planos deste material; $\varepsilon_{x}, \varepsilon_{y}$ e $\varepsilon_{z}$ são as deformações atuantes nas diferentes direções do material; e $\gamma_{x y}, \gamma_{y z}$ e $\gamma_{z x}$ são as deformações por cisalhamento atuantes nos diferentes planos do material em questão. 


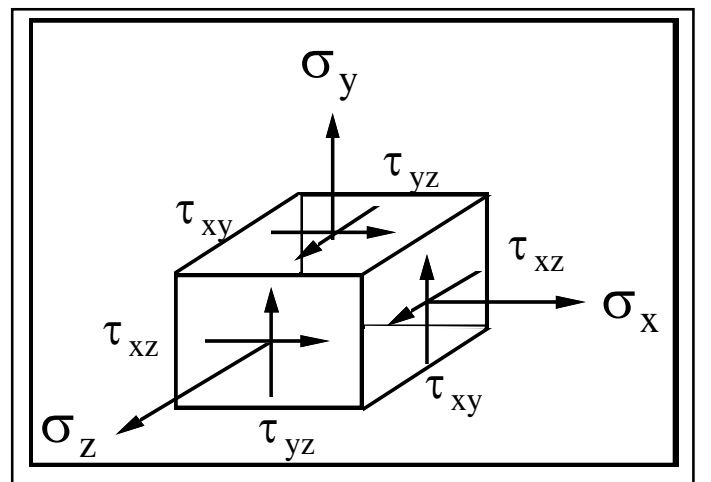

Figura 26 - Representação das componentes de tensões atuantes em um material, vista sob o aspecto tridimensional. (adaptado de DIETER, 1988)

Pode ser atribuída a seguinte relação às tensões mecânicas elásticas segundo a lei de Hooke: (COOK; MALKUS; PLESHA, 1989)

$$
\{\sigma\}=[k]\{\varepsilon\}
$$

Em que: [k] é a matriz simétrica de rigidez do material.

Substituindo as eqs.(4) e (5) na eq.(6), obtém-se:

$$
\left\{\begin{array}{c}
\sigma_{x} \\
\sigma_{y} \\
\sigma_{z} \\
\tau_{x y} \\
\tau_{y z} \\
\tau_{z x}
\end{array}\right\}=\left[\begin{array}{llllll}
k_{11} & k_{12} & k_{13} & k_{14} & k_{15} & k_{16} \\
k_{21} & k_{22} & k_{23} & k_{24} & k_{25} & k_{26} \\
k_{31} & k_{32} & k_{33} & k_{34} & k_{35} & k_{36} \\
k_{41} & k_{42} & k_{43} & k_{44} & k_{45} & k_{46} \\
k_{51} & k_{52} & k_{53} & k_{54} & k_{55} & k_{56} \\
k_{61} & k_{62} & k_{63} & k_{64} & k_{65} & k_{66}
\end{array}\right]\left\{\begin{array}{c}
\varepsilon_{x} \\
\varepsilon_{y} \\
\varepsilon_{z} \\
\gamma_{x y} \\
\gamma_{y z} \\
\gamma_{z x}
\end{array}\right\}
$$

Para a consideração de material isotrópico, as seguintes condições são previstas: (COOK; MALKUS; PLESHA, 1989)

$$
\begin{aligned}
& k_{11}=k_{22}=k_{33}=(1-v) \cdot\left[\frac{E}{(1+v)(1-2 v)}\right] \\
& k_{12}=k_{13}=k_{23}=v \cdot\left[\frac{E}{(1+v)(1-2 v)}\right] \\
& k_{44}=k_{55}=k_{66}=G=\frac{E}{2 \cdot(1+v)}
\end{aligned}
$$


Onde: E é o módulo de elasticidade; G é o módulo de cisalhamento; e $v$ é o coeficiente de Poisson.

Ao implementar as condições previstas pelas eqs.(8), (9) e (10) na eq.(7), a relação entre tensões e deformações, no âmbito tridimensional, é dado por: (COOK; MALKUS; PLESHA, 1989)

$$
\left\{\begin{array}{c}
\sigma_{x} \\
\sigma_{y} \\
\sigma_{z} \\
\tau_{x y} \\
\tau_{y z} \\
\tau_{z x}
\end{array}\right\}=\frac{E}{(1+v)(1-2 v)}\left[\begin{array}{ccccccc}
1-v & v & v & 0 & 0 & 0 \\
v & 1-v & v & 0 & 0 & 0 \\
v & v & 1-v & 0 & 0 & 0 \\
0 & 0 & 0 & 1-2 v & 0 & 0 \\
0 & 0 & 0 & 0 & 1-2 v & 0 \\
0 & 0 & 0 & 0 & 0 & 1-2 v
\end{array}\right]\left\{\begin{array}{c}
\varepsilon_{x} \\
\varepsilon_{y} \\
\varepsilon_{z} \\
\gamma_{x y} \\
\gamma_{y z} \\
\gamma_{z x}
\end{array}\right\}
$$

$\mathrm{Na}$ análise de tensões e deformações mecânicas em duas dimensões, duas vertentes de estudo se apresentam:

$>$ estado plano de deformações (EPD): neste caso, como o deslocamento na direção $z$ do sistema cartesiano (figura 26) vem a se anular, a seguinte premissa é tida em conta: (COOK; MALKUS; PLESHA, 1989)

$$
\varepsilon_{z}=\gamma_{y z}=\gamma_{z x}=0
$$

Substituindo a condição ditada pela eq.(12) na eq.(11), o resultado obtido para as tensões mecânicas, em função das deformações mecânicas, em um determinado material isotrópico no estado plano de deformações corresponde a eq.(13): (COOK; MALKUS; PLESHA, 1989)

$$
\left\{\begin{array}{c}
\sigma_{x} \\
\sigma_{y} \\
\tau_{x y}
\end{array}\right\}=\frac{E}{(1+v)(1-2 v)}\left[\begin{array}{ccc}
1-v & v & 0 \\
v & 1-v & 0 \\
0 & 0 & \frac{1-2 v}{2}
\end{array}\right]\left\{\begin{array}{c}
\varepsilon_{x} \\
\varepsilon_{y} \\
\gamma_{x y}
\end{array}\right\}
$$

Na qual: E é o módulo de elasticidade; $v$ é o coeficiente de Poisson; $\sigma_{x}$ e $\sigma_{y}$ são as tensões normais; $\tau_{x y}$ é a tensão de cisalhamento; $\varepsilon_{x}$ e $\varepsilon_{y}$ são as deformações; e $\gamma_{x y}$ é a deformação por cisalhamento. 
$>\quad$ estado plano de tensões (EPT): este caso é visto como uma placa fina, sendo que: (COOK; MALKUS; PLESHA, 1989)

$$
\sigma_{z}=\tau_{y z}=\tau_{z x}=0
$$

A partir da substituição da eq.(14) na eq.(11), as tensões mecânicas, em função das deformações mecânicas, em um determinado material isotrópico no estado plano de tensões se resumem na eq.(15): (COOK; MALKUS; PLESHA, 1989)

$$
\begin{gathered}
\left\{\begin{array}{c}
\varepsilon_{x} \\
\varepsilon_{y} \\
\gamma_{x y}
\end{array}\right\}=\frac{1}{E}\left[\begin{array}{ccc}
1 & -v & 0 \\
-v & 1 & 0 \\
0 & 0 & \frac{E}{G}
\end{array}\right]\left\{\begin{array}{c}
\sigma_{x} \\
\sigma_{y} \\
\tau_{x y}
\end{array}\right\} \\
\left\{\begin{array}{c}
\sigma_{x} \\
\sigma_{y} \\
\tau_{x y}
\end{array}\right\}=\frac{E}{1-v^{2}}\left[\begin{array}{ccc}
1-v & v & 0 \\
v & 1-v & 0 \\
0 & 0 & \frac{1-2 v}{2}
\end{array}\right]\left\{\begin{array}{c}
\varepsilon_{x} \\
\varepsilon_{y} \\
\gamma_{x y}
\end{array}\right\}
\end{gathered}
$$

Em que: E é o módulo de elasticidade; v é o coeficiente de Poisson; G é o módulo de cisalhamento; $\sigma_{x}$ e $\sigma_{y}$ são as tensões normais; $\tau_{x y}$ é a tensão de cisalhamento; $\varepsilon_{x}$ e $\varepsilon_{y}$ são as deformações; e $\gamma_{x y}$ é a deformação por cisalhamento.

3.6.2 Critérios para avaliação do campo de tensões mecânicas no material da ferramenta

Alguns critérios que podem ser discorridos, acerca da avaliação do campo de tensões em materiais, remetem ao escoamento do material (critérios de escoamento), tendo em vista o prévio conhecimento da tensão limite de escoamento quando o material se encontra submetido ao carregamento uniaxial, como, por exemplo, em um ensaio de tração. Neste caso, pode-se atribuir como uma das características dos critérios de escoamento o fato de serem relações empíricas. (DIETER, 1988) 
Em cumprimento às observações experimentais, Dieter (1988) enumera as seguintes condições aderidas aos critérios de escoamento:

(i-) as tensões combinadas atuantes em um material são associadas a um certo conjunto de tensões principais, fornecidas como estado inicial na figura 27. A partir deste conjunto de tensões, é feito o alicerce para a construção dos critérios de escoamento;

(ii-) ao ser exposto unicamente à pressão hidrostática, representada pela componente hidrostática da figura 27 , um dado sólido contínuo não vem a apresentar escoamento;

(iii-) em função da condição (i), a relevância da determinação da tensão-desvio, designada pela componente desviadora da figura 27 , sobrepuja a importância da busca da componente hidrostática para averiguar o escoamento do material;

(iv-) a partir da consideração de um material isotrópico, o critério de escoamento vem a ser representado como uma função invariante da tensão-desvio, sendo independente da seleção de eixos de análise.

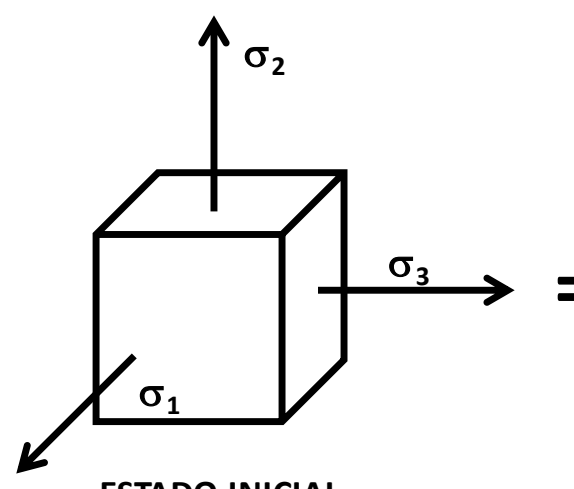

ESTADO INICIAL

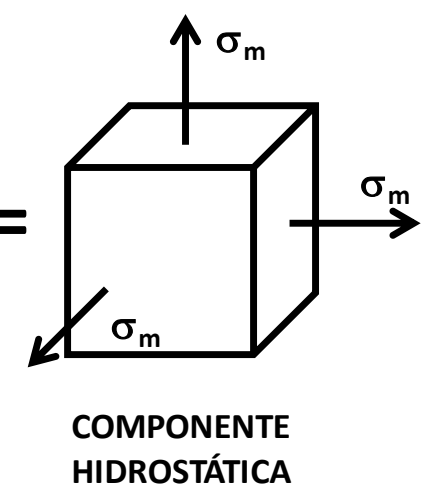

HIDROSTÁTICA

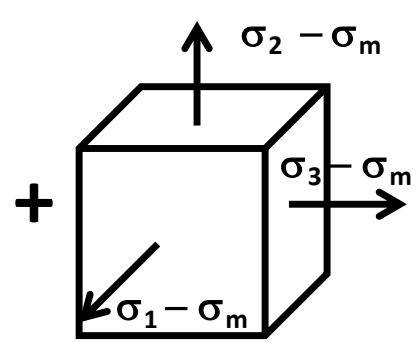

COMPONENTE DESVIADORA

Figura 27 - Decomposição das tensões principais em um sólido. (MORAIS, 2004)

Especificamente a tensão hidrostática, observada na figura 27, abrange apenas os efeitos de tração ou compressão pura responsáveis pelas variações volumétricas elásticas no material, e é considerada como uma tensão média $\left(\sigma_{m}\right)$ : (DIETER, 1988)

$$
\sigma_{m}=\frac{\sigma_{k k}}{3}=\frac{\sigma_{1}+\sigma_{2}+\sigma_{3}}{3}=\frac{\sigma_{x}+\sigma_{y}+\sigma_{z}}{3}
$$


Em que: $\sigma_{m}$ é a tensão média ou hidrostática; $\sigma_{1}, \sigma_{2}$ e $\sigma_{3}$ são as tensões principais no material em estudo; $\sigma_{x}, \sigma_{y}$ e $\sigma_{z}$ são as tensões principais, conforme o sistema cartesiano de coordenadas; $\sigma_{k k}$ é a soma das tensões principais.

Quanto à tensão-desvio ou desviadora (figura 27), representada pelo tensor $\sigma^{\prime}{ }_{i j}$, o seu campo abrange o efeito da tensão de cisalhamento no estado de tensões total, sendo relevante na geração de deformação plástica no material. (DIETER, 1988)

A fim de fornecer uma base de tensores para a posterior descrição dos principais critérios de escoamento, têm-se as formulações que se seguem: (DIETER, 1988)

- decomposição do tensor de tensão (soma da componente hidrostática e da componente desviadora):

$$
\underbrace{\sigma_{i j}}_{\text {tensor de tensão }}=\underbrace{\sigma^{\prime}{ }_{i j}}_{\text {tensão-desvio }}+\underbrace{\frac{1}{3} \delta_{i j} \sigma_{k k}}_{\text {tensão hidrostática }}
$$

- em função das eqs.(16) e (17), inicia-se a dedução do tensor da tensão-desvio:

$$
\underbrace{\sigma^{\prime}{ }_{i j}}_{\text {tensão-desvio }}=\underbrace{\sigma_{i j}}_{\text {tensor de tensão }}-\underbrace{\sigma_{m} \delta_{i j}}_{\text {tensão hidrostática }}
$$

Da eq.(18), infere-se na eq.(19) a respectiva relação para o tensor da tensãodesvio em função das tensões de cisalhamento, considerando-se o sistema de coordenadas cartesiano:

$$
\underbrace{\sigma^{\prime}{ }_{i j}}_{\text {tensão-desvio }}=\left[\begin{array}{ccc}
\frac{2 \sigma_{x}-\sigma_{y}-\sigma_{z}}{3} & \tau_{x y} & \tau_{x z} \\
\tau_{y x} & \frac{2 \sigma_{y}-\sigma_{z}-\sigma_{x}}{3} & \tau_{y z} \\
\tau_{z x} & \tau_{z y} & \frac{2 \sigma_{z}-\sigma_{x}-\sigma_{y}}{3}
\end{array}\right]
$$

Onde: $\sigma_{x}, \sigma_{y}$ e $\sigma_{z}$ são as tensões normais e $\tau_{x y}, \tau_{x z}, \tau_{y x}, \tau_{y z}, \tau_{z x}$ e $\tau_{z y}$ são as tensões cisalhantes. 
Dieter (1988) complementa a descrição do tensor da tensão-desvio, relatando que o mesmo se trata de um tensor de segunda ordem, apresentando eixos principais, e sendo que estes valores principais atribuídos são tidos como as raízes cúbicas da eq.(20):

$$
\left(\sigma^{\prime}\right)^{3}-J_{1}\left(\sigma^{\prime}\right)^{2}-J_{2}\left(\sigma^{\prime}\right)-J_{3}=0
$$

Sendo que os invariantes do tensor da tensão-desvio são:

$J_{1} \rightarrow$ soma dos termos da diagonal principal da matriz da tensão-desvio, segundo a eq.(19):

$$
\begin{gathered}
J_{1}=\frac{2 \sigma_{x}-\sigma_{y}-\sigma_{z}}{3}+\frac{2 \sigma_{y}-\sigma_{z}-\sigma_{x}}{3}+\frac{2 \sigma_{z}-\sigma_{x}-\sigma_{y}}{3}= \\
=\frac{3 \sigma_{x}-\left(\sigma_{x}+\sigma_{y}+\sigma_{z}\right)}{3}+\frac{3 \sigma_{y}-\left(\sigma_{x}+\sigma_{y}+\sigma_{z}\right)}{3}+\frac{3 \sigma_{z}-\left(\sigma_{x}+\sigma_{y}+\sigma_{z}\right)}{3} \\
\therefore J_{1}=\left(\sigma_{x}-\sigma_{m}\right)+\left(\sigma_{y}-\sigma_{m}\right)+\left(\sigma_{z}-\sigma_{m}\right)=0
\end{gathered}
$$

Onde: $\sigma_{m}$ é a tensão média ou hidrostática; $\sigma_{x}, \sigma_{y} e \sigma_{z}$ são as tensões principais descritas conforme o sistema de coordenadas cartesiano.

$J_{2} \rightarrow$ soma dos secundários principais da matriz da tensão-desvio, designada na eq.(19):

$$
\begin{gathered}
J_{2}=\left|\begin{array}{cc}
\frac{2 \sigma_{y}-\sigma_{z}-\sigma_{x}}{3} & \tau_{y z} \\
\tau_{z y} & \frac{2 \sigma_{z}-\sigma_{x}-\sigma_{y}}{3}
\end{array}\right|+\left|\begin{array}{cc}
\frac{2 \sigma_{x}-\sigma_{y}-\sigma_{z}}{3} & \tau_{x z} \\
\tau_{z x} & \frac{2 \sigma_{z}-\sigma_{x}-\sigma_{y}}{3}
\end{array}\right|+\left|\begin{array}{cc}
\frac{2 \sigma_{x}-\sigma_{y}-\sigma_{z}}{3} & \tau_{x y} \\
\tau_{y x} & \frac{2 \sigma_{y}-\sigma_{z}-\sigma_{x}}{3}
\end{array}\right| \\
J_{2}=\left(\frac{4 \sigma_{y} \sigma_{z}-2 \sigma_{x} \sigma_{y}-2 \sigma_{y}{ }^{2}-2 \sigma_{z}^{2}+\sigma_{x} \sigma_{z}+\sigma_{y} \sigma_{z}-2 \sigma_{x} \sigma_{z}+\sigma_{x}{ }^{2}+\sigma_{x} \sigma_{y}}{9}\right)-\tau_{y z}{ }^{2}+ \\
+\left(\frac{4 \sigma_{x} \sigma_{z}-2 \sigma_{x}^{2}-2 \sigma_{x} \sigma_{y}-2 \sigma_{y} \sigma_{z}+\sigma_{x} \sigma_{y}+{\sigma_{y}}^{2}-2{\sigma_{z}}^{2}+\sigma_{x} \sigma_{z}+\sigma_{y} \sigma_{z}}{9}\right)-\tau_{x z}{ }^{2}+
\end{gathered}
$$




$$
\begin{gathered}
+\left(\frac{4 \sigma_{x} \sigma_{y}-2 \sigma_{x} \sigma_{z}-2 \sigma_{x}^{2}-2 \sigma_{y}^{2}+\sigma_{y} \sigma_{z}+\sigma_{x} \sigma_{y}-2 \sigma_{y} \sigma_{z}+\sigma_{z}^{2}+\sigma_{x} \sigma_{z}}{9}\right)-\tau_{x y}{ }^{2}= \\
=\frac{2}{2}\left[\frac{-3 \sigma_{x}{ }^{2}-3 \sigma_{y}{ }^{2}-3{\sigma_{z}}^{2}+3 \sigma_{x} \sigma_{y}+3 \sigma_{y} \sigma_{z}+3 \sigma_{x} \sigma_{z}}{9}\right]-\tau_{y z}{ }^{2}-\tau_{x z}{ }^{2}-\tau_{x y}{ }^{2}= \\
=\left[\frac{-3\left(\sigma_{x}{ }^{2}+{\sigma_{x}}^{2}+{\sigma_{y}}^{2}+{\sigma_{y}}^{2}+{\sigma_{z}}^{2}+{\sigma_{z}}^{2}-2 \sigma_{x} \sigma_{y}-2 \sigma_{y} \sigma_{z}-2 \sigma_{x} \sigma_{z}\right)}{18}\right]-\tau_{y z}{ }^{2}-\tau_{x z}{ }^{2}-\tau_{x y}{ }^{2}= \\
=\frac{-\left[\left(\sigma_{x}-\sigma_{y}\right)^{2}+\left(\sigma_{y}-\sigma_{z}\right)^{2}+\left(\sigma_{z}-\sigma_{x}\right)^{2}\right]}{6}-\tau_{y z}{ }^{2}-\tau_{x z}{ }^{2}-\tau_{x y}{ }^{2}=
\end{gathered}
$$

$\therefore$ em módulo, $J_{2}=\frac{1}{6}\left[\left(\sigma_{x}-\sigma_{y}\right)^{2}+\left(\sigma_{y}-\sigma_{z}\right)^{2}+\left(\sigma_{z}-\sigma_{x}\right)^{2}+6\left(\tau_{y z}{ }^{2}+\tau_{x z}{ }^{2}+\tau_{x y}{ }^{2}\right)\right]$

$\boldsymbol{J}_{3} \rightarrow$ determinante da matriz da tensão-desvio, apresentada na eq.(19).

Baseado nos tensores da tensão-desvio e da tensão hidrostática, assumindo a nomenclatura de tensões principais observada na figura 27, e partindo-se da relação de tensões principais atuantes nas direções distintas como $\sigma_{1}>\sigma_{2}>\sigma_{3}$, é iniciado 0 estudo específico dos critérios de escoamento. Estes são utilizados na previsão do campo de tensões e de deformações em softwares de elementos finitos. No conjunto desses critérios de escoamento de materiais dúcteis, os comumente explanados na literatura são:

> Critério da tensão normal máxima (Rankine): no caso de materiais dúcteis, relata que a falha ocorre quando a tensão normal aplicada vem a atingir o valor da tensão de escoamento uniaxial, obtida em um ensaio de tração. (NORTON, 2006)

> Critério de von Mises (energia de distorção máxima): afirma que o escoamento do material ocorre a partir do momento que o segundo invariante da tensão-desvio $\left(J_{2}\right)$ atinge um dado valor crítico, de acordo com a expressão da eq.(23): (DIETER, 1988) 


$$
J_{2}=k^{2}
$$

Na qual: $J_{2}$ é determinado pela eq.(22) e $k^{2}$ é o valor crítico.

O valor da tensão de escoamento, segundo este critério, é previsto considerando-se as condições para o escoamento do material na situação de tração uniaxial. Assim, substituindo as referidas condições na eq.(23), tem-se: (DIETER, 1988)

$$
\begin{aligned}
& J_{2}=k^{2} \\
& \frac{1}{6}\left[\left(\sigma_{1}-\sigma_{2}\right)^{2}+\left(\sigma_{2}-\sigma_{3}\right)^{2}+\left(\sigma_{3}-\sigma_{1}\right)^{2}+6\left(\tau_{23}{ }^{2}+{\tau_{13}}^{2}+\tau_{12}{ }^{2}\right)\right]=k^{2} \\
& \text { Condições: }\left\{\begin{array}{c}
\sigma_{1}=\sigma_{0} ; \\
\sigma_{2}=\sigma_{3}=0 ; \\
\text { ensaio de tração } \rightarrow \text { não há cisalhamento. }
\end{array}\right. \\
& 2 \sigma_{0}^{2}=6 k^{2} \\
& \sigma_{0}=\sqrt{3} k
\end{aligned}
$$

Inserindo a eq.(24) na eq.(23), a tensão de von Mises em caso de escoamento no ensaio de tração é dada por: (DIETER, 1988)

$$
\begin{gathered}
\sigma_{0}=\sqrt{3} k \\
J_{2}=\frac{\sigma_{0}^{2}}{3} \\
\frac{1}{6}\left[\left(\sigma_{1}-\sigma_{2}\right)^{2}+\left(\sigma_{2}-\sigma_{3}\right)^{2}+\left(\sigma_{3}-\sigma_{1}\right)^{2}\right]=\frac{\sigma_{0}^{2}}{3} \\
\therefore \sigma_{0}=\frac{\sqrt{2}}{2}\left[\left(\sigma_{1}-\sigma_{2}\right)^{2}+\left(\sigma_{2}-\sigma_{3}\right)^{2}+\left(\sigma_{3}-\sigma_{1}\right)^{2}\right]^{1 / 2}
\end{gathered}
$$


A consideração de cisalhamento no material transforma a eq.(25) no critério mais geral para o cálculo do escoamento perante o critério de von Mises:

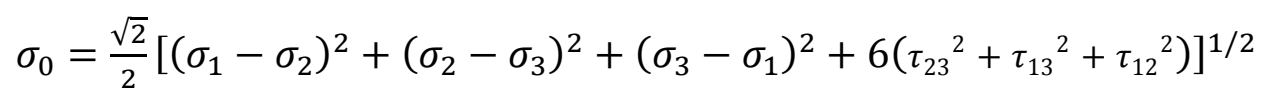

Em que: $\sigma_{0}$ é tensão de escoamento; $\sigma_{1}, \sigma_{2}$ e $\sigma_{3}$ são as tensões principais e $\tau_{23}, \tau_{13}$ e $\tau_{12}$ são as tensões cisalhantes.

Segundo Norton (2006), quanto à interpretação física deste critério, pode-se dizer que é válido, também, aceitar que o critério de von Mises implica que o escoamento do material tem seu início quando a tensão de cisalhamento octaédrica ultrapassa a sua condição no estado uniaxial de tração (ponto crítico). A tensão de cisalhamento octaédrica, por sua vez, é calculada a partir da eq.(27):

$$
\begin{gathered}
\tau_{o c t}=\frac{1}{3}\left[\left(\sigma_{1}-\sigma_{2}\right)^{2}+\left(\sigma_{2}-\sigma_{3}\right)^{2}+\left(\sigma_{3}-\sigma_{1}\right)^{2}\right]^{1 / 2} \\
\therefore \tau_{o c t}=\frac{1}{3} \cdot \sqrt{2} \sigma_{0} \\
\tau_{o c t}=\frac{\sqrt{2}}{3} \sigma_{0}
\end{gathered}
$$

Onde: $\sigma_{0}$ é tensão de escoamento do material; $\tau_{o c t}$ é a tensão de cisalhamento octaédrica; e $\sigma_{1}, \sigma_{2}$ e $\sigma_{3}$ são as tensões principais no material em estudo.

$>\quad$ Critério de tensão de cisalhamento máxima (Tresca): reporta que a falha por escoamento do material vem a ocorrer a partir da situação de igualdade entre o valor da tensão de cisalhamento máxima e o valor da tensão de cisalhamento resultante do ensaio de tração uniaxial. (DIETER, 1988; NORTON, 2006)

A tensão máxima de cisalhamento, por sua vez, é fornecida como:

$$
\tau_{\text {máx }}=\frac{\sigma_{1}-\sigma_{3}}{2}
$$


Onde: $\sigma_{1}$ e $\sigma_{3}$ são as tensões principais maior e menor (em sua forma algébrica), respectivamente.

Levando-se em conta o caso de tração uniaxial em um material dúctil, segundo Dieter (1988), têm-se as seguintes considerações:

$$
\left\{\begin{array}{l}
\sigma_{1}=\sigma_{0} \\
\sigma_{2}=\sigma_{3}=0
\end{array}\right.
$$

Substituindo as condições descritas, matematicamente, nas eqs.(29) e (30) na eq.(28), o resultado obtido é:

$$
\begin{aligned}
& \tau_{\text {máx }}=\frac{\sigma_{0}}{2} \\
& \therefore \sigma_{0}=\sigma_{1}-\sigma_{3}
\end{aligned}
$$

Em que: $\sigma_{0}$ é tensão de escoamento uniaxial; $\tau_{\text {máx }}$ é a tensão máxima de cisalhamento; $\sigma_{1}, \sigma_{2}$ e $\sigma_{3}$ são as tensões principais no material em estudo.

De acordo com Dieter (1988), outra forma de descrever a tensão de escoamento pelo critério de Tresca é feita pela adaptação da eq.(32).

$$
\sigma_{0}=\sigma_{1}-\sigma_{3}=2 k
$$

Sendo que o valor da constante k na eq.(33) é calculado com o auxílio dos invariantes $\left(J_{2}\right.$ e $\left.J_{3}\right)$ componentes do tensor da tensão-desvio:

$$
4 J_{2}{ }^{3}-2 J_{3}{ }^{2}-36 k^{2} J_{2}{ }^{2}+96 k^{4} J_{2}-64 k^{6}=0
$$

Nota-se que a implementação da eq.(34), que designa o critério da tensão de cisalhamento máxima, é mais complexa do que a da eq.(23), representativa do 
critério de von Mises. Em virtude deste fato, opta-se, em muitos casos práticos, pela aplicação do critério de energia de distorção máxima. (DIETER, 1988)

$\mathrm{Na}$ figura 28, encontra-se a representação gráfica bidimensional dos critérios de escoamento aqui comentados: o quadrado de Rankine; o hexágono de Tresca; e a elipse de von Mises.

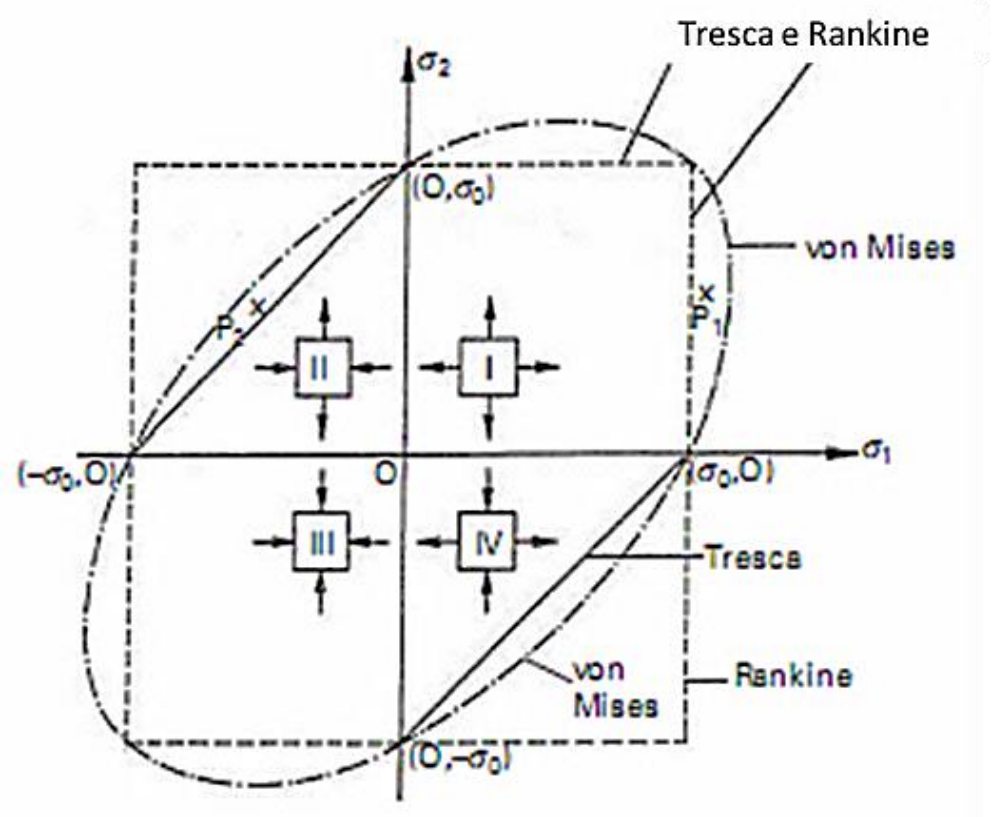

Figura 28 - Gráfico representativo dos critérios de Rankine, Tresca e von Mises para duas dimensões. $\sigma_{0}$ é a tensão de escoamento; $\sigma_{1}$ e $\sigma_{2}$ são as tensões principais no material; e $\sigma_{3}$ é a tensão assumida como nula. (MEYERS; CHAWLA, 2009)

\subsubsection{Transferência de calor por condução}

A fim de proporcionar uma boa compreensão acerca das trocas térmicas que procedem ao longo do processo de fabricação por conformação a quente, é importante a definição dos três mecanismos básicos de transferência de calor: condução, convecção e radiação. No caso do presente trabalho, onde ser analisa o transporte de calor na matriz de forjamento, o mecanismo importante é o de condução de calor.

A condução é promovida por um gradiente de temperatura existente no interior do meio. 
O fluxo de calor por condução para o caso da placa plana infinita, a qual é atribuída à simplificação de um sistema unidimensional com fluxo de calor por condução em estado estacionário, é ditado pela lei de Fourier exposta na eq.(35): (GEIGER; POIRIER, 1973)

$$
q_{k}=-k \cdot \frac{d T}{d x}
$$

Em que: $q_{k}$ é o fluxo de calor por condução $\left(\mathrm{Wm}^{-2}\right) ; \mathrm{k}$ é a condutividade térmica do material $\left(\mathrm{Wm}^{-10} \mathrm{C}^{-1}\right) ; \mathrm{T}$ é temperatura $\left({ }^{\circ} \mathrm{C}\right) ; \mathrm{x}$ é a dimensão característica da placa na direção onde há o gradiente térmico $(\mathrm{m})$.

A equação geral da condução é comumente fornecida na literatura da seguinte forma: (GEIGER; POIRIER, 1973; BLANCH, 2011):

$$
\vec{\nabla} \cdot(k \cdot \vec{\nabla} T)=\rho \cdot c_{p} \cdot \frac{\partial T}{\partial t}
$$

ou

$$
\frac{\partial}{\partial x}\left(k \cdot \frac{\partial T}{\partial x}\right)+\frac{\partial}{\partial y}\left(k \cdot \frac{\partial T}{\partial y}\right)+\frac{\partial}{\partial z}\left(k \cdot \frac{\partial T}{\partial z}\right)=\rho \cdot c_{p} \cdot \frac{\partial T}{\partial t}
$$

Onde: $\mathrm{k}$ é a condutividade térmica do material $\left(\mathrm{Wm}^{-1} \mathrm{C}^{-1}\right)$; T é temperatura $\left({ }^{\circ} \mathrm{C}\right) ; \mathrm{x}, \mathrm{y}$ e $z$ são as posições em função do sistema de coordenadas cartesiano; $\rho$ é a densidade do material $\left(\mathrm{kgm}^{-3}\right) ; c_{p}$ é o calor específico do material a pressão constante $\left(\mathrm{Jkg}^{-1} \mathrm{C}^{-1}\right)$; e t é o tempo (s).

Geiger e Poirier (1973) acrescentam, ainda, a condição de regime permanente para a condução. Tal condição é obtida quando a temperatura do sólido é independente do tempo $\left(\frac{\partial T}{\partial t}=0\right)$. Quando a condutividade térmica é constante, a eq.(36) pode ser escrita no formato que se segue:

$$
\nabla^{2} T=0
$$

Em que: $\nabla^{2}$ é o operador laplaciano $\rightarrow \nabla^{2} T=\frac{\partial^{2} T}{\partial x^{2}}+\frac{\partial^{2} T}{\partial y^{2}}+\frac{\partial^{2} T}{\partial z^{2}}$. 
Quando o formato do meio onde ocorre a condução de calor puder ser aproximado por uma placa "infinita" (figura 29), ou seja, com efeitos de borda desprezíveis, a eq.(37) pode ser escrita na forma unidirecional:

$$
\frac{\partial^{2} T}{\partial x^{2}}=0
$$

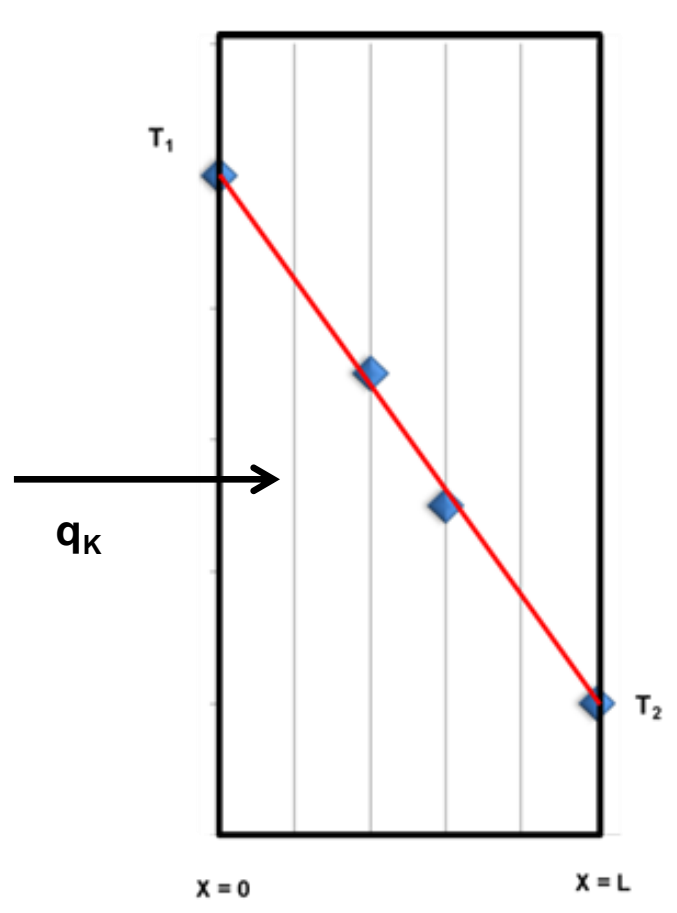

Figura 29 - Perfil de temperatura em uma placa "infinita", sendo que é assumida a condição de regime permanente para a troca de calor por condução. (adaptado de GEIGER; POIRIER, 1973)

A solução para a eq.(38) representa um perfil linear de temperatura. Se as temperaturas nas extremidades do domínio (laterais direta e esquerda da figura 29) forem fornecidas, o perfil torna-se simplesmente:

$$
\mathrm{T}=\mathrm{T}_{1}+\frac{\left(\mathrm{T}_{2}-\mathrm{T}_{1}\right)}{\mathrm{L}} \mathrm{x}
$$


Onde: $\mathrm{T}$ é temperatura $\left({ }^{\circ} \mathrm{C}\right) ; \mathrm{T}_{1}$ é a temperatura $\left({ }^{\circ} \mathrm{C}\right)$ na posição $\mathrm{x}=0 ; \mathrm{T}_{2}$ é a temperatura $\left({ }^{\circ} \mathrm{C}\right)$ na posição $\mathrm{x}=\mathrm{L}$; $\mathrm{L}$ é o comprimento da placa $(\mathrm{m})$; e $\mathrm{x}$ é a dimensão característica da placa na direção onde há o gradiente térmico $(\mathrm{m})$.

Quando o perfil de temperatura da eq.(39) é substituído na eq.(35), obtém-se:

$$
q_{k}=-k \cdot \frac{\left(\mathrm{T}_{2}-\mathrm{T}_{1}\right)}{L}
$$

Em que: $q_{k}$ é o fluxo de calor por condução transferido da superfície 1 para a superfície $2\left(\mathrm{Wm}^{-2}\right) ; \mathrm{k}$ é a condutividade térmica do material $\left(\mathrm{Wm}^{-1}{ }^{\circ} \mathrm{C}^{-1}\right) ; \mathrm{T}_{1}$ é a temperatura $\left({ }^{\circ} \mathrm{C}\right)$ na posição $\mathrm{x}=0 ; \mathrm{T}_{2}$ é a temperatura $\left({ }^{\circ} \mathrm{C}\right)$ na posição $\mathrm{x}=\mathrm{L}$; $\mathrm{L}$ é o comprimento da placa $(\mathrm{m})$; e x é a dimensão característica da placa na direção onde há o gradiente térmico $(\mathrm{m})$.

Partindo da base teórica de transferência de calor, faz-se necessário tecer explicações específicas direcionadas aos carregamentos térmicos na conformação mecânica a quente.

Em um modelo térmico, a operação de conformação a quente pode ser assumida: em condições isotérmicas, nas quais a ferramenta se encontra submetida a temperaturas relativamente próximas à temperatura da peça; ou como o caso mais encontrado na prática, que ocorre quando a temperatura da ferramenta é muito menor do que a temperatura da peça. (WILSON; SCHMID; LIU, 2004)

$\mathrm{Na}$ análise macroscópica do forjamento a quente, as duas principais fontes que geram calor são a deformação plástica da peça e o atrito existente na interface peça-ferramenta. Visando à simulação numérica por elementos finitos, é válido acrescentar que, em geral, é especificado um coeficiente de troca de calor constante na região de contato entre peça e ferramenta. (WILSON; SCHMID; LIU, 2004)

Especificamente na superfície da peça, devido à sua elevada temperatura, o mecanismo de condução de calor para a ferramenta é o mais relevante, ficando a convecção, com o ambiente e um possível meio interfacial, e de radiação para o ambiente como os mecanismos de transferência de calor menos significativos. (WILSON; SCHMID; LIU, 2004)

$\mathrm{Na}$ ferramenta, e direcionando a análise para o nível microestrutural, o mecanismo predominante continua sendo a condução de calor, proveniente da peça, 
por meio do contato entre as asperezas. Ocasionalmente, a troca de calor desta ferramenta pode ocorrer por meio de um filme lubrificante. (WILSON; SCHMID; LIU, 2004)

\subsubsection{Equacionamento das tensões térmicas}

Uma primeira aproximação a ser feita em relação à resposta aos carregamentos atuantes na ferramenta de conformação a quente é que a mesma se encontra exposta às tensões e deformações de origem térmica e mecânica. No tocante à microestrutura da ferramenta, como não são consideradas a princípio as transformações de fases, são desprezadas as tensões que estas possam vir a acarretar. Nessas condições, considerando regime elástico do material, a equação geral prevista para as tensões em função das deformações é a eq.(41): (COOK; MALKUS; PLESHA, 1989)

$$
\{\sigma\}=[k]\left\{\varepsilon_{m}\right\}+\left\{\sigma_{t}\right\}
$$

Onde: [k] é a matriz simétrica de rigidez do material; $\left\{\varepsilon_{m}\right\}$ é o vetor da deformação mecânica; e $\left\{\sigma_{t}\right\}$ é o vetor da tensão térmica.

Focando apenas nas tensões térmicas em um sólido isotrópico, as mesmas podem ser descritas, sob o âmbito tridimensional, da forma que se segue: (COOK; MALKUS; PLESHA, 1989)

$$
\left\{\sigma_{t}\right\}=-\frac{E \alpha T}{1-2 v}\left[\begin{array}{cccccc}
1 & 1 & 1 & 0 & 0 & 0
\end{array}\right]^{T}
$$

Em que: $\left\{\sigma_{t}\right\}$ é o vetor da tensão térmica; E é o módulo de elasticidade do material; $\alpha$ é o coeficiente de expansão térmica do material; T é a temperatura do material em estudo; e $v$ é o coeficiente de Poisson do material. 
Com a consideração de EPT, obtém-se a seguinte simplificação da eq.(42) para as tensões e deformações térmicas, respectivamente, as eqs.(43) e (44): (COOK; MALKUS; PLESHA, 1989)

$$
\begin{aligned}
& \left\{\sigma_{t}\right\}=-\frac{E \alpha T}{1-v}\left[\begin{array}{llll}
1 & 1 & 0 & 0
\end{array}\right]^{T} \\
& \left\{\varepsilon_{t}\right\}=\left[\begin{array}{llll}
\alpha T & \alpha T & 0
\end{array}\right]^{T}
\end{aligned}
$$

Onde: $\left\{\sigma_{t}\right\}$ é o vetor da tensão térmica; $\left\{\varepsilon_{t}\right\}$ é o vetor da deformação térmica; $E$ é o módulo de elasticidade; $\alpha$ é o coeficiente de expansão térmica; T é a temperatura do material em estudo; e $v$ é o coeficiente de Poisson.

Não obstante, no EPD, a simplificação da eq.(42) para as tensões e deformações térmicas, respectivamente, resulta nas eqs.(45) e (46): (COOK; MALKUS; PLESHA, 1989)

$$
\begin{aligned}
& \left\{\sigma_{t}\right\}=-\frac{E \alpha T}{1-2 v}\left[\begin{array}{llll}
1 & 1 & 0 & 0
\end{array}\right]^{T} \\
& \left\{\varepsilon_{t}\right\}=(1+v)\left[\begin{array}{llll}
\alpha T & \alpha T & 0
\end{array}\right]^{T}
\end{aligned}
$$

Onde: $\left\{\sigma_{t}\right\}$ é o vetor da tensão térmica; $\left\{\varepsilon_{t}\right\}$ é o vetor da deformação térmica; $\mathrm{E}$ é o módulo de elasticidade; $\alpha$ é o coeficiente de expansão térmica; T é a temperatura do material em estudo; e $v$ é o coeficiente de Poisson.

$>$ As eqs.(47), (48) e (49) são expostas, juntamente com as suas considerações, na tabela 6 a fim de complementar as informações a respeito das tensões e das deformações mecânicas e térmicas, conforme citado por Persson; Hogmark e Bergström (2004) e Hasselman e Singh (1986) apud Serantoni Silva (2003): 
Tabela 6 - Resumo de formulações de tensões e deformações térmicas relacionadas a um material isotrópico.

\section{Material Isotrópico}

Estado plano de tensões;

$$
\sigma=\frac{E \cdot \Delta \alpha \cdot \Delta T}{1-u}
$$

- Microestrutura bifásica;

- Efeito apenas térmico considerado.

(HASSELMAN; SINGH, 1986 apud

Onde: $\Delta \alpha$ é a diferença entre os coeficientes de expansão térmica da fase em estudo e da outra presente no material. SERANTONI SILVA, 2003) (matriz+carbonetos, por exemplo); $\Delta \mathrm{T}$ é a diferença de temperatura no material bifásico; $\mathrm{E}$ é o módulo de elasticidade da fase em estudo; e v é o coeficiente de Poisson da referida fase.

- Estado plano de tensões;

- Material em regime elástico de

$\varepsilon_{t}(T)=\alpha(T)\left(T-T_{\text {mín }}\right)$ deformações;

- Efeito apenas térmico considerado.

(PERSSON; HOGMARK; BERGSTRÖM, 2004)

Onde: $\varepsilon_{t}(T)$ é a deformação térmica em função da temperatura; $\alpha(T)$ é o coeficiente de expansão térmica em função da temperatura; T é a temperatura do material; e $T_{m i n}$ é a temperatura mínima à qual 0 material é submetido.

- Considerações do dos efeitos mecânicos e térmicos na deformação.

(PERSSON; HOGMARK; BERGSTRÖM, 2004)

$\varepsilon_{m}(T)=\varepsilon_{t o t}(T)-\varepsilon_{t}(T)$

Onde: $\varepsilon_{m}(T)$ é a deformação mecânica em função da temperatura; $\varepsilon_{t o t}(T)$ é a deformação total em função da temperatura; e $\varepsilon_{t}(T)$ é a deformação térmica em função da temperatura.

\subsection{SIMULAÇÃO NUMÉRICA PELO MEF}

Uma das primeiras utilizações do Método dos Elementos Finitos (MEF) foi feita por Turner et al. (1956), que aplicaram tal método para obter uma solução aproximada da rigidez de componentes estruturais de aeronaves; o equacionamento foi desenvolvido a partir de abordagens simplificadas de treliças, de vigas e de placas. Segundo os autores, os resultados numéricos obtidos via este método deveriam ser adequados para a realização de posteriores estudos aerodinâmicos.

Conforme descrição de Rodrigues e Martins (2010), a base do MEF consiste em resolver, de forma aproximada, equações diferenciais que designam, matematicamente, a resposta dos materiais metálicos em nível macroscópico. Para isso, discretiza-se o domínio abrangido por essas equações por meio de subdomínios finitos nomeados de elementos, sendo que os elementos são 
constituídos por nós que apresentam variáveis físicas que, por sua vez, estão associadas a valores decorrentes de interpolações entre os nós. Portanto, o aumento do número de nós acarreta em uma maior aproximação do resultado numérico obtido por MEF do valor exato/analítico. (TURNER et al., 1956)

Cook, Malkus e Plesha (1989) acrescentaram uma sequência envolvida na análise por elementos finitos:

- gerar a malha de elementos finitos no componente, fazendo-se uso, por exemplo, de pré-processadores;

- definir as propriedades dos elementos, sendo que no caso da análise de tensões é necessário determinar as condições de carregamento nos nós em conformidade com a deformação permissível para os elementos; e no caso da análise de transferência de calor é cabível realizar a determinação do fluxo de calor nos nós sustentada pelos campos de temperatura permissíveis para os elementos;

- fazer a montagem dos elementos de maneira a construir os alicerces para o modelo de elementos finitos;

- carregamentos nodais conhecidos são aplicados de modo a resolver a parte mecânica e a parte térmica do referido modelo;

- definição de condições de contorno condizentes com o que está se reproduzido; ou seja, atribui-se aos nós: no caso da análise de tensões, deslocamentos nodais conhecidos, muitas vezes sendo estes parâmetros como nulos; pode-se concluir que no caso da análise térmica são impostas temperaturas também conhecidas aos nós específicos;

- cabe aos solvers, nesta etapa, o papel de resolver as equações algébricas, dimensionando os deslocamentos e as temperaturas nodais, conforme a análise mecânica e/ou térmica que está sendo considerada;

- por último, empregam-se pós-processadores que efetuam interpolação de saída e possibilitam interface gráfica dos resultados: as deformações são calculadas nos elementos mediante interpolação dos deslocamentos nodais e, finalmente, calculamse as tensões a partir destas deformações. Na parte térmica, o fluxo de calor nos elementos é previsto por meio da interpolação do campo de temperaturas nodais.

Para complementar as informações voltadas ao MEF, é apresentado na figura 30, de forma esquemática, o procedimento envolvido neste método de análise. 


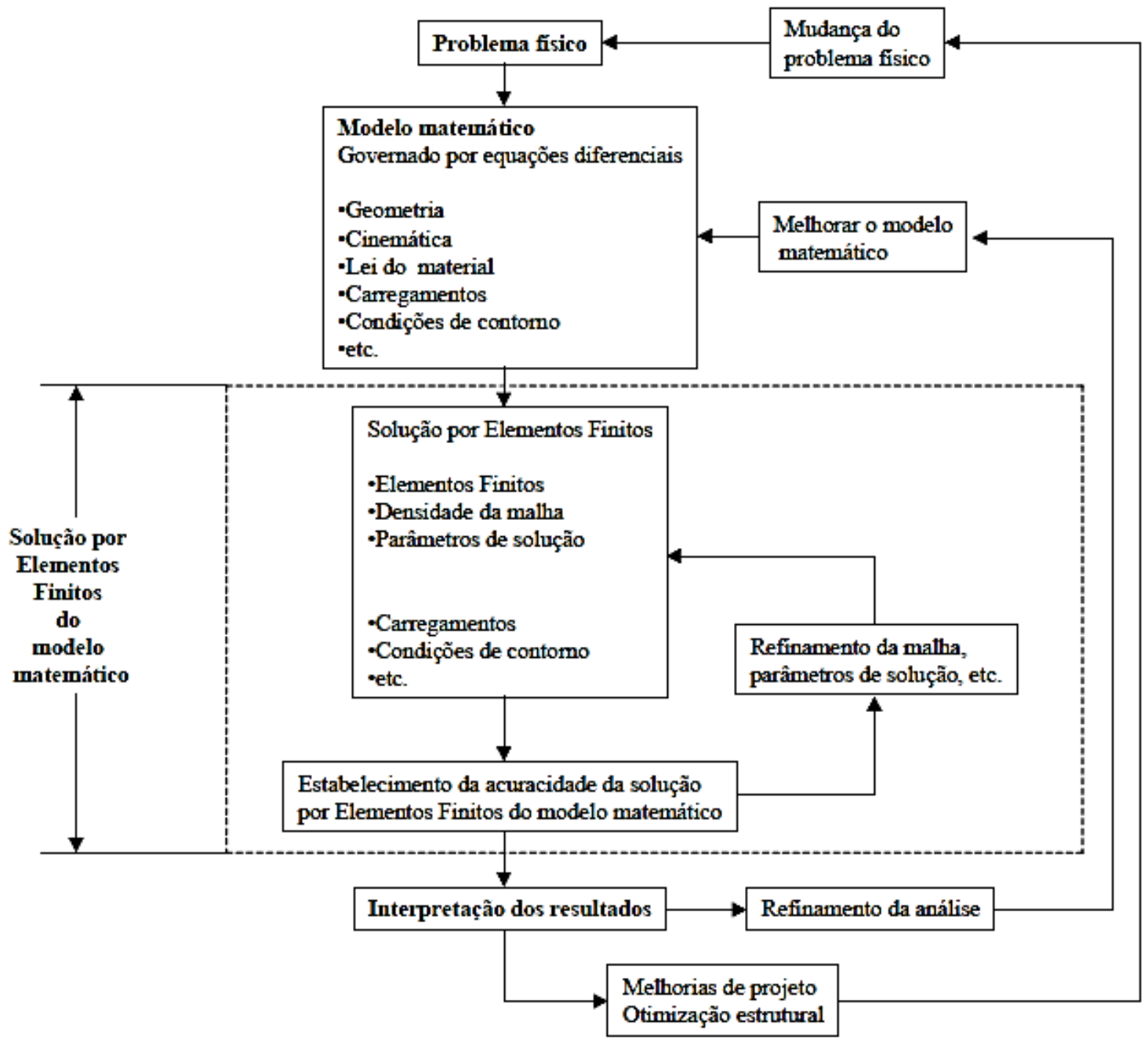

Figura 30 - Fluxograma da análise por elementos finitos elaborado por Bathe (1996) e adaptado por Moreno (2000).

A disseminação e o aprofundamento dos conceitos relacionados ao MEF possibilitaram o seu emprego no âmbito da simulação numérica em situações que reproduzem processos complexos de deformação plástica. Tais análises podem levar em conta, inclusive: (i-) o comportamento elastoplástico com a ocorrência de encruamento dos materiais; (ii-) variações das propriedades do material com a taxa de deformação e a temperatura; (iii-) distintas considerações de atrito na interface entre peça e ferramenta; e (iv-) modelos que tendem a reproduzir situações de dano nestes materiais. (RODRIGUES; MARTINS, 2010)

Embora a simulação numérica possa ser empregada como uma ferramenta para analisar a conformação mecânica de materiais, é indispensável se realizar a validação numérica, e se possível experimental, dos resultados obtidos. No 
modelamento por elementos finitos, algumas fontes comuns de erros numéricos podem ser atribuídas, tais como citado por Rodrigues e Martins (2010): seleção do tipo de elementos e forma de integração; designação do incremento de tempo; discretização da malha em elementos finitos (com regiões que precisam e não possuem refinamento de malha); e critério de convergência.

Direcionando a análise da resposta da ferramenta, em função do campo de tensões, no decorrer do forjamento a quente, as seguintes definições, relatadas de forma sucinta, são relevantes para a compreensão da metodologia, exposta na continuidade deste trabalho. Acrescenta-se que todas estas definições foram descritas com base na referência de Simulia (2012):

> A análise do processo (fenômeno físico) pode ser realizada no estado plano de tensões ou no estado plano de deformações.

O EPT é ditado pela inexistência de tensões em uma determinada direção. Esta abordagem diz respeito às chapas finas, deformadas plasticamente por estampagem, por exemplo.

$O$ EPD é definido quando uma das deformações principais equivalem à zero. Esta atribuição é feita geralmente para laminação de placas, com aproximação de modelagem de aspecto bidimensional.

Assim, no caso de uma placa retangular, simplificada em um modelo 2-D como uma geometria com comprimento na direção $x$ e como largura na direção $y$, consideram-se: (i-) no EPT, a tensão na direção da espessura (eixo z) como nula; e (ii-) no EPD, a deformação na direção da espessura (eixo z) como nula;

$>$ sabendo que na fabricação de materiais por meio do trabalho a quente ocorre geração de calor, proveniente da deformação plástica desses materiais e do atrito da interface peça-ferramenta, é importante distinguir dois procedimentos para o tratamento da variável temperatura e dos resultados de tensões: sequencial (ligação fraca); e termomecânico acoplado (ligação forte).

No procedimento sequencial, apesar da solução para o campo de tensões depender da solução térmica, a variação de temperatura é definida independentemente da resposta mecânica em função destas tensões; isto é, dimensiona-se numericamente a temperatura, e esta solução é inserida, em seguida, na análise mecânica do processo, não havendo uma realimentação de 
informações capazes de alterar o comportamento da temperatura. Por esse motivo, este procedimento é conhecido como ligação fraca.

No procedimento termomecânico acoplado, a resposta do campo de tensões depende da temperatura, bem como o campo de temperaturas apresenta dependência das tensões, havendo, portanto, um forte acoplamento de temperatura e tensões;

> outra distinção pode ser feita entre a formulação dinâmica explícita e a formulação quase-estática implícita.

A dinâmica explícita é oriunda de análises de impactos a altas velocidades, considerando efeitos de inércia na solução de equações diferenciais que tentam reproduzir o fenômeno físico. Esta formulação é robusta, porém necessita de incrementos de tempo muito pequenos e não fornece garantia do equilíbrio das equações ao final de cada incremento, podendo haver erros acumulados nos incrementos.

A análise quase-estática implícita não leva em conta os efeitos da inércia nas soluções das equações diferenciais, sendo assim recomendada para situações de velocidades reduzidas em relação à situação dinâmica. Acrescido a esse fato aparecem os algoritmos de integração temporal implícitos, que fazem uso de meios iterativos para fornecer a solução para cada incremento de tempo, tornando a convergência final do modelo mais rápida.

3.7.1 Simulação numérica de ciclos térmicos em microestruturas de ferramentas de conformação mecânica

A análise por meio de elementos finitos de microestruturas de ferramentas de conformação a quente, conforme informado inicialmente, ainda não é muito abordada na literatura (SERANTONI SILVA, 2003). Algumas justificativas que, possivelmente, podem ser atribuídas a este fato são:

(i-) complexidade de considerações a serem levadas em conta no modelo, como:

- definição e atribuição de fases e suas interfaces ao material, em uma malha de elementos finitos (construção inicial da malha); 
- determinação das propriedades das fases variando com a temperatura (modelo elástico, elastoplástico ou viscoelastoplástico);

- condições de carregamento em dimensões microestruturais;

- grau de representatividade da área microscópica na análise da ferramenta;

- emprego dos modelos de falha (especificamente, neste trabalho, cita-se como exemplo a nucleação e propagação de trincas por fadiga térmica);

- efeitos indiretos na microestrutura: condições de atrito; convecção e radiação na ferramenta (macroscópica); diminuição da dureza do material; entre outros.

Dois exemplos de estudos microestruturais que retratam algumas das dificuldades relatadas são: Cusolito, Mapelli e Nicodemi (2002) que estudaram inclusões em aços extrudados e aços forjados a quente, adotando a simplificação de tais partículas como vazios no interior da matriz metálica; e Saldarriaga (2008) que analisou o efeito da morfologia de inclusões elipsoidais em aços por simulação numérica (MEF), com carregamentos mecânicos que reproduziam condições de torneamento; porém, a única propriedade das inclusões considerada nas análises, neste caso, foi o módulo de elasticidade.

(ii-) aplicação diretamente tecnológica que vem, crescentemente, sendo incorporada aos trabalhos de modo que simulações macroestruturais do sistema de conformação peça-meio interfacial-ferramenta sobrepujam as simulações microestruturais que trazem consigo, a princípio, estudos mais voltados à parte acadêmica de entendimento das possíveis causas de falhas em ferramentas desta categoria.

Todavia, um dos esforços em compreender a resposta de ferramentas no trabalho a quente, fazendo o uso de MEF para simulações dos ciclos térmicos em microestruturas de materiais de cilindros de laminação, foi o estudo de Serantoni Silva (2003). A figura 31 mostra um resultado do campo de tensões, obtido pela autora, em uma microestrutura de ferro fundido branco multicomponentes após um ciclo térmico (aquecimento da amostra até $600^{\circ} \mathrm{C}$, em 5 segundos, e resfriamento em água até atingir a temperatura de $25{ }^{\circ} \mathrm{C}$ em outros 5 segundos, mantendo esta temperatura ambiente no decorrer de 45 segundos). 


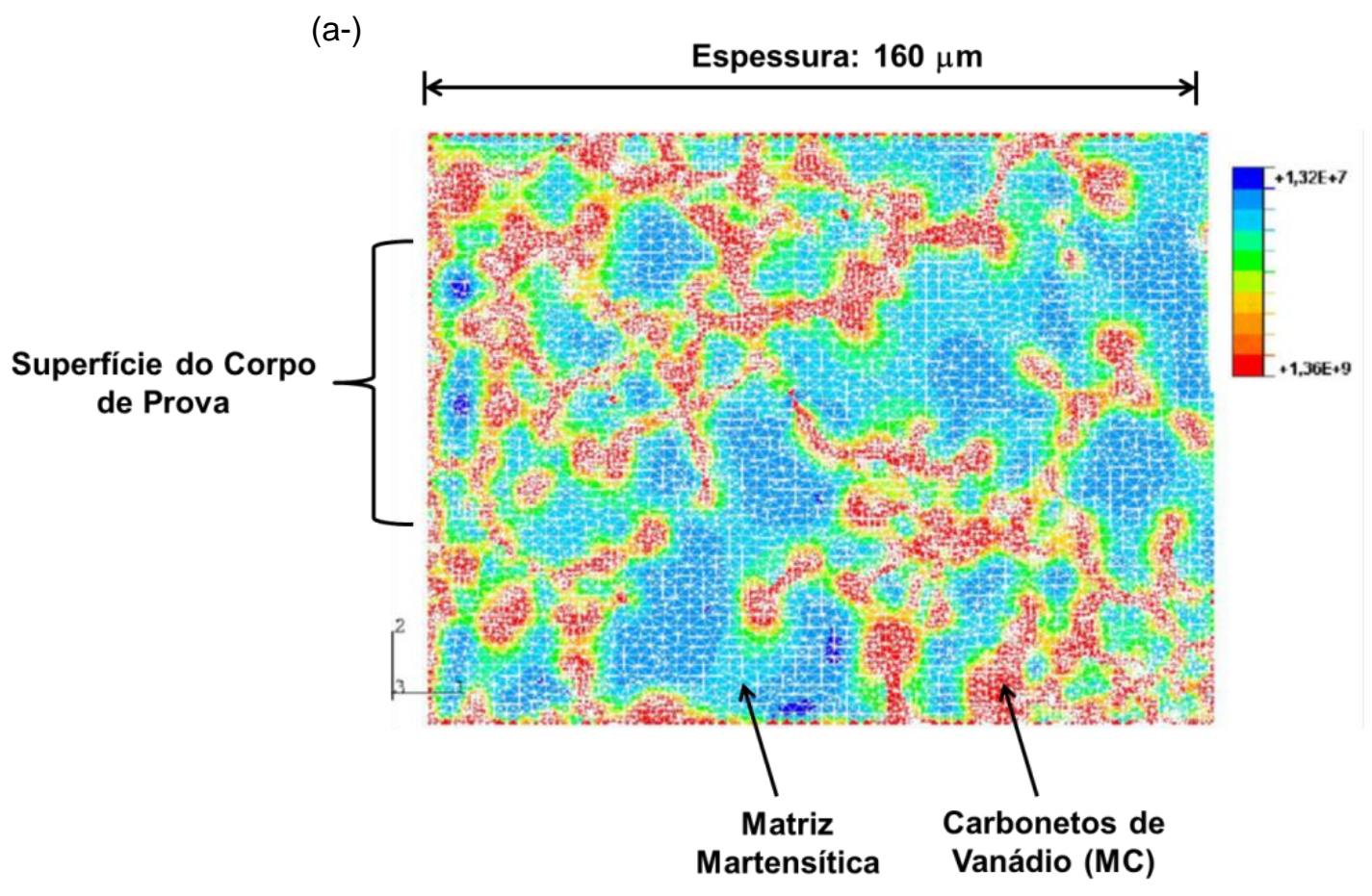

(b-)
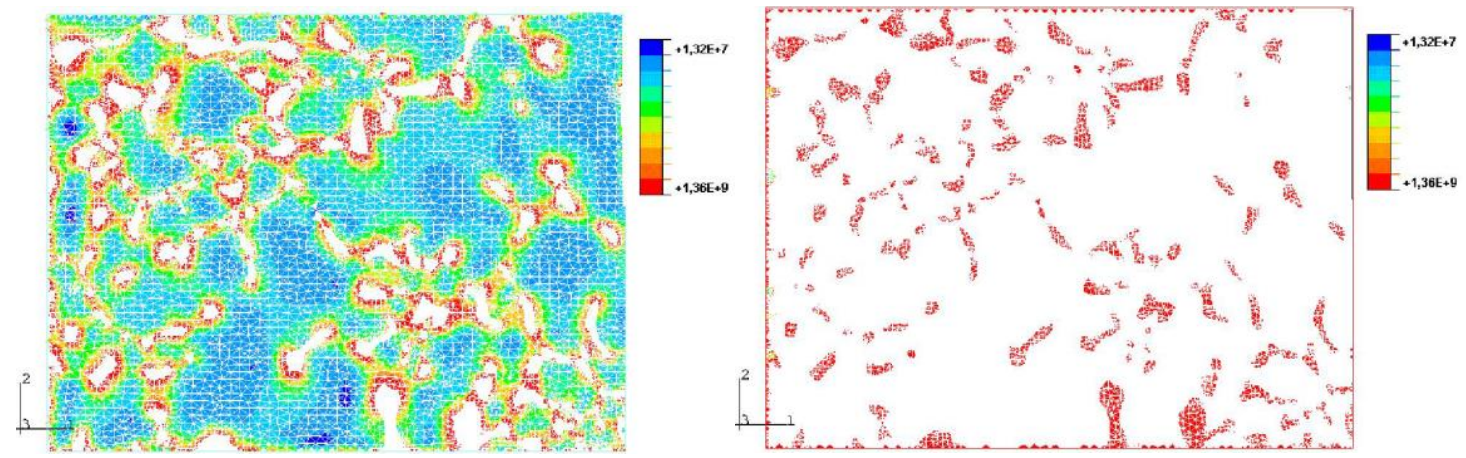

Figura 31 - Tensões de von Mises na microestrutura de cilindro de laminação de tiras a quente, decorrido um ciclo térmico: (a-) visão geral das tensões na microestrutura bifásica; (b-) concentrações de tensões na interface matriz-precipitado e no interior do precipitado, respectivamente. (adaptado de SERANTONI SILVA, 2003)

Serantoni Silva (2003) concluiu, frente aos ensaios experimentais de fadiga térmica e a sua simulação numérica fornecida na figura 31 , os seguintes aspectos em sua pesquisa:

> modificação na composição química do material (teor de carbono e vanádio, por exemplo): o aumento da fração volumétrica do carboneto eutético de vanádio (MC) surtiu consequência direta no aumento da densidade de trincas, causadas por fadiga térmica. Desse modo, Serantoni Silva (2003) afirma que as trincas por fadiga 
térmica têm origem a partir da presença de concentradores de tensões (neste caso, os precipitados) que, por sua vez, propiciam a ocorrência de deformação plástica microscópica localizada;

> modificação nas propriedades mecânicas do material: em contrapartida, ao tornar o material mais resistente à deformação plástica localizada, o aumento da dureza da matriz faz com que a probabilidade de nucleação de trincas por fadiga térmica seja reduzida;

> propriedades mecânicas e térmicas mais representativas na concentração de tensões na microestrutura do material de cilindro de laminação: conforme Serantoni Silva (2003), os valores distintos de módulo de elasticidade e coeficiente de expansão térmica da matriz e dos precipitados são os principais responsáveis pela ocorrência das concentrações de tensões nas regiões de interface matriz-precipitado e no interior do precipitado da microestrutura (figura 31b);

> importância do estudo a partir da superfície da ferramenta: é atribuído ao mecanismo de dano por fadiga térmica em um determinado corpo de prova, o fato de que a influência dos campos tensão-deformação-temperatura diminui a partir do afastamento em relação à superfície deste corpo (Serantoni Silva, 2003);

> papel do parâmetro distância livre entre as partículas de segunda fase $\left(\underline{D}_{m}\right)$ : de acordo com Serantoni Silva (2003), tendo em vista que a tenacidade à fratura ( $\left.K_{I C}\right)$ do material é diretamente proporcional à raiz quadrada da distância livre média entre as partículas de segunda fase $\left(D_{m}\right)$, pode-se assumir, a priori, que quanto maior 0 valor de $D_{m}$ (maior o valor de $K_{I C}$ ), menor será a taxa de propagação de trincas por fadiga térmica na microestrutura do material em estudo;

> papel do parâmetro continuidade (C) das partículas de segunda fase: o aumento da continuidade de precipitados na microestrutura resulta, por sua vez, no consequente aumento na taxa de propagação de trincas por fadiga térmica, haja vista que tais partículas de segunda fase agem como concentradores de tensão que facilitam a nucleação e a propagação das trincas térmicas (SERANTONI SILVA, 2003); 
$>\quad$ relação entre os parâmetros $D_{m}$ e C na microestrutura da ferramenta de conformação: Serantoni Silva (2003) alerta para a importância de se obter o valor do parâmetro $D_{m}$ entre os precipitados na região cujo valor de $C$ seja mais elevado, e não obtê-lo como um valor médio na microestrutura tratada como um todo. A autora propõe, ainda, uma relevante relação designada por $\mathrm{C} / \mathrm{D}_{\mathrm{m}}$ : quanto maior esta razão, maior também será a taxa de propagação de trincas por fadiga térmica ao longo da microestrutura do material em análise;

$>$ outra importância que justifica o estudo do efeito dos precipitados na microestrutura exposta à fadiga térmica: pode-se acrescentar que a distribuição dos precipitados na microestrutura é o fator decisivo na disputa entre a nucleação e a propagação de trincas térmicas pela dissipação de energia acumulada no material macroscópico. (SERANTONI SILVA, 2003) 


\section{MATERIAIS E MÉTODOS}

A metodologia desenvolvida ao longo deste trabalho se destina a analisar os efeitos de carregamentos térmicos e mecânicos na microestrutura do aço ferramenta AISI H13, utilizado como matriz aberta de forjamento a quente. As cargas mecânicas são previstas tendo em vista que a matriz de forjamento superior é acionada por um equipamento classificado como uma prensa hidráulica.

Para o desenvolvimento de um procedimento que propicie a referida análise, em função do campo de tensões atuantes no material selecionado, recorreu-se à simulação numérica no âmbito bidimensional, fazendo-se uso, essencialmente, do software de elementos finitos Abaqus $^{\circledR}$, no modo Standard (economia de tempo computacional nas considerações quase-estáticas de forjamento). Além disso, a fim de gerar a malha de elementos finitos na microestrutura do aço AISI H13, foi empregado o software OOF ${ }^{\circledR}$ (versão 2.1.3), criado pelo National Institute of Standards and Technology (NIST). Neste software, a técnica selecionada para a construção da malha é designada por "refine" com "adaptive mesh", que cria uma malha de elementos quadriláteros (tetra) na microestrutura e refina apenas a região dos contornos dos carbonetos com um conjunto de elementos triangulares (tri) e tetra de modo a evitar distorções demasiadas, quando realizada a simulação com as condições de contorno e de carregamento.

As definições da malha de elementos finitos selecionada para a microestrutura do aço AISI H13, bem como os parâmetros de simulação e as hipóteses simplificadoras atribuídas ao modelo numérico, foram realizadas segundo a descrição exposta a seguir:

(i-) Determinação da microestrutura do aço AISI H13 a ser estudada, e posterior tratamento da imagem da microestrutura digitalizada:

Com base no trabalho de Mesquita, Haddad e Barbosa (2008), é concluído que até uma distância de, aproximadamente, $1 \mathrm{~mm}$ da superfície da ferramenta, fabricada com o aço VHSUPER que possui comportamento mecânico similar ao H13, há efeitos de revenimento no material durante o uso (figura 32). Desse modo, 
como ponto de partida para a escolha da área da microestrutura do $\mathrm{H} 13$ a ser estudada, tem-se a análise macroscópica da ferramenta, que contribui de forma a isolar uma possível região crítica (inferior a $1,0 \mathrm{~mm}$ da superfície da matriz de forjamento) para a ocorrência do dano por fadiga térmica.

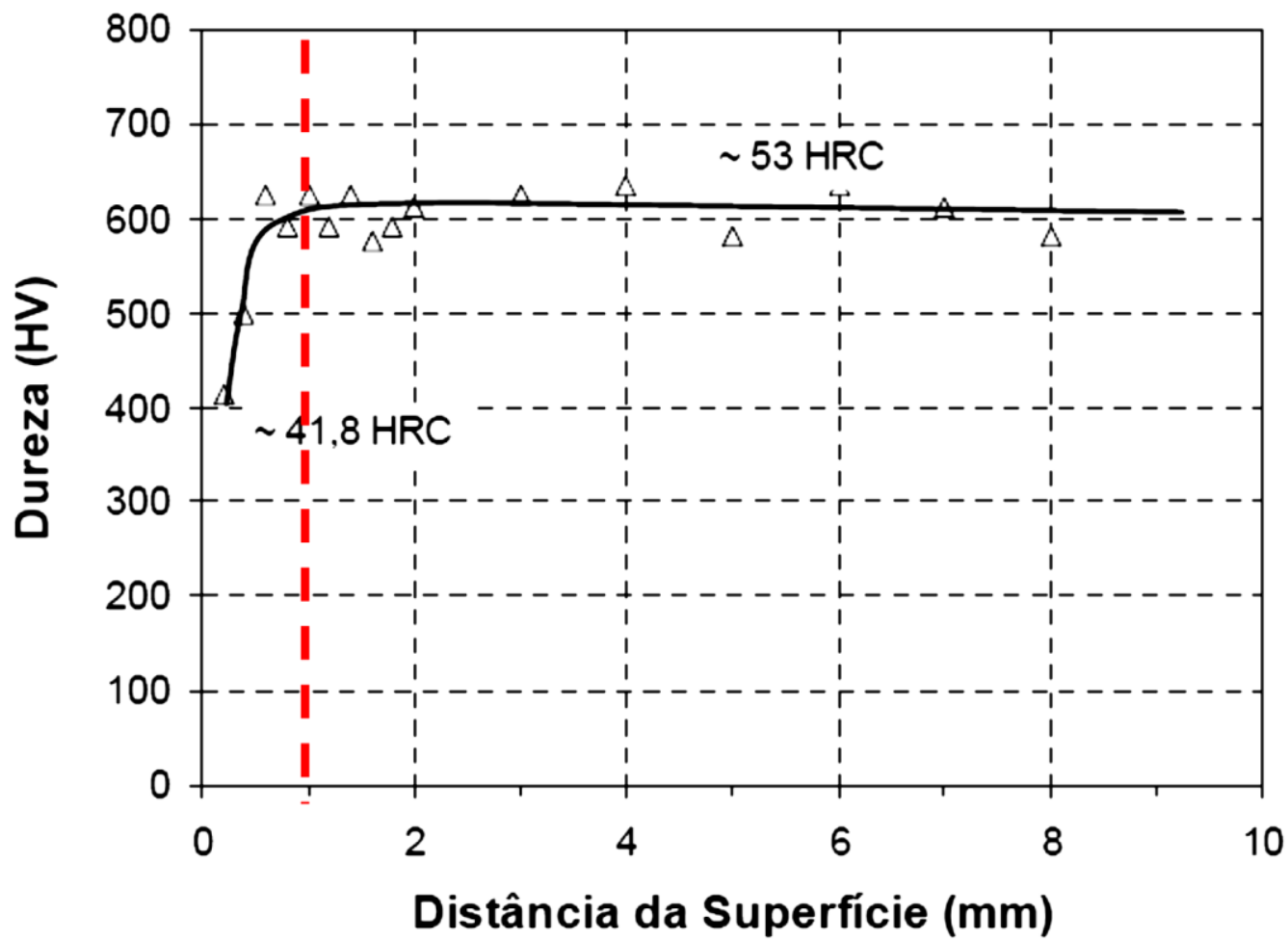

Figura 32- Perda de dureza da matriz de forjamento a quente, a partir de uma posição da sua superfície denominada de distância crítica. (adaptada de MESQUITA; HADDAD; BARBOSA, 2008)

Como segundo quesito, realizou-se a consulta à literatura de microestruturas do aço AISI $\mathrm{H} 13$, com a presença de matriz martensítica e precipitados de $\mathrm{M}_{23} \mathrm{C}_{6}$ (carbonetos de cromo estáveis). Três trabalhos foram destacados nesta etapa, sendo que em todos eles o aço AISI H13 passou, inicialmente, por tratamentos térmicos de austenitização, têmpera e revenimento para obter a matriz martensítica com os precipitados:

- Hu et al. (2006b), cuja microestrutura obtida por microscopia eletrônica de transmissão ressalta o quão pequenos são os precipitados encontrados no $\mathrm{H} 13$ (figura 33a);

- ASM Internacional (2004), no qual a microestrutura é obtida por técnicas de microscopia óptica, e, por meio da observação da figura 33b, é possível notar também o coalescimento de alguns precipitados no $\mathrm{H} 13$; 
- Sjöström (2004), que apresenta em seu trabalho, por microscopia eletrônica de transmissão e difração de raios- $\mathrm{X}$, a existência de carbonetos de cromo metaestáveis $\left(\mathrm{M}_{7} \mathrm{C}_{3}\right)$ e estáveis $\left(\mathrm{M}_{23} \mathrm{C}_{6}\right)$ na microestrutura de um aço ferramenta DIEVAR, que possui composição química e comportamento mecânico similar ao aço AISI H13 (figura 33c). Esse trabalho foi utilizado apenas para ilustrar a presença de carbonetos de cromo em aços ferramenta desta categoria.

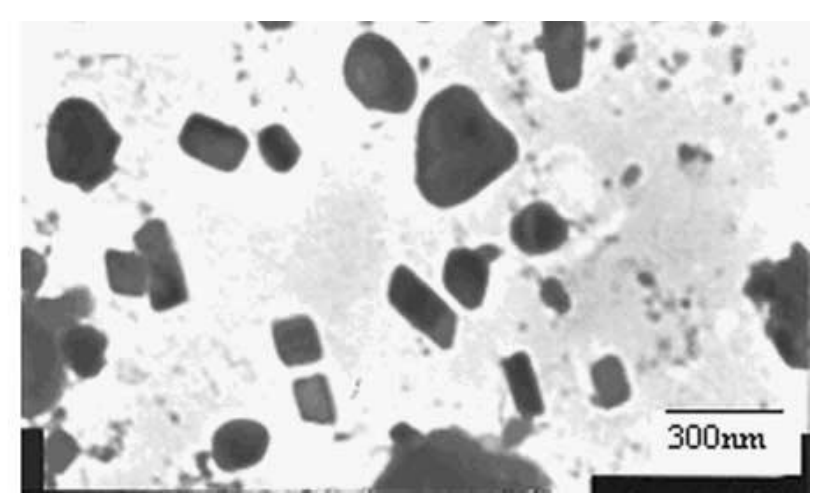

(a-)

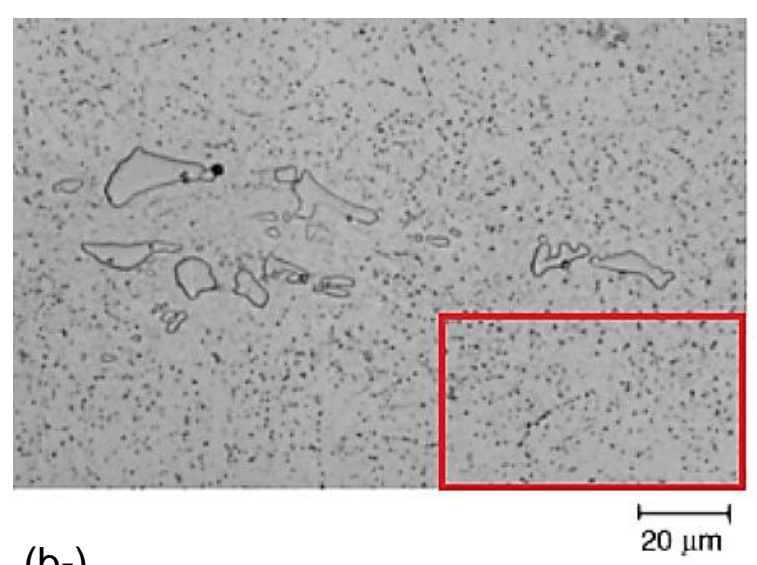

(b-)

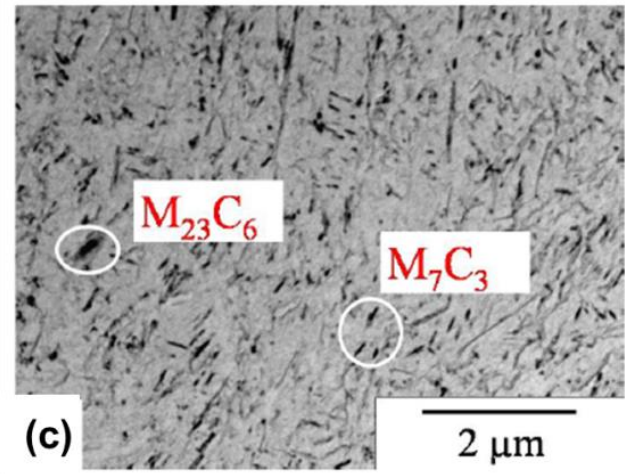

Figura 33 - Microestruturas de aço ferramenta consultadas na literatura: (a-) micrografia do AISI H13, adaptada do trabalho de Hu et al. (2006b), que possui uma matriz martensítica e precipitados do tipo carboneto $\mathrm{M}_{23} \mathrm{C}_{6}$; (b-) micrografia do AISI $\mathrm{H} 13$, com a seguinte composição química: $\mathrm{Fe}-0.40 \% \mathrm{C}$ 0.8\%Si-5.25\%Cr-1\%V-1.35\%Mo; ataque químico: $2 \%$ nital (ASM INTERNATIONAL, 2004); (c-) micrografia do DIEVAR, ilustrando a morfologia e distribuição dos carbonetos de cromo.

A seleção da microestrutura a ser analisada foi feita entre as figuras 33a e 33b. De um lado, a microestrutura do aço AISI H13, fornecida na figura 33a, tem dimensões por volta de $2 \times 1 \mu \mathrm{m}^{2}$, o que não traria gradientes de temperatura significativos em uma análise do campo de tensões e de deformações térmicas, que é necessária no estudo das regiões críticas à fadiga térmica. Utilizando a eq.(40), pode-se prever uma diferença de temperatura entre a superfície da ferramenta e a região mais afastada desta equivalente a $0,08{ }^{\circ} \mathrm{C}$. Por outro lado, para que os 
precipitados da microestrutura fossem passíveis de análise por simulação numérica, a microestrutura apresentada na figura 33b não possibilitaria tal abordagem, uma vez que as partículas de segunda fase se mostram como pontos, com o aumento utilizado, ou como precipitados de dimensão de, aproximadamente, $10 \mu \mathrm{m}$ (coalescidos). Para tornar a análise possível, realizou-se um balanceamento da área representativa da microestrutura do aço $\mathrm{H} 13$ e da possível distribuição térmica em estado estacionário, e foi feita uma adaptação desta área com considerações do fator de escala para não interferir no tamanho real dos precipitados encontrados. Optou-se, assim, pelo estudo de uma área de $60 \times 40 \mu \mathrm{m}^{2}$ desta microestrutura, conforme destacado pelo retângulo vermelho na figura 33b.

Ao término desta etapa de seleção, fez-se um tratamento na imagem digitalizada da microestrutura do aço ferramenta, utilizando-se de recursos de segmentação por meio do software Image $J^{\circledR}$, para tornar a imagem o mais próxima possível da microestrutura original. Segundo o procedimento descrito por Fukumasu et al. (2005), formaram-se regiões binárias na imagem: à matriz martensítica foi atribuída a cor preta e aos precipitados foi atribuída a cor branca. Dessa maneira, é facilitada a designação das fases da microestrutura quando esta é inserida no software OOF $2^{\circledR}$, que gera a malha de elementos finitos. Nota-se, na figura 34 , o resultado da segmentação da imagem da microestrutura com a área delimitada nesta etapa do trabalho.

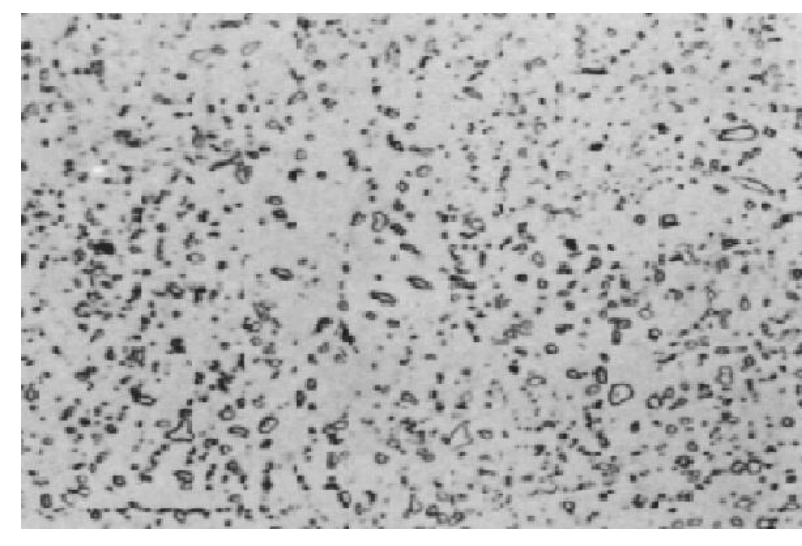

(a-)

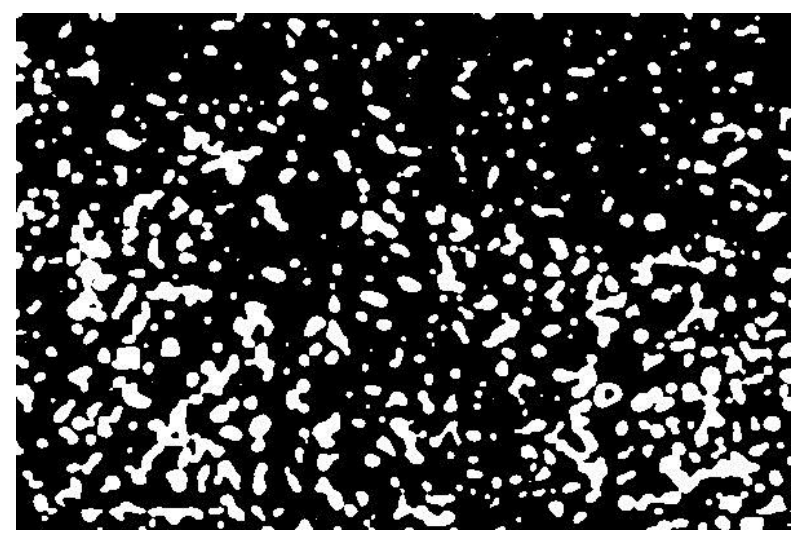

(b-)

Figura 34 - Microestrutura do aço AISI H13, adaptada de ASM Internacional (2004). A área foi delimitada em $60 \mu \mathrm{m}$ de comprimento e $40 \mu \mathrm{m}$ de largura. (a-) imagem real; (ii-) imagem segmentada, considerando o devido fator de escala. 
Para validar a região selecionada, realizou-se, ainda, um estudo da diferença de temperatura na microestrutura a fim de verificar o quão significativa ela era, considerando-se o seu alcance nesta área microscópica. Desse modo, considerouse um fluxo de calor $\left(q_{k}\right)$, transferido por condução da peça para a ferramenta, e citado na literatura (VELAY et al., 2002) para operações de forjamento a quente, como $2 \mathrm{MW} / \mathrm{m}^{2}$. Com a aplicação da eq.(40) e observando a figura 35, que parte de uma região bidimensional imposta de $60 \times 40 \mu \mathrm{m}^{2}$, e sendo a condutividade térmica da matriz do aço ferramenta AISI $\mathrm{H} 13$ aproximada para $25 \mathrm{~W} /\left(\mathrm{m} .{ }^{\circ} \mathrm{C}\right)$ em temperaturas de trabalho a quente próximas de $400{ }^{\circ} \mathrm{C}$ (AFAZOV; RATCHEV; SEGAL, 2011), tem-se a estimativa da respectiva diferença de temperatura nesta região por meio da eq.(40):

$$
\begin{gathered}
q_{k}=\frac{k}{L}\left(T_{1}-T_{2}\right) \\
\Delta T=\frac{40 \times 10^{-6} \mathrm{~m}}{\left(25 \frac{\mathrm{W}}{\mathrm{m} \cdot{ }^{\circ} \mathrm{C}}\right)}\left(2 \times 10^{6}\right) \frac{\mathrm{W}}{\mathrm{m}^{2}} \rightarrow \therefore \Delta T=3,2^{\circ} \mathrm{C}
\end{gathered}
$$

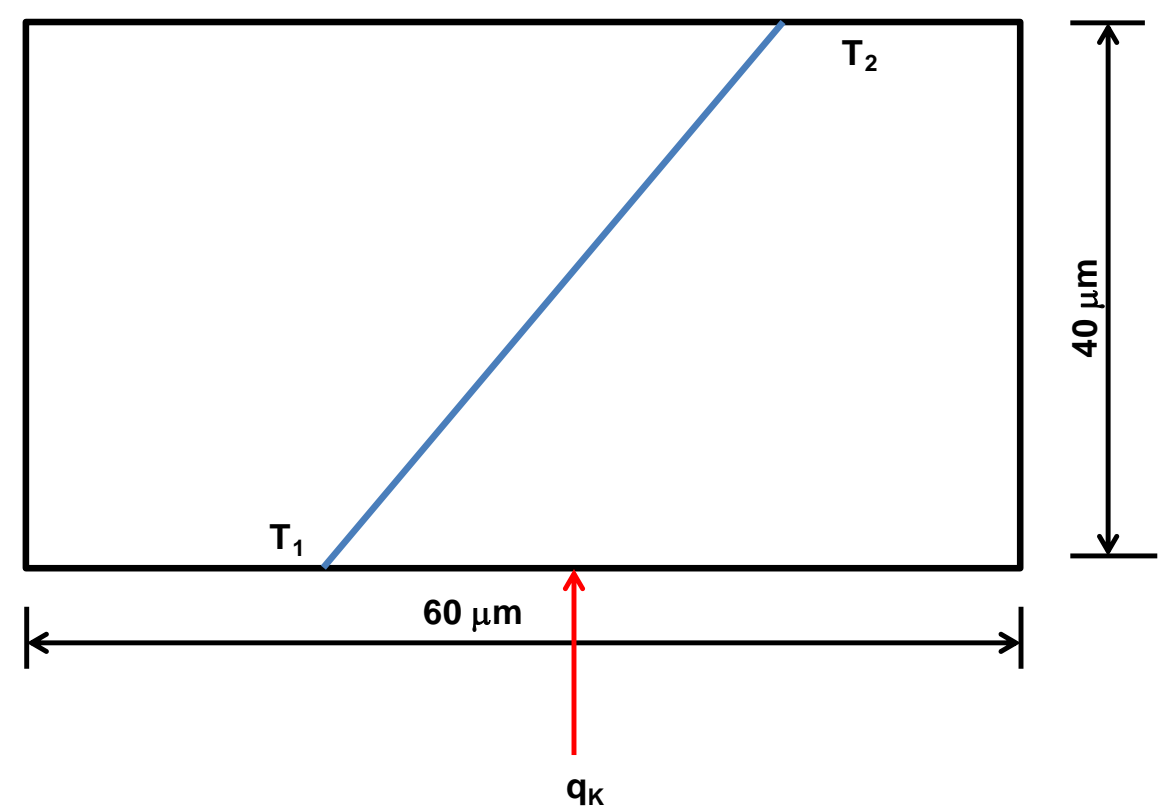

Figura 35 - Esquema da área microestrutural prevista para o estudo térmico.

A partir do resultado de um $\Delta \mathrm{T}$ de cerca de $3{ }^{\circ} \mathrm{C}$ atuante na região microestrutural imposta, foi tomado este valor como significativo sendo ele superior a $1{ }^{\circ} \mathrm{C}$ (condição mínima imposta). 
(ii-) Análise de convergência para a decisão da malha de elementos finitos a ser trabalhada:

Após a seleção da microestrutura do aço ferramenta AISI H13 a ser trabalhada, há um empenho em se verificar qual a malha de elementos finitos, que venha a propiciar um resultado com o menor efeito de malha possível. Para tal decisão, recorre-se a investigação por meio de uma curva de convergência.

Agarwal (2012) relata que, no caso da ocorrência de possíveis pontos de concentradores de tensão na malha (como são previstos para os precipitados), o critério mais indicado para a análise de convergência é fazer o monitoramento da variável energia de deformação elástica ao invés da tensão de von Mises, que é comumente utilizada. No caso da convergência por energia de deformação elástica, é esperado que apenas o refinamento da malha ou a ordem do elemento (linear ou quadrático) possam afetar os resultados médios da energia de deformação elástica.

Com base nestas informações, foram feitos testes com 5 malhas diferentes sobre a microestrutura selecionada anteriormente. As malhas foram geradas no $\mathrm{OOF}^{\circledR}$, e as simulações numéricas se deram no software Abaqus ${ }^{\circledR}$ a partir das seguintes condições (figura 36):

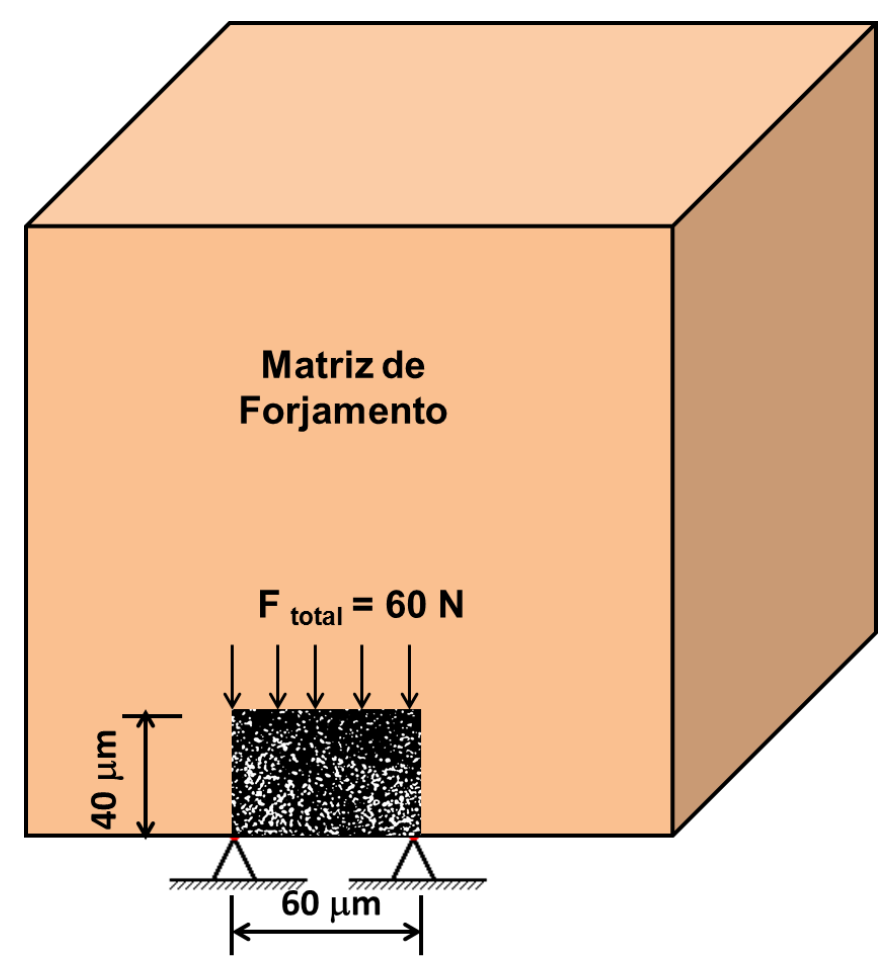

Figura 36 - Desenho esquemático dos carregamentos e das condições de contorno impostas para a análise de convergência. 
As propriedades térmicas e mecânicas das duas fases constituintes da microestrutura do aço AISI H13 são assumidas, daqui por diante neste trabalho, de acordo com a descrição nas tabelas 7 e 8 . Os intervalos nos quais não são fornecidos os dados, referentes às propriedades da matriz, foram interpolados pelo software de elementos finitos Abaqus ${ }^{\circledR}$. A fração volumétrica, a distribuição e a morfologia dos carbonetos de cromo são mantidas também daqui por diante.

Tabela 7 - Propriedades do carboneto, considerado elástico e presente no aço AISI H13, empregadas no modelo numérico. (BAUCCIO, 1994)

\begin{tabular}{cccccc}
$\begin{array}{c}\text { Densidade } \\
{\left[\mathbf{k g} / \mathbf{m}^{3}\right]}\end{array}$ & $\begin{array}{c}\text { Módulo de } \\
\text { Elasticidade } \\
{[\mathrm{GPa}]}\end{array}$ & $\begin{array}{c}\text { Coeficiente de } \\
\text { Poisson }\end{array}$ & $\begin{array}{c}\text { Condutividade } \\
\text { Térmica }\left[\mathbf{W} /\left(\mathbf{m} \cdot{ }^{\circ} \mathbf{C}\right)\right]\end{array}$ & $\begin{array}{c}\text { Coeficiente de } \\
\text { Expansão } \\
\text { Térmica a 20 }{ }^{\circ} \mathbf{C} \\
{\left[{ }^{\circ} \mathbf{C}^{-1}\right]}\end{array}$ & $\begin{array}{c}\text { Calor Específico } \\
\text { a Pressão } \\
\text { Constante } \\
{\left[\mathbf{J} /\left(\mathbf{k g} \cdot{ }^{\circ} \mathbf{C}\right)\right]}\end{array}$ \\
\hline 6680 & 373 & 0,22 & 46 & $1,06 \mathrm{E}-05$ & 203 \\
\hline
\end{tabular}

Tabela 8 - Propriedades térmicas e elastoplásticas da matriz do aço AISI H13 consideradas nas simulações numéricas realizadas. Para complementar, a densidade do material corresponde a 7800 $\mathrm{kg} / \mathrm{m}^{3}$ e o coeficiente de Poisson é 0,3. (AFAZOV; RATCHEV; SEGAL, 2011)

\begin{tabular}{|c|c|c|c|c|c|c|}
\hline $\begin{array}{c}\text { Temperatura } \\
{\left[{ }^{\circ} \mathbf{C}\right]}\end{array}$ & $\begin{array}{c}\text { Módulo de } \\
\text { Elasticidade } \\
\text { [GPa] }\end{array}$ & $\begin{array}{c}\text { Tensão de } \\
\text { Escoamento } \\
\text { [MPa] }\end{array}$ & $\begin{array}{c}\text { Condutividade } \\
\text { Térmica } \\
{\left[\mathbf{W} /\left(\mathbf{m} .{ }^{\circ} \mathbf{C}\right)\right]}\end{array}$ & $\begin{array}{c}\text { Coeficiente de } \\
\text { Expansão } \\
\text { Térmica }\left[{ }^{\circ} \mathrm{C}^{-1}\right]\end{array}$ & $\begin{array}{c}\text { Calor } \\
\text { Específico à } \\
\text { Pressão } \\
\text { Constante } \\
{\left[\mathbf{J} /\left(\mathbf{k g} .^{\circ} \mathbf{C}\right)\right]}\end{array}$ & Referências \\
\hline 20 & 207 & 1240 & - & - & 430 & $\begin{array}{c}\text { Afazov; Ratchev; } \\
\text { Segal (2011); } \\
\text { Velay et al. (2002). } \\
\text { Afazov: Ratchev; }\end{array}$ \\
\hline 27 & - & - & 17,6 & - & - & $\begin{array}{c}\text { Segal (2011); } \\
\text { Grobaski, (2004). } \\
\text { Afazov; Ratchev; }\end{array}$ \\
\hline 100 & 200 & - & - & $1,04 \mathrm{E}-05$ & 470 & $\begin{array}{c}\text { Segal (2011); } \\
\text { Grobaski, (2004). } \\
\text { Afazov; Ratchev; }\end{array}$ \\
\hline 200 & - & 1080 & - & - & 521 & $\begin{array}{l}\text { Segal (2011); Velay } \\
\text { et al. (2002). } \\
\text { Afazov; Ratchev; }\end{array}$ \\
\hline 204 & - & - & 23,4 & $1,13 \mathrm{E}-05$ & - & $\begin{array}{c}\text { Segal (2011); } \\
\text { Grobaski, (2004). } \\
\text { Afazov; Ratchev; }\end{array}$ \\
\hline 300 & 186 & 1020 & - & - & 571 & $\begin{array}{c}\text { Segal (2011); Velay } \\
\text { et al. (2002). } \\
\text { Afazov; Ratchev; }\end{array}$ \\
\hline 316 & - & - & - & $1,24 \mathrm{E}-05$ & - & $\begin{array}{c}\text { Segal (2011); } \\
\text { Grobaski, (2004). } \\
\text { Afazov; Ratchev; }\end{array}$ \\
\hline 400 & - & 890 & - & - & 621 & $\begin{array}{l}\text { Segal (2011); Velay } \\
\text { et al. (2002). }\end{array}$ \\
\hline 427 & - & - & 25,2 & 1,31E-05 & - & $\begin{array}{l}\text { Afazov; Ratchev; } \\
\text { Segal (2011). } \\
\text { Afazov; Ratchev; }\end{array}$ \\
\hline 500 & - & 750 & - & - & 673 & $\begin{array}{c}\text { Segal (2011); } \\
\text { Velay et al. (2002). }\end{array}$ \\
\hline 540 & 158 & - & - & $1,35 \mathrm{E}-05$ & - & $\begin{array}{l}\text { Afazov; Ratchev; } \\
\text { Segal (2011). } \\
\text { Afazov; Ratchev; }\end{array}$ \\
\hline 600 & - & 430 & - & - & 722 & $\begin{array}{l}\text { Segal (2011); Velay } \\
\text { et al. (2002). }\end{array}$ \\
\hline 649 & - & - & 26,8 & - & - & $\begin{array}{c}\text { Afazov; Ratchev; } \\
\text { Segal (2011); } \\
\text { Grobaski, (2004). }\end{array}$ \\
\hline
\end{tabular}


> Cargas mecânicas compressivas, totalizando $60 \mathrm{~N}$, atuantes no topo da microestrutura selecionada, simulando o efeito da propagação da força da prensa hidráulica atuante na matriz de forjamento. Vale acrescentar que a força de $60 \mathrm{~N}$ foi prevista a fim de se atingir uma tensão normal máxima por volta de $1000 \mathrm{MPa}$ na microestrutura, tendo em vista que a área da seção transversal desta é $0,06 \mathrm{~mm}^{2}$ (60 $\mu \mathrm{m}$ de comprimento e, como definido por default no Abaqus ${ }^{\circledR}, 1 \mathrm{~mm}$ de espessura). Conforme pode ser visto na tabela 8 , neste valor de tensão ocorre 0 escoamento da matriz na faixa de temperatura entre 300 e $400{ }^{\circ} \mathrm{C}$, que pode ser descrita como a faixa de temperatura máxima na ferramenta no decorrer do forjamento a quente.

Desconsideram-se, a princípio, os efeitos térmicos no balanço de energia. Isto porque, nesta situação, a energia de deformação média pode ser prevista, analiticamente, a partir da seguinte equação para o caso de tensão gerada unicamente por compressão uniaxial: (VABLE, 2012)

$$
U=\frac{F^{2} \cdot l}{2 A E_{e f}}
$$

Onde: $U$ é a energia de deformação elástica [mJ]; $F$ é a força compressiva constante [N]; I é a largura da microestrutura [mm]; A é a área da seção transversal da microestrutura, prevista com espessura de $1 \mathrm{~mm}\left[\mathrm{~mm}^{2}\right]$; $E_{\text {ef }}$ é o módulo de elasticidade efetivo da microestrutura bifásica [MPa];

No cálculo de módulo de elasticidade efetivo, são reportados, na literatura, vários tratamentos para materiais bifásicos a serem feitos, tendo em vista os estados de tensão e deformação do material. Neste trabalho, uma vez que os valores dos coeficientes de Poisson da matriz e dos carbonetos de cromo são muito próximos, foi considerada uma forma simplificada para o estudo do módulo de elasticidade efetivo que é o modelo de Voigt (iso strain). Tal modelo assume que a matriz e os precipitados estão distribuídos em um arranjo, que garanta a mesma deformação em ambas as fases (UPADHYAY; SINGH, 2012). A equação representativa de tal modelo é obtida a partir da regra das misturas:

$$
E_{e f}=E_{1} f_{V 1}+E_{2} f_{V 2}
$$


Em que: $E_{\text {ef }}$ é o módulo de elasticidade efetivo da microestrutura bifásica [MPa]; $E_{1}$ e $E_{2}$ são os módulos de elasticidade da matriz e dos precipitados, respectivamente [MPa]; e $f_{V 1}$ e $f_{V 2}$ são as frações volumétricas da matriz e dos precipitados, respectivamente.

Conforme visto, a eq.(51) depende da fração volumétrica das fases existentes na microestrutura do aço AISI H13. Para a estimativa das frações volumétricas, utilizou-se uma comparação a partir dos resultados obtidos dos softwares Abaqus ${ }^{\circledR} \mathrm{e}$ OOF2 ${ }^{\circledR}$. No Abaqus ${ }^{\circledR}$, a fração volumétrica é obtida a partir do volume de elementos distribuídos nas fases do material. Neste caso, gera-se um relatório com a variável de saída EVOL. Por outro lado, no software OOF2 ${ }^{\circledR}$, a fração volumétrica pode ser aproximada, empregando-se a contagem automática de pixels que compõem a área de cada fase. Na tabela 9, são disponibilizadas as frações volumétricas previstas para as duas fases do aço ferramenta em estudo.

Tabela 9 - Fração volumétrica das duas fases presentes na microestrutura imposta do aço AISI H13: matriz martensítica e carboneto de cromo.

\begin{tabular}{|c|c|c|c|c|c|}
\hline & \multirow[t]{2}{*}{ Fase } & \multirow{2}{*}{$\begin{array}{c}\begin{array}{c}\text { Volume } \\
{\left[\mathrm{mm}^{3}\right]}\end{array} \\
\text { Abaqus }^{\circledR}\end{array}$} & \multirow{2}{*}{$\begin{array}{c}\text { Pixels } \\
\text { Característicos } \\
\text { OOF2 }^{\circledR}\end{array}$} & \multicolumn{2}{|c|}{ Fração Volumétrica [\%] } \\
\hline & & & & Abaqus $^{\circledR}$ & $\mathrm{OOF}^{\circledR}$ \\
\hline & Matriz Martensítica & 1,770E-03 & 176998 & 73,87 & 74 \\
\hline & Carboneto $\mathrm{M}_{23} \mathrm{C}_{6}$ & 0,624E-03 & 63002 & 26,13 & 26 \\
\hline Total & & 2,394E-03 & 240000 & 100,00 & 100 \\
\hline
\end{tabular}

A substituição dos valores numéricos nas eqs.(50) e (51) fornecem a seguinte energia de deformação elástica média analítica a ser inserida na curva de convergência como valor assintótico:

$$
\begin{gathered}
E=E_{1} f_{V 1}+E_{2} f_{V 2} \rightarrow E=(207000 \mathrm{MPa} \times 0,74)+(373000 \mathrm{MPa} \times 0,26) \\
\therefore E \cong 250160 \mathrm{MPa} \\
U=\frac{F^{2} x l}{2 A E} \rightarrow U=\frac{60^{2} \mathrm{~N}^{2} \times 40 \times 10^{-3} \mathrm{~mm}}{2\left(60 \times 10^{-3} \mathrm{~mm} \times 1 \mathrm{~mm}\right)(250160 \mathrm{MPa})} \\
\therefore U \cong 4,80 \times 10^{-3} \mathrm{mI}
\end{gathered}
$$


$>$ A aresta inferior da microestrutura, que supostamente está em contato com a peça a ser conformada, é restringida por apoio fixo. A princípio, neste caso, poderia ser assumida uma restrição por apoios móveis. Porém, com esta consideração, o material da microestrutura do aço ferramenta pode se deslocar na direção horizontal, vindo a ocasionar uma possível energia cinética distinta em cada malha, o que resultaria em uma energia final diferente para cada sistema de malha em análise;

> O tempo de teste de um ciclo de forjamento foi aproximado como 1 segundo, com abordagem implícita (Abaqus/Standard ${ }^{\circledR}$ );

$>\quad$ Os números de elementos, lineares e com a consideração de estado plano de tensões, e de nós de cada malha são indicados na tabela 10. As malhas de elementos finitos testadas, por sua vez, podem ser observadas na figura 37;

Tabela 10 - Informações do número de nós e dos elementos das malhas testadas para a análise de convergência.

\begin{tabular}{ccccc}
\hline Malha & Nós & Elementos & $\begin{array}{c}\text { Elementos } \\
\text { Quadriláteros } \\
\text { (CPS4RT) }\end{array}$ & $\begin{array}{c}\text { Elementos } \\
\text { Triangulares } \\
\text { (CPE3T) }\end{array}$ \\
\hline 01 & 13740 & 22608 & 4563 & 18045 \\
02 & 20733 & 32742 & 8400 & 24342 \\
03 & 68582 & 115644 & 20837 & 94827 \\
04 & 140576 & 211836 & 68774 & 143062 \\
05 & 132737 & 216516 & 48130 & 168386 \\
\hline
\end{tabular}

$>\quad$ Ao término da simulação, realizada no Abaqus ${ }^{\circledR}$, com as mesmas condições de carregamento e de contorno nas cinco malhas, calculou-se o erro das tensões normais e das energias de deformação, obtidas do modelo numérico, em relação ao valor teórico para cada condição de refinamento de malha. Os resultados obtidos com esta análise são apresentados na tabela 11, sendo que o sistema de coordenadas cartesiano é utilizado para todas as análises.

A discrepância verificada para as tensões axiais teórica e resultantes da simulação podem ser justificadas em função da possível existência de concentradores de tensão, que influenciam mais ou menos o elemento na malha dependendo do grau de refinamento desta (tabela 11). Este resultado inicial corrobora a afirmação de Agarwal (2012) a respeito de que, neste caso, a melhor escolha para a análise de convergência não seria com base na tensão de von Mises. 
Um fato interessante ao confrontar as tabelas 10 e 11 é que aumentando em, aproximadamente, 10.000 elementos na malha (malhas 01 e 02), o erro relativo diminuiu em cerca de 1,4\%. Porém, ao refinar ainda mais a malha, acrescentando um número por volta de 80.000 elementos (malhas 02 e 03), o erro relativo diminuiu apenas em 1,2\%. Isso é um dos primeiros indicativos que denota, provavelmente, que uma convergência está sendo atingida com as malhas testadas.

Por fim, traça-se a curva de convergência mostrada na figura 38. Embora, a malha mais refinada (malha 05) tenha apresentado um erro de 3,04\% relativo ao valor da energia de deformação elástica teórica, pode-se dizer que a qualidade da referida malha foi considerada adequada para dar seguimento às análises. Uma justificativa para esta adoção consiste no fato de que mesmo a energia de deformação elástica teórica poderia ser corrigida, levando-se em consideração que o módulo de elasticidade efetivo do material bifásico não tem em conta a diferença entre os coeficientes de Poisson da matriz $(0,3)$ e dos precipitados $(0,22)$. Assim, o valor assintótico (energia de deformação teórica) da curva de convergência, possivelmente, seria corrigido de modo a propiciar valores mais próximos dos resultados obtidos por simulação numérica (figura 38 ).

Conclui-se que a malha 05, por fornecer efeitos de malha que podem ser considerados desprezíveis, é a escolhida para a continuidade do estudo da microestrutura da ferramenta de forjamento a quente.

Tabela 11 - Comparação entre os resultados obtidos por simulação numérica e os resultados teóricos para a tensão, em um mesmo elemento para todas as malhas, e para a energia de deformação.

\begin{tabular}{|c|c|c|c|c|c|c|}
\hline \multirow[t]{2}{*}{ Malha } & \multicolumn{3}{|c|}{$\begin{array}{c}\text { Tensão axial } \\
\text { (direção vertical) }\end{array}$} & \multicolumn{3}{|c|}{$\begin{array}{c}\text { Energia de deformação } \\
\text { no material bifásico }\left(\text { ALLSE no Abaqus }{ }^{\circledR}\right)\end{array}$} \\
\hline & $\begin{array}{l}\sigma_{y}[\mathrm{MPa}] \\
\text { Teórica }\end{array}$ & $\begin{array}{l}\sigma_{y}[\mathrm{MPa}] \\
\text { Abaqus }^{\circledR}\end{array}$ & Erro [\%] & $\begin{array}{l}\text { U [mJ] } \\
\text { Teórica }\end{array}$ & $\begin{array}{c}\mathrm{U}[\mathrm{mJ}] \\
\text { Abaqus }^{\circledR}\end{array}$ & Erro [\%] \\
\hline 01 & & -1616 & 61,6 & & $4,4682 \times 10^{-3}$ & 6,91 \\
\hline 02 & & -1295 & 29,5 & & $4,5342 \times 10^{-3}$ & 5,54 \\
\hline 03 & -1000 & -1331 & 33,1 & $4,80 \times 10^{-3}$ & $4,5938 \times 10^{-3}$ & 4,30 \\
\hline 04 & & -1331 & 33,1 & & $4,6421 \times 10^{-3}$ & 3,30 \\
\hline 05 & & -1331 & 33,1 & & $4,6541 \times 10^{-3}$ & 3,04 \\
\hline
\end{tabular}




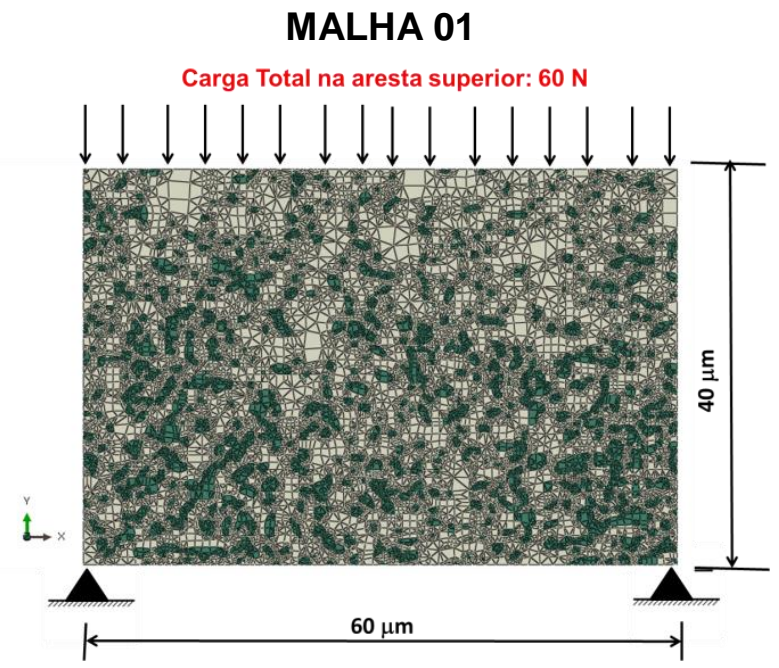

MALHA 03

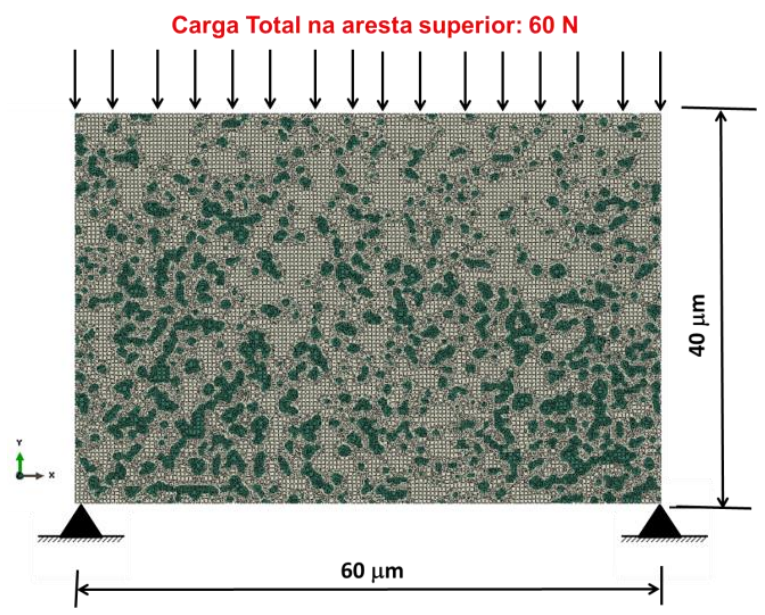

MALHA 02

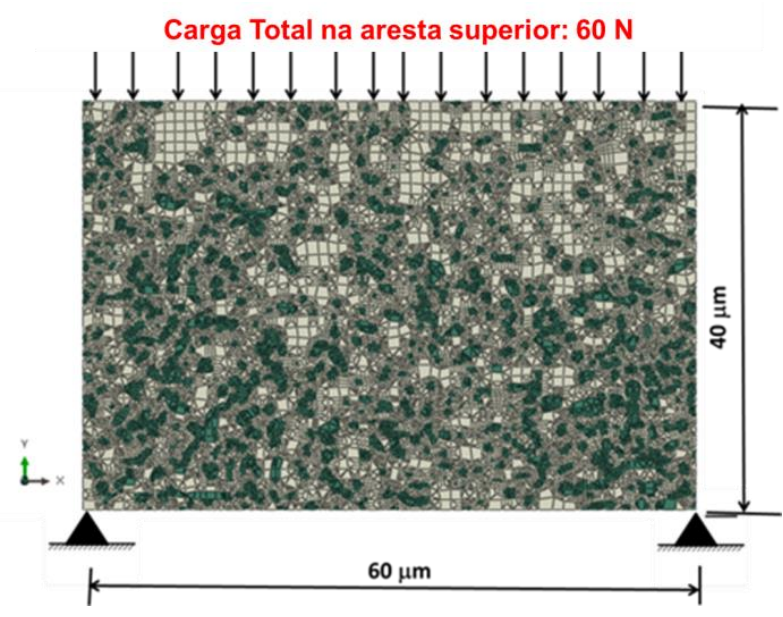

MALHA 04

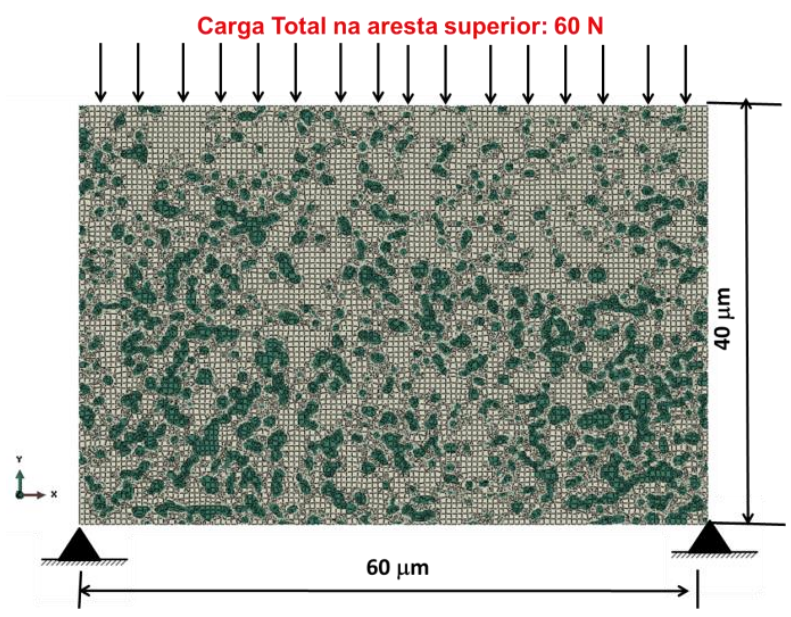

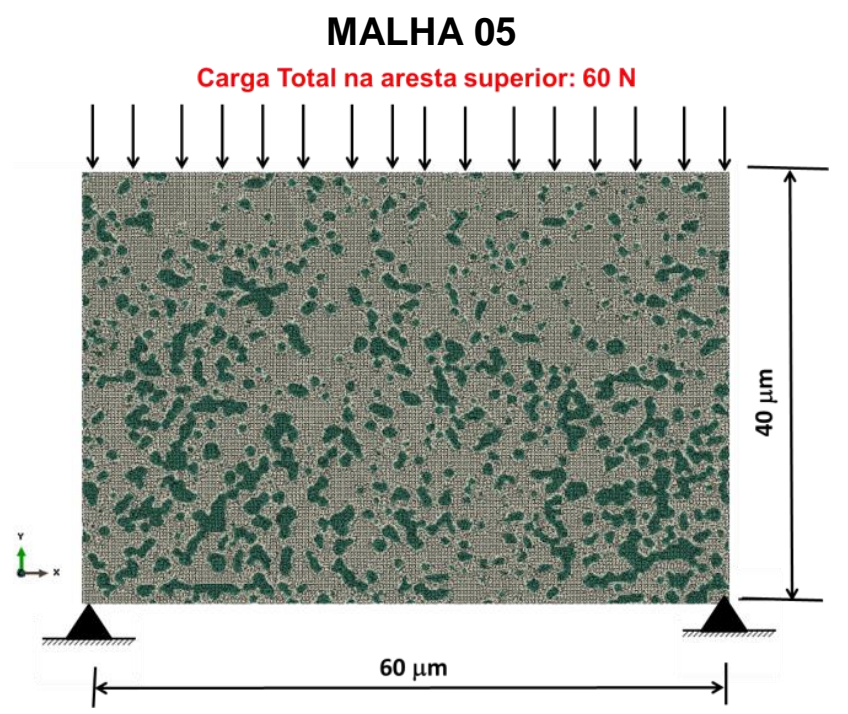

Figura 37 - Cinco malhas de elementos finitos com graus de refinamento distintos, e que foram geradas sobre a microestrutura do aço AISI H13 por meio do software OOF2 ${ }^{\circledR}$. 


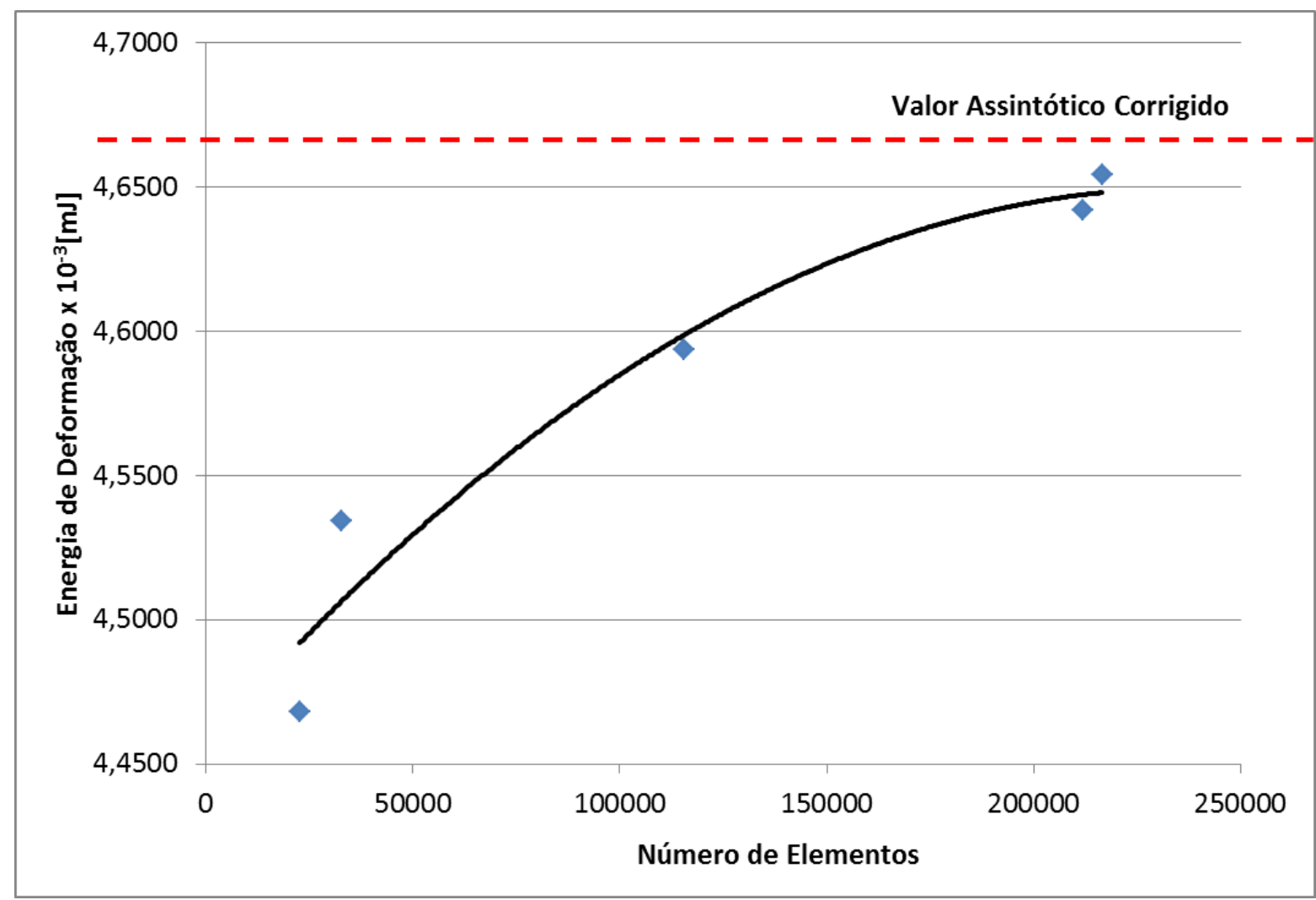

Figura 38 - Curva de convergência resultante da análise das malhas na microestrutura do aço ferramenta AISI H13. O valor assintótico é previsto por meio do resultado analítico obtido para a energia de deformação, e pode ser levada em consideração uma possível correção em função dos valores distintos de coeficiente de Poisson das fases.

(iii-) Definição das temperaturas inicial e de operação a serem atribuídas à matriz:

A temperatura inicial atribuída à microestrutura do aço AISI $\mathrm{H} 13$ foi de $150{ }^{\circ} \mathrm{C}$. Esta determinação foi feita baseada no trabalho de Sjöström (2004), que realizou as medições de temperatura (figura 39a) de uma matriz aberta de forjamento a quente, constituída de aço AISI H13, com uma câmera infravermelha, durante etapas sucessivas de conformação de um aço empregado em virabrequim. $O$ autor notou que, após o primeiro ciclo de contato peça-ferramenta e subsequente resfriamento da ferramenta, a temperatura desta ferramenta estava entre 150 e $200{ }^{\circ} \mathrm{C}$ no início do segundo ciclo. Portanto, no presente trabalho de mestrado, foi desconsiderado o primeiro ciclo quando a ferramenta é colocada em operação, e se encontra à temperatura ambiente $\left(25^{\circ} \mathrm{C}\right)$. Sendo que foi considerada como condição inicial e mínima para o estudo da microestrutura, durante a operação de forjamento a quente, a temperatura de $150{ }^{\circ} \mathrm{C}$.

Quanto à aproximação da temperatura máxima na superfície da ferramenta, dois trabalhos, reportados na literatura, foram importantes para a decisão deste 
parâmetro. Primeiramente, a abordagem de Babu, Ribeiro e Shivpuri (1999) que mostrou, conforme a figura 14, que os efeitos do revenimento no aço ferramenta AISI H13 vêm a se manifestar para temperaturas acima de $550{ }^{\circ} \mathrm{C}$. Em contrapartida, na análise de Sjöström (2004), as medições de temperatura com a câmera infravermelha mostraram que as maiores temperaturas na matriz de forjamento a quente se localizam na faixa entre 300 e $350{ }^{\circ} \mathrm{C}$, havendo "hot spots" de $600{ }^{\circ} \mathrm{C}$ (figura 39b). Com estas considerações, definiu-se para a pesquisa aqui realizada uma temperatura máxima de $400{ }^{\circ} \mathrm{C}$ para o momento do ciclo de forjamento a quente, em que ocorre o contato e a transferência de calor por condução da peça para a ferramenta.
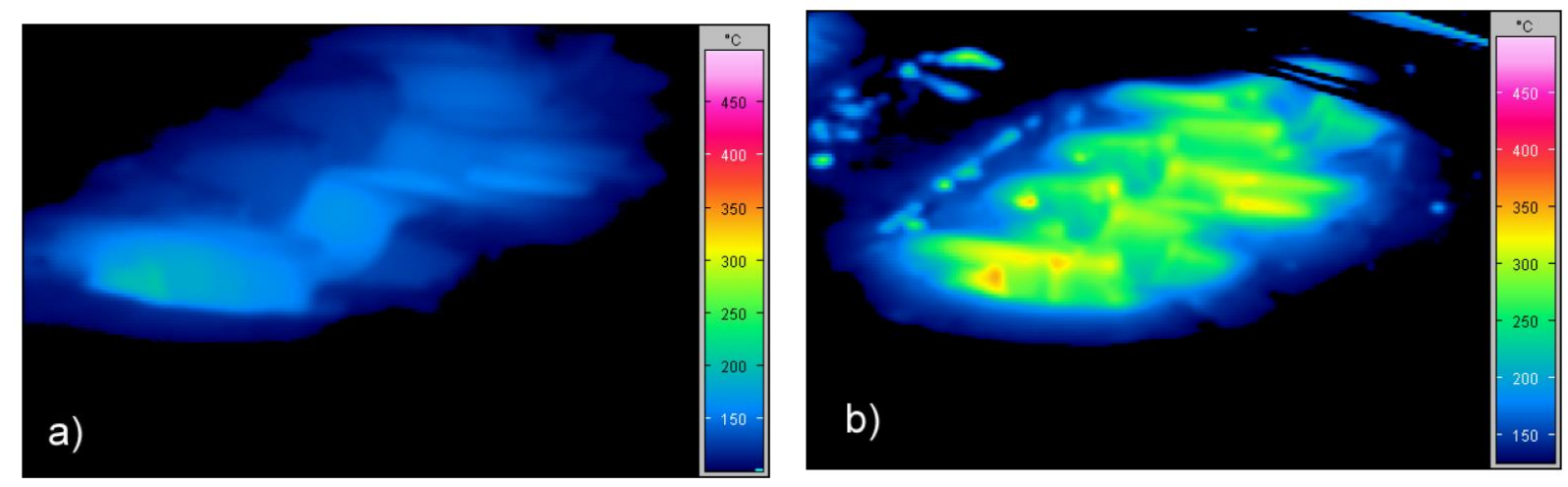

Figura 39 - Distribuição térmica no aço AISI H13, aplicado como ferramenta em um processo de forjamento a quente: (a-) resultado após resfriamento da superfície da ferramenta; (b-) resultado imediatamente após o ciclo de forjamento (temperatura máxima verificada para a ferramenta). (SJÖSTRÖM, 2004)

Tecidos os comentários a respeito dos materiais e métodos gerais para 0 desenvolvimento da pesquisa aqui relatada, foram definidas duas sequências (uma térmica e a outra termomecânica) específicas de etapas envolvidas no decorrer do trabalho relativo ao modelo simulado numericamente. Hipóteses simplificadoras foram consideradas, porém buscou-se aproximar o citado modelo numérico dos possíveis fenômenos que ocorrem na microestrutura da ferramenta durante o processo de conformação por forjamento a quente.

Visto que a análise de dano na ferramenta está focada em prever as regiões mais susceptíveis à ocorrência de fadiga térmica, como uma primeira hipótese definiu-se uma ferramenta na qual os efeitos de desgaste e a taxa de deformação (que afeta diretamente na deformação plástica do material) não são levados em consideração. 
(iv-) Elaboração do procedimento de análise, por simulação numérica, puramente térmica:

O objetivo da realização deste procedimento foi fazer uma abordagem comparativa do campo de tensões térmicas na microestrutura do aço AISI H13, decorrentes do contato entre a ferramenta e a peça, com os resultados de Serantoni Silva (2003) e Weronski e Hejwowski (1991). Para proporcionar, ainda, a citada comparação, utilizou-se de análises no EPT. A figura 40 ilustra e representa as hipóteses simplificadoras consideradas neste procedimento de análise térmica.

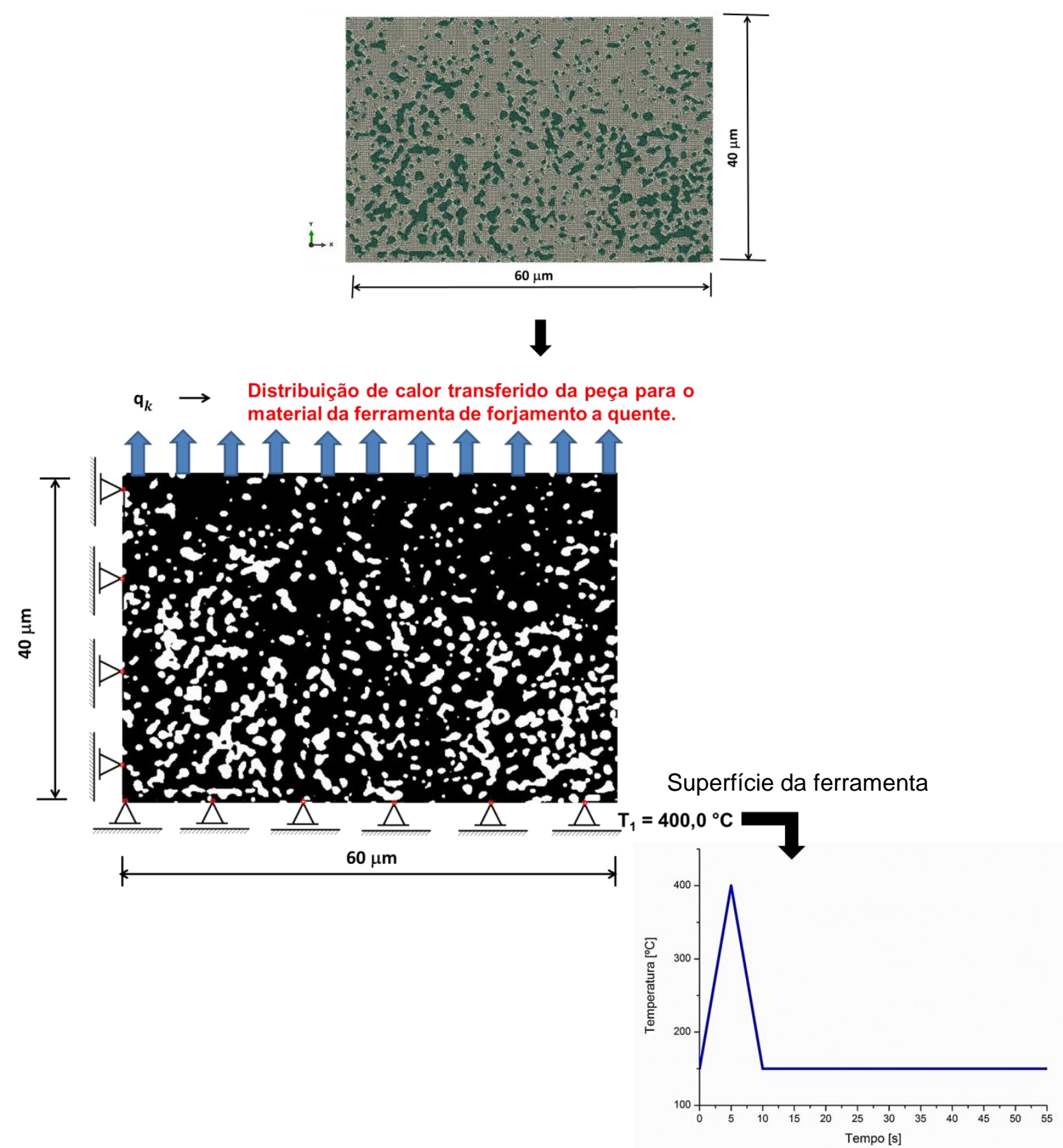

Figura 40 - Desenho esquemático das condições de contorno e carregamento puramente térmico definidos para o primeiro modelo numérico elaborado. 
As hipóteses simplificadoras impostas na simulação numérica, por meio de elementos finitos, a título de se realizar um estudo do comportamento mecânico da microestrutura da ferramenta, foram:

> A microestrutura do aço ferramenta AISI H13 foi empregada como constituinte da matriz aberta superior que entra em contato com a peça. As fases consideradas presentes nesta microestrutura são a matriz martensítica e os carbonetos de cromo $\mathrm{M}_{23} \mathrm{C}_{6}$, cujas propriedades mecânicas e térmicas são fornecidas nas tabelas 7 e 8;

> A região microestrutural do aço $\mathrm{H} 13$ estudada foi limitada a uma área retangular (tratamento 2D) de $60 \times 40 \mu \mathrm{m}^{2}$. Esta área foi selecionada, tendo em vista, também, o investimento em um menor tempo de processamento e recursos computacionais envolvidos na simulação, e desenvolver um estudo comparativo entre o comportamento macroscópico da ferramenta em serviço e os aspectos microestruturais, com as devidas ressalvas;

> A simulação numérica por MEF foi executada no Abaqus/Standard ${ }^{\circledR}$, no step Coupled temp-displacement, que possibilita a análise termomecânica acoplada. A microestrutura foi discretizada, de acordo com a informação da tabela 10 (malha 05), em 48130 elementos tetra do tipo CPS4RT e 168396 elementos tri do tipo CPE3T (no EPT);

$>$ Conforme pode ser observado na figura 40, na superfície da ferramenta, sujeita à troca de calor por condução com a peça, tem-se uma temperatura inicial de $150^{\circ} \mathrm{C}$, atingindo uma temperatura máxima de $400{ }^{\circ} \mathrm{C}$ no momento de contato com $\mathrm{O}$ forjado. As temperaturas em questão são entradas do modelo numérico, e são

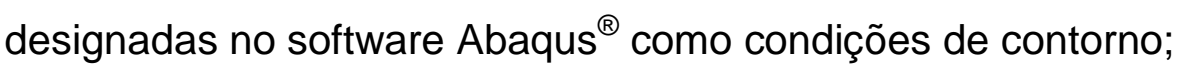

$>\quad$ Na região mais afastada da superfície da ferramenta (topo da microestrutura), é simulada a troca de calor por condução com o material envoltório da referida ferramenta (figura 40). Para esta ação, insere-se uma extração de calor na forma de fluxo de calor por área (entrada no Abaqus $^{\circledR}$ como carregamento térmico) de 2 $\mathrm{MW} / \mathrm{m}^{2}$ (VELAY et al., 2002), que corresponde ao mesmo valor previsto como parâmetro de entrada para o cálculo térmico na microestrutura em regime permanente. Assim, mantém-se a condição de equilíbrio na microestrutura, sendo que a quantidade de calor que entra no volume de controle (microestrutura) é igual a quantidade de calor que sai do mesmo;

$>\mathrm{O}$ ciclo térmico, por sua vez, foi definido com base nos experimentos laboratoriais de fadiga térmica realizados por Serantoni Silva (2003) e Silva (2006). 
As taxas de aquecimento e de resfriamento são iguais e equivalem a $50{ }^{\circ} \mathrm{C} / \mathrm{s}$. Pode ser visto na figura 40, que o aço ferramenta é aquecido por 5 s e resfriado em outros 5 s por uma solução de grafita coloidal, por exemplo. Mantém-se a temperatura mínima do ciclo nos últimos $45 \mathrm{~s}$ de modo a reproduzir, o mais fielmente possível, os ensaios de fadiga térmica;

> Foram impostos 10 ciclos térmicos na simulação numérica realizada, em virtude do custo computacional definido pelo tempo de processamento da referida simulação;

$>$ Para evitar a movimentação inadequada da microestrutura em estudo, considerou-se a superfície da ferramenta e a lateral esquerda da citada microestrutura restringidas por apoios móveis, que limitam um grau de liberdade referente ao movimento de translação (figura 40). A justificativa para tal adoção consiste nos seguintes argumentos: (a-) o avanço da ferramenta deve ser restringido, uma vez que a superfície da ferramenta entrará em contato com a peça; e (b-) apenas a lateral esquerda da microestrutura é restringida, possibilitando as livres expansão e contração desta microestrutura, de modo a evitar distorções demasiadas que ocorreriam no campo de tensões no caso da restrição de ambas as laterais;

$>\quad$ As microtensões teóricas foram calculadas, e confrontadas com os resultados de tensões (saídas) da simulação numérica por elementos finitos, com o intuito de estimar as regiões da microestrutura mais susceptíveis à nucleação de dano por fadiga térmica. A eq.(52) permite calcular a microtensão $(P)$ na superfície de precipitados admitidos com morfologia circular (WERONSKI; HEJWOWSKI,1991):

$$
P=\frac{\left(\alpha_{2}-\alpha_{1}\right) \mathrm{T}}{\frac{0,5\left(1+v_{2}\right)+\left(1-2 v_{2}\right) \mathrm{d}^{3}}{\mathrm{E}_{2}\left(1-\mathrm{d}^{3}\right)}+\frac{1-2 v_{1}}{\mathrm{E}_{1}}}
$$

Onde: $\alpha_{2}$ é o coeficiente de expansão térmica da matriz; $\alpha_{1}$ é o coeficiente de expansão térmica do carboneto; $v_{2}$ é o coeficiente de Poisson da matriz; $v_{1}$ é o coeficiente de Poisson do carboneto; $\mathrm{E}_{2}$ é o módulo de elasticidade da matriz; $\mathrm{E}_{1}$ é o módulo de elasticidade do carboneto, T é a temperatura, adotada pelos autores como a temperatura máxima do ciclo a título de simplificação dos cálculos [K]; e d é 
a razão entre $R_{1}$ e $R_{2}$, sendo $R_{1}$ o raio do carboneto e $R_{2}$ é a distância entre as superfícies dos carbonetos.

(v-) Elaboração do procedimento de análise, por simulação numérica, com considerações termomecânicas:

Neste caso, objetivou-se incluir condições de contorno e cargas mecânicas ao procedimento térmico simplificado, para reproduzir com maior veracidade a situação da microestrutura da ferramenta.

Desse modo, as hipóteses simplificadoras do modelo numérico térmico bidimensional continuam sendo válidas, com a única retificação feita no quesito referente à temperatura que, é constante, no presente procedimento, em $400{ }^{\circ} \mathrm{C}$ durante o tempo de $1 \mathrm{~s}$ (aquecimento pelo contato com o forjado). São acrescidas às seguintes imposições mecânicas ao procedimento térmico:

$>\quad \mathrm{Na}$ superfície do aço ferramenta AISI H13, é inserido um carregamento mecânico, de $30 \mathrm{~N}$ variando no tempo (figura 41), conforme informações reportadas por Rodrigues e Martins (2010) que denotam o comportamento da força da prensa hidráulica atuante na matriz de forjamento. Tal condição de entrada na microestrutura, inserida no Abaqus $^{\circledR}$, é dimensionada com base na tensão de escoamento inicial da peça de aço AISI 1045 que equivale a aproximadamente 553 MPa (DUAN et al, 2009), e a área da seção transversal desse forjado que corresponde a $0,06 \mathrm{~mm}^{2}$;

$>\quad \mathrm{Na}$ lateral esquerda da microestrutura em estudo, é considerada uma condição de simetria a fim de representar a continuidade do material envoltório da ferramenta de conformação (figura 41). A abordagem de simetria ou axissimetria adotada para processos de fabricação por forjamento foi, e continua sendo, muito reportada na literatura também. (BEHRENS et al, 2008; BEHRENS et al, 2010; DESHPANDE, 2011; VALBERG, 2010);

$>\quad \mathrm{Na}$ aresta inferior da microestrutura do aço ferramenta (região de contato com o forjado), é construída uma geometria retangular de $60 \times 1 \mu \mathrm{m}^{2}$ (figura 41), que diz respeito à superfície da peça que sofre deformação plástica a quente. $O$ material atribuído à peça é o aço AISI 1045 com propriedades térmicas e mecânicas listadas na tabela 12. Em relação às condições de contorno, também é considerada a simetria na lateral esquerda da superfície a ser forjada. Para restringir a 
movimentação vertical desta superfície, que sofre cargas compressivas, são impostos apoios móveis na base da peça. (figura 41).

Além disso, visto que a faixa de temperatura para forjar a quente o aço AISI 1045 é de 850 a $1250{ }^{\circ} \mathrm{C}$ (TATA STEEL NZ, 2012), estipulou-se em $1100{ }^{\circ} \mathrm{C}$ a temperatura da peça.

A região de contato entre as superfícies da ferramenta (aço $\mathrm{H} 13$ ) e da peça (aço 1045) também possui certas especificações, tais como:

(a-) coeficiente de atrito, dado pelo modelo de atrito de Tresca, na região de contato entre peça e ferramenta. Com base nos trabalhos publicados por Kim et al. (2005) e Rodrigues; Martins (2010), como o forjado a quente é um aço e admitindo-se que ocorre o resfriamento da superfície da ferramenta com o auxílio de um spray lubrificante de base grafitada, o valor do fator de atrito por cisalhamento constante (m) corresponde a 0,3;

(b-) a condutância térmica $\left(h_{k}\right)$ da peça para a ferramenta, para um valor mínimo de pressão de contato entre as superfícies, foi prevista a partir da eq.(53) que leva em conta a conservação de energia. Assim, o fluxo de calor por condução na ferramenta, calculado pela eq.(40), é mantido também na interface peça-ferramenta, formando um circuito em série analogamente a um circuito elétrico: (JAIN, 1990)

$$
\mathrm{h}_{\mathrm{k}}=\frac{\mathrm{q}_{\mathrm{k}}}{\left(\mathrm{T}_{\text {peça }}-\mathrm{T}_{\text {ferramenta }}\right)}
$$

Onde:

$q_{k}=2 \mathrm{MW} / \mathrm{m}^{2} \rightarrow$ fluxo de calor transferido por condução, durante operações de forjamento a quente (VELAY et al., 2002); $\mathrm{T}_{\text {peça }}=1100{ }^{\circ} \mathrm{C} \rightarrow$ temperatura inicial da peça; e $\mathrm{T}_{\text {ferramenta }}=150^{\circ} \mathrm{C} \rightarrow$ temperatura inicial da ferramenta.

$$
\therefore \mathrm{h}_{\mathrm{k}}=\frac{2 \times 10^{6} \mathrm{~W} / \mathrm{m}^{2}}{(1100-150)^{\circ} \mathrm{C}} \cong 2105 \frac{W}{m^{2 \circ} \mathrm{C}}
$$

Este valor de condutância térmica estimado para o contato entre a peça e a ferramenta pode ser sustentado também pelo trabalho de Shapiro (2009), que descreveu uma condutância de $2000 \mathrm{~W} /\left(\mathrm{m}^{2} .{ }^{\circ} \mathrm{C}\right)$ para o contato de material metálico contra material metálico em operações de conformação mecânica a quente. 
Tabela 12 - Propriedades do forjado: aço AISI 1045. (DUAN et al, 2009; DAVIES et al, 2003)

\begin{tabular}{lcl}
\hline Densidade $\left[\mathbf{k g} / \mathbf{m}^{3}\right.$ ] & 7800 & DAVIES et al, 2003 \\
Módulo de Elasticidade [GPa] & 200 & DAVIES et al, 2003 \\
Coeficiente de Poisson & 0,3 & DAVIES et al, 2003 \\
Condutividade Térmica $\left[\mathbf{W} /\left(\mathbf{m} .{ }^{\circ} \mathbf{C}\right)\right]$ & 55 & DAVIES et al, 2003 \\
Calor Específico a Pressão Constante $\left[\mathbf{J} /\left(\mathbf{k g} \cdot{ }^{\circ} \mathbf{C}\right)\right]$ & 374 & DAVIES et al, 2003 \\
Fração de deformação plástica convertida em calor & 0,90 & DAVIES et al, 2003 \\
\hline
\end{tabular}

\begin{tabular}{|c|c|c|c|c|c|c|c|}
\hline \multicolumn{8}{|c|}{$\begin{array}{c}\text { Modelo de Plasticidade: Johnson-Cook: } \bar{\sigma}=\left[A+B(\bar{\varepsilon})^{n}\right]\left[1+C \cdot \ln \left(\frac{\dot{\varepsilon}}{\overline{\varepsilon_{0}}}\right)\right]\left[1-\left(\frac{T-T_{a m b}}{T_{f u s a ̃ o}-T_{a m b}}\right)^{m}\right] \\
\text { (DUAN et al, 2009) }\end{array}$} \\
\hline $\begin{array}{c}\text { Tensão } \\
\text { Inicial de } \\
\text { Escoamento }\end{array}$ & $\begin{array}{l}\text { Módulo de } \\
\text { Encruamento }\end{array}$ & $\begin{array}{l}\text { Expoente de } \\
\text { Encruamento }\end{array}$ & $\begin{array}{l}\text { Coeficiente de } \\
\text { Dependência } \\
\text { na Taxa de } \\
\text { Deformação }\end{array}$ & $\begin{array}{l}\text { Coeficiente de } \\
\text { Amolecimento } \\
\text { Térmico }\end{array}$ & $\begin{array}{l}\text { Taxa de } \\
\text { Deformação } \\
\text { Inicial }\end{array}$ & $\begin{array}{r}\text { Tempe } \\
\text { Re }\end{array}$ & $\begin{array}{l}\text { aturas de } \\
\text { rência }\end{array}$ \\
\hline $\mathrm{A}[\mathrm{MPa}]$ & $\mathrm{B}$ [MPa] & $n$ & C & $\mathrm{m}$ & $\overline{\varepsilon_{0}}\left[\mathrm{~s}^{-1}\right]$ & $\begin{array}{l}T_{\text {fusão }} \\
{\left[{ }^{\circ} \mathrm{C}\right]}\end{array}$ & $\begin{array}{c}\mathrm{T}_{\text {ambiente }} \\
{\left[{ }^{\circ} \mathrm{C}\right]}\end{array}$ \\
\hline 553 & 600 & 0,234 & 0,013 & 1,0 & 0,001 & 1400 & 20 \\
\hline
\end{tabular}

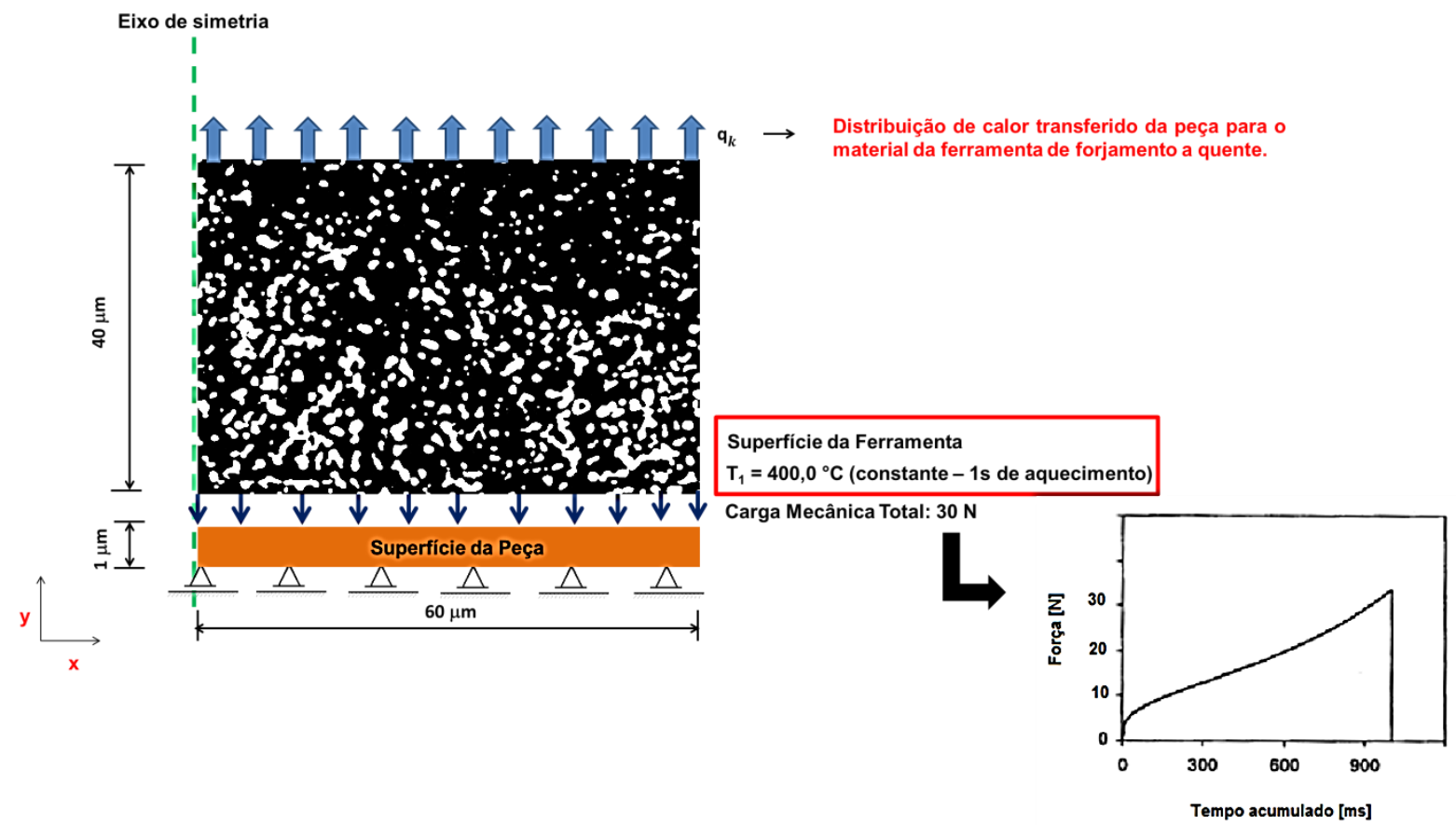

Figura 41 - Desenho esquemático das condições de contorno e carregamento definidas para o modelo numérico termomecânico elaborado. 


\section{RESULTADOS E DISCUSSÕES}

A apresentação dos resultados obtidos em paralelo às suas discussões foi dividida em tópicos, com o objetivo de propiciar um entendimento mais abrangente da evolução do trabalho bem como o efeito das variáveis do processo de fabricação por forjamento a quente avaliadas na presente pesquisa.

\subsection{ASPECTOS GERAIS VERIFICADOS NOS RESULTADOS OBTIDOS DO MODELO TÉRMICO}

Os resultados da simulação numérica do modelo com considerações térmicas foram avaliados, a princípio, quanto às respostas da distribuição de temperaturas e tensões na microestrutura do aço ferramenta AISI H13. Para esta ação, selecionaram-se elementos de cada fase posicionados em três regiões distintas da microestrutura de acordo com a figura 42 .

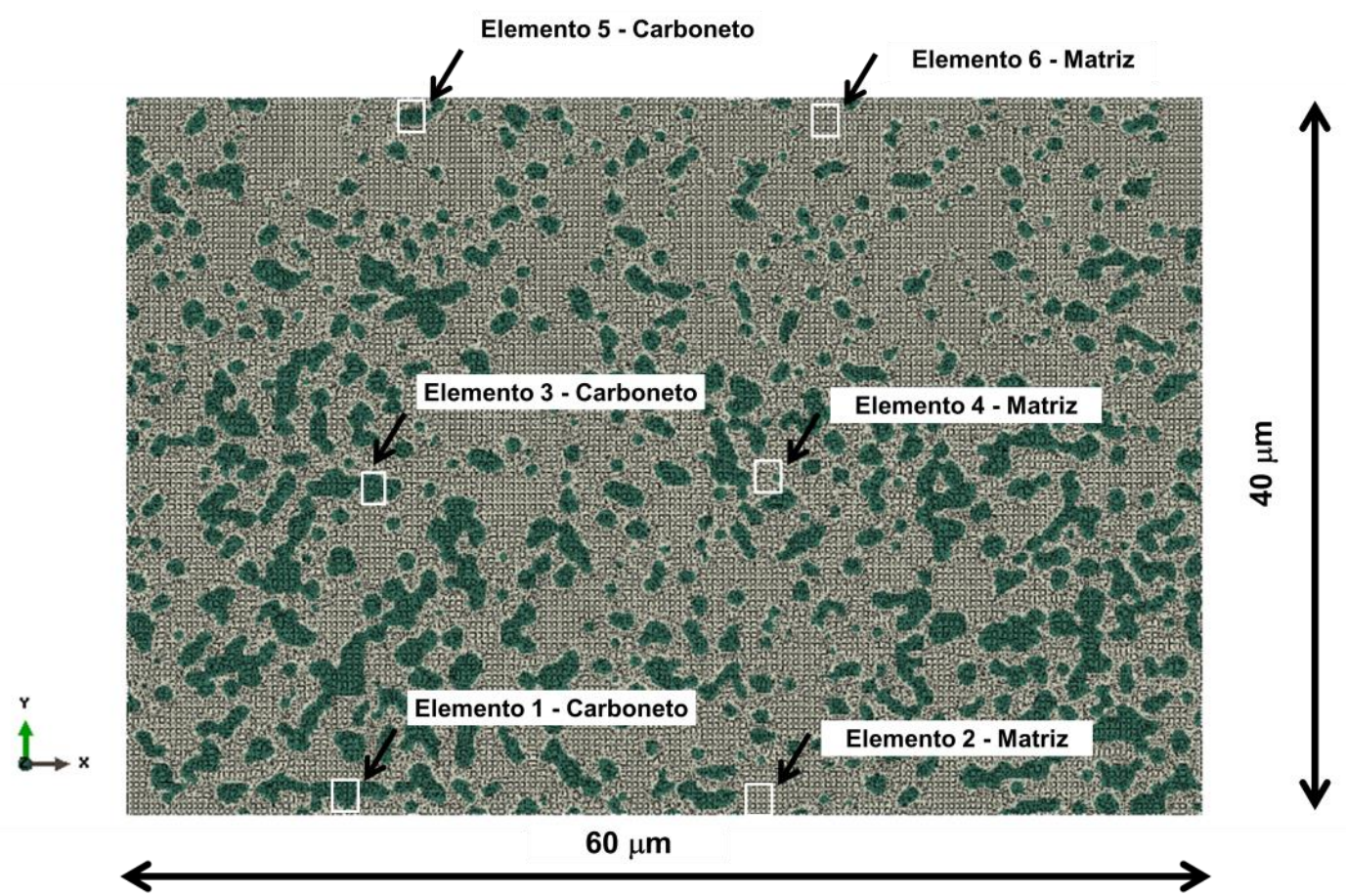

Figura 42 - Localização das amostras de elementos estudados para as duas fases presentes na microestrutura do aço AISI H13. 
Quanto ao efeito da temperatura, são mostrados na figura 43 os resultados referentes à distribuição desta variável na microestrutura da ferramenta nas condições posteriores ao aquecimento e ao resfriamento.

(a-)
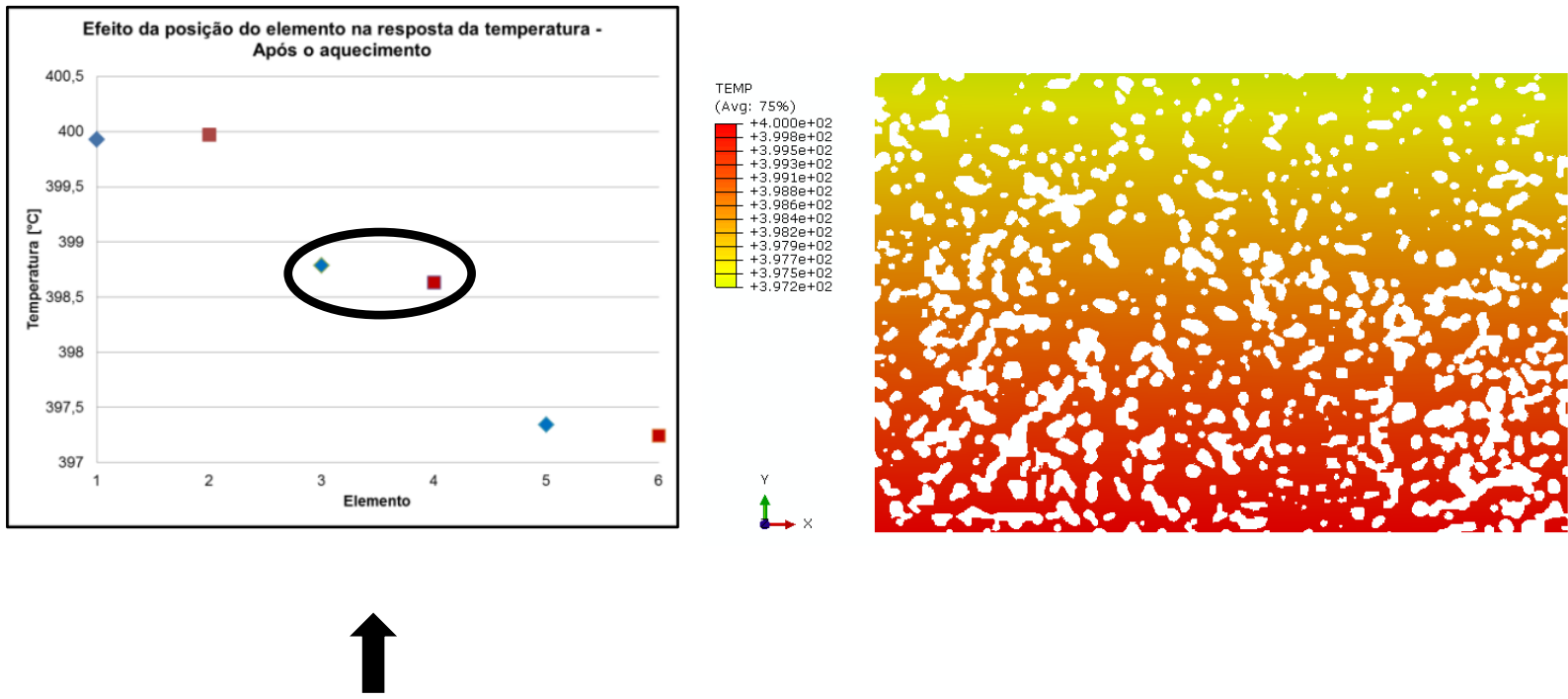

Diferença na ordem de centésimos de ${ }^{\circ} \mathrm{C}$ nos elementos, localizados em uma mesma região de análise.

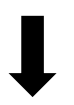

(b-)
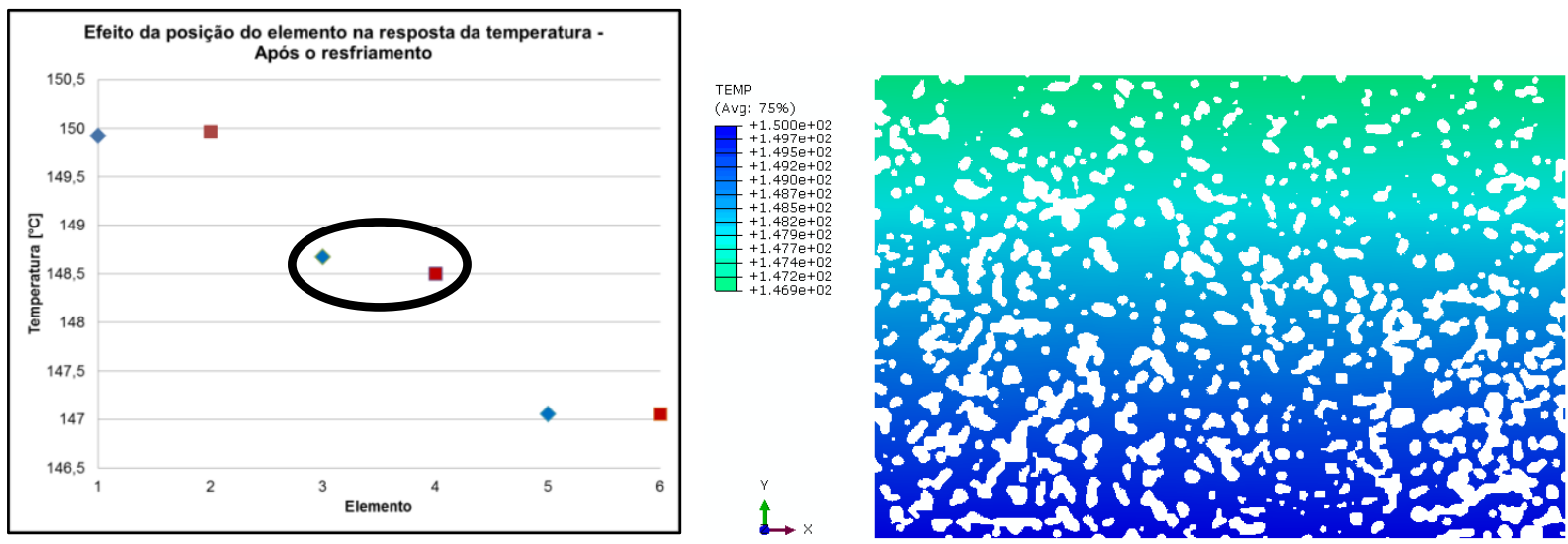

Figura 43 - Variação de temperatura $\left[{ }^{\circ} \mathrm{C}\right.$ ] ao longo da área microestrutural, após os momentos de: (a) aquecimento e (b) resfriamento dos ciclos térmicos impostos. 
Nota-se, a partir dos resultados apresentados, a sensibilidade da faixa de temperatura em função da posição do elemento na malha. Na figura 43 , observamse exemplos da variação térmica na microestrutura em análise nas etapas de:

- pós-aquecimento $\rightarrow$ obtém-se $400{ }^{\circ} \mathrm{C}$ nos elementos próximos à superfície (elementos 1 e 2); $398,7^{\circ} \mathrm{C}$ nos elementos localizados na região intermediária da microestrutura (elementos 3 e 4); e $397,2{ }^{\circ} \mathrm{C}$ nos elementos mais afastados da superfície (elementos 5 e 6 );

- pós-resfriamento $\rightarrow$ obtém-se $150{ }^{\circ} \mathrm{C}$ nos elementos próximos à superfície (elementos 1 e 2); $148,5^{\circ} \mathrm{C}$ nos elementos localizados na região intermediária da microestrutura (elementos 3 e 4); e $146,9{ }^{\circ} \mathrm{C}$ nos elementos mais afastados da superfície (elementos 5 e 6 );

Estes resultados sustentam a diferença térmica estimada, para regime permanente de transferência de calor, em aproximadamente $3{ }^{\circ} \mathrm{C}$ ao longo da microestrutura selecionada da ferramenta de forjar a quente.

Além disso, pelos gráficos apresentados na figura 43, da temperatura disposta no eixo das ordenadas e o elemento informado no eixo das abscissas, podem ser vistas ainda algumas variações de temperatura nas fases, na ordem de centésimo de grau Celsius. Isso porque os elementos, empregados no estudo de uma mesma região, não foram selecionados exatamente a uma mesma cota vertical em relação à superfície do aço $\mathrm{H} 13$.

Um último aspecto interessante em relação aos resultados explorados na figura 43 é que, embora as condutividades térmicas das duas fases do material em estudo sejam distintas, o gradiente de temperatura não ocorre entre as fases, mas sim ao longo da microestrutura em forma faixas de temperaturas. Uma distribuição térmica similar foi obtida com a consideração de fluxo de calor, como carregamento, da base para o topo da microestrutura em um trabalho reportado por Seriacopi, Chagas e Machado (2012).

A título de ilustrar o comportamento das tensões nos elementos, é fornecido, de modo exemplificado, na tabela 13, um panorama dos dados de tensões obtidas como respostas para os elementos 1 e 2 . 
Tabela 13 - Comparação entre os valores das tensões resultantes de von Mises e de Rankine nos elementos 1 e 2, posicionados na superfície da microestrutura.

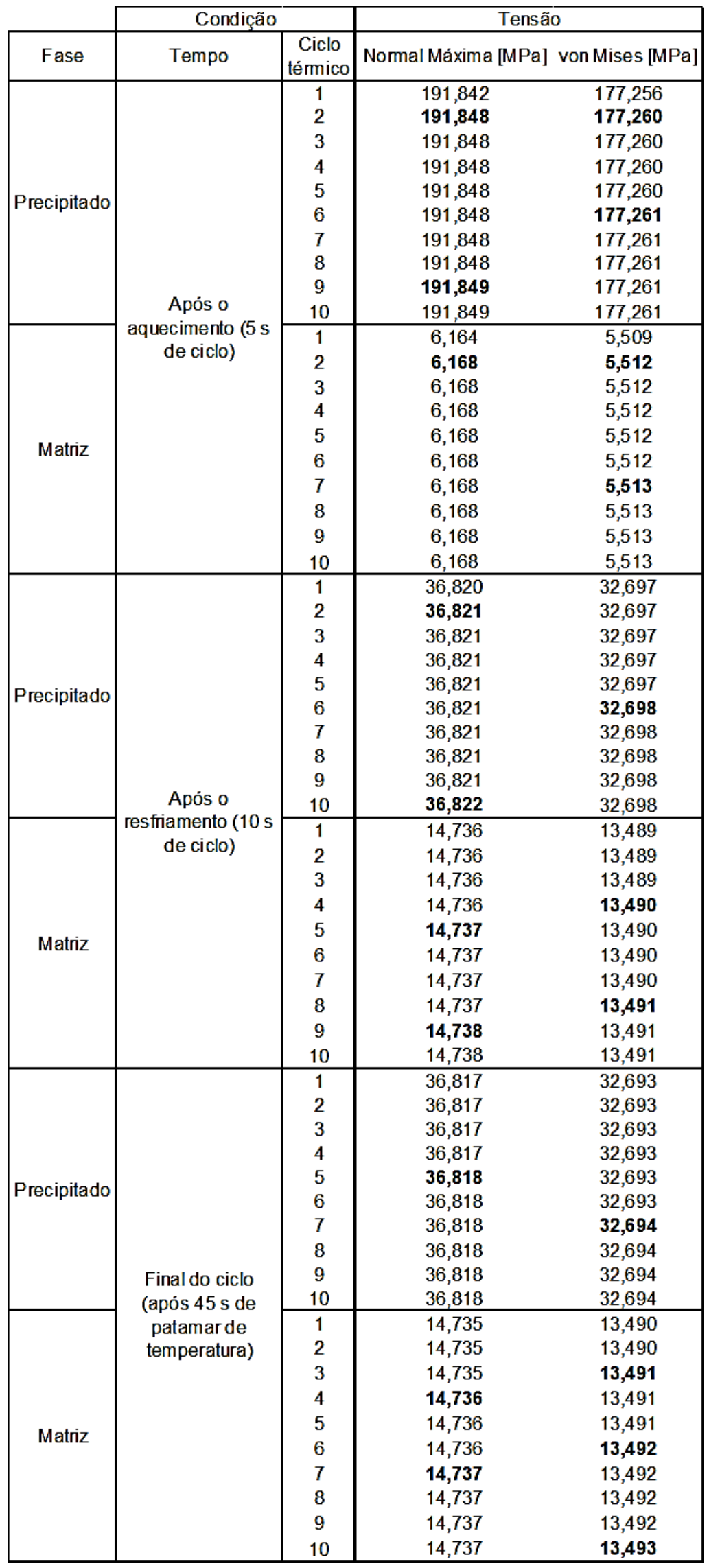


Em linhas gerais, foi verificado a partir do procedimento adotado que as respostas do modelo estão coerentes nos aspectos que se seguem:

(i-) valores diferentes apresentados para as tensões de von Mises e de Rankine: a análise das tensões nas fases do material da ferramenta, exemplificada na tabela 13 tendo em vista os elementos 1 e 2 da figura 42, permite constatar a diferença entre as tensões fornecidas pelo critério de von Mises e da tensão normal máxima (Rankine).

É possível observar, na tabela 13, que os valores das tensões de Rankine são maiores do que os das tensões de von Mises, apesar do critério de Rankine ser mais conservativo do que o de von Mises. Uma provável explicação para esta ocorrência é que os tipos de carregamentos térmicos impostos possam estar ocasionando as situações esquematizadas no segundo e no quarto quadrantes da figura 28 , que envolvem em ambos os casos cargas compressivas no material. De fato, devido à diferença dos coeficientes de expansão térmica das fases presentes na microestrutura, uma das fases estará sujeita à tração, tentando se expandir, e propiciando a compressão da outra fase.

Do ponto de vista do fenômeno em estudo pode ser mais relevante analisar as tensões pelo critério da tensão máxima principal, uma vez que o objeto de análise neste trabalho não se trata do escoamento do aço AISI H13, mas sim o foco está nas tensões normais de origem térmica que possam vir a causar a nucleação de trincas por fadiga térmica (modo I de falha por fadiga).

(ii-) previsão da condição térmica mais crítica para cada fase no processo de forjamento a quente:

- $\quad$ segundo as informações disponibilizadas na tabela 13 , as tensões nos carbonetos de cromo (precipitado) são maiores após o aquecimento do material em relação às situações posteriores ao resfriamento e ao patamar de temperatura. Desse modo, e visto que foi atribuído aos precipitados o comportamento elástico, a etapa de aquecimento se torna a mais crítica para esta fase, sendo que nesta ocasião há uma alteração significativa da condição térmica da microestrutura ( $T$ $400{ }^{\circ} \mathrm{C}$ ) em relação à condição inicial considerada como remanescente da última etapa do ciclo anterior $\left(\mathrm{T} \sim 150{ }^{\circ} \mathrm{C}\right)$. Por outro lado, depois do resfriamento, as 
tensões nos carbonetos de cromo são menores devido à contração térmica do material da ferramenta;

- para a matriz martensítica, verifica-se, por intermédio da tabela 13, que a situação mais crítica do ciclo térmico é o resfriamento. As tensões na matriz decorrentes do resfriamento se mostram maiores do que as resultantes do aquecimento do material em virtude do comportamento elástico e perfeitamente plástico designado para esta fase. O período de resfriamento acarreta em um alívio de cargas térmicas na matriz, geradas durante o período de aquecimento. Todavia, as tensões resultantes do aquecimento vêm agravar a resposta da matriz no resfriamento, aumentando a cada ciclo o efeito da deformação plástica na matriz que, por sua vez, favorece o dano por fadiga térmica na referida região martensítica.

(iii-) aumento das tensões nas fases no decorrer dos ciclos térmicos: observa-se essa ocorrência nas situações exibidas na tabela 13, podendo isto ser considerado como parâmetro indicativo de dano acumulado devido à aplicação de carregamentos térmicos cíclicos. A variação das tensões se dá na ordem do milésimo transcorridos alguns ciclos térmicos, o que leva a predizer que um elevadíssimo número de ciclos térmicos necessitaria ser simulado para a caracterização do dano de fato;

(iv-) importância do estudo dos efeitos das partículas de segunda fase na microestrutura do material da ferramenta: conforme os dados apresentados na tabela 13, ressalta-se que as tensões de von Mises e de Rankine nos carbonetos de cromo são quase 30 vezes maiores do que na matriz martensítica, na condição que sucede o aquecimento da ferramenta. Posteriormente ao resfriamento, a diferença entre as tensões nas fases é amenizada, mas os carbonetos de cromo continuam fornecendo valores de tensão superiores ao dobro daqueles obtidos na matriz martensítica. Esse fato é um dos indicativos que as partículas de segunda fase atuam com o papel de concentradores de tensão na microestrutura do aço ferramenta. Tal relato vai de encontro com os trabalhos experimentais de Serantoni Silva (2003) e Silva (2006) que mostram, entre outros aspectos, que os precipitados e as interfaces matriz-precipitado são sítios de nucleação de trincas por fadiga térmica. 


\subsection{INFLUÊNCIA DAS PROPRIEDADES DAS FASES NA RESPOSTA DO CAMPO DE TENSÕES TÉRMICAS NA MICROESTRUTURA DA FERRAMENTA}

Os precipitados são as regiões da microestrutura do aço ferramenta nas quais ocorrem as tensões mais elevadas. Especificamente no caso das tensões térmicas calculadas, considerando-se o estado plano de tensões, e tendo em vista as eqs.(50) e (54), a justificativa para as maiores tensões nos precipitados pode ser relacionada com as propriedades das fases e com a temperatura da ferramenta durante o forjamento. Em temperaturas que podem ser aproximadas a $400{ }^{\circ} \mathrm{C}$, o módulo de elasticidade do carboneto $\mathrm{M}_{23} \mathrm{C}_{6}$ é $373 \mathrm{GPa}$, ao passo que o valor dessa propriedade na matriz martensítica está próximo de $175 \mathrm{GPa}$. Na temperatura de $150^{\circ} \mathrm{C}$, o módulo de elasticidade do carboneto $\mathrm{M}_{23} \mathrm{C}_{6}$ continua próximo de $373 \mathrm{GPa}$, já o módulo de elasticidade da matriz martensítica aumenta para aproximadamente 196,5 GPa. Comparadas ao grau de influência do módulo de elasticidade nas tensões térmicas, as outras variáveis analisadas, por sua vez, não têm efeito significativo:

(i-) $O$ efeito dos gradientes de temperatura analisado não é considerado como justificativa na diferença dos resultados de tensões na matriz e nos precipitados, dispostos de modo ilustrativo na tabela 13, e isso se deve ao alinhamento horizontal das regiões selecionadas (elementos 1 e 2 da figura 42). Em qualquer condição existente nos três momentos dos ciclos térmicos (aquecimento, resfriamento e patamar de temperatura) o precipitado sempre apresentará as maiores tensões;

(ii-) Em relação ao coeficiente de expansão térmica, no precipitado este valor corresponde a $1,06 \mathrm{e}-05{ }^{\circ} \mathrm{C}^{-1}$ enquanto que o da matriz martensítica equivale a aproximadamente $1,30 \mathrm{e}-05^{\circ} \mathrm{C}^{-1}$, à temperatura máxima de $400{ }^{\circ} \mathrm{C}$, os quais são muito próximos.

O coeficiente de expansão térmica, por ser um pouco maior na matriz, poderia vir a ocasionar uma tensão maior na mesma, visando unicamente a eq.(43). Porém, como a diferença desta propriedade térmica na referida matriz e nos precipitados é pequena quando comparado à diferença dos módulos de elasticidade, o efeito que este último vem a ocasionar é majoritário; 
(iii-) Quanto aos valores dos coeficientes de Poisson nas duas fases, têm-se 0,22 e 0,30 , respectivamente, para os carbonetos de cromo e para a matriz, o que também não é relevante levando-se em conta as eqs.(43) e (47). O coeficiente de Poisson poderia possibilitar uma maior tensão na matriz do que nos carbonetos, uma vez que a tensão térmica é descrita pela eq.(43) como sendo inversamente proporcional a diferença entre a unidade e o citado coeficiente de Poisson. Entretanto, novamente este aumento na tensão não é significativo, quando se compara o resultado desta subtração no denominador que corresponde a uma constante multiplicando as tensões térmicas em 1,4 vezes no caso da matriz e em 1,3 vezes no caso do precipitado;

Com base nas informações explanadas, é possível concluir que a maior influência nos resultados, neste caso, é o módulo de elasticidade.

A fim de consolidar o papel dos precipitados como concentradores de tensões na microestrutura do aço ferramenta, são apresentadas as figuras 44 e $45 \mathrm{com}$ os campos de tensões pelos critérios da tensão máxima principal e de von Mises, respectivamente, atuantes na microestrutura durante a simulação dos ciclos térmicos. 
(a-)

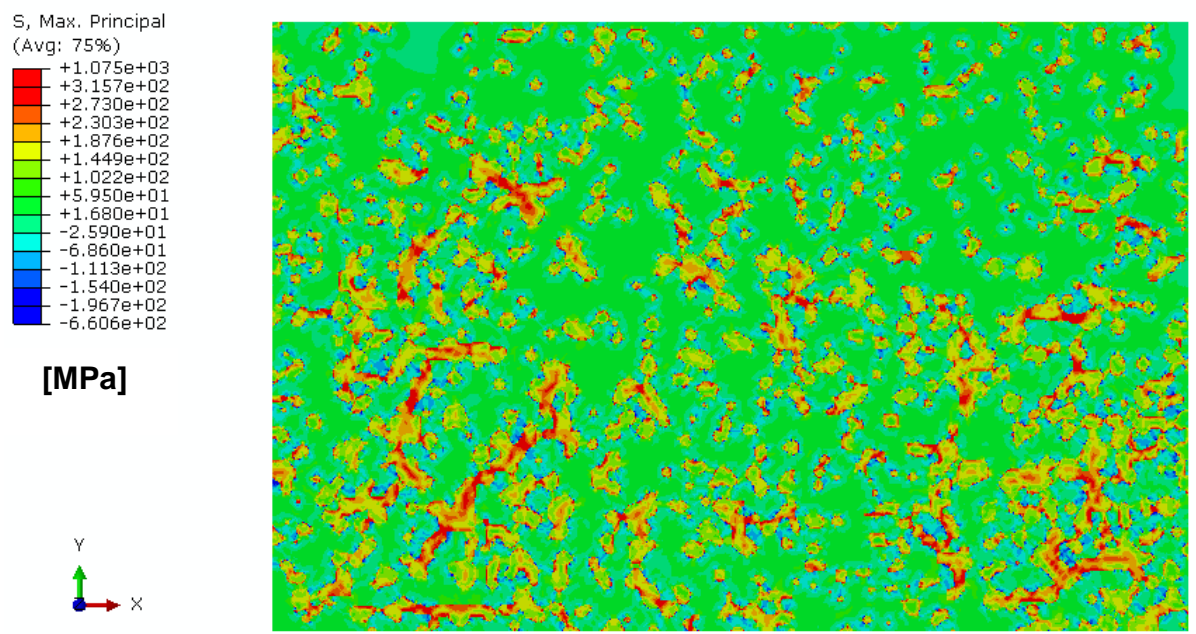

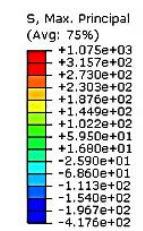

[MPa]

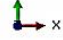

\section{(b-)}

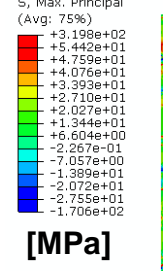

$\stackrel{y}{a}$
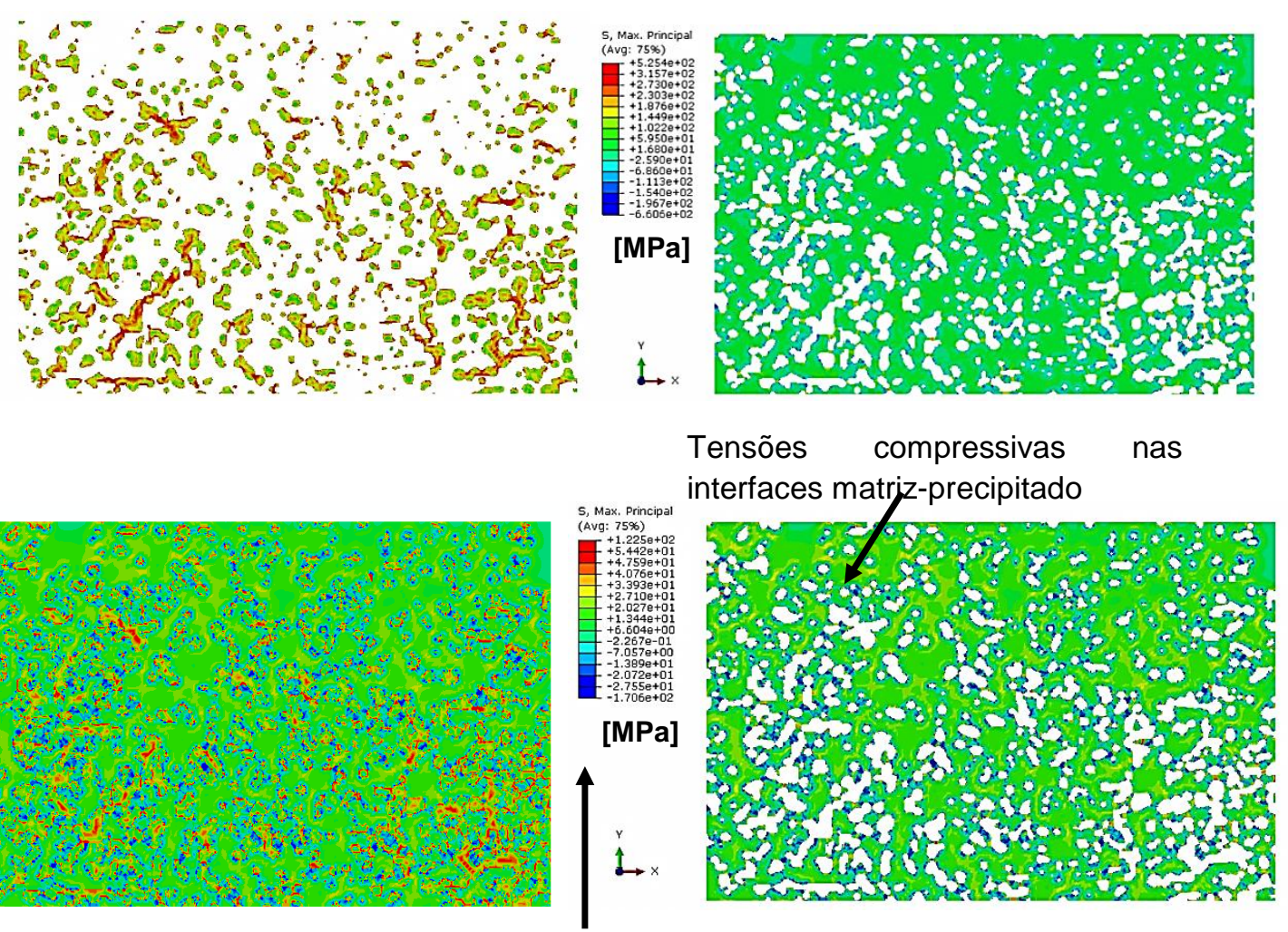

Direção do resfriamento.

Figura 44- Distribuição da tensão máxima principal [MPa] na matriz e nos carbonetos do aço AISI $\mathrm{H} 13$, ao término dos 10 ciclos térmicos nas seguintes etapas: (a-) pós-aquecimento; (b-) pósresfriamento. 
(a-)
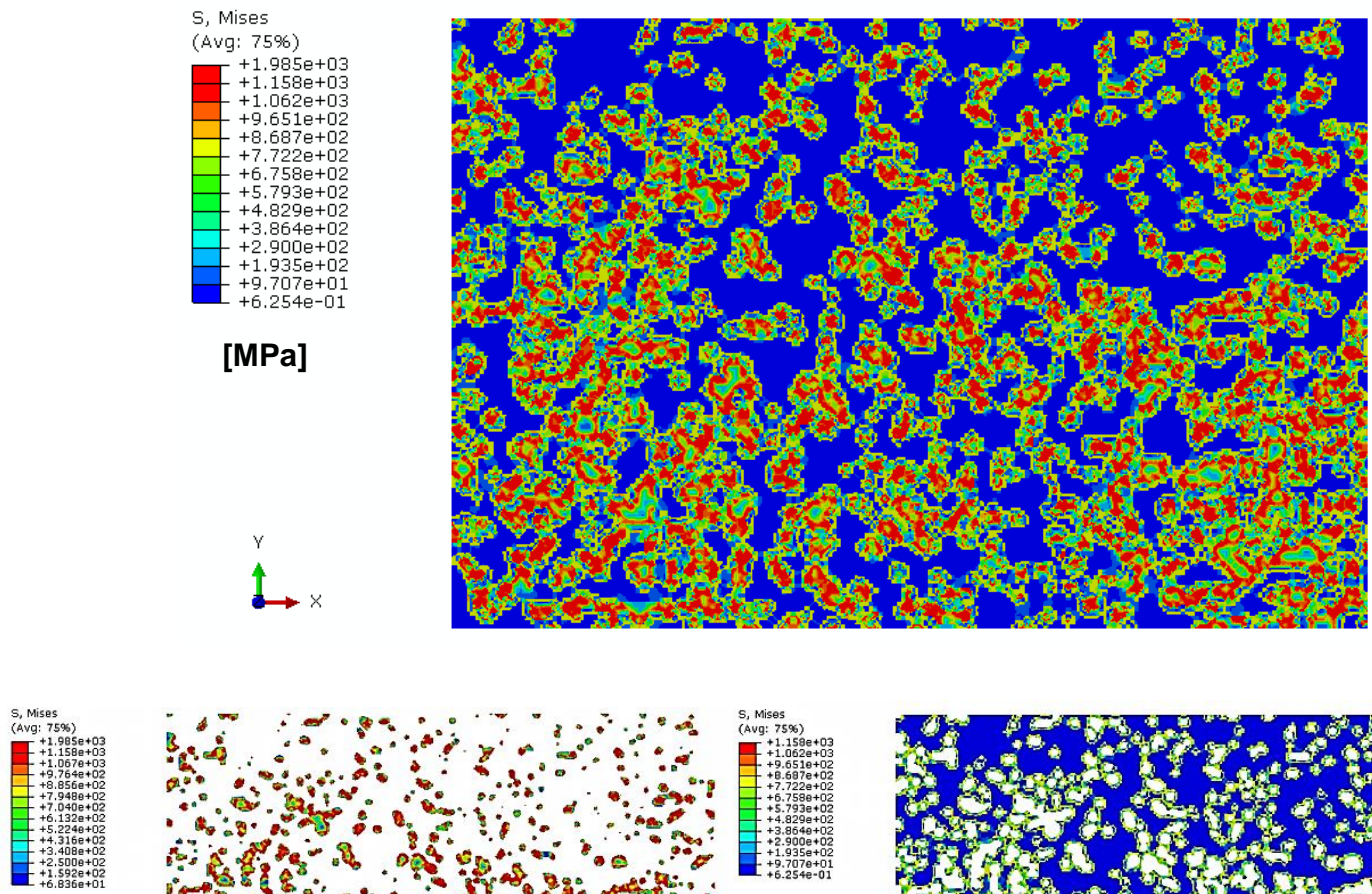

on

[MPa]

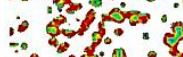

s.

$\because 7$ as

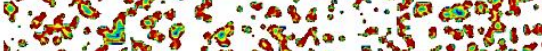

$\stackrel{y}{\perp} \rightarrow x$

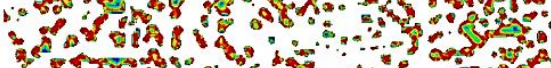

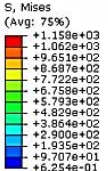

[MPa]

$\stackrel{y}{\perp \rightarrow x}$

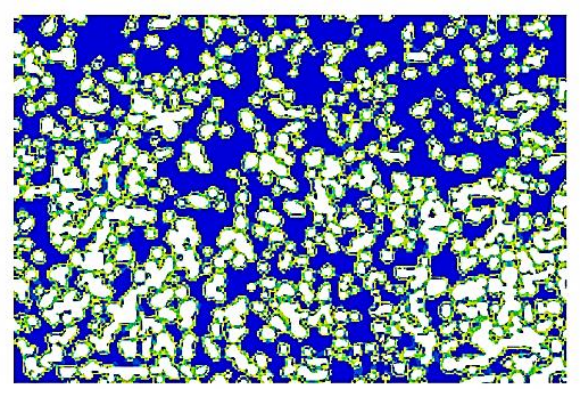

(b-)
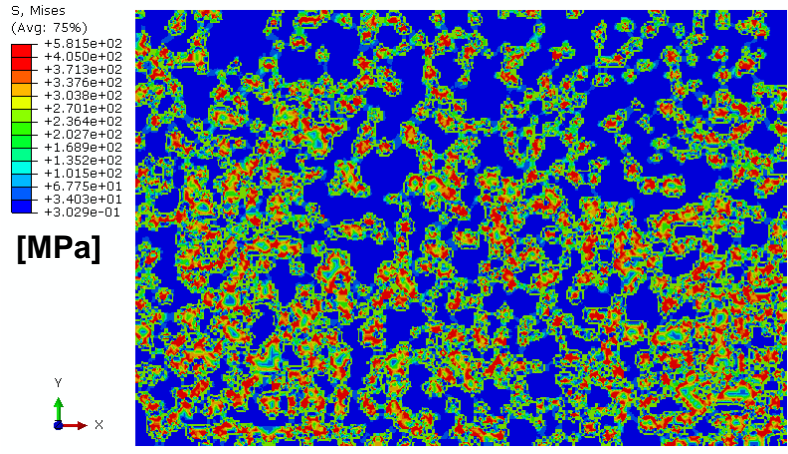

Mesma ordem de grandeza nas tensões das interfaces matriz-precipitado e nos precipitados.

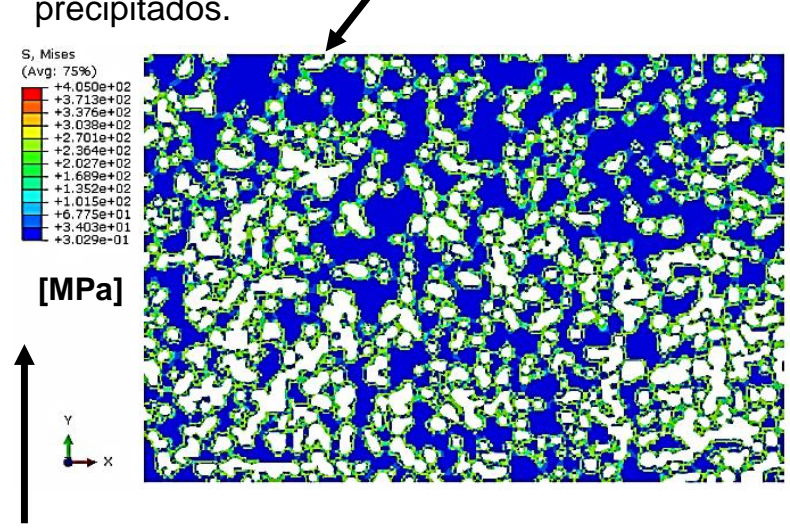

Direção do resfriamento.

Figura 45 - Distribuição da tensão de von Mises [MPa] na matriz e nos carbonetos do aço AISI H13, ao final dos 10 ciclos térmicos nas seguintes etapas: (a-) pós-aquecimento; (b-) pós-resfriamento. 
$\mathrm{Na}$ figura 44a, são vistas as distribuições da tensão máxima principal resultantes ao final do aquecimento no décimo ciclo térmico. Nessas condições, pode-se verificar a proximidade da formulação do modelo numérico com a teoria a partir da comparação das tensões máximas atuantes, por exemplo, nos carbonetos de cromo cujas propriedades térmicas e mecânicas não variam com a temperatura (a título de facilitar a validação). Assim, analiticamente, a tensão térmica prevista para esta fase com a aplicação dos ciclos térmicos, e conforme a adaptação da eq.(43), é:

$$
\sigma=\frac{373 \times 10^{3} \times\left(1,06 \times 10^{-5}\right) \times(400-150)}{1-0,22} \rightarrow \sigma \cong 1267 \mathrm{MPa}
$$

Em relação à tensão nos carbonetos pelo critério da máxima principal, ao comparar o resultado da simulação por MEF (1075 MPa) e o resultado analítico (1267 MPa), obtém-se uma diferença de aproximadamente $15 \%$. A diferença do valor obtido por simulação do valor teórico levanta a questão da influência do coeficiente de expansão térmica da outra fase (matriz martensítica) e a resposta das interfaces nas tensões obtidas, e permite as seguintes hipóteses:

$>\quad \mathrm{Na}$ etapa de pós-aquecimento, verificam-se tensões compressivas em algumas regiões da matriz martensítica (figura 44a), possivelmente porque a matriz está sendo impedida de continuar a sua dilatação térmica. É atingindo um valor mínimo de tensão na interface matriz-carboneto, na ordem de $-660 \mathrm{MPa}$, ao término do aquecimento, devido à reação da matriz com os carbonetos, que possuem menor coeficiente de expansão térmica a $400{ }^{\circ} \mathrm{C}$;

As regiões críticas da microestrutura à nucleação de trincas térmicas, nesta etapa de pós-aquecimento, são confirmadas como sendo as interfaces e os precipitados (figura 45a). Neste caso, complementa-se a hipótese das partículas de segunda fase como concentradores de tensões, enfatizando-se a justificativa que o módulo de elasticidade dessas partículas é muito maior que o da matriz.

Além disso, a análise apenas da matriz, com os carbonetos omitidos como retratado na figura $45 \mathrm{a}$, permite acompanhar diferentes ordens de grandeza 
decrescentes (cores vermelha e verde) para as tensões nos carbonetos e nas interfaces;

> Novamente, após o resfriamento da microestrutura, notam-se, conforme as figuras $44 b$ e 45b, áreas concentradoras de tensões, representadas pelos carbonetos de cromo e interfaces matriz-precipitado. Conforme enfatizado na figura 45b, obtêm-se tensões de von Mises da mesma ordem de grandeza (centena de $\mathrm{MPa}$ ) atuando nas interfaces em questão (regiões em verde), apesar das concentrações de tensões no interior dos precipitados (regiões em vermelho);

> Quanto à resposta da distribuição de tensão máxima principal, com o decorrer do resfriamento, podem ser observadas tensões compressivas em regiões da interface matriz-carboneto (figura 44b), uma vez que os valores de coeficiente de expansão térmica das fases são muito próximos a $150{ }^{\circ} \mathrm{C}$. Esse fato pode vir a contribuir para a nucleação de trincas térmicas nas referidas interfaces. (SERANTONI SILVA, 2003)

Assim, como encerramento deste tópico, pode ser ressaltada a importância do estudo da microestrutura da ferramenta, representada por um material bifásico, e as consequências que isso ocasiona no campo de tensões resultantes do trabalho a quente.

\subsection{INFLUÊNCIA DAS PROPRIEDADES DAS FASES E DA TEMPERATURA NA DEFORMAÇÃO ELÁSTICA DO MATERIAL DA FERRAMENTA}

Iniciando o estudo das deformações térmicas, são apresentadas, na figura 46, as deformações elásticas resultantes dos dez ciclos térmicos impostos na microestrutura do aço $\mathrm{H} 13$. 
(a-)
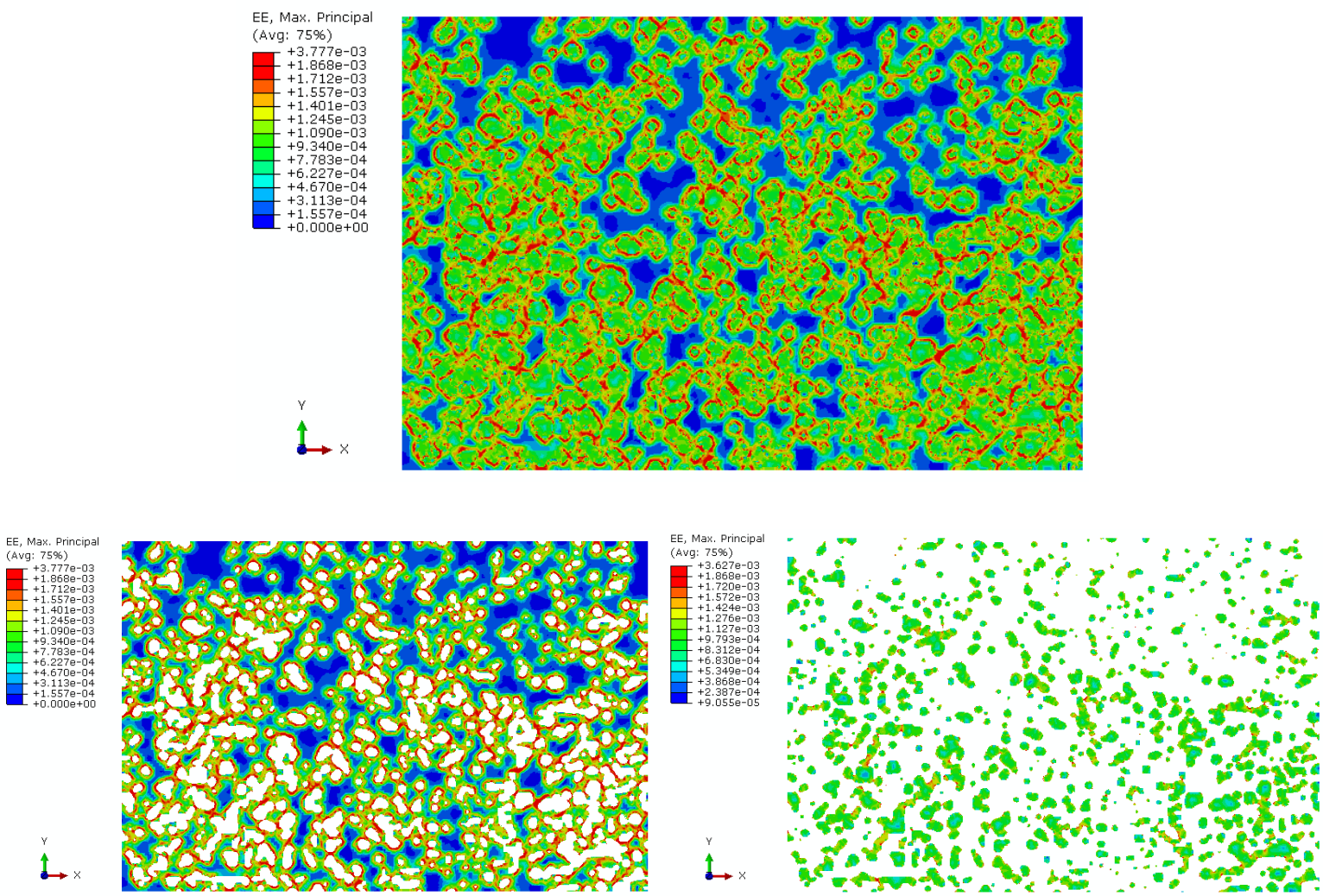

(b-)
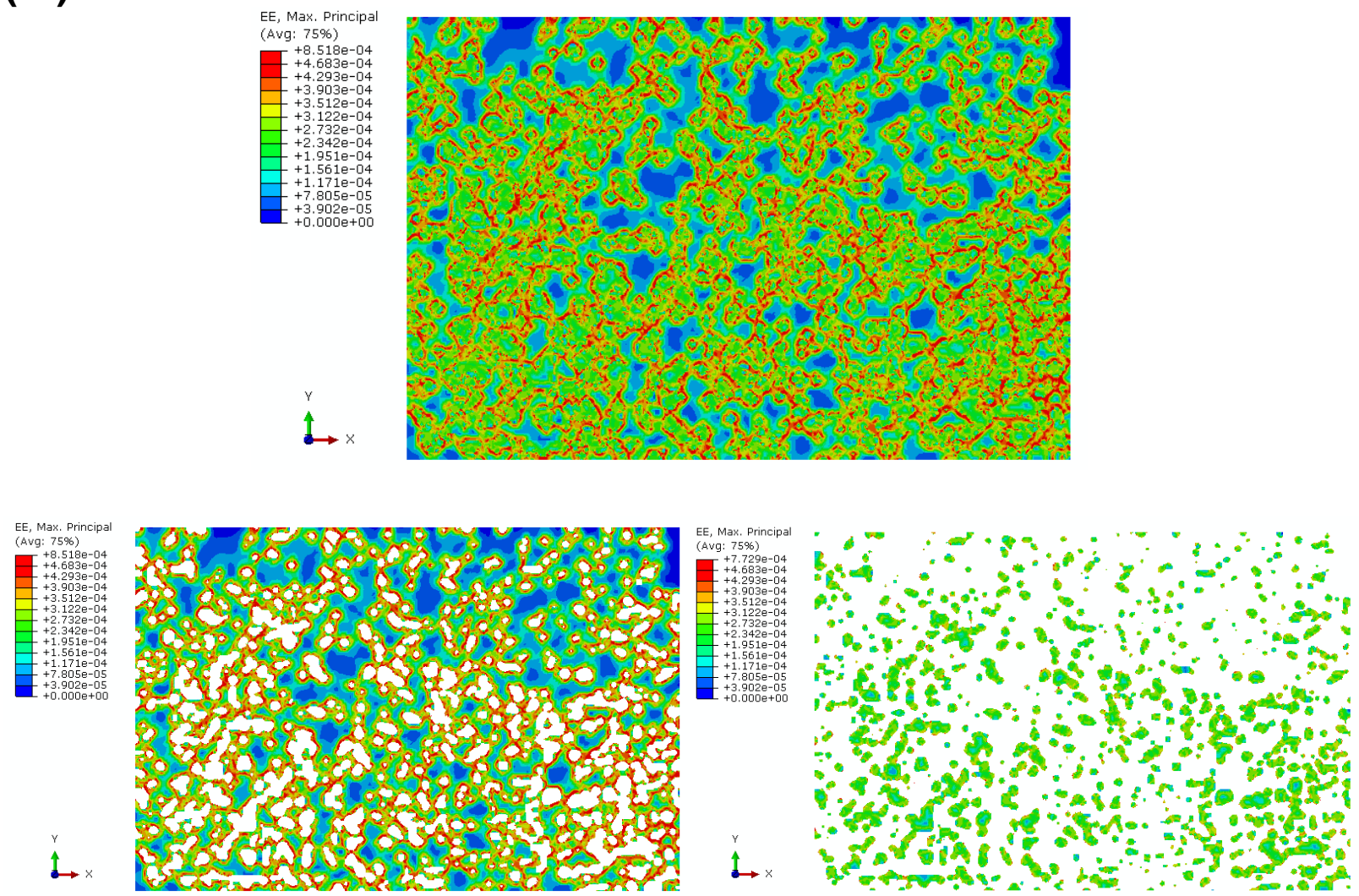

Figura 46- Distribuição da deformação térmica na matriz e nos carbonetos do aço AISI H13, ao final dos 10 ciclos térmicos nas seguintes etapas: (a-) pós-aquecimento; (b-) pós-resfriamento. 
Conforme designado pelas eqs.(44) e (48), no caso das deformações térmicas previstas para a consideração de EPT, os resultados são decorrentes dos dois aspectos que se seguem:

(i-) da temperatura a qual as fases são expostas no decorrer dos ciclos;

(ii-) do coeficiente de expansão térmica das fases do material;

Uma primeira análise da figura 46 permite constatar que, tanto na condição de aquecimento quanto de resfriamento da microestrutura, as regiões mais críticas (em vermelho) são as interfaces matriz-carboneto.

Por meio dos resultados da figura 46 , observa-se ainda que, com a passagem da etapa de pós-aquecimento (figura 46a) para o momento posterior ao resfriamento (figura 46b), as deformações elásticas nas interfaces são reduzidas em uma ordem de grandeza. Portanto, o resultado em questão é decorrente do fato que a temperatura da ferramenta é reduzida, pela ação de um spray, por exemplo, e o material desta ferramenta tende a se contrair durante o seu resfriamento.

Em se tratando de um material bifásico, a propriedade coeficiente de expansão térmica de cada fase é também responsável por definir os distintos comportamentos de deformação na microestrutura:

- Na temperatura de $400{ }^{\circ} \mathrm{C}$ (máxima do ciclo), o coeficiente de expansão térmica na matriz martensítica equivale a $1,29 \mathrm{e}-05^{\circ} \mathrm{C}^{-1} \mathrm{e} o$ valor desta propriedade no carboneto $\mathrm{M}_{23} \mathrm{C}_{6}$ é $1,06 \mathrm{e}-05^{\circ} \mathrm{C}^{-1}$. Nesse caso, quando o material como um todo vem a se dilatar, o carboneto não se expande na mesma condição que a matriz, propiciando deformações elevadas nas interfaces (figura 46a).

- Na temperatura de $150^{\circ} \mathrm{C}$ (mínima do ciclo), o coeficiente de expansão térmica na matriz martensítica corresponde a $1,08 \mathrm{e}-05{ }^{\circ} \mathrm{C}^{-1}$ e para o carboneto de cromo é de $1,06 \mathrm{e}-05{ }^{\circ} \mathrm{C}^{-1}$. Com a proximidade dos valores desta propriedade térmica nas fases, uma hipótese que poderia ser feita, a princípio, diz respeito a uma maior homogeneidade da distribuição das deformações térmicas na microestrutura após o resfriamento. Conforme observado na figura $46 \mathrm{~b}$ e comparação desta com a figura 46a, comprova-se que tal hipótese não corresponde à realidade. A justificativa para corroborar o resultado do modelo numérico está embasada no estudo das tensões. 
A tabela 13 mostrou que o resfriamento é a condição mais crítica para a matriz martensítica, em virtude das propriedades plásticas atribuídas a ela e as possíveis tensões residuais que possam atingir esta fase; o que não ocorre com os carbonetos de cromo, uma vez estes são elásticos. Em função das tensões, a heterogeneidade da distribuição das deformações continua a existir durante o resfriamento porque outras propriedades das fases, além do coeficiente de expansão térmica, são relevantes e influenciam de forma significativa os resultados.

Acrescenta-se, neste ponto, que as eqs.(43) e (44) tratam-se de um modo simplificado de calcular as tensões e as deformações térmicas, no estado plano de tensões, em um material monofásico. Os materiais polifásicos são muito complexos e as propriedades térmicas e mecânicas são, comumente, prescritas em função de outras variáveis como, por exemplo, da temperatura. Recorrer, então, aos cálculos iterativos, tal como pelo emprego do método dos elementos finitos, se torna bastante relevante.

Finalmente, isolando cada fase da microestrutura, e ao examinar as deformações térmicas mostradas na figura 45, instiga-se que os resultados para os carbonetos (em geral, na cor verde) são maiores do que para a matriz (representada pelas regiões azuis, em sua maioria), em decorrência das tensões mais elevadas estarem atuando nos citados carbonetos. Com o mapeamento das deformações elásticas apresentadas para a microestrutura, salienta-se mais uma vez o papel de alguns precipitados como elementos que facilitam a ocorrência de dano por fadiga térmica no material da ferramenta, em função de sua morfologia, distribuição e tamanho.

\subsection{EFEITO DO TEMPO NA DETERMINAÇÃO DAS TEMPERATURAS IMPOSTAS NOS CICLOS}

Até o momento, foi discutida mais especificamente a influência das propriedades das fases e da temperatura no comportamento da microestrutura, em termos de tensões e deformações térmicas. Outro parâmetro relevante é o tempo, envolvido nas etapas dos carregamentos térmicos e cíclicos do forjamento, que 
pode ser visto como parâmetro do processo de fabricação. Nas simulações numéricas realizadas, encontraram-se certos empecilhos em se mensurar a representação do fator tempo nos quesitos sequentes:

(i-) problema do estudo térmico feito na área microestrutural, a priori, em regime permanente:

$\mathrm{Na}$ descrição da metodologia desenvolvida para a realização do presente trabalho, podem ser destacados dois pontos importantes para a previsão das temperaturas ao longo da microestrutura de $60 \times 40 \mu \mathrm{m}^{2}$ : (a-) somente a condutividade térmica da matriz martensítica $\left(\sim 25 \mathrm{~W} \cdot \mathrm{m}^{-1} .{ }^{\circ} \mathrm{C}^{-1}\right)$ foi utilizada para estimar a diferença de temperatura entre a superfície e a aresta mais afastada desta; e (b-) $3{ }^{\circ} \mathrm{C}$ foram resultantes de um cálculo térmico, baseado na formulação de troca de calor por condução em regime permanente.

Quanto às duas considerações apresentadas, poderia ser esperado um distanciamento dos resultados obtidos por simulação numérica das condições reais. Porém, devem ser ressaltados os seguintes argumentos:

- A condutividade térmica efetiva de um material bifásico pode ser prevista por meio do equacionamento de Maxwell, destinado, por exemplo, ao cálculo da condutividade de um material, com a presença de uma matriz e uma pequena fração volumétrica de inclusões distribuídas aleatoriamente (KUMAR et al., 2011). A eq.(54) denota tal formulação adaptada de Maxwell:

$$
k_{e}=k_{m} \frac{k_{p}+2 k_{m}+2 f_{V 2}\left(k_{p}-k_{m}\right)}{k_{p}+2 k_{m}-f_{V 2}\left(k_{p}-k_{m}\right)}
$$

Onde: $k_{e}$ é a condutividade térmica efetiva do material bifásico; $k_{m}$ é a condutividade térmica da matriz martensítica; $k_{p}$ é a condutividade térmica do precipitado (carboneto de cromo); e $f_{V 2}$ é a fração volumétrica de precipitados.

Substituindo a eq.(54) com alguns dados das tabelas 7 e 8 , e com a fração volumétrica dos carbonetos de cromo, obtém-se que a condutividade térmica efetiva do material bifásico equivale a aproximadamente: 


$$
k_{e}=25\left[\frac{46+(2 \times 25)+2(0,24)(46-25)}{46+(2 \times 25)-0,24(46-25)}\right] \cong 29 \frac{W}{m^{\circ} \mathrm{C}}
$$

Para este valor de condutividade térmica efetiva, o $\Delta \mathrm{T}$ resultante da eq.(40) para atuar da superfície para o interior da ferramenta corresponde a cerca de $3{ }^{\circ} \mathrm{C}$ também. Isso mostra que a adoção da condutividade térmica da matriz a $400{ }^{\circ} \mathrm{C}$ é viável para ser considerada como base para o modelo numérico, uma vez que a fração volumétrica desta fase é predominante em relação à das partículas de segunda fase.

- Teoricamente, o fluxo de calor transferido por condução foi avaliado tendo em vista a eq.(40), que parte da premissa de regime permanente, e acarretou em uma diferença de temperatura $(\Delta \mathrm{T})$ de $3^{\circ} \mathrm{C}$ na microestrutura do aço AISI H13.

Por outro lado, na simulação numérica, a condição de transiente para a transferência de calor foi imposta no software Abaqus $^{\circledR}$, visto que a resposta da ferramenta no processo de forjamento a quente é dependente do tempo. Entretanto, possivelmente por se tratar de uma área em estudo em dimensões microestruturais, o resultado fornecido na figura 43 mostrou que a distribuição de temperatura aponta para um $\Delta \mathrm{T}$ de, aproximadamente, $3^{\circ} \mathrm{C}$ tanto na situação de aquecimento quanto na situação de resfriamento, mesmo em condições transientes de troca térmica.

Por conseguinte, há indicações que para a região da ferramenta considerada na análise, a transferência de calor na condição transiente está bem próxima da condição de regime permanente.

(ii-) dificuldades em predizer se o tempo imposto é suficiente para aquecer e/ou resfriar a microestrutura em estudo:

Uma questão que é levantada na avaliação do tempo, que define as rampas de aquecimento e de resfriamento dos ciclos térmicos no forjamento, diz respeito a quantificar as temperaturas ao término dos tempos considerados. Pensando em âmbito industrial, um tarugo é forjado e transfere calor para a ferramenta (rampa de aquecimento) e, com a retirada da peça fabricada, a ferramenta é resfriada com uma solução de grafita coloidal, por exemplo, (rampa de resfriamento). Logo após, um novo tarugo é posicionado para ser forjado em matriz aberta, sendo que 
possivelmente a ferramenta ainda não retornou a sua temperatura inicial do ciclo anterior, ganhando talvez alguns décimos de ${ }^{\circ} \mathrm{C}$ a cada ciclo térmico.

Todavia, a estimativa deste ganho de calor e do tempo que garanta a taxa de troca térmica desejada é difícil de ser examinada sem um ensaio experimental ou trabalho de campo.

Visando ao trabalho por modelamento numérico, surge, nesse momento, a importância da dinâmica da simulação para constatação dos possíveis estados transientes. Não obstante, estas simulações intermediárias exigem recursos computacionais aprimorados e os custos envolvidos na análise aumentam consideravelmente.

Nestas condições, é relatado um artifício pelos autores (SIMA; ÖZEL, 2010; LIST; SUTTER; BOUTICHE, 2012) que estudam os gradientes de temperatura em ferramentas de usinagem por meio de simulação numérica. Aumenta-se o valor da condutância térmica no contato peça-ferramenta a fim de facilitar a convergência do modelo numérico, no que se refere ao estudo do efeito da variação de temperatura em pequenos incrementos de tempo, por se tratar frequentemente de análises por integração explícita. Desse modo, a condutância térmica em questão é manipulada, realizando-se testes por tentativa e erro com o intuito de calibrar o modelo numérico e torná-lo apto a representar o efeito de transientes no decorrer do material da ferramenta. A condutância térmica é trabalhada, na literatura, variando na ordem de $10^{3}$ a $10^{6} \mathrm{~kW}\left(\mathrm{~m}^{-2} \mathrm{~K}^{-1}\right)$ até o ponto em que os resultados numéricos de temperatura na ferramenta de usinagem venham a se aproximar de medidas obtidas experimentalmente.

O recurso de aumentar o valor da condutância térmica no contato peçaferramenta possibilita o rápido aumento da temperatura da ferramenta, uma vez que provoca o aumento do fluxo de calor transferido por condução da peça para a ferramenta, e objetiva economizar custos computacionais e facilitar a análise dinâmica do processo de fabricação.

(iii-) adoção do procedimento de análise implícita ao invés da explícita:

A abordagem implícita (Abaqus/Standard ${ }^{\circledR}$ ) foi selecionada neste trabalho de mestrado porque se considerou a condição de quase-estática para a ferramenta de forjamento a quente. O equipamento previsto para a movimentação de tal ferramenta foi uma prensa hidráulica, que não resulta em impactos como é o caso 
do martelo de queda. Contudo, este tipo de análise apresenta problemas de convergência no quesito da variação contínua no tempo do campo de tensões, por exemplo, e perdem-se informações intermediárias (em tempos relativamente curtos) das distribuições de tensões no material em estudo.

Do outro lado, tem-se a análise explícita que permite atingir a convergência dos resultados, a partir da solução das matrizes de rigidez sem a ocorrência de interações a cada passo de integração no tempo. Esta abordagem necessita, então, para a sua execução de pequenos incrementos de tempo (FLAUSINO, 2010). Nesse caso, consegue-se obter as informações temporais e intermediárias do mapeamento de tensões na microestrutura. No entanto, o tempo computacional é excessivamente elevado.

Os cenários fornecidos levam a concluir que a escolha do procedimento a ser adotado na análise depende do nível de detalhamento que se deseja obter nos resultados, e salienta a relevância do fator tempo computacional que, por sua vez, é superior ao tempo real.

\subsection{DIFICULDADES NA PRÉ-DEFINIÇÃO DO NÚMERO DE CICLOS A SEREM SIMULADOS NUMERICAMENTE}

A princípio, a ideia envolvida na definição do número de ciclos térmicos consistia em simular ciclos até que fosse possível a visualização do escoamento inicial em algumas regiões da matriz martensítica (início do dano). Entretanto, devido ao custo computacional envolvido com o emprego desta metodologia, optou-se por parar as simulações no décimo ciclo, mesmo sem a verificação significativa de alterações no campo de deformações plásticas da matriz. A continuidade da simulação numérica dos ciclos, provavelmente, possibilitaria prever, de modo aprimorado, as áreas de deformação plástica localizada na matriz, representativas do início de dano por fadiga de baixo ciclo (como é o caso da fadiga térmica).

No quesito da determinação do número de ciclos térmicos a serem simulados numericamente, podem ser citados como fatores agravantes: 
(i-) O fato da área de estudo ser muito pequena implica em condições de contorno e de carregamento proporcionais, ou seja, relativamente pequenos. O desafio, nesse caso, consistiu em transportar as condições macroscópicas do processo e associálas aos componentes microestruturais;

(ii-) O modelo reproduziu apenas respostas no campo de deformação no regime elástico, após os 10 ciclos térmicos, conforme visto na figura 46. Em tal situação, o resultado mais importante que se obtém é o campo de tensões, capaz de mostrar que as partículas de segunda fase e as interfaces matriz-carboneto atuam como concentradores de tensões e facilitadores para as trincas térmicas (figuras 44 e 45 ).

Como alternativa para atingir uma maior proximidade dos resultados do modelo numérico às condições reais, e em contrapartida visar à economia do custo computacional por meio da aceleração das simulações numéricas, os seguintes pontos foram avaliados:

- Primeiro ponto: a deformação plástica, que vem a denotar o início do dano na ferramenta, ocorre em regiões microlocalizadas;

- Segundo ponto: conforme retratado no estudo de Sjöström (2004), verifica-se a existência de picos de temperatura (hot spots), equivalentes a $600^{\circ} \mathrm{C}$, no material da ferramenta.

Unindo ambas as informações, que se complementam, pode-se supor a hipótese de $600{ }^{\circ} \mathrm{C}$ na superfície da ferramenta, mantendo as demais condições prédeterminadas, para atingir a tensão de escoamento da matriz martensítica. A simulação numérica com esta consideração parte do princípio que a área microestrutural de $60 \times 40 \mu \mathrm{m}^{2}$ tende a reproduzir a região de deformações microlocalizadas do material macroscópico. Esse recurso pode ser entendido também como o aumento da condutância térmica no contato peça-ferramenta, aplicado em usinagem, para acelerar 0 processo de análise das variações de temperatura na ferramenta.

Os campos de tensão e de deformação plástica, resultantes da simulação da superfície da ferramenta a $600^{\circ} \mathrm{C}$, são expostos na figura 47 . 
(a-)
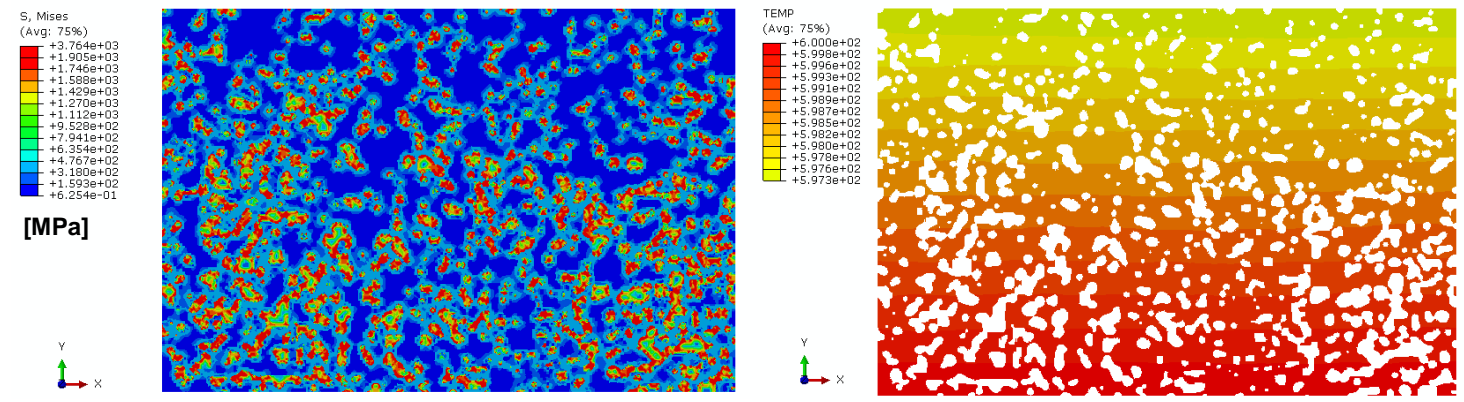

(b-)
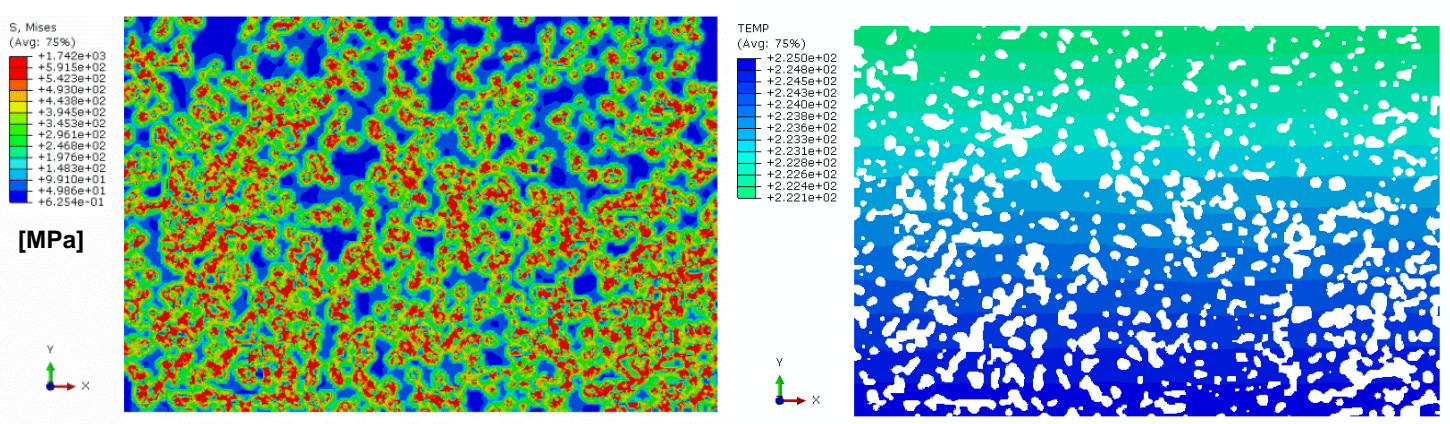

(c-)
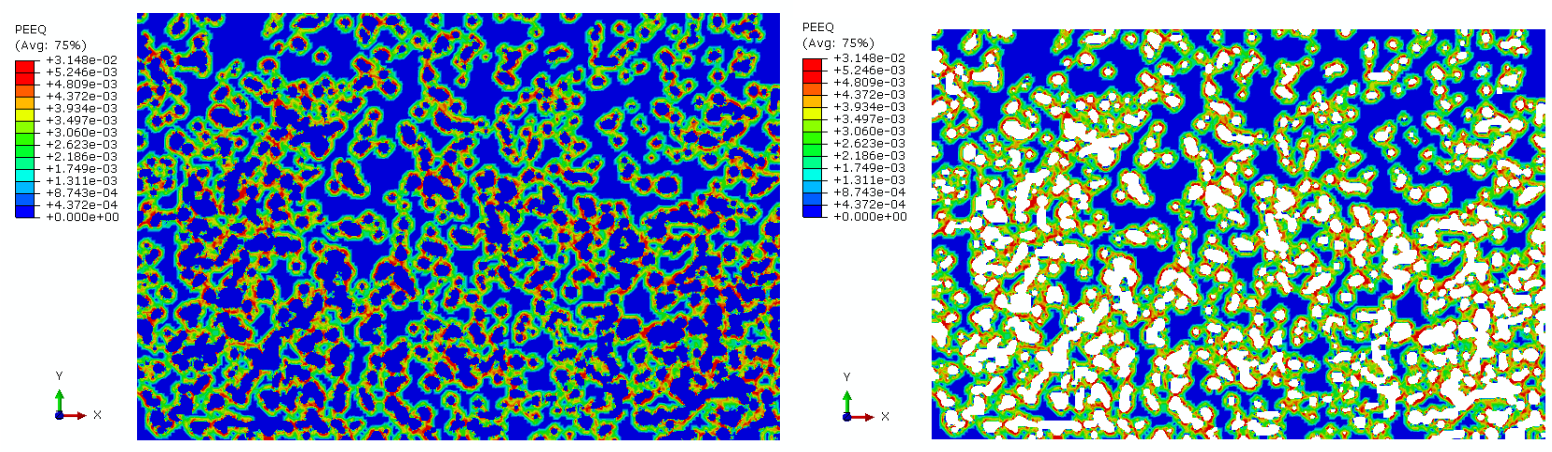

Figura 47 - Tensões de von Mises $[\mathrm{MPa}]$ e temperatura $\left[{ }^{\circ} \mathrm{C}\right]$ na microestrutura da ferramenta após: (a-) o aquecimento até $600{ }^{\circ} \mathrm{C}$; e (b-) o resfriamento até $225^{\circ} \mathrm{C}$. Em (c-), tem-se a deformação plástica obtida como resultado na microestrutura do aço $\mathrm{H} 13$ ao atingir a temperatura de $600^{\circ} \mathrm{C}$. 
Os resultados apresentados na figura 47 evidenciam a comprovação da hipótese feita. Nas figuras $47 \mathrm{a}$ e $\mathrm{b}$, as tensões obtidas novamente mostram as regiões críticas como sendo os carbonetos de cromo e as interfaces. Estas distribuições de tensões, ao serem comparadas com as figuras $45 a$ e b, mostram maiores valores de tensões de von Mises em virtude das maiores temperaturas de operação impostas à microestrutura. Em adição, na figura 47c, nota-se que as deformações plásticas se manifestam nas citadas interfaces matriz-precipitado e indicam que o acúmulo de dano devido aos carregamentos cíclicos da ferramenta, possivelmente, venha a se concentrar nestas regiões críticas. Isto vai de encontro aos estudos com ênfase experimental de Serantoni Silva (2003) e Silva (2006).

(iii-) Há diferença no número de ciclos para a ocorrência da nucleação do dano por fadiga térmica, dependendo de o material atingir ou não a tensão de escoamento. Segundo a curva $\varepsilon \times N$ (deformação versus número de ciclos para a fadiga), quando o material se deforma elasticamente verifica-se a fadiga de alto ciclo, com um número de ciclos na ordem de $10^{6}$ antes do início do dano; sob outro ângulo, quando o material atinge o regime plástico, tem-se a fadiga de baixo ciclo, sendo que a deformação age de modo a reduzir significativamente o número de ciclos para o aparecimento de dano por fadiga nesse material. (MEYERS; CHAWLA, 2009)

Desse modo, a diferença entre os resultados obtidos a partir da temperatura da superfície a $400{ }^{\circ} \mathrm{C}$ e a $600{ }^{\circ} \mathrm{C}$ é explicada: a microestrutura se deformou apenas elasticamente a $400{ }^{\circ} \mathrm{C}$ em 10 ciclos (figura 46); e a matriz martensítica começou a exibir deformações plásticas a $600{ }^{\circ} \mathrm{C}$ nos mesmos 10 ciclos térmicos (figura $47 \mathrm{c}$ ).

Portanto, é necessário fazer um balanceamento entre as condições macroscópicas da ferramenta durante o processo de forjamento e o alto custo computacional envolvido para a verificação da ocorrência de tensões residuais e pontos de encruamento na microestrutura. A aplicação das condições macroscópicas deve ser feita com cautela e com as devidas considerações na área microestrutural. O fato do número de ciclos para a nucleação do dano ser elevado exige, em muitos casos, o uso de artifícios na simulação numérica, mas cuidados são necessários porque o efeito do aumento da temperatura, em se tratando de microestrutura, pode provocar transformações de fases no material, que não serão previstas de forma direta pelo software. 
(iv-) Há limitações no software de elementos finitos em se trabalhar com dimensões e aspectos microscópicos do material, que influenciam os ciclos para a fadiga: podem ser relatadas algumas restrições, neste quesito, no que se refere à inclusão direta dos efeitos micro ou nanoestruturais que podem vir a descrever o dano como, por exemplo, a inserção de defeitos na forma de bandas de deformação. (MEYERS; CHAWLA, 2009; SERANTONI SILVA, 2003)

Aqui, vale ser comentado e reforçado que o resultado oriundo do software e foco dessa pesquisa se trata de um mapeamento que indica as prováveis regiões críticas para a nucleação de fadiga térmica. A inclusão dos defeitos na microestrutura e outros mecanismos e fenômenos com outros graus de complexidade não se encontram no escopo deste trabalho (exemplo: o deslizamento de discordâncias com o surgimento de extrusões e intrusões não é reproduzido no modelo numérico).

\subsection{COMPARAÇÃO DO MODELO NUMÉRICO COM A TEORIA}

Os resultados das tensões térmicas obtidos nos precipitados foram comparados com certas formulações encontradas na literatura, visando à investigação da influência dos parâmetros: tamanho e distribuição dessas partículas de segunda fase nos campos de tensão, atuantes na microestrutura do aço AISI H13.

(i-) Microtensões nos precipitados admitidos com morfologia regular: (WERONSKI; HEJWOWSKI, 1991)

Para o cálculo das microtensões, segundo a eq.(52), foram selecionadas regiões da microestrutura do $\mathrm{H} 13$ que possuíam carbonetos de cromo passíveis da aproximação de morfologia circular. Objetivando possibilitar a comparação entre as microtensões analíticas e as numéricas, calculadas pelo critério da tensão normal máxima, atuantes na superfície dos precipitados, dez destes foram considerados como amostras de acordo com a indicação da figura 48. Para a substituição dos valores do tamanho e da distância entre as partículas de segunda fase, 
selecionaram-se precipitados com similaridade à morfologia circular e aos pares para a medição das distâncias.

A título de refinar ainda mais a análise de cada par de carbonetos mostrados na figura 48, foi feita a designação com o índice (a) para o precipitado com maior grau de regularidade de superfície e índice (b) para o precipitado de morfologia menos regular.

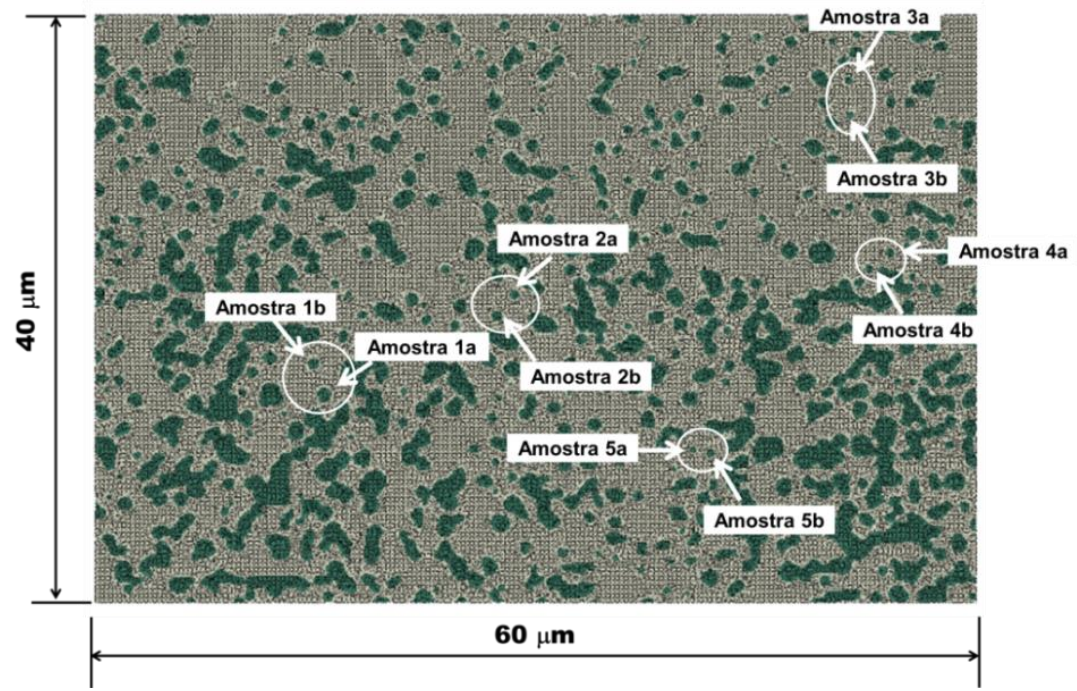

Figura 48 - Localização das amostras de precipitados da microestrutura do aço $\mathrm{H} 13$, com área de $60 \times 40 \mu \mathrm{m}^{2}$, nas quais foram feitas as análises de microtensões.

A comparação das microtensões teóricas, previstas com base na eq.(52) reportada em Weronski e Hejwowski (1991), e as tensões resultantes da aplicação do MEF são dispostas na tabela 14 para os carbonetos $M_{23} C_{6}$, que foram especificados na figura 48.

Tabela 14 - Comparação entre as microtensões teóricas e simuladas por MEF em alguns carbonetos de cromo da microestrutura do aço AISI H13.

\begin{tabular}{|c|c|c|c|c|c|c|}
\hline Amostra & $\begin{array}{c}\mathrm{R}_{1}[\mu \mathrm{m}] \\
\text { (raio do } \\
\text { precipitado) }\end{array}$ & $\begin{array}{c}\mathrm{R}_{2}[\mu \mathrm{m}] \\
\text { (distância entre } \\
\text { os precipitados) }\end{array}$ & $\begin{array}{c}\mathrm{d} \\
\text { (razão } \\
\mathrm{R}_{1} / \mathrm{R}_{2} \text { ) }\end{array}$ & $\begin{array}{c}\mathrm{P}[\mathrm{MPa}] \\
\text { (microtensão } \\
\text { teórica) }\end{array}$ & $\begin{array}{c}\text { Tensão } \\
\text { Máxima } \\
\text { Principal } \\
\text { [MPa] } \\
\text { (simulação) }\end{array}$ & $\begin{array}{c}\text { Diferença entre o } \\
\text { resultado obtido da } \\
\text { simulação numérica e o } \\
\text { resultado teórico [\%]-em } \\
\text { módulo }\end{array}$ \\
\hline $1 a$ & 0,47 & 1,35 & 0,35 & 281 & 277 & 1,4 \\
\hline $2 a$ & 0,32 & 1,17 & 0,27 & 289 & 269 & 6,9 \\
\hline $3 a$ & 0,24 & 1,91 & 0,13 & 295 & 297 & 0,7 \\
\hline $4 a$ & 0,27 & 1,15 & 0,23 & 291 & 263 & 9,6 \\
\hline $5 a$ & 0,19 & 0,72 & 0,26 & 289 & 252 & 12,8 \\
\hline $1 \mathrm{~b}$ & 0,38 & 1,35 & 0,28 & 288 & 192 & 33,2 \\
\hline $2 \mathrm{~b}$ & 0,36 & 1,17 & 0,31 & 286 & 198 & 30,8 \\
\hline $3 b$ & 0,25 & 1,91 & 0,13 & 295 & 224 & 24,1 \\
\hline $4 b$ & 0,25 & 1,15 & 0,22 & 292 & 260 & 11,0 \\
\hline $5 b$ & 0,25 & 0,72 & 0,35 & 281 & 225 & 20,0 \\
\hline
\end{tabular}


Verifica-se, com o auxílio da tabela 14, que as amostras de precipitados com as melhores aproximações de morfologia circular fornecem resultados de tensão máxima principal, obtidos por simulação numérica, mais próximas aos resultados teóricos com uma diferença percentual inferior a $13 \%$. Tal fato se torna, portanto, um indicativo da validação do modelo numérico com condições térmicas na microestrutura do aço ferramenta.

Pode-se justificar, ainda, que as diferenças percentuais dos resultados do modelo numérico em relação aos teóricos se devem ao fato: (a-) da simplicação da morfologia dos carbonetos como circulares; e (b-) dos valores da tensão máxima principal da tabela 14 serem tomadas como valores médios das tensões resultantes nas superfícies dos carbonetos em questão.

(ii-) Levantamento da questão das distintas tensões resultantes em um mesmo precipitado:

Visto que a eq.(52) é um modelo simplificado, que tem como base a premissa dos precipitados admitidos como regulares, à medida que se considera uma amostra de precipitados reais com morfologias variáveis, os resultados numéricos das microtensões obrigatoriamente se tornam mais distantes do valor resultante da teoria relatada por Weronski e Hejwowski (1991). Uma possível solução na tentativa de correlacionar os citados precipitados reais com a teoria seria o emprego, nesta formulação teórica, de um fator de forma que englobasse o efeito do fator intensificador de tensões $\left(\mathrm{K}_{\mathrm{t}}\right)$. A partir da adoção desses novos parâmetros em um modelo teórico, as partículas de segunda fase apresentariam diferentes valores de microtensões em sua superfície (DIETER, 1988; DOWLING, 2006), como é reproduzido pelo modelo de elementos finitos elaborado neste trabalho de mestrado.

Assim, os concentradores de tensão, que favorecem a nucleação das trincas térmicas, poderiam ser estimados e confrontados visando correlacionar a simulação à teoria com uma maior acurácia. Alguns exemplos de resultados fornecidos pelo modelo numérico que mostram a influência do fator de forma na dispersão dos valores de tensão máxima principal, na superfície de carbonetos aleatórios, são mostrados no gráfico da figura 49. 

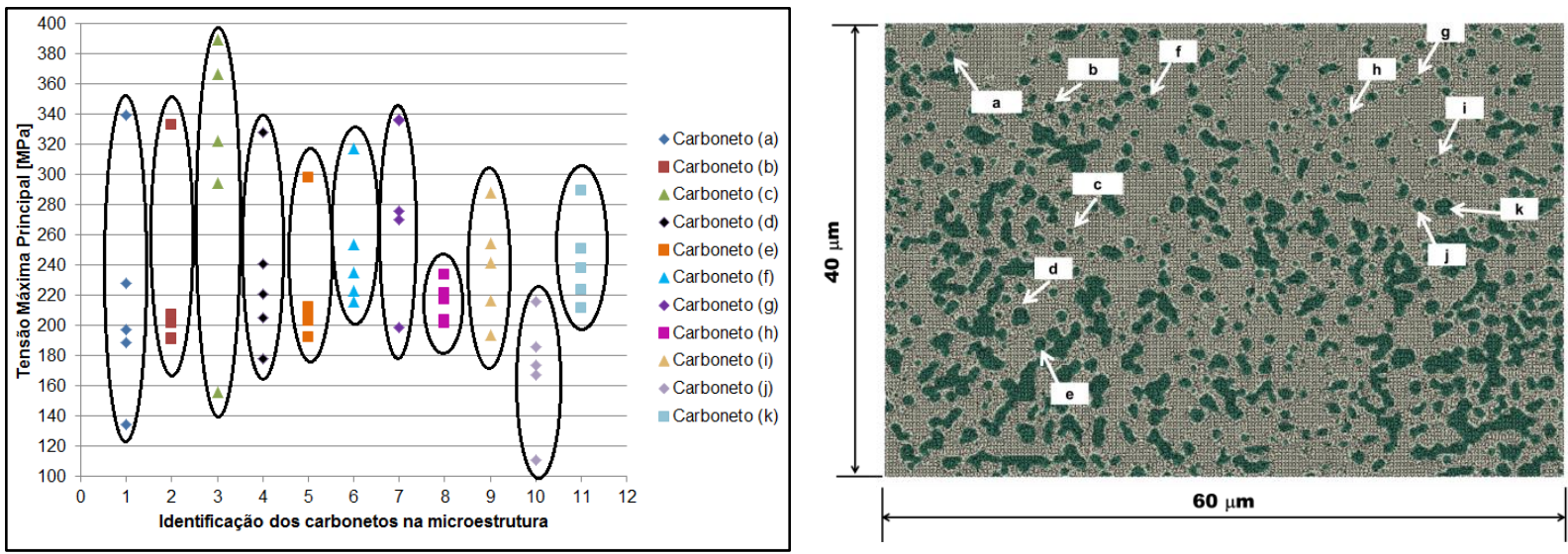

Figura 49 - Variação da tensão máxima principal na superfície de onze precipitados do aço AISI H13.

(iii-) Comparação com certos parâmetros relatados no trabalho de Serantoni Silva (2003):

Partindo-se da hipótese que o maior valor da tensão é tido como representativo da região crítica, do ponto de vista de concentrador de tensão, seleciona-se este valor para prosseguimento na abordagem qualitativa, direcionada aos efeitos do tamanho dos precipitados na nucleação de trincas por fadiga térmica no aço ferramenta AISI H13. Com o auxílio do software ImageJ ${ }^{\circledR}$, identifica-se automaticamente cada carboneto da microestrutura por meio de numeração crescente e, a partir da conversão de pixels para unidade de área $\left(\mu \mathrm{m}^{2}\right)$, dimensiona-se a área ocupada por um dado carboneto na microestrutura. Tendo em vista a obtenção destas áreas, é possível considerar, de modo simplificado, tal fator como o parâmetro de continuidade das partículas de segunda fase (C) sugerido na pesquisa de Serantoni Silva (2003), que realizou a comparação entre diferentes microestruturas de ferros fundidos brancos multicomponentes.

Nota-se, então, por meio da representação gráfica da figura 50, que uma maior continuidade (ou tamanho) de carboneto apresenta a tendência de aumentar os valores das microtensões máximas. Nesta suposição, parte-se da consideração de uma distância média $\left(D_{m}\right)$ constante entre os carbonetos de cromo distribuídos ao longo da microestrutura em estudo. Além disso, este resultado, originado da simulação numérica por MEF, vem a reforçar a atuação dos precipitados como concentradores de tensões, tornando as regiões de precipitados grandes como agravantes em propiciar a nucleação das trincas térmicas. 

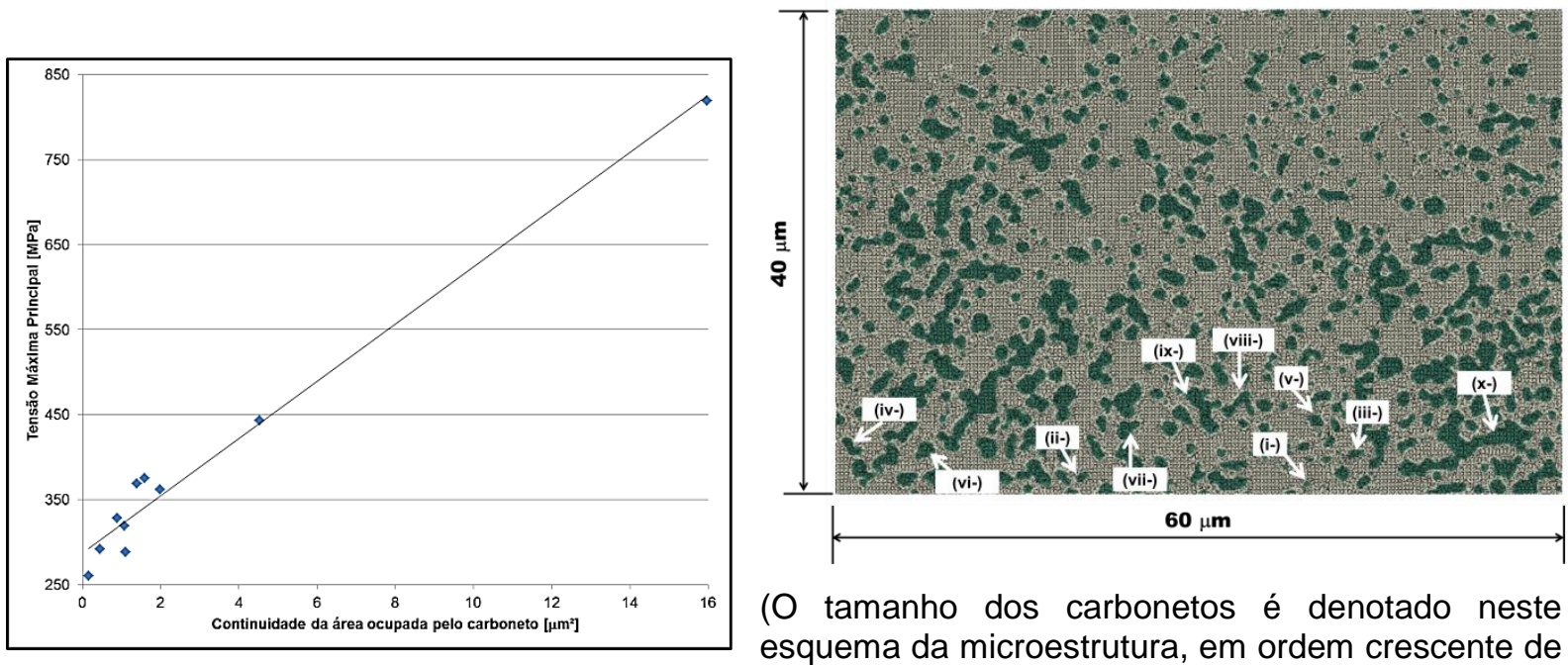

(O tamanho dos carbonetos é denotado neste esquema da microestrutura, em ordem crescente de numeração romana).

Figura 50- Resposta da tensão máxima principal com a variação da continuidade do carboneto.

Vale lembrar que o estudo de Serantoni Silva (2003), destinado ao entendimento da propagação de trincas térmicas, concluiu que o aumento do parâmetro continuidade entre os carbonetos, mantendo-se uma distância média entre eles (razão $C / D_{m}$ ), acarreta em uma maior taxa de propagação de trincas. Ao que indica a figura 50, o mesmo ocorre com a nucleação das trincas térmicas aqui estudada.

Na metodologia adotada para fins de comparação do trabalho aqui relatado com a análise de Serantoni Silva (2003), merecem ser destacados, ainda, dois aspectos: (a-) a distância média entre os precipitados não foi determinada, uma vez que somente faria sentido realizar a comparação deste parâmetro em microestruturas diferentes do mesmo aço ferramenta. Possivelmente, uma adaptação de $D_{m}$ poderia ser tomada, considerando-se a distância entre dois precipitados como, por exemplo, ocorre com o parâmetro $R_{2}$ da eq.(60). Contudo, a escolha do par de precipitados é totalmente aleatória, visto que existem vários vizinhos que podem ser considerados para um designado precipitado e, dessa maneira, alguns erros podem estar incorporados na análise; e (b-) observa-se, na figura 50, que as partículas de segunda fase analisadas são retiradas de uma certa região selecionada, especificamente com uma proximidade boa da superfície da ferramenta. Justifica-se esta abordagem com a finalidade de minimizar a interferência da variação da temperatura, disposta na figura 43, que tem influência no campo de tensões, embora seja minoritária quando comparada ao módulo de elasticidade das fases. 


\subsection{IMPLICAÇÕES DA EXISTÊNCIA DE CARREGAMENTOS MECÂNICOS NA MICROESTRUTURA DA FERRAMENTA DE FORJAMENTO A QUENTE}

A análise da microestrutura da ferramenta de forjar a quente com a inclusão dos efeitos do carregamento mecânico em conjunto com o térmico foi considerada, neste trabalho, do ponto de vista qualitativo. Devido ao tempo computacional consumido, foi simulado por elementos finitos um segundo de aplicação da carga mecânica com amplitude variável (RODRIGUES; MARTINS, 2010) e aquecimento da região até a temperatura máxima de $400{ }^{\circ} \mathrm{C}$ perdurando neste tempo. Os resultados obtidos, que podem ser tidos como preliminares, são expostos na figura 51 em forma de evoluções do campo de tensões da microestrutura durante o tempo considerado.

(a-) 0,058 segundo:

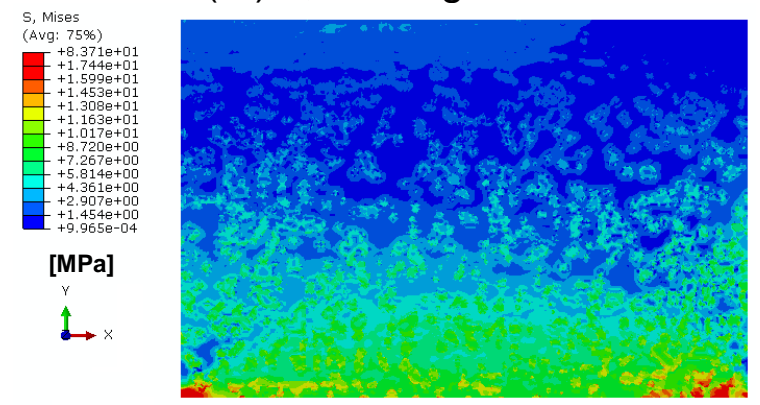

(c-) 0,216 segundo:
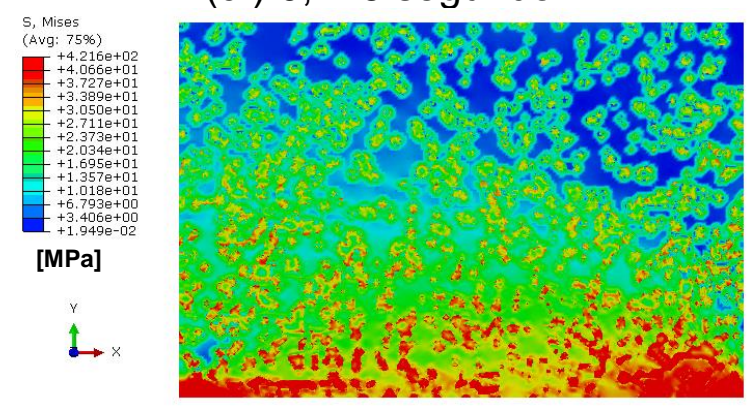

(b-) 0,110 segundo:
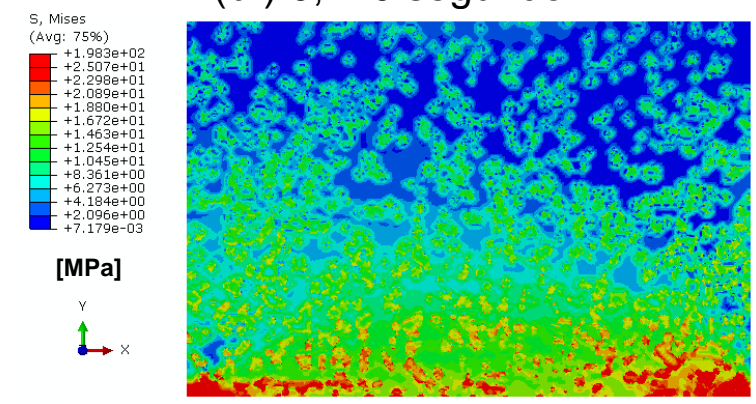

(d-) 0,425 segundo:
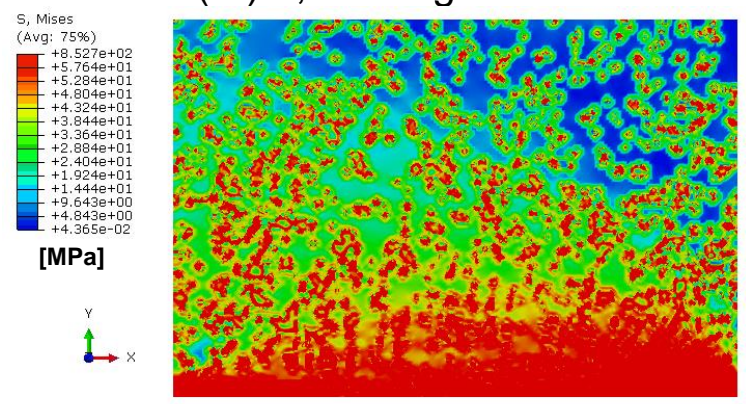

(e-) 1,0 segundo:

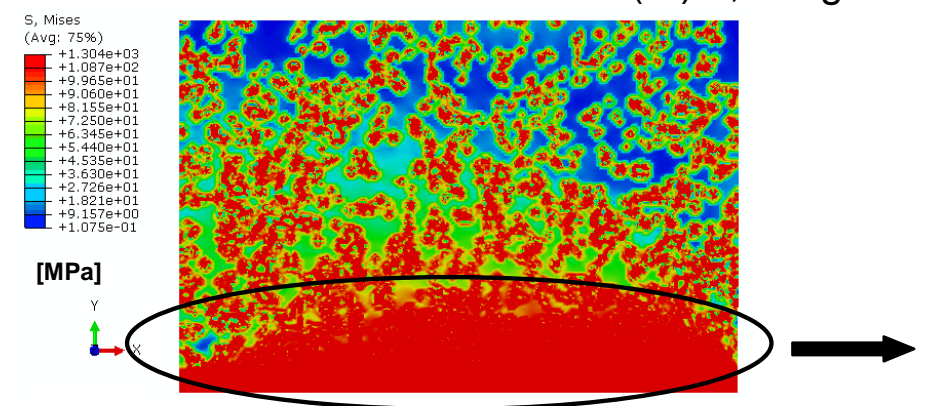
Detalhe das tensões na superfície da
ferramenta após 1 segundo. Os
precipitados continuam a atuar como
regiões concentradoras de tensão:

Figura 51 - Evolução no comportamento de tensões de von Mises [MPa] na microestrutura do aço ferramenta AISI H13, decorrente $1 \mathrm{~s}$ de aquecimento em paralelo com a aplicação de carregamento mecânico. 
Com o suporte fornecido pela figura 51 , podem ser explanados os seguintes tópicos como comentários gerais a respeito das modificações nos campos de tensões da microestrutura da ferramenta, a partir da realização do procedimento termomecânico, e outros fatores relevantes deste procedimento:

- Os carbonetos de cromo e as interfaces matriz-precipitado continuam a atuar como regiões concentradoras de tensões, sendo, portanto, apontados como pontos críticos que favorecem a nucleação de trincas por fadiga térmica;

- Ao contrário dos resultados atingidos pelo emprego do procedimento térmico, se torna nítido na abordagem termomecânica que as tensões na superfície da ferramenta são muito superiores às tensões nas áreas mais afastadas;

- A soma dos efeitos térmicos e mecânicos para o cálculo das tensões têm em conta não somente os carregamentos considerados como entradas no modelo numérico, mas também: (i-) o atrito no contato das superfícies da ferramenta e da peça conformada que gera calor, provocando o aumento das tensões térmicas na microestrutura da ferramenta que recebe $50 \%$ desse calor (padrão do software de $\mathrm{MEF}$ ); e (ii-) a deformação plástica do material conformado, cuja porcentagem de $90 \%$ é convertida em calor no sistema e distribuída em parcelas iguais à ferramenta e à peça. Em virtude desse ganho considerável de calor da ferramenta, além da aplicação dos carregamentos mecânicos, nota-se na figura 51e que a superfície desta é preenchida totalmente pela coloração vermelha, que representa os elevados valores de tensão;

- A simulação numérica prolongou-se porque a convergência foi dificultada devido à grande deformação plástica na superfície da peça. Como sugestões de melhoria nesse caso, podem ser mencionados o estudo e a aplicação das técnicas de remalhamento e utilização de malhas adaptativas para os elementos discretizados da superfície da peça; 
- A adoção do modelo de Johnson-Cook, que é destinado comumente a problemas que envolvem altas taxas de deformação (DUAN et al., 2009), parece ser viável para reproduzir condições envolvidas no forjamento a quente. Tendo em vista a velocidade da prensa hidráulica de $50 \mathrm{~mm} / \mathrm{s}$, e a área da superfície da peça de $60 \times 1 \mu \mathrm{m}^{2}$, obtém-se uma estimativa para a taxa de deformação da peça na ordem de $10^{3} \mathrm{~s}^{-1}$. Contudo, para a execução de tal análise de um modelo com carregamento da ferramenta ditado em termos de velocidade, o mais indicado seria fazer uso do procedimento de integração explícita no tempo que necessita de incrementos de tempo muito pequenos. 


\section{CONCLUSÕES}

Os resultados obtidos permitem concluir, de forma geral, que a metodologia de análise utilizada para o desenvolvimento do modelo numérico, com procedimentos térmico e termomecânico, possibilitou analisar as tensões e as deformações na microestrutura do aço AISI H13. Verificou-se que as interfaces e os precipitados atuam como concentradores de tensões, o que coincide com trabalhos da literatura (SERANTONI SILVA, 2003; SILVA, 2006). O modelo numérico elaborado tem em conta inclusive o efeito da morfologia e da distribuição das partículas de segunda fase na resposta microestrutural. Desse modo, é salientada a importância de englobar o fator de forma em modelos analíticos.

As conclusões específicas deste trabalho são:

> na distribuição de tensões, constata-se que os carbonetos de cromo têm o papel de concentradores de tensões na microestrutura. A propriedade das fases de maior influência nos resultados dos campos de tensão é o módulo de elasticidade, sendo este valor muito superior nos carbonetos quando comparado à matriz martensítica. Essa afirmação é verdadeira desde que exista uma diferença, mesmo que mínima, nos valores dos coeficientes de expansão térmica das fases;

$>\quad$ em termos de tensões, a condição térmica mais crítica para os precipitados é o aquecimento em vista das propriedades elásticas atribuídas ao mesmo, e também da maior diferença nos módulos de elasticidade e coeficientes de expansão térmica deste precipitado e da matriz ao atingir a temperatura máxima do ciclo. Já para a matriz martensítica, a condição mais crítica é decorrente do resfriamento da microestrutura devido ao comportamento elástico e perfeitamente plástico designado para esta fase. As tensões resultantes do aquecimento aumentam a cada ciclo a probabilidade de ocorrência da matriz atingir o regime plástico;

$>\quad$ verificou-se o aumento das tensões nas fases no decorrer dos ciclos térmicos, na ordem do milésimo, sendo tal fato considerado como parâmetro indicativo de dano acumulado devido à aplicação de carregamentos térmicos cíclicos; 
$>$ a diferença entre os coeficientes de expansão térmica da matriz e dos precipitados resulta no aparecimento de tensões compressivas nas interfaces matriz-precipitado, designadas pela tensão de Rankine;

$>$ as deformações elásticas apresentam seus maiores valores nas interfaces em virtude dos coeficientes de expansão térmica das fases. Isto se deve às deformações nos carbonetos serem maiores do que na matriz;

a representação da temperatura imposta no ciclo térmico é ressaltada no campo de deformações: a passagem da etapa de pós-aquecimento para o momento posterior ao resfriamento acarreta na redução da deformação nas interfaces em uma ordem de grandeza;

> as amostras de precipitados com boas aproximações de morfologia regular (circular) fornecem resultados de tensão máxima principal (simulação) próximos aos resultados de microtensões calculados pela teoria relatada por Weronski e Hejwowski (1991), indicando a validação do modelo numérico com condições térmicas na microestrutura. À medida que se considera uma amostra de partículas de segunda fase reais com morfologias variáveis, os resultados obtidos por simulação numérica no campo de tensões se tornam mais distantes da teoria;

> quanto maior a continuidade da área ocupada pela partícula de segunda fase (C), maiores são os valores correspondentes de microtensões máximas e, por conseguinte, mais susceptivel à nucleação de trincas a partir da presença de concentradores de tensões;

$>$ apesar dos resultados do procedimento termomecânico serem tomados como preliminares, foram possíveis, neste caso, as respectivas verificações: (a-) tanto as partículas de segunda fase quanto as interfaces matriz-precipitado continuam sendo concentradores de tensões, que podem vir a favorecer a nucleação de trincas por fadiga; e (ii-) no sistema tribológico em estudo, as inclusões dos carregamentos mecânicos, do atrito e do forjado com propriedades de plasticidade geraram um 
maior gradiente de tensões neste procedimento quando comparado ao procedimento térmico. 


\section{TRABALHOS FUTUROS}

A título de considerações para a continuidade do trabalho discorrido, enumeram-se como sugestões as propostas de trabalhos futuros que se seguem:

> desenvolver um modelo numérico da microestrutura da ferramenta em 3-D. Neste aspecto, cabe o comentário do cuidado a ser tomado com as adaptações das condições macroscópicas para o nível microestrutural, sendo que confrontar as regiões críticas, no campo de tensões, da ferramenta (macro) com as simplificações de sua superfície (micro) se torna um bom ponto de partida;

> incluir, nas considerações da simulação numérica por MEF da microestrutura da ferramenta, um modelo de dano para a nucleação e propagação do dano por fadiga térmica. No decorrer dos ciclos térmicos impostos pelo forjamento a quente, podem-se encontrar diferentes caminhos possíveis para a propagação da trinca por fadiga, tais como: interfaces matriz-precipitado; interior das partículas de segunda fase (fratura frágil); e ao longo da matriz, dependendo da distribuição dos concentradores de tensão, nos quais se têm caminhos que favorecem as referidas nucleação e propagação de trincas;

> estudar os detalhes $\mathrm{e}$ as alternativas que possibilitem abranger a melhor relação entre tempo do processo de fabricação e tempo computacional, e englobem a dinâmica do processo em questão, tendo o foco a princípio direcionado, por exemplo, às análises por integrações implícita e explícita no tempo;

> a partir da devida abordagem que envolve o fator tempo, pode ser iniciado o aprofundamento das análises de carregamentos mecânicos na microestrutura da ferramenta. Neste âmbito, insere-se também a inclusão da análise de fadiga mecânica, e dos desgastes abrasivo e por deslizamento na superfície da ferramenta, partindo-se, por exemplo, da equação de Archard e sub-rotinas a serem implementadas no software Abaqus ${ }^{\circledR}$. 


\section{REFERÊNCIAS}

ABACHI, S.; AKKÖK, M.; GÖKLER, M. I. Wear analysis of hot forging dies. Tribology International, v.43, n.1-2, p. 467-473, Jan-Feb. 2010.

AFAZOV, S. M.; RATCHEV, S. M.; SEGAL, J. Prediction and experimental validation of micro-milling cutting forces of AISI H13 steel at hardness between 35 and 60 HRC. The International Journal Advanced Manufacturing Technology, v.62, n.9-12, p.887-899, Oct.2012.

AGARWAL, R. B. ME160, SEC01 - Introduction to finite element method. Greensheet, San Jose State University, Spring 2012. Disponível em:

$<$ http://www.engr.sjsu.edu/ragarwal/ME273/pdf/Chapter_1_-_Introduction.pdf>.

Acesso em: 01 nov. 2012.

ALTAN, T. Forging equipment, materials and practices. Metals and Ceramics Information Center (MClC-HB-3), 1973. 496p.

ALVARENGA JÚNIOR, A. Avaliação experimental dos efeitos da fadiga térmica nas propriedades mecânicas de um aço inoxidável austenítico. 2006. 145p. Tese (Doutorado). Universidade Federal de Minas Gerais, Belo Horizonte, 2006.

ARCHARD, J. F. Contact and rubbing of flat surfaces. Journal of Applied Physics, v.24, n.8, p. 981-988, Aug. 1953.

ASM INTERNATIONAL. ASM handbook: friction, lubrication and wear technology. 2. ed. Estados Unidos da América: ASM International, 1995. v. 18. 1879p.

ASM INTERNATIONAL. ASM Handbook - metallography and microstructures. 2.ed. Estados Unidos da América: ASM International, 2004. v.9. 2733p.

ASM INTERNATIONAL. ASM handbook - metalworking: bulk forming. 1. ed. Estados Unidos da América: ASM International, 2005a. v.14A. 816p.

ASM INTERNATIONAL. ASM Handbook - properties and selection: irons, steels, and high performance alloys. Estados Unidos da América: ASM International, 2005b. v.1. $2521 \mathrm{p}$.

AVNER, S. H. Introduction to physical metallurgy. 2. ed. McGraw-Hill International Editions, 1974. 696p.

BABU, S.; RIBEIRO, D.; SHIVPURI, R. Material and surface engineering for precision forging dies. Ohio. Aerospace Institute and National Center for Manufacturing Sciences, 1999. 146p.

BARRAU, O.; VERGNE, C.; BOHER, C.; REZAI-ARIA, F. E; GRAS, R. Investigations of friction and wear mechanisms of hot forging tool steels. In: 
International Tooling Conference, 6., 2002, Karlstad (Suécia). Proceedings of the $6^{\text {th }}$ International Tooling Conference. Karlstad, 2002, p. 95-111.

BATHE, K. J. Finite element procedures. New Jersey: Prentice Hall, 1996. 1036p.

BAUCCIO, M. ASM engineered materials reference book, 2. ed. ASM International, Materials Park, $\mathrm{OH}, 1994.580 \mathrm{p}$.

BEDDOES, J.; BIBBY; M. J. Principles of metal manufacturing processes. Canadá: Butterworth-Heinemann, 1999. 326 p.

BEHRENS, B.A.; BOUGUECHA, A.; RAEDT, H. W.; HADIFI, T. Numerical investigations on the fatigue failure of forging tools due to thermo-mechanical cyclic loading. International Journal of Material Forming, v.3, n.1, p. 339-342, 2010.

BEHRENS, B.A.; SCHÄFER, F.; HUNDERTMARK, A.; BOUGUECHA, A. Numerical analysis of tool failure in hot forging processes. In: International Scientific and Technical Conference "Design and Technology of Drawpieces and Die Stampings", 17., Poznan-Wasowo. Proceedings of the $17^{\text {th }}$ International Scientific and Technical Conference "Design and Technology of Drawpieces and Die Stampings". PoznanWasowo: Sept. 2008, p. 163-175.

BERNHART, G.; MOULINIER, G.; BRUCELLE, O.; DELAGNES, D. High temperature low cycle fatigue behaviour of a martensitic forging tool steel. International Journal of Fatigue, v.21, p. 179-186, 1999.

BLANCH, L. G. Two-dimensional modeling of steady state heat transfer in solids with use of spreadsheet (MS EXCEL), 2011. 74p. Tese (Mestrado) - Faculty of Mechanical Engineering and Computer Science of University of Bielsko- Biała, Bielsko-Biała (Poland), 2011.

CALLISTER JÚNIOR, W. D. Materials science and engineering: an introduction. 7. ed. EUA: John Wiley \& Sons, 2007. 122p.

CALISKANOGLU, D.; SILLER, I.; EBNER, R.; LEITNER, H.; JEGLITSCH, F.; WALDHAUSER. W. Thermal fatigue and softening behavior of hot work tool steels. In: International Tooling Conference, 6., 2002, Karlstad (Suécia). Proceedings of the $6^{\text {th }}$ International Tooling Conference. Karlstad, 2002, p. 707-719.

COOK, R. D.; MALKUS, D. S.; PLESHA, M. E. Concepts and applications of finite elements analysis. 3. ed. EUA: John Wiley\&Sons, 1989. 630p.

CUSOLITO, M.; MAPELLI, C.; NICODEM, I. W. Correct management of inclusional defect based on a failure analysis. Metallurgical Science and Technology, v.20, p.9-16, 2002.

DAVIES, M.A.; CAO, Q.; COOKS, A.L.; IVESTER, R. On the measurement and prediction of temperature fields in machining AISI 1045 steel. CIRP Annals Manufacturing Technology, v.52, n.1, p. 77-80, 2003. 
DESHPANDE, M. Improvements in hot forging process - using alternative die materials and finite element analysis for wear prediction and die design optimization, 2011. 90p. Tese (Mestrado) - Graduate School of the Ohio State University, Ohio (EUA), 2011.

DIETER, G. E. Mechanical metallurgy. Londres (UK): McGraw-Hill Book Company, 1988. 766 p.

DOEGE, E.; NAEGELE, H.; SCHLIEPHAKE, U. Aspects of wear prediction in precision forging. Proceedings of the Institution of Mechanical Engineers, Part B: Journal of Engineering Manufacture, v.280, n.2, p. 111-119, May 1994.

DOWLING, N. E. Mechanical behavior of materials: engineering methods for deformation, fracture and fatigue. 3. ed. New Jersey: Prentice Hall, 2006. 800p.

DUAN, C.Z.; DOU, T.; CAI, Y.J.; LI, Y.Y. Finite element simulation and experiment of chip formation process during high speed machining of AISI 1045 hardened steel. International Journal of Recent Trends in Engineering, v.1, n.5, p. 46-50, May 2009.

EVANS, R. W.; SCHARNING, P. J. Axisymmetric compression test and hot working properties of alloys. Materials Science and Technology, v.17, p. 995-1004, Aug. 2001.

FLAUSINO, P. C. A. Desgaste de uma matriz de forjamento a quente considerando o amaciamento devido ao revenimento. 2010. 111p. Dissertação (Mestrado). Universidade Federal de Minas Gerais, Belo Horizonte, 2010.

FUKUMASU, N. K.; PELEGRINO, P. L.; CUEVA, G.; SOUZA, R. M.; SINATORA, A. Numerical analysis of the stresses developed during the sliding of a cylinder over compact graphite iron. Wear, v.259, n.7-12, p. 1400-1407, July- Aug. 2005.

GABARDO, J. F.; OKIMOTO, P. C. Estudo de tratamentos térmicos aplicados às ferramentas fabricadas com o aço AISI H13 visando o aumento de sua vida útil. In: Congresso Brasileiro de Engenharia de Fabricação- COBEF,6., 20011, Caxias do Sul (Brasil). Proceedings of the $6^{\text {th }}$ Brazilian Conference on Manufacturing Engineering. Caxias do Sul: 2011.

GEIGER, G. H.; POIRIER, D. R. Transport phenomena in metallurgy. 1. ed. EUA: Addison-Wesley Publishing Company,1973. 616p.

GROBASKI, T. C. Preliminary research for the development of a hot forging die life prediction model, 2004. 119p. Tese (Mestrado) - Department of Mechanical Engineering and the Russ College of Engineering and Technology, Ohio (EUA), 2004.

GUIRE, M. R. EMSE201 - Introduction to materials science \& engineering. Ohio, Case Western Reserve University, Oct. 2003. Disponível em:

<http://dmseg5.case.edu/classes/emse201/overheads/Thermal.pdf>. Acesso em: 01 mar. 2012. 
HARTLEY, P.; PILLINGER, I. Numerical simulation of the forging process. Comput. Methods Appl. Mech. Engrg., v.195, p. 6676-6690, 2006.

HASSELMAN, D. P. H.; SINGH, J. P. Criteria for the thermal stress failure of brittle structural ceramics. In: Hetnarski, R. B. Thermal stresses I., v. 1. New York: North-Holland, 1986. p. 263-298.

HONEYCOMBE, R. W. K. Aços: microestrutura e propriedades. Lisboa: Fundação Calouste Gulbenkian, 1985. 348p.

HORNBOGEN, E. Overview no 37 on the microstructure of alloys. Acta Metallurgica, v.32, n.5, p. 615-627, May 1984.

HU, X.; LI, L.; WU, X.; ZHANG, M. Simulations of coarsening behavior for $\mathbf{M}_{\mathbf{2 3}} \mathbf{C}_{6}$ carbides in AISI H13 steel. J. Mater. Sci. Technol., v. 22, n.2, p. 153-158, 2006a.

HU, X.; LI, L.; WU, X.; ZHANG, M. Coarsening behavior of $\mathbf{M}_{23} \mathbf{C}_{6}$ carbides after ageing or thermal fatigue in AISI H13 steel with niobium. International Journal of Fatigue, v. 28, n.3, p. 175-182, $2006 \mathrm{~b}$.

JAIN, V. K. Determination of heat transfer coefficient for forging applications. Journal of Materials Shaping Technology, v.8, n. 3, p. 193-202, Mar. 1990.

KANG, J.H.; PARK, I.W.; JAE, J.S.; KANG, S.S. A study on a die wear model considering thermal softening: (I) construction of the wear model. Journal of Materials Processing Technology, v.96, n.1-3, p. 53-58, Nov. 1999.

KANNAPPAN, A. Wear in forging dies - a review of world experience. Metal Forming, v.36, n.12, p. 335, Dec. 1969.

KIM, D.H.; LEE, H.C.; KIM, B.M.; KIM, K.H. Estimation of die service life against plastic deformation and wear during hot forging processes. Journal of Materials Processing Technology, v. 166, n. 3, p. 372-380, Aug. 2005.

$\mathrm{KIM}, \mathrm{Y}$; $\mathrm{CHOI}, \mathrm{C}$. A study on life estimation of hot forging die. International Journal of Precision Engineering and Manufacturing, v.10, n.3, p. 105-113, July 2009.

KUMAR, S.; BHOOPAL, R. S.; SHARMA, P. K.; BENIWAL, R. S.; SINGH, R. Nonlinear effect of volume fraction of inclusions on the effective thermal conductivity of composite materials: a modified Maxwell model. Open Journal of Composite Materials, v.1, n.1, p. 10-18, Oct. 2011.

LIST G.; SUTTER, G.; BOUTHICHE, A. Cutting temperature prediction in high speed machining by numerical modelling of chip formation and its dependence with crater wear. International Journal of Machine Tools and Manufacture, v.54-55, p. 1-9, Mar. - Apr. 2012. 
MENG, C.; ZHOU, H.; CONG, D.; WANG, C.; ZHANG, P.; ZHANG, Z.; REN; L. Effect of biomimetic non-smooth unit morphology on thermal fatigue behavior of H13hot-work tool steel. Optics \& Laser Technology, v.44, p. 850-859, 2012.

MESQUITA, R. A.; HADDAD, P. T.; BARBOSA, C. A. A aplicação do aço VHSUPER em matrizes de forjamento. In: SENAFOR, 28., 2008, Porto Alegre (Brasil). Anais do $28^{\circ}$ Senafor e $12^{2}$ Conferência Internacional de Forjamento. Porto Alegre: 2008, p. 49-62.

MEYERS, M. A.; CHAWLA, K. K. Mechanical behavior of materials. 2. ed. Cambridge, 2009. 856p.

MORAIS, W. A. Capítulo 1 - Tensões e deformações, UNISANTA - Santos (SP), jul.-nov. de 2004. Disponível em:

< http://cursos.unisanta.br/mecanica/cpm-0864.html >. Acesso em: 01 set. 2012.

MORENO, M. E. Desenvolvimento e implementação de metodologia de otimização da geometria do blank em processos de conformação de chapas metálicas. 2000. 88p. Dissertação (Mestrado). Escola de Engenharia de São Carlos, Universidade de São Paulo, São Paulo, 2000.

NORTON, R. L. Machine Design: integrated approach. 3. ed. New Jersey: Pearson Prentice Hall, 2006. 983p.

OLIVARES, F. J.; CAMACHO, A. M.; SEBASTIÁN, M. A. Analysis comparative of different simulation techniques by the finite element method in the study of an open die forging process. In: AIP Conf. Proc., $4^{\text {th }}$ Manufacturing Engineering Society International Conference (MESIC 2011), v.1431, p. 668-675, 2012.

OLIVEIRA, M. F.; ZOBY, M. R. G.; SOUZA, R. M. Simulação da evolução de tensões térmicas em cilindros de laminação. In: Congresso Nacional de Engenharia Mecânica - CONEM, 2., 2002, João Pessoa (Brasil). Proceedings of the II Congresso Nacional de Engenharia Mecânica. João Pessoa: 2002, p. 12-16.

PADILHA, A. F. Materiais de engenharia: microestrutura e propriedades. 1ed. Hemus, 2000. 349p.

PERSSON, A.; HOGMARK, S.; BERGSTRÖM, J. Simulation and evaluation of thermal fatigue cracking of hot work tool steels. International Journal of Fatigue, v.26, n.10, p. 1095-1107, Oct. 2004.

ROBERTS, G.; KRAUSS, G.; KENNEDY, R. Tool steels. 5. ed. ASM International, 1998. 335 p.

RODRIGUES, J.; MARTINS, P. Tecnologia mecânica - tecnologia da deformação plástica: fundamentos teóricos. 2. ed. Lisboa: Escolar Editora, 2010. v.1. 695 p.

SALDARRIAGA, P. A. C. Estudo dos campos de tensão gerados por inclusões durante o processo de torneamento em aços ABNT 1045 utilizando o método 
dos elementos finitos. 2008. 102p. Dissertação (Mestrado). Escola Politécnica, Universidade de São Paulo, São Paulo, 2008.

SERANTONI SILVA, C. R. Fadiga térmica de ferros fundidos brancos multicomponentes. 2003. 131p. Dissertação (Mestrado). Escola Politécnica, Universidade de São Paulo, São Paulo, 2003.

SERIACOPI, V.; CHAGAS, G. M. P.; MACHADO, I. F. Estudo da fadiga térmica no aço AISI H13 via simulação numérica. In: Congresso Nacional de Engenharia Mecânica - CONEM, 7., 2012, São Luís (Brasil). Proceedings of the VII Congresso Nacional de Engenharia Mecânica. São Luís: 2012, ISSN 2178-180X.

SHAPIRO, A. B. Using LS-Dyna for hot stamping. In: European LS-Dyna Conference, $7^{\text {th }}, 2009$, Salzburg (Austria) and Bad Reichenhall (Alemanha).

SHARMA, R. S.; RAJ, K. H. Finite element modelling and simulation of hot upsetting process to minimize central bulge in manufacturing. In: National Systems Conference, 32., 2008, NSC. Proceedings of the XXXII National Systems Conference. NSC, Dec. 17-19, 2008, p. 485-489.

SHIRGAOKAR, M. Forging processes: variables and descriptions. In: Altan, Taylan; Ngaile, Gracious; Shen, Gangshu (USA). Cold and hot forging: fundamentals and applications. Ohio: ASM International, 2005. Cap. 2, p. 7-15.

SILVA, P. F. Desgaste e fadiga térmica de ligas (aço matriz+NbC). 2006. 164p. Dissertação (Mestrado). Escola Politécnica, Universidade de São Paulo, São Paulo, 2006.

SIMA, M.; ÖZEL, T. Modified material constitutive models for serrated chip formation simulations and experimental validation in machining of titanium alloy Ti-6Al-4V. International Journal of Machine Tools \& Manufacture, v. 11, n.50, p. 943-960, Nov. 2010.

SIMULIA. Abaqus 6.11: documentation. 2011. Tutorial do software de elementos finitos Abaqus CAE (Versão 6.11). Disponível em:

<https://www.sharcnet.ca/Software/Abaqus/6.11.2/books/exa/default.html>. Acesso em: 05 abr. 2012.

SJÖSTRÖM, J. Chromium martensitic hot-work tool steels - damage, performance and microstructure, 2004. 53p. Dissertação (Doutorado) -University of Karlstad, Karlstad (Sweden), 2004. ISSN: 1403-8099. ISBN: 91-85335-21-5.

SJÖSTRÖM, J.; BERGSTRÖM, J. Thermal fatigue testing of chromium martensitic hot-work tool steel after different austenitizing treatments. Journal of Materials Processing Technology, v. 153-154, n.10, p. 1089-1096, Nov. 2004.

TATA STEEL INTERNATIONAL (Nova Zelândia), 2012. Engineering steels medium tensile steel - AISI 1045. Disponível em:

<http://www.tatasteelnz.com/downloads/MeduimTens_AISI1045.pdf>. Acesso em: 15 out. 2012. 
TURNER, M. J.; CLOUGH, R. W.; MARTIN, H. C.; TOPP, L. J. Stiffness and deflection analysis of complex structures. Journal of Aeronautical Sciences, v. 23, n.854, p. 13-32, Sept. 1956.

UDOMPHOL, T. Chapter 2 - Forging. Tailândia, Suranaree University of Technology, Jan.-Mar. de 2007. Disponível em:

< http://eng.sut.ac.th/metal/images/stories/pdf/02_Forging.pdf>. Acesso em: 01 mar. 2012.

UPADHYAY, A.; SINGH, R. Prediction of effective elastic modulus of biphasic composite materials. Modern Mechanical Engineering, v. 2, n.1, p. 6-13. Fev. 2012.

VABLE, M. Intermediate Mechanics of Materials: Chapter 7. Houghton, Michigan Technological University, Aug. de 2012. Disponível em:

<http://www.me.mtu.edu/ mavable/MEEM4150/Slides/IMOM\%20Chap\%207\%20Slid es.pdf>. Acesso em: 10 nov. 2012.

VALBERG, H. S. Applied metal forming including FEM analysis. 1. ed. United Kingdom: Cambridge University Press, 2010. 466 p.

VELAY, V.; BERNHART, G.; PENAZZI, L.; PERSSON, A.; BERGSTRÖM, J. Thermal fatigue of a tool steel: experiment and numerical simulation. In: International Tooling Conference, 6., 2002, Karlstad (Suécia). Proceedings of the $6^{\text {th }}$ International Tooling Conference. Karlstad, 2002, p. 793-814.

WEI, Z.; YONG, L.; LI, W.; BIN, L. Numerical simulation and physical analysis for dynamic behaviors of $\mathrm{P} / \mathrm{M}$ TiAl alloy in hot-packed forging process. Trans. Nonferrous Met. Soc. China, v.22, p. 901-906, 2012.

WERONSKI, A.; HEJWOWSKI, T. Thermal fatigue of metals. 1. ed. EUA: Marcel Dekker, 1991. 366p.

WILSON, W. R. D.; SCHMID, S. R.; LIU, J. Advanced simulations for hot forging: heat transfer model for use with the finite element method. Journal of Materials Processing Technology, v. 155-156, n. 30, p. 1912-1917, Nov. 2004.

ZHANG, Z. J.; DAI, G. Z.; WU, S. N.; DONG, L. X.; LIU, L. L. Simulation of 42CrMo steel billet upsetting and its defects analyses during forming process based on the software DEFORM-3D. Materials Science and Engineering A, v. 499, p. 49-52, 2009.

ZHANG, Z.; DELAGNES, D.; BERNHART, G. Microstructure evolution of hotwork tool steels during tempering and definition of a kinetic law based on hardness measurements. Materials Science and Engineering A, v. 380, n. 1-2, p. 222-230, Aug. 2004.

ZHAO, D; CONTROLS, J. Hot tension and compression testing. In: ASM handbook: mechanical testing and evaluation. Estados Unidos da América: ASM International, 2000, 1. ed., v. 8, p. 357-374. 